University of Louisville

ThinkIR: The University of Louisville's Institutional Repository

Electronic Theses and Dissertations

$12-2012$

\title{
The art of natality : Virginia Woolf's and Kathe Kollwitz's aesthetics of becoming.
}

Jennifer Brooke Goldberg 1973-

University of Louisville

Follow this and additional works at: https://ir.library.louisville.edu/etd

\section{Recommended Citation}

Goldberg, Jennifer Brooke 1973-, "The art of natality : Virginia Woolf's and Kathe Kollwitz's aesthetics of becoming." (2012). Electronic Theses and Dissertations. Paper 510.

https://doi.org/10.18297/etd/510

This Doctoral Dissertation is brought to you for free and open access by ThinkIR: The University of Louisville's Institutional Repository. It has been accepted for inclusion in Electronic Theses and Dissertations by an authorized administrator of ThinkIR: The University of Louisville's Institutional Repository. This title appears here courtesy of the author, who has retained all other copyrights. For more information, please contact thinkir@louisville.edu. 
THE ART OF NATALITY:

VIRGINIA WOOLF'S AND KÄTHE KOLLWITZ'S AESTHETICS OF BECOMING

\author{
By \\ Jennifer Brooke Goldberg \\ B.A., University of Tennessee, Knoxville, 1994 \\ M.A., University of Illinois, Urbana-Champaign, 1997

\begin{abstract}
A Dissertation
Submitted to the Faculty of the

College of Arts and Sciences of the University of Louisville in Partial Fulfillment of the Requirements

for the Degree of
\end{abstract}

Doctor of Philosophy

Department of Humanities

University of Louisville

Louisville, Kentucky

December 2012 


\section{Copyright 2012 by Jennifer Brooke Goldberg}

All rights reserved 
THE ART OF NATALITY:

VIRGINIA WOOLF'S AND KÄTHE KOLLWITZ'S AESTHETICS OF BECOMING

By

Jennifer Brooke Goldberg

B.A., University of Tennessee, Knoxville, 1994

M.A., University of Illinois, Urbana-Champaign, 1997

A Dissertation Approved on

November 7, 2012

by the following Dissertation Committee:

Annette C. Allen

Dissertation Director

Benjamin Hufbauer

Mary Ann Stenger 


\section{DEDICATION}

To Michael, Caleb, and Ethan,

who awaken me continually to the wonders of becoming... 


\section{ACKNOWLEDGMENTS}

I owe my dissertation director, Annette Allen, more than I can express. I first became acquainted with Virginia Woolf under Dr. Allen's tutelage, and through this exposure I have been granted an unexpected and miraculous sense of belonging in the world. Dr. Allen continually fosters my creativity and contributes to my flourishing. This project could not have come to fruition without the intervention of those whose commitments to natality have given me faith in beginnings. To my parents, Anne and Rusty Jackson, I extend gratitude. I am especially thankful to my mother for bestowing upon me a creative approach to living. My beloved grandparents, Georgia Louise Houser (1925-2011) and Calvin Kermit Houser, best represent the world of my childhood. Their home is my Bachelardian paradise. I attribute much of my adult zest for life to that of my mother-in-law and father-in-law, Betty and Joshua Goldberg. And the unconditional love, companionship, and curiosity showered on me by Buttercup, Shiloh, and Lyra affirm interconnectivity between species.

My children, Caleb and Ethan, have been my constant guides in this project in embodying becoming and in nurturing me. They provide a sense of home. To my husband, Michael Emanuel Goldberg, I offer my deepest love. His intellectual acuity and readiness to discuss the nuances of natality have been invaluable. Most invaluable, however, has been his loving creation of the home we share with our children and dogs, which would have collapsed had he not nurtured it and all who inhabit it. 


\begin{abstract}
The Art of Natality: Virginia Woolf's and Käthe Kollwitz's Aesthetics of Becoming Jennifer Brooke Goldberg
\end{abstract}

November 30, 2012

Though Virginia Woolf's and Käthe Kollwitz's personal histories and specific cultural circumstances were quite different, their aesthetics share fundamental qualities. This dissertation demonstrates that both artists affirm memory, the maternal, and creativity as coalescent, and through doing so assert a principle of connectivity that counters the turmoil of their times. Through this constellation, Woolf's and Kollwitz's aesthetics exude faith in the continued viability of beauty and of possibility, faith that a commitment to becoming will undermine the sources of hopelessness that enshroud the modern world. Channeling their losses into their creative endeavors, Woolf and Kollwitz appropriated crises from their pasts for moments of personal and cultural edification. They establish maternity as exemplary of the human need for mutuality and maternal desire as a search for interrelation that must be exercised imaginatively. Charting the cataclysms of modernity evident in thought, technology, and warfare, Chapter I demonstrates modernity's collective sense of homelessness. Chapter II situates theoretically the presences Woolf and Kollwitz assert as potentializing a rediscovery of home; Svetlana Boym's reflective nostalgia and Grace Jantzen's ethic of natality prove especially instrumental here. Chapters III, IV, and V interpret Woolf's "A Sketch of the Past" and To the Lighthouse as manifestations of Woolf's creative memory work, of her 
search for her mother and her lost home. Sketching her mother as an artist, Woolf identifies Julia Stephen as the source of her daughter's creativity and suggests art as a regenerative expression of love. Chapters VI and VII transition to a consideration of Käthe Kollwitz's autobiography and diaries, and of her War series and The Mourning Parents memorial. These chapters illuminate her alignment of the sensuality of mothering with the sensuality of creation, and establish that she experienced her son's death in World War I as a death of becoming. Chapter VII in particular probes the depths of Kollwitz's grief and describes the creative process as a means through which she soothed herself. Creating art enabled her to work toward a world that does not desecrate interconnectivity, imagination, and childhood, a world worthy of her deceased son and of her own mothering. 
TABLE OF CONTENTS

ACKNOWLEDGMENTS..................................................................

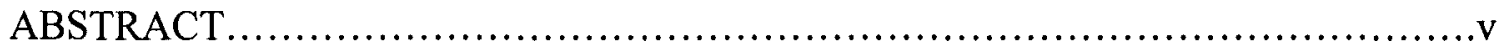

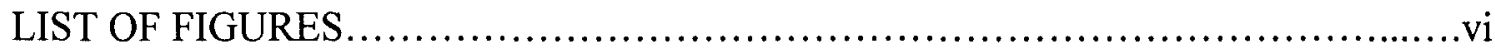

INTRODUCTION

"THESE FRAGMENTS I HAVE SHORED AGAINST MY RUINS" ..................

CHAPTER I

THE HOMESICK MODERN SOUL ..............................................21

CHAPTER II

RETURNING TO INTERSUBJECTIVE ROOTS: FINDING A HOME

WITHIN HOMELESSNESS...................................................47

CHAPTER III

INHABITING: VIRGINIA WOOLF AND THE ART OF HOME ......................75

CHAPTER IV

ASSEMBLING: MRS. RAMSAY AND THE ART OF CONNECTION................97

CHAPTER V

REMEMBERING: LILY AND THE ART OF RETURN..............................140

CHAPTER VI

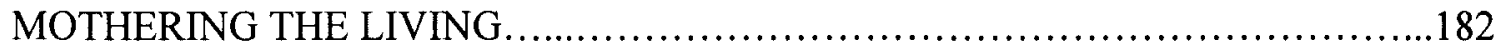

CHAPTER VII

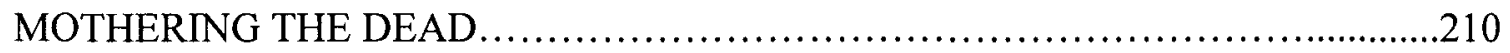

CONCLUSION

TO NURTURE AND TO BE NURTURED......................................260

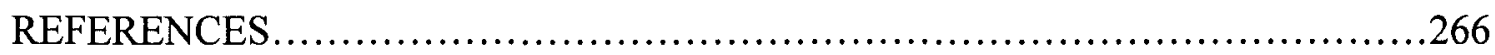


APPENDIX

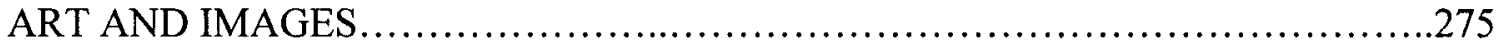

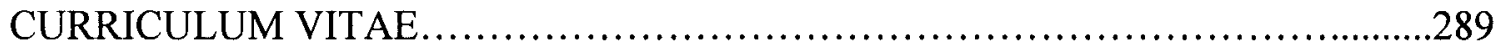




\section{LIST OF FIGURES}

\section{FIGURE}

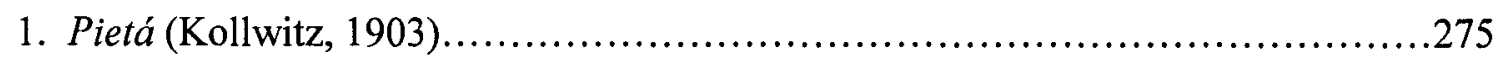

2. Woman With Dead Child (Frau mit Totem Kind) (Kollwitz, 1903)....................276

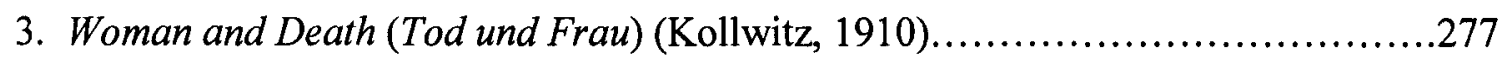

4. Vampire (Edward Munch, 1894) ...........................................2278

5. The Sacrifice (Das Opfer) (Kollwitz, 1922 - 1923)..................................279

6. The Volunteers (Die Freiwilligen) (Kollwitz, 1922 - 1923)........................280

7. The Parents (Die Eltern) (Kollwitz, 1922 - 1923).................................281

8. The Widow, I (Die Witwe, I) (Kollwitz, 1922 - 1923)............................282

9. The Widow, II (Die Witwe, II) (Kollwitz, 1922 - 1923)............................283

10. The Widow, II (Die Witwe, II) (Kollwitz, 1922 - 1923)............................284

11. The People (Das Volk) (Kollwitz, 1922 - 1923)................................285

12. Lamentation Over the Body of Christ (Bellini, ca. 1500 )........................286

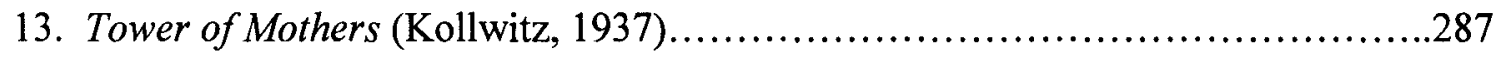

14. The Mourning Parents (Trauernden Eltern) (Kollwitz, 1914 - 1932)..............288 


\section{INTRODUCTION}

\section{"THESE FRAGMENTS I HAVE SHORED AGAINST MY RUINS"1}

For successful excavations a plan is needed. Yet no less indispensable is the cautious probing of the spade in the dark loam, and it is to cheat oneself of the richest prize to preserve as a record merely the inventory of one's discoveries, and not this dark joy of the place of the finding itself. Fruitless searching is as much a part of this as succeeding, and consequently remembrance must not proceed in the manner of a narrative or still less that of a report, but must, in the strictest epic and rhapsodic manner, essay its spade in ever-new places, and in the old ones delve to ever-deeper layers.

\section{Walter Benjamin, "Berlin Chronicle"2}

Home is where one starts from. As we grow older the world becomes stranger, the pattern more complicated Of dead and living. Not the intense moment Isolated, with no before and after, But a lifetime burning in every moment And not the lifetime of one man only But of old stones that cannot be deciphered. There is a time for the evening under starlight, A time for the evening under lamplight (The evening with the photograph album).

\section{T.S. Eliot, "East Coker"”}

Perhaps searching in earnest requires childlike wonder. Perhaps more than a little faith in humanity is necessary to sustain such a search in an inhospitable climate, one in which the very idea of meaning lacks credence. The excavatory aims of this dissertation have been inspired by the excavatory disposition of modernism itself, a disposition

\footnotetext{
${ }^{1}$ Eliot, "The Waste Land" 50.

${ }^{2} 611$.

${ }^{3} 129$.
} 
inclined to search for fragments of meaning among the ruins of past ways of being that might be salvaged and assembled differently to create a more hospitable present. For, despite its "make it new" ethos, modernism did not, in fact, strive for creation ex nihilo. Quite the contrary, modernist art might be understood as delicately-wrought mosaics composed of carefully chosen remnants from the past.

This dissertation focuses on Virginia Woolf, an Englishwoman, and Käthe Kollwitz, a woman from Germany, two modernist artists whose negotiations of the past define their oeuvres. Channeling their losses into their creative endeavors, Woolf and Kollwitz appropriated events from their pasts that were nothing short of identityshattering for moments of personal and cultural edification, moments charged with imperatives that when heeded render life more conducive to flourishing. The most profound of Woolf's and Kollwitz's losses entailed the deaths of loved ones, and rather than severing ties with the deceased as Freud advises in "Mourning and Melancholia," both Woolf and Kollwitz tunneled into their beloveds' pasts to keep them and their legacies alive in the present. Though Woolf lost her mother to illness when she was only thirteen, many of her adult writings remain impressed with this primal loss. Kollwitz's loss was of a different tenor: her son Peter fell in World War I shortly after he enlisted in the German army in 1914. The shape of her lost son inhabits her subsequent art. Personal grief pervades both artists' works, but Woolf and Kollwitz avoid narcissism through creation, a personal act infused with cultural as well as individual import, an act that ushers the experience of pain into the light to be seen by those lacking means to express their own losses. Channeling their personal losses into an aesthetic that spoke to 
a culture in crisis, both demonstrate that rehabilitating the present demands concentrated immersion in the past.

Though Woolf's and Kollwitz's personal histories and specific cultural circumstances were quite different, their aesthetics share fundamental qualities. Both artists affirm memory, the maternal, and creativity as coalescent, and through doing so assert a principle of connectivity that counters the crises of their times. Through this constellation, Woolf's and Kollwitz's aesthetics exude faith in the continued viability of beauty and of possibility, faith that a commitment to becoming will effectively undermine the sources of hopelessness that enshroud the modern world. Both women offer capacious alternatives to the claustrophobic edifices that had crumbled, alternatives constructed from humane shards reclaimed from the rubble.

As will be rehearsed thoroughly in Chapter I, the modernity of the late-nineteenth and early-twentieth centuries provoked an urgent plea for meaning. The collapse of the philosophical and ideological edifices that had seemed to shelter Western culture resulted in a pervasive sense of homelessness, a sense of having lost that which was essential to identity. ${ }^{4}$ This sense of loss escalated with the onset of World War I, the single event that most dramatically signaled the degradation of home. The Great War was nothing short of apocalyptic, revelatory of the corruption that underlay discourses and images of home, revelatory of a possible end.

\footnotetext{
${ }^{4} \mathrm{My}$ understanding of metaphysical and psychological homelessness in the context of modernity has been informed by a number of sources. Notably, as elaborated in the first chapter, Friedrich Nietzsche, Matthew Arnold, Sigmund Freud, and early sociologists Ferdinand Tönnies, Georg Simmel, Emile Durkheim, and Max Weber speak to the subject. Peter Berger's classic sociological study, The Homeless Mind: Modernization and Consciousness, links sociology and psychology in correlating modernization, pluralization, the erosion of community, and psychological homelessness.
} 
World War I was in large part the product of a ubiquitous misconception among European powers that war would preserve cherished traditions, cherished ways of life, a protected homeland. The failure of that ideology was inevitable, for the values deemed in desperate need of preservation were the very values that engendered militarism. In short, misguided nostalgia threatened to perpetuate a climate of bellicosity, a climate in which individuals continued to wither due to deprivation of that which humans need to thrive: a secure sense of home and a modicum of human connectivity unencumbered by commodification. But how to conceptualize a model of home and human relations outside of dominant, nationalistic narratives?

For Virginia Woolf and Käthe Kollwitz, such conceptualization necessitated revisiting and re-visioning the personal past. In Woolf's case, this entailed accessing moments of childhood imagination and situating her creativity as bound in relationship with her lost mother, while in Kollwitz's it consisted of accessing her children's childhoods, recognizing in retrospect their infinite potential, and, ultimately, employing childhood as a trope that illuminates the modern world's assault on its own flourishing. In either case, while childhood represents possibility, it is also associated with acute loss. The question of what to do in the face of such loss occupied these women throughout their years of artistic productivity—-the problem of innocence betrayed encapsulated the personal and cultural crises that defined Woolf's and Kollwitz's existences. Tunneling back to pasts with their loved ones, Woolf and Kollwitz isolate childhood moments as pregnant with meaning that spills into the present and endows it with possibility.

Begotten of personal pain and compassion for a grieving world, Virginia Woolf's and Käthe Kollwitz's aesthetics are governed by a principle of connectivity that affirms 
reverence for interrelation as fundamental to addressing the ills that afflicted their own psyches and the cultures in which they lived. Specifically, their aesthetics demonstrate maternity, nostalgic desire, and creativity as interwoven life forces that counteract Western culture's life-denying inclinations. Each establishes maternity as exemplary of the fundamental human need for mutuality and desire for the mother as a search for interrelation that must be exercised creatively if it is to be of value to the self and the world. Maternity is also representative of the sacredness of natality, the beauty and possibility inherent in the life force as materialized in birth and its attendant becoming. Through exercising their creativity, Woolf and Kollwitz embodied mutuality. Rather than succumbing to personal devastation, these two artists channeled the very constituents of their aesthetics for personal and cultural healing. The creative process carried Virginia Woolf into a deeper communion with her lost mother through awakening her to her artistic gift as a manifestation of her mother's legacy. The creative process allowed Käthe Kollwitz to soothe her grief through working toward a world that does not desecrate the interconnectivity and imagination of which childhood is representative, a world worthy of her deceased son. Appropriating maternity and employing it as a trope in their works, both Woolf and Kollwitz extend motherhood to incorporate all acts undertaken in love for the world and the natals who inhabit it. Chapter II engages philosophically the presences Virginia Woolf and Käthe Kollwitz posit as potential remedies to modern alienation and angst. Specifically, as both artists identified their personal pasts as rife with salvageable resources for remediating the present, Chapter II considers the ethics of nostalgia as articulated in Svetlana Boym's The Future of Nostalgia. Boym qualifies what constitutes beneficent nostalgia; namely, a 
type of nostalgia that she terms reflective nostalgia, which is, as its name denotes, characteristically introspective. Reflective nostalgia acknowledges its rootedness in desire for an object that is unattainable, and recognizes the insubstantiality of the object of its affection. What renders this nostalgia sound, she avers, is that it promises to do something in and for the present. As she explores extensively the notion of home and its hold on the human psyche, Boym's concerns intersect those of Woolf and Kollwitz. For the idea of home is central to their art.

To Woolf and Kollwitz, home is inseparable from considerations of the first relationship, that of mother and child. The second chapter of this dissertation explores specifically the implications of a nostalgia rooted in an imagined mother-child dyad, a desire that has been criticized by feminists because it locks female identity in the heterosexual-reproductive paradigm. The misogyny of this paradigm is overt in Freudian psychoanalysis, which was certainly in the air as Woolf and Kollwitz engaged in their creative processes. While Freud's notion of the mother-child relationship is conceived through the lens of the precarious development of a human psyche teeming with crises of fusion and individuation, Woolf and Kollwitz conceptualize the dyad in terms of mutuality and its attendant possibility.

Of particular applicability to the scope of this study are psychoanalytic theorists of the mother-child relationship who focus on mutuality. Julia Kristeva's groundbreaking essay "Stabat Mater" extends conceptions of the maternal to the realm of ethics. Most salient is her illumination of the maternal as modeling right relations with the other: "The other is inevitable, ... make a God of him if you like; he won't be any less natural if you do, for this other still comes from me, which is in any case not me but an endless 
flux of germinations, an external cosmos. The other proceeds from itself and myself to such a degree that ultimately it doesn't exist for itself' (151). An ethics of maternity, Kristeva suggests, would acknowledge and embody humanity's interdependency. In her later "Motherhood Today," she reinforces her conviction of the maternal as demonstrative of human connection at its most salubrious. Here Kristeva calls for the development of a much-needed discourse of maternal passion, a passion that "constitutes the prototype for the love relation." Woolf and Kollwitz fashion an aesthetic demonstrative of such passion.

Luce Irigaray's call for reconceiving relations with the mother proves equally foundational to this project. Like Kristeva's, her proposal extends beyond the motherchild dyad. Irigaray's considerations of the mother-child relationship promote an ethics of care applicable to all human relations, which renders them especially suited to addressing the works of Woolf and Kollwitz. Irigaray calls for awe-filled regard of the unreachability and dynamism of all identity and advocates attendant regard for the other and her regard for us. In this way, her approach is compatible with that of American psychoanalyst Jessica Benjamin, who rejects the traditional object-relations account of human development and advocates instead a conception of human growth and development that pivots on intersubjectivity, which emphasizes awareness of one's own subjectivity as contingent upon the discovery of the subjectivity of the other.

Chapter II's exposure of the emancipatory potential of the perspectives of Kristeva, Irigaray, and Benjamin culminates in a consideration of a model of human relations articulated by theologian Grace Jantzen in Becoming Divine: Toward a Feminist Philosophy of Religion. Jantzen deems vital unearthing a symbolic of becoming 
inherent in Western thought that is repressed by a rationalistic world-view. Specifically, she calls for the development of an approach to relations with and within the world that affirms connectivity and possibility. Such an approach rests on a symbolic of natality, which, as its name suggests, embraces beginnings. Natality encompasses imagination and its attendant faith in beginnings yet to be realized, yet to be conceived. From the Latin nätälis, pertaining to birth or origins, natality seizes upon each moment as pregnant with possibility and pays particular homage to the mother as the harbinger of newness. Applying Jantzen's conception of natality to Woolf's and Kollwitz's art illuminates the aesthetics of both as bound in a reverence for becoming, as bound in hope.

Salient in Jantzen's proposal of an ethic of natality is the conviction of the divinity innate in all, residing within those perceived to be the lowest, within what is perceived to be quotidian. Reminiscent of modernism's focus on the everyday as abounding with untapped meaning, this attunement to the minutiae of experience inspires discernment of significance within what has hitherto been deemed insignificant. An ethic of natality demands embracing the divinity of our fellow natals, treating others and the world in accordance with the awe with which we are filled as we continually brush against that divinity. Jantzen's injunction to behold the divinity that already surrounds and permeates us and to act accordingly is directed toward the present, but this does not invalidate its applicability to Woolf's and Kollwitz' aesthetics. Rather, hers is an injunction to treat the world and its inhabitants maternally, to exercise creativity and wonder in regarding them, to exude faith in their becoming. Responding to this injunction demands recollection of being nurtured, recollection of the wonder-filled faith of childhood. Approaching Woolf's and Kollwitz's work through Jantzen illuminates the 
hope that emanates from Woolf's texts and reveals Kollwitz as warning that a world that desecrates natality diminishes possibility.

Chapters III, IV, and V carry the concerns articulated in the first two chapters more extensively into analysis of Virginia Woolf's life and work. The novel and autobiographical essay under consideration in this study—To the Lighthouse and "A Sketch of the Past" - were chosen because they illuminate how the crises of modernity were experienced and negotiated on a personal level, and because considering them in tandem enhances efforts to understand Woolf's treatment of loss. Moreover, both offer a rich immersion in Woolf's symbolic universe, which is remarkably similar in her novel (1925-1927) and in her unfinished autobiographical essay (1938-1941). Though the composition of To the Lighthouse was begun over a decade before that of "A Sketch of the Past," I begin in exploring the latter because it provides biographical details that prove invaluable in interpreting Woolf's autobiographical novel. Moreover, the terms it sets forth regarding what constitutes autobiography prove to be a viable hermeneutic through which to confront To the Lighthouse.

"A Sketch of the Past" demonstrates memory and the past as perpetually in process. In Modernism, Memory, and Desire: T.S. Eliot and Virginia Woolf, Gabrielle McIntyre aptly describes Woolf's approach to memory in terms of relationship:

The past in their [Eliot's and Woolf's] work is a cherished, if occasionally dangerous , material that is required to flesh out-sometimes in a flashthe fragile and the fleeting (almost absent) fullness of the present. We find a palpable thematization of attempts to accept that, like a beloved Other, the past cannot give itself to us once and for all, no matter how much we might desire such a fantastic resolution .... For memory, like an Other, manifests a separate and ongoing coming-into-being that demands a ceaseless reopening to the work of its translation and transfiguration. (6)

McIntyre's explanation of Eliot's and Woolf's negotiations of the past as infused with 
intensive, regenerative desire proves compatible with the present study's emphasis on memory as bound in the emotive and psychological contingencies of the dynamic present. Woolf's present was frequently scored with a desire for an enhanced connectivity that she associated most closely with her relationship with her mother, a remembered connectivity that she believed capable of ameliorating the present. Chapter III considers "A Sketch of the Past" as Woolf's reflection on her childhood undertaken in the hopes of making sense of the troubled times in which she lived. "A Sketch of the Past" represents Woolf's innovative attempt to create a form of life-writing true to women's experiences, particularly those of the mother she knew for only thirteen years. Woolf comes to know her mother not by charting objective facts of Julia Stephen's life, but by infusing what she does know with empathy, imagination, and love. As Woolf's official biographer, Hermione Lee, explains in her definitive biography of Woolf, in "A Sketch of the Past" Woolf discloses "the elusiveness of the self" and the arduous path that is the search for the essence of another (18).

Michael Lackey's “Anti-Philosophicalism and Virginia Woolf's Critique of Philosophy" establishes her rejection of phallocentric accounts of being exemplified by the philosophical tradition on which she had been reared, "a cumulative system of immutable truths," in favor of "the contingent knowledge of the human life ..., knowledge of the unconscious" (84). Such an approach to knowing the self informs "A Sketch of the Past," and, as Lackey illustrates well, this approach is likewise embodied by Lily Briscoe and Mrs. Ramsay in To the Lighthouse. Characterizing it somewhat differently, in "History's Child: Virginia Woolf, Heritage, and Historical Consciousness," Mia Carter explains Woolf's ability to resist traditional historical 
solidity as emanating from "one of the great signs of health in Virginia Woolf's life[,] . . . her ability to maintain a child's exquisite outlandishness and irreverence, a child's sense of mystery and discovery, a child's elastic sense of time and appreciation of non-sense, and a child's relative insulation from the institutionalized, disciplined, and ritualized adult world" (69). Carter confers with Lackey's characterization of Woolf as associating accounts of being marked by certitude as dictatorial. While characterizing Woolf as childlike might be taken as pejorative (certainly Daniel Albright's classification of Woolf's imagination as "retain[ing] a certain infantile quality" reads in this way), Carter captures in her description something of the elasticity of Woolf's prose at its most exuberant-and in Woolf's worldview such flexibility signifies right relations with one's world (Albright 1$)^{5}$

The poignancy of "A Sketch of the Past" derives from the fact that Woolf had come to the bountiful place of having harbored the memories about which she writes for decades. As she explains in a diary entry dated March 18, 1925, "the past is beautiful because one never realises an emotion at the time. It expands later, $\&$ thus we don't have complete emotions about the present, only about the past" (5). By this logic, the distance between experience and reflection heightens rather than diminishes the capacity for truth-

\footnotetext{
${ }^{5}$ In contrast to Carter, in The Flight of the Mind: Virginia Woolf's Art and Manic-Depressive Illness, Thomas C. Caramagno attributes what Carter casts as a healthy relation to one's world to Woolf's presumed bipolar disorder, much as the majority of the essays in Suzette Henke's and David Eberly's Virginia Woolf and Trauma: Embodied Texts read Woolf through the lens of pathology. While the effects of sexual abuse and trauma undoubtedly shaped Woolf's oeuvre, I have eschewed such readings in this dissertation in order to escape the labyrinth of pathology. In The Persistence of Modernism, Madelyn Detloff astutely characterizes such pathology-driven interpretations as "reifying readings" that "contrast her [Woolf's] own resilient responses" (24). Woolf, it seems, identified as capable and competent, and it is $\mathrm{my}$ intention to honor her integrity. Nonetheless, I do acknowledge the inevitable jarring of the psyche traumatic experience and mental illness inflicts. Louise DeSalvo's Virginia Woolf: The Impact of Childhood Sexual Abuse on Her Life and Work proves compelling in its suggestion of the presence of intimations of this particular trauma in a number of Woolf's texts. The present study certainly assumes as primary the enduring pain of losing a parent.
} 
telling, as past memories flood the mind and are intensified through the conjunction of receptive and creative sensibilities. Woolf elides neither the extent to which remembering well necessitates creativity nor the extent to which recollection is an intricate, fluctuating composite of past and present.

Because Woolf's memories as they are created in "A Sketch of the Past" and To the Lighthouse are rooted so securely in the domestic spaces of her childhood, Gaston Bachelard's The Poetics of Space and Edward Casey's Getting Back Into Place undergird the chapters on Woolf. In particular, Bachelard's description of the childhood home as a cradle that achieves its primary purpose in sheltering the nascent dreamer resonates with the story Woolf tells us of her childhood at St. Ives. Bachelard tells us what Woolf has already: Memories of childhood continue to sustain the dreamer long after she leaves the cradle. Not only do they continue to sustain, but the sustenance they provide renders reminiscent dreamers "near poets, ... [their] emotion perhaps nothing but an expression of a poetry that was lost" (6). Bachelard interweaves memory, creativity, home, and the maternal, and through doing so provides a penetrative lens through which to explore Woolf's aesthetic. Supplementing Bachelard's phenomenological interpretation of home, Edward Casey suggests that, to some degree, returning home necessitates becoming a child again. As Casey explains, truly reinhabiting the lost home, getting back into place, finding steadiness, requires an adoption of "the proper rhythm[,] [which] is slow rather than swift, a matter of gravitas rather than celeritas" (297). A return through immersion in the writing process, through the poetic, proves infinitely compatible with Woolf's gradual resumption of becoming at home, a process that brings her into her mother's 
presence. Casey's theory provides a rich philosophical context for interpreting Woolf's search for the woman behind the iconic mother and the identity work that it facilitates.

Following Woolf's search as Woolf embarked upon it in fictional form some fifteen years before as she composed To the Lighthouse, Chapters IV and V attend to the maternal center of the novel and to the fictional and authorial daughters who seek desperately to know her. Chapter IV focuses on Mrs. Ramsay, the center and orchestrator of human connection in To the Lighthouse; she is the archetypal Mother. In overseeing and creating the little world that is the setting of To the Lighthouse-a fictionalized St. Ives-Mrs. Ramsay is an artist who ministers to the flourishing of its inhabitants through bringing to light the miraculous in the everyday. This chapter explores the interpenetration of human connection, the recognition of beauty, and the exercise of imagination, what one does with that beauty to integrate it into one's conception of and practice of becoming. Sketching her mother as an artist, Woolf identifies Julia Stephen as a source of her daughter's creativity, just as she suggests creativity as a natural expression of love remarkable in its ceaseless proliferation. Chapter IV illuminates that in carrying her and the mother she seeks into an infinitelybroad human community, art sustains.

The primacy of connectivity in both "A Sketch of the Past" and To the Lighthouse derives from Woolf's conception of identity as inherently relational. Particularly in the texts under consideration in the present study, Woolf's characterization of identity as relational extends to her view of relations between the self and the non-human world. In these texts, the world and those who inhabit it are bound in an endlessly complex web of connections. As Bonnie Kime Scott explains, the sense of wholeness that Woolf claims 
in "A Sketch of the Past" the writing process affords her is not a wholeness begotten of "an isolated form[,] but understanding of contexts and interdependencies" (6). Given that scenario, the mother as she appears in the texts discussed here, representative as she is of heightened connection, enables a sense of wholeness, a glimpse into the intricacy of life's weave.

That weave, John Mepham illustrates in "Mourning and Modernism," encompasses connections between aesthetic artifacts and personal and historical reality. Woolf's representations of mourning, Mepham explains, performed grief work not only for Woolf herself, but for a culture at large reeling in the aftershocks of mass collective violence. Karen Smythe demonstrates that in order to speak to a culture in crisis, Woolf experimented with an effete elegiac form: "In Woolf's fiction elegies, the experimental rendering of human absence, of past presences no longer perceived, is directly related to her distrust of empiricism, and to her doubt about the epistemological status of the subject.... What is at stake in Woolf's fiction elegies ... is the potential merging of subjective epistemology (knowledge of self and others) and aesthetics (linguistic art), as well as the potential ability of the aesthetic to console structurally and tropologically" (65).

In his discussion of the "Time Passes" portion of To the Lighthouse as the "untraceable signature of the other, especially of the other's death, in which the self is involved in ways it cannot fully represent to itself," David Sherman takes Smythe's argument to the level of ethics (162). Sherman describes the artistry through which "Woolf represents the process in which the self, by achieving a proximity to the other that is not an epistemological relation, is reconfigured around the deaths it participates in 
besides its own. It is the self as it sacrifices itself in the death of the other" (177). In

Woolf, consolation demands recognition of one's own mortality as well as one's implication in others'.

The overarching questions that inform Chapter V's analysis of To the Lighthouse are ultimately questions of legacy. Are benign moments experienced in the past able to redeem an inhospitable present? To what extent does the past continue to exist, to what extent is it present? Can those who contributed to our being-those who continue to contribute to our being though they are physically absent—be said to live? These deepseated questions surely burdened Virginia Woolf as she wrote this elegy for her mother and for the relationship with her that was never granted the opportunity to come to fruition, just as they burdened a great many moderns who found themselves adrift in an unheimlich world. ${ }^{6}$ These questions are particularly pertinent to Chapter V's investigation of the novel's final section, "The Lighthouse."

"The Lighthouse" is a story of homecoming, a concept upon which this dissertation is founded. Homecoming here is both literal and figurative: the remaining Ramsays return to the seaside cottage in the wake of the death of the animator of home and place, and as such, they confront past identities, past relationships, and memories of specific moments. Through the act of writing, Virginia Woolf imagines herself going home, imagines finding her gift through confronting the loss of her mother, the loss of a

\footnotetext{
${ }^{6}$ My use of the term "unheimlich" here derives from Freud's use of the term in reference to the etymological phenomenon in which the word "heimlich," meaning "homely" and referring to that which is familiar, simultaneously carries as one of its definitions "unheimlich," that which is secret or hidden, unhomely. In "The Uncanny," Freud applies this linguistic irony to aesthetic and affective scenarios that bring the repressed into consciousness. Freud's theory is especially useful in interpreting the pervasive angst expressed by many moderns as they were forced to confront the fact that Western culture, the collective home, was synonymous with that which functioned to bring about its own violent downfall. Freud's essay is analyzed more extensively in Chapter 1.

Equally applicable but not explored in this dissertation is Heidegger's description of the word in Being and Time in terms of existential angst, a sense of being alienated from the world one inhabits.
} 
world. This journey complicates present identity and calls into question the possibility of belonging to the time and place in which one exists in the present. Here Edward Casey's conception of place expands my interpretation: "The Lighthouse" documents the artistdaughter's journey from alienation to reinhabitation, which is only possible when she resumes becoming as before. Woolf illustrates that this process of learning to become is bound in creativity, a process that is materialized in "A Sketch of the Past."

In a commitment to listening to the voice of the living mother, Chapters VI and VII turn to German Expressionist Käthe Kollwitz, whose relationship with maternity was likewise disfigured by loss. Though as a child the death of a younger sibling and her mother's consequent emotional withdrawal affected her profoundly, Kollwitz's most devastating loss was experienced in the context of her own motherhood. Like Virginia Woolf, Kollwitz found as a primary aim of creating art soothing her own grief, but, unlike Woolf, she struggled profoundly because the child she brought into being lost his life to a war she initially supported. Immersing herself in the idea of previous relations with her child, relations that she characterizes in her diary as fundamentally creative, failed to act as a salve to her wounds, but it enabled something that did.

Reflecting on the possibility that was inherent in her sons' infancies and childhoods, Kollwitz created art that exposed the violation of possibility. While the intense pain that is so salient in Kollwitz's works would hardly seem to achieve the purpose of inspiring hope, as her diaries and letters attest, the source of her hope lay in the potential for her exposure of innocence betrayed to effect change. The figures that people Kollwitz's works suffer from what Casey terms "place-panic," existing in a world that undermines the very concept of home. Acting upon her conviction that only art that 
features suffering in its raw despondency can lead to right action, she depicts universes that are notoriously bleak, notoriously placeless. In representing natals in crisis, Kollwitz exudes fidelity to an ethic of natality.

In the interest of contextualizing Kollwitz's most poignant grief-wrought works, the War (Krieg) cycle (fig. 5-11) and The Mourning Parents (Trauernden Eltern) (fig. 14), works that feature the mother-child dyad in crisis, Chapter VI reflects on Kollwitz's autobiographical writings, her diaries, and her pre-World War I depictions of mothers and children. Because her pre-World War I diaries illuminate her alignment of the sensuality of mothering with the sensuality of creation, considering Kollwitz in the context of Janzten's notion of natality proves illuminative. A good many entries from the years preceding World War I concern her recollection of the pleasure of mothering the young and her trepidation in recognizing that these years of intense mothering are for the most part behind her. Especially in the two years before the advent of war, Kollwitz alternates between this trepidation and joy in witnessing the fruits of her labors. Moreover, Kollwitz suggests her own (artistic) coming of age as concurrent with her sons'. In that way, her diaries limn a psychical connection between mother and child that exceeds neediness-mother and children thrive in their mutuality.

In addition to considering Kollwitz's enriching experience of mothering, creating her own home, Chapter VI explores her experience of being mothered and her childhood experience of home. Kollwitz's memories of being raised by her mother are devoid of the warmth that characterizes Woolf's memories of the abbreviated time she had with her mother, for Kollwitz's earliest memories are sullied by the deaths of siblings that rendered her mother a grieving shade. Citing three of Kollwitz's pre-World War I 
depictions of mothers and children that associate the relationship with loss - Pietà (fig. 1), Mother with Dead Child (Frau mit totem Kind) (fig. 2), and Woman and Death (Tod und Frau) (fig. 3) - Chapter VI emphasizes the impact of her childhood traumas. Tinting the mother-child relationship with death was a natural outcome of her upbringing, an upbringing that rather uncannily foreshadowed the tragedy she would face in her own maternity. The pain that colors these pre-World War I works might be seen as a pain of anticipatory loss, a pain that she had witnessed in her mother and was forced to internalize if she was to know her.

Transitioning to Chapter VII's focus on Kollwitz's artistic responses to war, Chapter VI ends in an evaluation of the diary genre as particularly suited to facilitating and recording personal growth. Documenting her transformation from a German woman who accepted the ideology of sacrifice as necessary for the health of the homeland, to a German mother who tentatively questioned its legitimacy, to a mother who finally openly identified herself as a pacifist committed to ending World War I and all wars, Kollwitz's diary illustrates her evolving perspective on war. In its lack of prescribed structure, in its defiance of prescriptions of consistency, the diary is a medium through which she holds in relief her conflicting identities and ultimately constructs herself in the image of a fierce maternal activist. Certainly the progression in thought evidenced here sheds light on her artistic responses to war in general and to her son's death in particular.

The final chapter focuses extensively on Kollwitz's grief, on her attempts to reconstitute herself and her world in the wake of personal and cultural ruin. Specifically, Chapter VII investigates her resistant mourning, the melancholic tenacity that inspired her to create out of preservative love, a love that was directed toward her son's legacy 
after his death. The creative processes and content of Kollwitz's War cycle and The Mourning Parents sculpture are particularly illuminative of the extent to which Kollwitz viewed these projects as fulfilling both her own and her culture's needs. As the mother of the fallen son she had half-encouraged to enlist in the German cause, Kollwitz suffered crushing guilt concerning her role in sending him off and the resultant generational travesty. Rather than collapsing under the weight of these grievous contingencies, Kollwitz fashioned herself into an agent who marshaled her personal pain to expose war as inexcusable, inherently detrimental to individuals, families, nations, to the world. In turn, Peter's legacy became a legacy of hope, despite the fact that nothing can justify his death. Paradoxically, it is Kollwitz's exposure of Peter's death as meaningless that allows it to mean something to a world deprived of his presence.

Kollwitz's most psychologically-wrenching work, The Mourning Parents, was over seventeen years in the making. As Chapter VII illustrates, early visions of a monument that would commemorate Peter sought to defy death, to deny it. Ultimately Kollwitz found embodying Peter in stone to be impossible, his youthful body irreplaceable. What continued to exist was the heaviness of absence, the weight of grief. As Käthe and Karl Kollwitz were so completely consumed by grief, it is that state that Kollwitz found herself capable of memorializing. Revealing the irresolvable permanence of death and its infliction of isolation on those who survive was an act of personal and cultural import, a reconstitution of the maternal self through an endeavor to create a world of art and life in which possibility is not violated. Creating parents in the unremitting throes of grief, creating a mother and father that speak the irreversibility of war's effects on families and the home, Kollwitz affirms maternal practice as essential to 
healing, and to hope. Kollwitz's search for home, her search for her lost son, could never be consummated. What could be consummated, however, is the aesthetic representation of this dire truth. Only Kollwitz's maternal sorrow delivered into a world of suffering can communicate this. Even this is a testament to natality.

Woolf and Kollwitz reveal maternal nostalgia as potentially fruitful in the search for meaning in a world in which meaning has been so grievously violated. Both artists exhibit awe in the face of natality, awe in the possibility enabled by and typified in the mother-child relationship and its faith in becoming. Theirs is a faith begotten of remembering, of recovering possibility from the past, of making something beautiful from that which is identity-shattering. This is not to say that the act of creation satisfied Woolf's and Kollwitz's longing, but it is a testament to their strength, resilience, and commitment to human flourishing. In reconstituting themselves, Woolf and Kollwitz worked to reconstitute their world, and ours. 


\section{CHAPTER I}

\section{THE HOMESICK MODERN SOUL}

Alas, if homesickness for the land should attack thee, as if there had been more freedom there-and there is no 'land' any longer!

Friedrich Nietzsche, The Gay Science ${ }^{7}$

Olonesomeness! my home, lonesomeness!

Friedrich Nietzsche, Thus Spake Zarathustra ${ }^{8}$

In 1882, Nietzsche warned that Western culture had "forsaken the land and gone to sea! We have destroyed the bridge behind us-more so, we have demolished the land behind us! Now, little ship look out!" (Gay 119). Nietzsche's pronouncement is at once dire and hopeful. While he bemoans the fact that Western culture has degraded to the extent that all meaningful ties to the past have been broken, he sees the present as an opportunity for the übermensch to step forward to create his own order, his own meaning. And while his sense of truth will not apply to all he encounters-Nietzsche's is a message of irrevocable subjectivity and isolation-meaning lies in the possibility that someone might dare to act outside of the strictures that no longer suture the decaying fabric of culture. Bereft of salutary human community as possibility or ideal,

\footnotetext{
7119.
}

${ }^{8} 223$. 
Nietzsche's ideal is the lone traveler in search of personal meaning. Nietzsche's hero has no home. ${ }^{9}$

For Nietzsche, community is equivalent to insincere conformity to norms that no more apply to its members than Christianity applies to Western culture, a culture in which God has been massacred by a crowd blindly subscribing to a creed that it neither understands nor believes. At his best, the übermensch would herald a new world order in which action equates with sincerity, where churches would not be "tombs and sepulchers of God" but houses of worship of the individual will. With no path, no direction-save the conviction that each should do that which he or she is called forth to do by his or her individual will—-these churches of the future would have been shockingly unrecognizable to the religious of his day. One can imagine how jarring Nietzsche's news would be to those already adrift in the current of modernity. Perhaps the sting would not so much be in the announcement of the death of a deity most only followed in obedience to custom, but in the brash revelation that communities of belonging are little more than collective delusion. When the canopy enveloping the sacred community is denounced as a decaying shroud, the ties that bind "the faithful" are severed.

Prophetic as they were, Nietzsche's radical ideas by no means occurred in isolation. Victorian poet Matthew Arnold, who found himself rejecting the supernatural aspects of Christianity in light of "Darwin's Blow," wrote of this collective loss of faith in "Dover Beach," published in 1862 (Beer 14). Like Nietzsche, Arnold himself seems

\footnotetext{
'In The Gay Science, Nietzsche attributes the hero's lack of a home to the brokenness of the world in which he exists: "We children of the future, how could we be at home in the present? We are unfavourable to all ideals which could make us feel at home in this frail, broken-down transition period" (192).
} 
rather prophetic in his anticipation of the World Wars of the twentieth century: "And we are here as on a darkling plain / Swept with confused alarms of struggle and flight / Where ignorant armies clash by night." "Dover Beach" portrays the natural world as emblematic of the world of ideas, which, as the sea throws about pebbles with a "grating roar," carry the unsuspecting faithful and then regurgitate them unmercifully. Arnold invokes the day when "the Sea of Faith" lay around the earth as a protective "girdle," yet this protection was far from innocently nurturing. Rather, it deluded those it nurtured concerning the real nature of the world, a world filled with sadness, misery, and melancholy: "for the world, which seems / To lie before us like a land of dreams, / So various, so beautiful, so new, / Hath really neither joy, nor love, nor light, / Nor certitude, nor peace, nor help for pain." Arnold likens past experiences of the sea with a sense of inherent belonging, amniotic, soothing, and protective, but as his habits of mind have changed, he fears he can never return to that pristine state. In "Dover Beach," the possibility of community is dim, yet its speaker sees as the only recourse clinging desperately to his lover. Given the nature of the world in this poem, this lover may not be true, may hardly be counted on for stability. Arnold's late-nineteenthcentury England has already gone to war in spirit. Yet he dares to hope.

The cataclysmic nature of $19^{\text {th }}$ century thought as witnessed in Nietzsche, Darwin, and Arnold is inextricable from a host of other cultural forces at play during this volatile time. In his introduction to The Cambridge Companion to Modernism, Michael Levenson asserts a mindset of crisis as a prerequisite of modernism: "The loss of faith, the groundlessness of value, the violence of war, and a nameless, faceless anxiety — no one is likely to be surprised by such a list of disturbances, at once 
individual and social .... It is fair, and indeed important, to preserve memory of an alienation, an uncanny sense of moral bottomlessness, a political anxiety. There was so much to doubt: the foundations of religion and ethics, the integrity of governments and selves, the survival of a redemptive culture" (5). My historical overview elaborates on this cultural ambience, the combined components of which conceivably led to anxiety, this sense of being somewhat regrettably finished with what had come before, this alienation, this pervasive feeling of homelessness.

In their exploration of "the makings of modernity," Robin Winks and Joan Neuberger attribute the cultural crisis of pre-World-War modernity to a host of conspiring forces masking as progress:

Many Europeans defined modernity as progress .... Yet, underneath that heady confidence lay an equally powerful sense of unease. Since the mid1870 's and accelerating in the 1890s, critiques that had long been implicit or limited to small groups of the skeptical and disenfranchised were more often voiced as grave doubts about progress and modernity. Advances in science and industry brought new wealth and comfort to an unprecedented number of people, but society was still unable to relieve the dreadful living conditions of the people who labored to produce capitalism's plenty. The same science, technology, and medicine that extended and improved life produced weapons that made it easier for modern armies to annihilate each other. The control of nature weakened faith in God and in a natural, divine order of things. Traditions of order and hierarchy were crumbling in the face of women's assertions that they could do men's work and deserved men's rights. While global capitalism and the imperial conquest extended the reach of European power and culture, contact with different cultures raised questions about the uniformity of human nature and inevitability of a progress defined as European. Finally, while peace had so far reigned among the Great Powers, colonial competition had already brought them to the brink of war and would do so with increasing regularity after the turn of the century. While some claimed that economic interdependence and the terrifying power of new weaponry would keep nations from going to war, others felt that a modern apocalypse was inevitable and imminent. (289) 
Quoting at length here captures the profusion of unsettling influences that would have contributed to a generalized sense of instability in the late-nineteenth and early-twentieth centuries. The material below focuses only briefly on a few kernels that relate closely to the project at hand, specifically, on changing notions of time, the birth of sociology that may be ascribed to the dismantling of tradition, Sigmund Freud's psychological theories of society and personality, and on the most violent of ruptures, that of an unprecedented annihilation via the use of humankind's brainchild—technology.

Stephen Kern's The Culture of Time and Space: 1880-1918 reviews comprehensively how time and space took on a new character, how technology and science converged to create for those living in the early twentieth century divergent and often disorienting ways of perceiving their world. Kern argues that the process of standardizing time at the end of the $19^{\text {th }}$ century, scientific questioning of absolute time that culminated in the popularization of Einstein's theory of relativity in 1919, and anthropological studies of time such as that of Emile Durkheim in The Elementary Forms of the Religious Life (1912) inspired an unprecedented amount of modernist art-literary, visual, and cinematic - focusing on time as neither objective nor uniform. As Kern points out, on a practical level, standardized time won the day—how much easier life became when, for instance, trains arrived more or less on a designated schedule. Yet, processing this psychologically may well have been a different matter. Modernist preoccupation with time attests to underlying anxiety (Kern 10-35).

While artists were not necessarily familiar with the scientific discoveries of time's incongruence with objectivity, many artists were privy to William James' and Henri Bergson's nineteenth century philosophical contemplations of time. Not only do James 
and Bergson speak to the need of many moderns to turn inward to access resources beyond the fragmented present, but both offer a somewhat consolatory notion of time by denying that the past is always past. Quite the contrary, in The Stream of Consciousness (1892), James explains consciousness as continuous, as necessarily partaking of that which came before and anticipating that which will come in the future:

The knowledge of some other part of the stream, past or future, near or remote, is always mixed in with our knowledge of the present thing.... Consciousness, then, does not appear to itself chopped up in bits. Such words as 'chain' or 'train' do not describe it fitly as it presents itself in the first instance. It is nothing jointed; it flows. A 'river' or a 'stream' are the metaphors by which it is most naturally described. In talking of it hereafter, let us call it the stream of thought, of consciousness, or of subjective life. (239)

In the novels of many a high modernist—James Joyce, Virginia Woolf, and William Faulkner to name but a few-the stream of consciousness technique effectively allows the author to communicate subjective experience as quite different from logical, objective assessments of human experience, and, equally important, it asserts that past and present do in fact amass amorphously. Stream of consciousness likewise proves an effective measure through which to communicate the fragmentation that characterizes modern existence. In To the Lighthouse, Virginia Woolf employs the stream of consciousness trope in the hybridized form that is the autobiographical novel. Woolf's particular novel at once acknowledges fragmentation as cultural and personal truth and affirms writing about the self — dousing oneself in the waters of the past that are now present-as a means by which to steady understandings of the individual's relation to herself and her world.

Even more overtly than James, Bergson avows the existence of the past in the present: 
Pure duration [duree] is the form which the succession of our conscious states assumes when our ego lets itself live, when it refrains from separating its present state from its former states. For this purpose it need not be entirely absorbed in the passing sensation or idea; for then, on the contrary, it would no longer endure. Nor need it forget its former states: it is enough that, in recalling these states, it does not set them alongside its actual state as one point alongside another, but forms both the past and the present states into an organic whole, as happens when we recall the notes of a tune, melting, so to speak, into one another. Might it be said that, even if these notes succeed one another, yet we perceive them in one another, and that their totality may be compared to a living being whose parts, although distinct, permeate one another just because they are so closely connected? (100)

Bergson rejects linear accounts of consciousness-chronological history has no place in his schematic. Rather, past and present exist equally and simultaneouslyinterpenetrating, they are much like a piece of music that must be taken holistically rather than segmented into staccato, individual notes. While our recognition of duree is sporadic at best, Bergson affirms the "bold novelist" as one who might awaken us to truth by "tearing aside the cleverly woven curtain of our conventional ego" (133). Bergson does assert the caveat that words inevitably fail to capture the true nature of consciousness, but his faith in art to move us closer to truth is consistent with the modernist project. For Bergson calls attention to, as Stanley Sultan puts it, "the modernists' commitment to authenticity, and to acknowledging the non-rational, ... [to] an emphasis on portraying consciousness" (92). Inevitably, exploring consciousness entails exploring experiences of time. Indeed, Virginia Woolf's modernist memoirs-and the genre of memoir in general-affirm the continuity of identity across time, which is not equivalent to a solidification of the notion of identity. Rather, this contiguity revels in the extent to which present and past impinge upon each other, the extent to which understandings of each depend upon a consideration of the other. 
As Kern argues, the fixation on time that permeates many a modernist text and work of visual art is neither isolated nor idiosyncratic. To recognize the modernist pattern of marking the past as integral to the present, we need only consider Marcel Proust's Remembrance of Things Past with the madeleine as unanticipated pathway to a sweet moment of past; James Joyce's use of Greek myth as an architectural principle upon which to build his Ulysses and Steven Dedalus's characterization of history as "a nightmare from which I am trying to awake"; William Faulkner's Yoknapatawpha and its debilitating burden of being unable to cast off a past marred by loss and guilt; and Virginia Woolf's exploration of time passing in To the Lighthouse. Despite Ezra Pound's insistence that modernists need only "make it new," the modernist writers cited above find doing so without incorporating the past inadvisable, myopic, even impossible. In visual art, one might reference Edvard Munch's trauma-ridden mother and child paintings, Gauguin's Primitivist paintings with their desire to get back to a simpler past untainted by modernity, and Dali's Persistence of Memory with its exaggerated statement of the extent to which memory is sterile and flaccid yet unable to be expunged. To what extent is this persistence in focusing on the past preservative, and to what extent is it selfdefeating? As will be explained in the next chapter, nostalgia has the potential to inspire productive ways of viewing and acting in the world when it is self-reflective and hence aware that it is rooted in fantasy and constructed according to present needs and expedience. As the next chapter will show, such nostalgia may productively be appropriated to forge community amongst the bereaved, and as Käthe Kollwitz's art reveals, at its best nostalgia may be marshaled for the end of effecting social justice. 


\section{Examining the Social}

Responding to the sense of collapse, sociology as a discipline emerged during this period. In The Sociological Tradition, Robert Nisbet argues that the birth of sociology was a response to the individualist rationalism begotten by the Enlightenment:

These ideas-community, authority, status, the sacred, and alienationtaken together constitute a reorientation of European thought quite as momentous ... as that very different, even opposite, reorientation of thought that had marked the waning of the Middle Ages three centuries earlier and the rise of the Age of Reason. Then it had been Individualistic rationalism asserting itself against medieval corporatism and authority. Now, in the early nineteenth century, it is the reverse: the reaction of traditionalism against analytic reason; of communalism against individualism; and of the non-rational against the purely rational . . . In widening areas of thought in the nineteenth century we see rationalist individualism ... assailed by theories resting upon a reassertion of tradition .... We see the historic premise of the innate stability of the individual challenged by a new social psychology that derived personality from the close contexts of society that made alienation the price of man's release from these contexts. (8)

The call for a return to tradition appears to be quite incongruous with Nietzsche's radical call for individualism, his rant against the conformity of the masses, yet Nisbet's identification of a move toward non-rationality is compatible with Nietzschean ideology. Perhaps Nisbet's reference to irrationality here captures the sense that human relations unencumbered by commodification are viewed within modernity as "irrational." They are bound in the emotional, that which cannot and should not be rationalized.

Alternatively, embracing the communal might also be construed as hyper-rational, for individualism has the potential to lead to crushing isolation.

Nisbit's The Sociological Tradition asserts boldly that, in its obsessive attention to "community, authority, tradition, the sacred," at its advent sociology was at root conservative, opposed to forces that were damaging to these pillars of social belonging 
(17). According to many founding sociologists, the secularization that began with the Protestant Reformation, shone brilliantly in the Enlightenment, and culminated in the Industrial Revolution led to a dissolution of society and to engulfing alienation. Nisbet describes this paradoxical personal and collective sense of abandonment:

Modern society seemed to give rise to more and more situations in which the individual found himself alone or else caught up in large-scale, relatively impersonal organizations characterized by the psychology of aloneness. With the spread of the democratic franchise, man voted alone as the legally isolated citizen; he gained his livelihood as the worker, distinct and discrete, bound to others only by what Carlyle called a cash nexus; even within marriage and religion, changes in law and custom placed the individual - first the man, then the woman, and finally the child - in a condition of relative separateness that often could conceal anxiety quite as much as it promised freedom. To nearly all minds ... the main currents of history seemed to foreshadow a release from tradition and communality, a plunging of the individual into the waters of egoism (22).

The following question will recur in the course of this project, but it is not remiss to consider now: Is nostalgic longing as we see it manifest in the sociology of the time pathological? Regressive? Might, say, a revisioning of notions of community, a revisioning based upon fond (even fondly-imagined) memories of the past be productive?

To whom? Nisbet characterizes the fathers of sociology-Ferdinand Tönnies (18551936), Georg Simmel (1858-1918), Emile Durkheim (1858-1917), and Max Weber (1864-1920)—as innovators to be sure, but perhaps reactionary in motivation. It might be fairer, however, to identify as their motivators the loneliness and sense of disconnection with which they diagnose society in their writings. Perhaps they were responding to the needs they perceived in the culture milieu in which they lived rather than simply militating against change with their minds and their pens. 
Ferdinand Tönnies' conservativism is evident in his Community and Civil Society (1887) and its distinction between Gemeinschaft and Gesellschaft: "The theory of Gemeinschaft is based on the idea that in the original or natural state there is a complete unity of human wills. This sense of unity is maintained even when people become separated" (22). On the other hand, "The theory of Gesellschaft takes as its starting point a group of people who, as in Gemeinschaft, live peacefully alongside another, but in this case without being essentially united-indeed, on the contrary, they are here essentially detached. In Gemeinschaft they stay together in spite of everything that separates them; in Gesellschaft they remain separate in spite of everything that unites them" (52). Of Gemeinschaft, Tönnies claims the predominant existence of "mutual affirmation" that resembles relationships between mother and child, man and woman in sexual embrace, and siblings (22). But the union of Gemeinschaft transcends sexuality and blood ties and extends to home, neighborhood, community, and town. Here shared space, memory of that space, and a commitment to preserving a consecration of that space draw people together into a collective sense of home. The known and the possibility of working together to better that known build and preserve shelter.

Attention to Tönnies' references to nurture in his introduction to Gemeinshaft in Community and Civil Society reveals the extent to which his notion of community is alluringly romantic. He likens the "seeds" of community to the relationship between mother and child, bound in "pure instinct and pleasure, and at the same time ... shading over from a physical to a purely spiritual relationship" (22). As the child becomes capable of caring for and protecting herself, the mother relinquishes control, but this does not lead to utter separation. Memory and gratitude remain as reminders and living 
legacy. No doubt a product of his time, Tönnies is committed to a solidification of gender roles--he touts a mother's love as much more intense than a father's, but does acknowledge these two types of love as comparable in duration. His family and community is a patriarchal one by nature's decree, but he values the intensity, intuition, and bonds of maternal affiliation. Above all, Tönnies' communal order is a "natural" one that thrives on mutuality and the sharing of resources. It is shared space-and a commitment to preserving and enhancing that shared space, whether that space be material, traditional, or emotional-that affects cohesion. His communal haven is rather Marxist in conception, and not coincidentally. Tönnies acknowledged his indebtedness to Marx.

In their shared disdain for the ills spawned by industrialization, rampant capitalism, and urbanization, Marx and Tönnies conceptualize community in decisively romantic terms. Tönnies associates Gesellschaft, on the other hand, with individualistic selfishness, a disregard for the dignity of others, commodification, and relationships based purely on economic rationale. Ultimately, urbanization and its accompanied Gesellschaft "down the common people to decay and death." Without authentic and legitimate human connection, and without a shared sense of home, thriving is impossible. A collective home is a prerequisite to existing well.

Associating the disintegration of community with a failure to thrive is by no means unique to Tönnies. In his overview of Emile Durkheim's sociology, Dominick LaCapra explains that Durkheim understood religion as "a feeling of being at home in the world" (243). Durkheim was not arguing for a reinvigoration of Christianity, rather he believed the disintegration of religious community as product of the French and Industrial 
Revolutions to be detrimental to human functionality. Durkheim's Suicide (1895) posits

Catholic countries' suicide rates as much lower than those of Protestant countries. Since both religious persuasions believe taking one's own life to be wrong, he attributes elevated rates to Protestantism's devaluation of community-its individualism-in contrast to Catholicism's close-knit parishes and hierarchy (Pals 97). As Daniel Pals explains in his account of Durkheim's approach to religion, for Durkheim, "the rituals of religion have priority; it is they that are always basic and actually create the beliefs that accompany them. If there is anything 'eternal' about religion, ... it is that a society always needs rites - ceremonial activities of renewal and rededication" (113). Pals is right to critique this approach to religion as reductionist, but this particular form of reductionism brings to light the central place the concept of community was occupying in early modernity and the potential ramifications of its dissolution.

LaCapra explains Durkheim's vision of healthy societies as pivoting on the presence of ritual and symbol:

Through ritual, the values created during the 'great times' of the past would become available as a mythical foundation for life in the present. Most important, the communitas - the perfect communal identity among equals - realized in liminal events like revolution would be instituted in ritual as a component of social solidarity. Members of society would ritually realize communitas, the substratum of all stable society. And this realization would flow into daily life as a living faith which mitigated the dangers of both structural differentiation and self-interest. (210)

Hence, in Durkheim's schematic, the development of community depends upon the interpenetration of past and present, and community arises as the "collective effervescence" of the glorious past is realized as possibility and hope in the present. Moreover, the past's brilliance is limned only in retrospect, through the lens of a present that christens it as an instantiation of the benign. As it relates to the project at hand, 
communitas is central because it imbues those who partake of it with a sense of being at home in the world. To find home, however, a symbolic pilgrimage to the past must be undertaken. Theoretically-speaking, being away from home inaugurates the search for what has been lost, and such a search undertaken for the benefit of the many bestows hope for a better present and future, hope for the possibility of human goodness.

Like Durkheim, both Weber and Simmel recognize the anomie of modern, urban life as detrimental to the individual. By Weber's assessment, the Protestant Work Ethic leads moderns to value and identify themselves in terms of the type of work in which they engage on a daily basis. Weber implicates capitalism in the deprecation of more authentic ways of living. In "The Metropolis and the Mental Life," Simmel defines an "intellectualistic quality" of existence as "a protection of the inner life against the domination of the metropolis" (326). In Simmel's metropolis, the authentic personality has been extirpated-one "becomes a single cog as over against the vast overwhelming organization of things and forces which gradually take out of his hands everything connected with progress, spirituality, and value" (Simmel 337). The vapid individualism of the city, while providing freedom, can be soul-crushing in its anonymity. One is alone without human recourse: "It is only the obverse of this freedom that, under certain circumstances, one never feels as lonely and as deserted as in this metropolitan crush of persons. For here, as elsewhere, it is by no means necessary that the freedom of man reflect itself in his emotional life only as a pleasant experience" (Simmel 334). In the modern metropolis, emotions are squelched, as are meaningful connections. Home is but a word without a referent. The individual drowns in her well of loneliness. 


\section{Explaining Neurosis: The Birth of Psychoanalysis}

Paradoxically, while he rejects objectivity in favor of a keen eye toward the subjective, Sigmund Freud posits a totalizing theory that explains the neurosis that pervades modernity. Yet, he does not blame a break with tradition for humanity's ailments. He blames the past—each individual's personal past that, like Bergson's past, swells into the present. Attempting to understand the past is essential to one's well-being, for the past determines the present. Freud's insistence that our understandings of ourselves are typically superficial shook the Western world from any self-satisfaction it retained and confirmed for many their sense of personal alienation. Freud's revision of the family surely begets a sense of disgust and self-imposed homelessness, as mothers become potential lovers, fathers become competition, and penises become prizes.

"The Uncanny" (1919), written shortly after the end of the first World War, identifies as a source of anxiety not homelessness, but a return to a home we are loathe to acknowledge. In brief, the uncanny refers to a confrontation with the unfamiliar that arouses terror not because of the encountered strangeness, but because that which seems strange is inexplicably familiar, and, as such, brings us into contact with psychic material that has been repressed. To explain this phenomenon, Freud illustrates the linguistic irony that the German "heimlich" holds as one of its definitions "unheimlich," which reveals the home as terrain that is both familiar and strange:

[I]f psychoanalytic theory is right in asserting that every affect belonging to an emotion impulse - of whatever kind-is converted into fear by being repressed, it follows that among those things that are felt to be frightening there must be one group in which it can be shown that the frightening element is something that has been repressed and now returns .... [I]f this really is the secret nature of the uncanny, we can understand why the German usage allows the familiar (das Heimliche, the 'homely') to switch to its opposite, the uncanny (das Unheimliche, the 'unhomely'), for this 
uncanny element is actually nothing new or strange, but something that was long familiar to the psyche and was estranged from it only through being repressed. (147-48)

Alienation is humanity's heritage, for to repress is to be human. The home is inherently unhomely, as our relation to that home is always compromised by the fact that so much of our experience of home is unrecognizable to us. That which arouses fright and discomfort is the repressed home of one's psyche. Homelessness is inherent in existence.

Of particular significance is Freud's association of the uncanny with the maternal body: "It often happens that neurotic men state that to them there is something uncanny about the female genitals. But what they find uncanny ('unhomely') is actually the entrance to man's old 'home,' the place where everyone once lived" (151). Man is disturbed by a reminder of the body from which he issued, a body that is simultaneously desired and repulsed. Connection with the mother, a return home, is rejected on the grounds of its uncanniness. Yet, that which is repelled is simultaneously desired, which renders the desirer in a state of perpetual, confused longing. The idea of a return to the maternal home will be explored in more depth later, as the crux of the present study's argument is that the modernism of the two women artists on whom I focus locates the mother and home as central symbolically to healing the raw wounds of modern alienation. Freud's cynicism contrasts greatly the hope that Woolf and Kollwitz exude. For these artists posit faith in the curative potential of human connection, a faith that retains its potency even as they confront boldly the most deleterious elements of modern life.

The female rests as central to Freud's conception of the drives; eros and thanatos are enacted through the body of the lover-mother. As a number of male-authored 
modernist texts attest-Marcel Proust's Swann's Way, James Joyce's Portrait of the Artist as a Young Man, and William Faulkner's The Sound and the Fury, Absalom!, Absalom!, and Light in August - - the mother is the reservoir of both desire and blame. Blame for an inability to move forward, blame for the angst of modernity. Symbolic of the deceptively benign cradle of the past, the mother is home. This proves relevant to modernism's perseverative questioning of home as that which seemed innocent enough but somehow condoned and even nurtured a cultural persona that was epitomized in World War I. For many modern thinkers, the impulse to look homeward for answers was met with visceral horror, for it resulted in a recognition that what had seemed to be benevolent was capable of cultivating mass violence. For what was World War I if not humanity asserting its prowess through destruction, through self-annihilation? Even in its infancy, it seemed in retrospect, modern culture had been infected with the seeds of war, a war driven by eros and thanatos.

Freud's most pessimistic of studies, the interstitial Civilization and its Discontents (1930) rather prophetically anticipated the horrors of the rise of Hitler and the unspeakable atrocities that would confirm Freud's worst imaginings. Here he establishes the Western world as that most unheimlich of the heimlich; here he proclaims that culture is both object and vehicle of aggression. Freud dismisses the possibility of altruism and the practicality of Christ's commandment to "love they neighbor as thyself" (20). Unlike the sociologists discussed above, Freud diagnoses the human need to congregate as a mode of protection against others' and our own violent impulses.

In a decisively Hobbesian tone, Freud characterizes human nature as nothing short of base: 
The element of truth behind all this, which people are so ready to disavow, is that men are not gentle creatures who want to be loved, and who at the most can defend themselves if they are attacked; they are, on the contrary, creatures among whose instinctual endowments is to be reckoned a powerful share of aggressiveness. As a result their neighbor is for them not only a potential helper or sexual object, but also someone who tempts them to satisfy their aggressiveness on him, to exploit his capacity for work without compensation, to use him sexually without his consent, to seize his possessions, to humiliate him, to cause him pain, to torture and kill him. Homo homini lupus. (Civilization 68-9)

Humanity's homelessness proves instructive in its nature-an authentic sense of home does not hold because home's foundation is lain against humanity's base inclinations, against the fact that, on a fundamental level, man is a wolf to man. Maintaining civilization translates to restraining the self that would rather be using indiscriminately the resources and people encountered by that self. The dream of overarching love, companionship, and goodwill is hence one in which failure is inevitable. Civilization totters on humans' incessant reckoning with their teeming aggression that constantly threatens to break from its tether. The period in which Civilization and Its Discontents was composed is of particular pertinence. Freud had witnessed the First World War and perceived that it had done nothing to satiate humanity's base inclinations.

Like that of most of the thinkers cited above, Freud's vision of history is most definitively not progressive. For Freud recognized that the "advanced" civilization that had been built in the West was but a façade of greatness, science but another method through which humans were enabled to enact their aggression:

Men have gained control over the forces of nature to such an extent that with their help they would have no difficulty in exterminating one another to the last man. They know this, and hence comes a large part of their current unrest, their unhappiness and their mood of anxiety. And now it is to be expected that the other of the two Heavenly Powers, eternal Eros will make an effort to assert himself in the struggle with his equally immortal 
adversary. But who can foresee with what success and with what result? (Civilization 112)

This last line, added, apparently, in 1931, suggests Freud was beginning to see the direction in which Germany was moving, was anticipating the terror of yet another world war.

\section{War and Its Discontents}

Nothing could have prepared even the most cynical of minds for the cataclysm that befell Europe in 1914. In Rites of Spring: The Great War and the Birth of the Modern Age, Modris Eksteins describes in poignant terms the beauty, optimism, and dangerous collectivism of the summer before the war:

The days of that summer were long and full of sunshine; the nights were mild and moonlit. That it was a beautiful and unforgettable season is part of the lore of that summer of 1914, part of its poignancy and mystique ... . [T] he fine days and nights of that July and August encouraged Europeans to venture out of their homes and to display their emotions and prejudices in public, in the streets and squares of their cities and towns. The massive exhibitions of public sentiment played a crucial role in determining the fate of Europe that summer. (55-56)

Despite the fact that sociologists were bemoaning the lack of community in the latenineteenth and early-twentieth centuries, humankind had not forgotten how to assemble. As the above attests, however, communion as it was still extant in Europe during the summer of 1914 tended towards an unholy one. According to Eksteins, fervor for authentic Germanness fostered unification among the recently-consolidated German states. He tells of an interdenominational, open-air church service in front of the Bismarck monument, a service uniting Protestants, Catholics, Church, and State (62). As Eksteins puts it, Germans were united in a "Wagnerian Gesamtkunstwerk in which material concerns and all mundane matters are surpassed by a spiritual life force" (62). 
Here Eksteins posits the main thesis of his Rites of Spring, that art and life become one through such mass celebration, and that collapsing the two ultimately led to a mindset in which war itself was construed as spiritual ecstasy.

While this surely oversimplifies the precursors to World War I, his thesis does illuminate the negative ends to which ostensible human connection can lead. Nationalism can be an insidious by-product of coexistence and a celebration of a shared home, a distortion of coming together with the other. This German reunion of sorts represents the worst possible nostalgic impulse, the impulse to replicate what one believes to be lost, in this case to recreate Germanness in unadulterated form. How tragic that what would seem to be the most benign of desires-the desires for home and kinship — could be the catalysts of unprecedented mass horror.

And so it began with a beautiful spring and summer, with the pulsing energy of life, with dutiful soldiers like Virginia Woolf's Mrs. Dalloway's Septimus Smith who "went to France to save an England which consisted almost entirely of Shakespeare's plays and Miss Isabel Pole in a green dress walking in a square" (86). In The Great War and Modern Memory, Paul Fussell asserts that "irony is the attendant of hope, and the fuel of hope is innocence. One reason the Great War was more ironic than any other is that its beginning was more innocent" (18). While Fussell argues in this 1975 study of World War I's assault upon the Western psyche that "the Great War took place in what was, compared to ours, a static world, where the values appeared stable and where the meanings of abstractions seemed permanent and reliable," the above primary sources convincingly suggest otherwise (21). Perhaps governmental officials and those volunteering for war believed they would somehow save tradition through this drastic 
measure, but tradition was clearly under fire or such a measure would not be presumed necessary in the first place.

Nonetheless, Fussell is surely correct in his assertion that the progressively violent and meaningless war eroded the last vestiges of innocence. When nothing remained to believe in, when death's pall was immanent, dying soldiers returned to childhood in a desperate attempt to comfort themselves. Eksteins gleans from a primary source, a letter written by a Reverend J.M.S. Walker, how a critically-injured soldier receiving his last communion at the Somme uttered a childhood prayer: "'Gentle Jesus meek and mild, look upon a little child etc'-God bless father, mother, grandfather, and make me a good boy—then the Lord's prayer" (174). An elderly and feeble Harry Patch, Duke of Cornwall's Light Infantry, interviewed in World War I in Colour (2004), speaks with respect and regret of his small group of five cohorts, "a little group together," three of whom died. He can no longer remember their proper names but still remembers their nicknames. He also speaks somberly of a mortally-wounded Cornish man he encountered who asked Patch and his cohorts to shoot him. They did not shoot himthey did not have time to do so-and Patch remembers sorrowfully that "the last word he uttered was 'mother.' That's haunted me all my life. Mother." Patch was so haunted, in fact, that he would or could not speak of his wartime experiences openly until 1998, when he was some 100 years old. Patch, whose death in 2009 at age 111 marked the passing of the last surviving World War I veteran, only spoke of his experiences during the last eleven years of his life. His decades of silence attest to the unutterable horror that accompanied a loss of faith in human goodness. 
Fussell claims that "the modern imagination that last summer has assumed the status of a permanent symbol for anything innocently but irrecoverably lost," citing David Lowe who compares such memory of loss with that of the postbellum South's melancholic remembrance of imagined antebellum greatness (24). It follows that Fussell then analyzes wartime memories, legends, and literature in terms of "reinvigorated myth" peopled by “'secrets,' conversions, metamorphoses, and rebirths” (115). Interpreting current adversity in terms of a tradition of the supernatural—most notably Christianity and Arthurian Legend-illuminates the tendency to rest on the past when the present threatens. Sadly, the very traditions in which those experiencing World War I most earnestly desired to locate truth were the very traditions crumbling in the wake of modernity. Hence World War I poetry exudes lost innocence, tradition betrayed, symbols collapsing upon themselves. This is, perhaps, an irony applicable not only to war, but to modern living in general.

In contrast to Fussell, Jay Winter's Sites of Memory, Sites of Mourning illustrates, despite accounts to the contrary, and despite the development of "a new language of truth-telling about war in poetry, prose and the visual arts"-what we have come to call "modernism"- -traditional forms of expression, symbols, and motifs best facilitated healing during and after World War I:

[T]he enduring appeal to many traditional motifs - defined as an eclectic set of classical, romantic, or religious images and ideas-is directly related to the universality of bereavement in the Europe of the Great War and its aftermath. The strength of what may be termed 'traditional' forms in social and cultural life, in art, poetry, and ritual, lay in their power to mediate bereavement. The cutting edge of 'modern memory,' its multifaceted sense of dislocation, paradox, and the ironic, could express anger and despair, and did so in enduring ways; it was melancholic, but it could not heal. Traditional modes of seeing the war, while at times less challenging intellectually or philosophically, provided a way of 
remembering which enabled the bereaved to live with their losses, and perhaps to leave them behind. (5)

Winter emphasizes that during the war, European communities were transformed into "communities of bereavement" (6). His focus on communal support is helpful in counterbalancing the arguments of both Fussell and Eksteins, both of whom are reluctant to acknowledge that those at home broke through their alienation, fragmentation, and terror to support each other through their collective losses. What Winter shows us is that despite the fact that European homes were shattered, never to be peopled by the sons, daughters, fathers, and mothers who found themselves involved in a war to which they lost their lives, home was a concept that many successfully endowed with enduring comfort. Of particular and reassuring salience is what Winter speaks of as "adoptive or informal kinship." Soldiers wrote to the families of their missing, injured, or dead cohorts with accurate and sometimes reassuring accounts of their beloved fellow soldiers, and the Red Cross and other aid agencies went above and beyond the call of duty in continuing to research and communicate to relatives the last hours of the missing or dead (40).

The erection of war memorials, according to Winter, was also a mode of communal healing, as memorials "marked the spot where communities were reunited, where the dead were symbolically brought home, and where the separations of war, both temporary and eternal, were expressed, ritualized, and in time, accepted" (98). Although especially in the immediate and near-immediate aftermath of war these war memorials were wrought with raw emotional intensity, Winter insightfully argues that "once the moment of initial bereavement had passed, once the widows had remarried, once the orphans had grown up and moved away, once the mission of veterans to ensure that the scourge of war would not return had faded or collapsed," the rawness of these sites 
diminished (98). They had performed their function and then became primarily sites of historical rather than personal and communal intensity.

As Bessel Van Der Kolk's landmark anthology of writings on posttraumatic stress disorder, Traumatic Stress: The Effects of Overwhelming Experience on Mind, Body, and Society, expounds, however, war veterans could not glibly put their experiences behind them and resume civilian life. Their journeys towards healing were generally much more perilous than civilians'. Matters were made worse by psychiatrists such as Karl Bonhoeffer (1868-1948) who blamed returning soldiers' neuroses on both personal weakness and on the desire to take advantage of governmental stipends for the disabled (Van Der Kolk, Weisaeth, and Van Der Hart 51). In Mrs. Dalloway, Virginia Woolf illustrates movingly the calamity of Post-Traumatic Stress Disorder (PTSD) among war veterans through the figure of Septimus Smith, who ultimately kills himself because he is unable to escape his traumatic past. He alternately "cannot feel," is consumed by survivor's guilt, and is plagued by intrusive memories in which he experiences past war atrocities as occurring in the present.

Yet, still—and this is in no way intended to underestimate the pain, suffering, physical and mental illness, and death that resulted from participation in and exposure to such mandated violence—-soldiers bonded in the trenches and after the war formed support networks amongst themselves (Winter 45). Most reassuring, and, ultimately most heartbreaking, is the impromptu truce of Christmas 1914, when sworn enemies at a number of battlefields spontaneously stopped fighting to celebrate Christmas together, to sing carols and enjoy the Germans' candle-illuminated tannenbaum (Eksteins 109-14). Soldiers brought traditions of home to the battlefield and expanded them through contact 
with the enemy's traditions. Perhaps it was not only comrades killed but memories of brief fraternization like that of Christmas 1914 that gouged the memory most.

Stephen Kern emphasizes that World War I "contradicted the historicist thrust of the preceding century that conceived of the past as a continuous source of meaning for the present," and this is true, to an extent (293). Kern convincingly shows that the modern world differed greatly from the worlds that preceded it:

Modern technology also collapsed the vault of heaven. Never before the age of the wireless and airplane did the heavens seem to be so close or so accessible - a place of passage for human communication and for human bodies in man-made machines. The omnipresence and penetrating capacity of wireless waves rivaled miraculous action and reversed the direction of divine intervention. Planes invaded the kingdom of heaven, and their exhaust fumes profaned the realm of spirit. Upwards was still the direction of growth and life, but in this period it lost much of its sacred aspect. (317)

For soldiers who fought in the war and families who lost their sons, fathers, brothers, mothers, and sisters, the futuristic spectacle of modern warfare became a disorienting, horror-driven rhythm that jarred the mind and body. As the evidence from Winter makes clear, ties with the past were not absolutely severed; yet, the world had changed. Suffering in a decimated and impoverished Germany, millions longed for a sense of enduring and meaningful community (Eksteins 312 ). And so the Nazi party found a following with a propagandistic appeal to Gemeinshaft, to spirit, to purity, all of which seemed to symbolize the innocence of yesteryear. Yet, the innocence of yesteryear was no longer innocent.

We are left with a conception of modernity that is perhaps best illustrated by Walter Benjamin's image of "The Angel of History." Thwarted in his attempt to escape Nazi-occupied France via the French-Spanish border, Benjamin took his own life on the 
night of Wednesday, September 25, 1940 in Porbou, Spain. He was to be extradited to France the next morning, where Nazi authorities were awaiting him. In retrospect, the pessimism of "The Concept of History" (1940), written just months before his suicide, anticipates his last act:
A Klee drawing named "Angelus Novus" shows an angel looking as though he is about to move away from something he is fixedly contemplating. His eyes are staring, his mouth is open, his wings are spread. This is how one pictures the angel of history. His face is turned toward the past. Where we perceive a chain of events, he sees one single catastrophe that keeps piling ruin upon ruin and hurls it in front of his feet. The angel would like to stay, awaken the dead, and make whole what has been smashed. But a storm is blowing from Paradise; it has got caught in his wings with such violence that the angel can no longer close them. The storm irresistibly propels him into the future to which his back is turned, while the pile of debris before him grows skyward. This storm is what we call progress. (257-58)

Powerless to intervene in a history that is already done, a history comprised of atrocity after atrocity, brittle shard upon brittle shard, the angel is impotent. That the angel's back faces the future reveals the blindness that characterizes an attempt to move forward ethically and salubriously; the rubbish heap of atrocities accumulates exponentially. Even an angel - a forlorn dream of divine intervention — cannot save humankind. 


\section{CHAPTER II}

\section{RETURNING TO INTERSUBJECTIVE ROOTS: FINDING A HOME WITHIN HOMELESSNESS}

What recourse may be sought when angelic voices are stifled by rubble, consumed by past becoming present, amassing atrocity posing as progress? Recognizing the travesties of both the past and the present, Walter Benjamin's angel is nonetheless powerless to intervene. It is no wonder that the past haunts so much of artistic, literary, philosophical, and sociological discourse from the late-nineteenth and early-twentieth centuries: greater historical awareness combined with a pace of life becoming exponentially more rapid and less humane left many wondering where they had been and how they found themselves in such an unheimlich place. However, like Benjamin's angel, they could no more make sense of their pasts than reverse the accumulation of historical waste. As many of the thinkers cited in the previous chapter articulate, disconnectedness, a failure to thrive, and a sense of homelessness characterize the experience of modernity.

The task of this dissertation is to illustrate how two modernist artists navigate such uncertainty and to investigate the types of presence they posit to fill the sepulchral void. It is through the figure of the mother that Virginia Woolf and Käthe Kollwitz evoke the notion of home, though by no means do their visions of that home confine female identity in the domestic as it has been traditionally understood. Rather, they associate the maternalized home with creativity, imagination, and love, qualities that 
liberate rather than disenfranchise. Home nourishes the becoming of all of its inhabitants, and, as such, it is a site of hope for the future.

The proposal that these artists bestow models of home as potential remedies to modernity demands explanation, as, on the surface, this appears to be a nostalgic, regressive, and even disempowering proposition. Rita Felski's The Gender of Modernity, for example, exposes the insidiousness of modernity's tendency to locate woman outside the parameters of culture:

By being positioned outside the dehumanizing structures of the capitalist economy as well as the rigorous demands of public life, women become a symbol of nonalienated, and hence nonmodern, identity. A proliferating body of scientific, literary, and philosophical texts sought to prove that women were less differentiated and less self-conscious than men and more rooted in an elemental unity. As a result, for a range of female as well as male thinkers, women could enter modernity only taking on the attributes that had been traditionally classified as male. (19)

Felski maintains that situating women as such is a product of "masculine fantasy" that preserves for itself a female "home," a firm foundation to which men can return when the strenuous projects of modernity drain them of vitality (21). A similar argument is made by psychoanalytic revisionists Luce Irigaray and Jessica Benjamin, discussed below. What this scenario suggests is the tolls that rugged individualism in action takes upon those actively engaged in its precepts. Paradoxically, a good dose of femininity is unconsciously prescribed as a remedy for what ails the modern man beset with the ideology of separate spheres, an ideology that privileges masculine potency. Going home arises as a dire need.

Felski diagnoses modernity with a particularly insidious form of nostalgia directed toward the mother: 
The maternal body is seen to embody a fullness of presence, a fantasmic image of originary harmony that is contrasted to the adult consciousness of alienation and lack.... The psychic investment in an idealized, maternal precultural realm is itself a function of the privatization of the family within Western culture, with the mother assuming exclusive responsibility for the care of her children, and of emerging norms of the self which define women as natural and emotional creatures in the context of an increasing demarcation between the private and public worlds. (39)

The ideology of separate spheres, then, equates with nostalgia for childhood simplicity shielded from heavy gusts of modern angst. This, in turn, secures women in a prescriptive cycle of sustaining others rather than tending to their own needs. Not only are women confined in the domestic in this scenario, but those whom they sustain fail to recognize women as the foundation of their empowerment.

\section{The Future of Nostalgia}

Rita Felski and the theorists discussed in the "Psychoanalysis and its Discontents" portion of this chapter warn that a reactionary nostalgia for the mother as home perpetuates male dominance. Psychoanalytic positions on nostalgia will be considered later in this chapter, but at this juncture it is incumbent to pursue a refreshingly unique view of nostalgia, the view of an exile from the former Soviet Union who experienced first-hand a loss of home and community. The discussion of Svetlana Boym's The Future of Nostalgia will keep at hand the following considerations: What is the function of nostalgia, and does it inevitably amount to wallowing insidiously in a desire for that which can never be secured? Does nostalgia compromise the efficacy and ethics of the present?

Writing as a member of a diaspora, Boym explores thoughtfully the above concerns. Rather poignantly, she explains nostalgia for home as infinitely regressive: "The object of longing ... is not really a place called home but this sense of intimacy 
with the world; it is not the past in general, but that imaginary moment when we had time and didn't know the temptation of nostalgia" (351). The phrase "intimacy with the world" is key here, affiliated as it is with an association of childhood with closeness and reciprocity. While Boym does not discuss maternity specifically, nostalgia for the mother might well be analyzed through the lens of Boym's account, as hers is an examination of connection with others and with one's surroundings. Nostalgia occurs when one's present is pulled into the past and the past swells into the present in Bergsonian fashion, perhaps not in vain.

Boym proceeds to show in a chapter on "Diasporic Intimacy" a paradoxical birth of community that pivots on a shared loss, a shared homelessness:

'[D]iasporic intimacy' . . . is not opposed to uprootedness and defamiliarization but is constituted by it. Diasporic intimacy can be approached only through indirection and intimation, through stories and secrets. It is spoken of in a foreign language that reveals the inadequacies of translation. Diasporic intimacy does not promise an unmediated fusion, but only a precarious affection - no less deep, yet aware of its transience. In contrast to utopian images of intimacy as transparency, authenticity, and ultimate belonging, diasporic intimacy is dystopic by definition; it is rooted in the suspicion of a single home, in shared longing without belonging. It thrives on the hope of the possibilities of human understanding and survival, of unpredictable chance encounters, but this hope is not utopian. Diasporic intimacy is haunted by the images of home and homeland, yet it discloses some of the furtive pleasures of exile. (252-53)

Central here is an enlightened awareness of the fact that the subject of one's longing will not suffice indefinitely, that desire is an integral aspect of human experience. It is, in fact, loss that foments relationship among those who have survived, but that does not translate into a community of misery. On the contrary, laden with memories and ideas of what might constitute the good life, members of the community of the exiled come 
together through a shared humanity, never forgetting the ineffability of each member's portion.

Recognizing this undergirding fabric of connectivity does not amount to finding oneself as the other or the other as oneself. Boym clarifies that "[n]ostalgia is paradoxical in the sense that longing can make us more empathetic toward fellow humans, yet the moment we try to repair longing with belonging, the apprehension of loss with a rediscovery of identity, we often part ways and put an end to mutual understanding. Algia - longing - is what we share, yet nostos - the return home-is what divides us .... The danger of nostalgia is that it tends to confuse the actual home and the imaginary one" (xv-xvi). Applying nostalgia indiscriminately constitutes real threat. Such application potentially leads to nationalism, an obliteration of identity, and the failure to account for the uniqueness of each. As is discussed below, both Luce Irigaray and Jessica Benjamin assert an ideal of fusion as delusional and unethical. This nostalgic tendency, which Boym terms "restorative nostalgia[,] puts emphasis on nostos and proposes to rebuild the lost home and patch up memory gaps ... [Restorative] ... nostalgics do not think of themselves as nostalgic; they believe that their project is about truth" (41). Unable or unwilling to acknowledge the fleeting nature of truth, restorative nostalgics are motivated by a desperate loss that they believe can only be quenched by the reemergence of what they imagine has disappeared. Theirs is a desire untempered by active thought.

On the contrary, what Boym describes as reflective nostalgia:

reveals that longing and critical thinking are not opposed to one another, as affective memories do not absolve one from compassion, judgment, or critical reflection. Reflective nostalgia does not pretend to rebuild the place called home; it is 'enamored of distance, not of the referent itself.' 
Nostalgics of the second type [reflective nostalgia] are aware of the gap between identity and resemblance; the home is in ruins .... This defamiliarization and sense of distance drives them to tell their story, to narrate the relationship between past, present and future .... The past is not made in the image of the present or seen as foreboding of some present disaster; rather, the past opens up a multitude of potentialities, nonteleological possibilities.... (49-50)

Reflective nostalgics, as the name indicates, reflect on the past, recognize its deficiencies and virtues, and delve below the surface to revel in the many dimensions of the referent. Most significant, these reflections on the past may be used to better the present and future: " $[R]$ eflective nostalgia can foster a creative self[,] . . [but] the dreams of imagined homelands cannot and should not come to life. They can have a more important impact on improving social and political conditions in the present as ideals, not as fairy tales come true" (355). In this way, Boym's theory of nostalgia may be applied constructively to the "'transcendental homelessness' and permanent exile" of modernity rehearsed in the earlier historical overview (256). In the cases of Virginia Woolf and Käthe Kollwitz, creativity is indeed fostered by nostalgia for a home that in retrospect was benign and accommodated imaginative engagement with the world, and their artistic projects explored in this study reflect a commitment to re-creating their presents to reflect an attunement to the most salutary and humane values potentialized by the idea of the lost home.

Boym's position as one physically exiled from what was her homeland is not unlike the alienation that encumbered many moderns, some exiled from their countries of origin due to the ravages of war, some exiled from their idea of home that was likewise obliterated as World War I dragged on interminably. As will be discussed later in reference to Virginia Woolf and Käthe Kollwitz, Boym's theory of exile and nostalgic 
return applies equally well to individual moderns whose personal histories eerily paralleled those occurring on the cultural level. Woolf translates her own reflective nostalgia into literary theme and technique that render poignantly modern loss, and in doing so she models a response that is salutary both to the self and to the other with whom that art is shared. Clearly, nostalgia for the mother as discussed by Felski yields little fruit, but a re-characterization of that nostalgia might bring to light benefits that those who are in principle averse to nostalgia hesitate to acknowledge. The end of this chapter much more explicitly addresses potential merits of nostalgia, but, for now, let us consider the following questions: What if what is termed "nostalgia for the mother" encompasses a desire not for reunion or duplication, but for connection? What if desire for the mother is inextricable from desire for sustained relations with another subject or other subjects? What if the mother is recognized as she who chose to connect, she with whom I was once connected, not fused? What if desire for the other is not mere narcissism or ego reparation, what if it constitutes a yearning to be immersed in the ethical? Freudian psychoanalysis would deny these possibilities, but revisionist psychoanalysts are not closed to such hope.

\section{Psychoanalysis and its Discontents}

As detailed in the previous chapter, Sigmund Freud's Hobbesian account of civilization and of psychosocial development as inextricable from the impersonal forces of eros and thanatos precludes the idea of spiritual connection through communion with an other or others. In Civilization and its Discontents, Freud discounts the "oceanic" feeling of interconnectedness as misplaced and misunderstood. A being who nurtures and controls the child, Freud's mother is a sexual object over which son and father 
contend. Freud's consignment of woman to the role of passive container feeds feminist suspicion of desire for the mother as a form of patriarchal imprisonment. As the brief discussion of Freud's "The Uncanny" in the previous chapter attests, in his universe, desire for the mother is proximal thanatos. To return to the mother is to indulge one's appetite for death.

In her introduction to Freud on Women, Elisabeth Young-Bruehl elaborates on objections to Freud's account of femininity and motherhood: "Freud ... viewed femininity as failed masculinity. His claim that the libido is not just active but masculine has correlatives in every facet of his theory. Females start out like males and thendisappointed in their mother-love, humiliated over their lack of a penis, self-deprived of their masturbatory pleasure - take a fall into femininity. A girl who finds she cannot be a man settles for being a mother with a "penis-child"' (41). In this scenario, for the male child a return to the mother represents the inclination to dominate, and for the female child a return entails relishing in her own (impotent) ability to dominate another inferior. Either way, the mother is hardly empowered or active, except to the extent that she plays a role in the development of her inevitably neurotic offspring. Freud's women reside in the home, but the home is no haven.

Like Nietzsche's, Freud's theories were pivotal in awakening moderns to the dysfunction of the culture in which they lived, pivotal in promulgating a hermeneutic of suspicion. Though Freud's theories of human relations run counter to the faith in humanity that Woolf and Kollwitz maintained in the face of their recognition that human relations had deteriorated into abject baseness, Freud did play an important role in exposing the deleterious ends to which supposed progress might be directed. His 
theories, that is, worked to dispel any last vestiges of the smugness toward which the West had been notoriously prone. Moreover, despite its limitations, Freudian psychoanalysis lay the foundation for revisionist psychoanalysts who would appropriate the discipline for the theorization of ethical ways of becoming with the other.

Surely desire for another need not be viewed only through the lens of crisis; surely coming together with the other can be fulfilling and affirming in itself. And, while desire might be insatiable, rather than envisioning desire as emanating from a wound, we might theorize it as responding to beauty and to love of the world, without which we are truly wounded. To varying extents, Julia Kristeva, Luce Irigaray, and Jessica Benjamin move in such a direction.

Julia Kristeva's attention to the experience of motherhood makes a formidable contribution to psychoanalysis. Though feminists are not unanimously in favor of Kristeva's thought—-the extent that she does not break free altogether from Freud's male chauvinism—select ideas are certainly useful in considering the mother-child relation. Kristeva's notion of the semiotic, the non-referential element in signification aligned closely with the bodily rhythms, gurgles, and preverbal intonations experienced and produced by the fetus and infant in concert with the maternal body, proves particularly applicable to Woolf's and Kollwitz's views of art as begotten in a reverence to connectivity. As distinguished from the symbolic, the semiotic is described best as fluid. As such, echoes of its intonations, nonlinearity, and rhythms may be sensed in the language of poetry, a language that in its unconventionality disrupts the status quo. Because the semiotic has the potential to dismember and expose society's power structures and tools of oppression, however, it is repressed. Only in coming into 
(imagined) corporeal contact with our own experiences of the semiotic-with our experience of being mothered, our experience of the body, and, potentially, with our own motherhood—can the semiotic begin to achieve its revolutionary capabilities.

Most applicable to the current project is Kristeva's call for a much-needed discourse of maternity. In "Stabat Mater," she argues that for centuries an obsession with the Virgin Mary contained cultural anxiety regarding motherhood, but that with modernity the sway of Mariology diminished. Hence the need for an alternative. The Virgin, Kristeva argues, was able "to calm social anxiety and supply what the male lacks, but also to satisfy a woman, in a way that the community of the sexes is established beyond, and in spite of, their flagrant incompatibility and permanent state of war" (135). Desexualized, the Virgin quelled the male subject's fear of female sexuality and his irrevocable connection with it. While this desexualization comforted the male, it proved quite injurious to the female in its renunciation of the female reproductive body and its devaluation of relations between women, specifically that of mother and daughter. Only the Virgin's milk and tears, her superfluous bodily fluids that attest to the physiologically- and emotionally-consuming process of mothering but also affirm the female body, offer something with which the maternal subject can identify. The collapse of the cult of the Virgin accompanying the secularization of Western society has rendered urgent the development of a new maternal discourse, one that Kristeva hopes will be liberating to women, one that will not deny the pleasures and the non-language comprised of the unique communicative rhythms of the maternal body, one that will speak maternal experience authentically. 
Kristeva avers that bearing children inevitably leads to a consideration of one's own experience of being mothered, the perhaps distant memory of having been nurtured, and this proves pertinent to understanding both Kollwitz and Woolf. "Stabat Mater's" juxtaposition of academic discourse with Kristeva's stream-of-consciousness reflections on her own motherhood makes an overture toward introducing maternally-earnest language. Significantly, her words appear on the left side of the page, are spoken in the first person, and are highly emotive. At least in this essay, Kristeva, like Helene Cixous, expresses an interest in writing the body, "Let a body finally venture out of its shelter, expose itself in meaning beneath a veil of words. WORD FLESH. From one to the other, eternally, fragmented visions, metaphors of the invisible" (134). It is significant that her corporeal writing is deliberately "fragmented"-its fractures derive from the body they attempt to trace, emanate. In that way, they deny essentialism. Kristeva's experience of maternity as she articulates it is complicated, full of pain and joy, dominated only by the child to whom she has given birth.

While a duplication of the correct layout of Kristeva's essay here is impossible, the following excerpt from her personal reflections conveys a sense of their tenor:

Wind in the grass the cry of a gull in the distance, echoes of the waves, of sirens, of voices, or of nothing? Or his, my newborn child's, tears, syncopated spasm of the void. Now I hear nothing, but my eardrum continues to transmit this sonorous vertigo to my skull, to the roots of my hair. My body is no longer mine, it writhes, suffers, bleeds, catches cold, bites, slavers, coughs, breaks out in a rash, and laughs. Yet when his, my son's, joy returns, his smile cleanses only my eyes. But suffering, his suffering - that I feel inside; that never remains separate or alien but embraces me at once without a moment's respite. One does not bear children in pain, it's pain that one bears: the child is pain's representative and once delivered moves in for good" (141). 
Although Kristeva very overtly focuses on how her body and mind become captivated with her child, in particular with her child's pain, resentment is not the affect communicated here. Rather, it is as if giving birth has burdened her with the weight of human suffering, and while it is not the only route to ethical action, it does reveal ethics in action. The helplessness of an infant in many ways represents crisis at its height, and it is up to us, its caregivers-male or female - to make it right, recognizing all the while that bringing life into the world demands bequeathing to our children the tragic truth that "And you, one day a sword will pass through your soul" (141).

This account of motherhood does not capture the flavor of intersubjectivity per se, a topic engaged below in the discussion of Jessica Benjamin, because it does not reveal the child responding to or interacting with the mother. However, it does capture empathy at its deepest, an empathy springing from corporeality. Elsewhere in "Stabat Mater," Kristeva speaks of the bodily sensations, many of them pleasurable, involved with mothering, sensations that inhabit even her dreams. Indeed, the body is at the forefront of the above passage-witness the litany of visceral vibrations and emanations expressed through the body of the mother. Kristeva ends this reverie with "My son." A sweet conclusion.

Returning repeatedly to the sense in which motherhood bores a deep wound in identity, Kristeva ultimately calls for a herethics to be promoted by women, an ethics not loathe to acknowledge the flesh:

If it is true that an ethic for the modern age is no longer to be confused with morality, and if confronting the problem of ethics means not avoiding the embarrassing and inevitable issue of the law but instead bringing to the law flesh, language, and jouissance, then the reformulation of the ethical tradition requires the participation of women. Women imbued with the desire to reproduce; . . . women ready to help our verbal species, afflicted 
as we are by the knowledge that we are mortal, to bear up under the menace of death; mothers. For what is ethics divorced from morals? Heretical ethics - herethics - may just be that which makes life's bonds bearable, that which enables us to tolerate thought, and hence the thought of death. 'Herethics' is a-mort, amour. Eia mater, fons amoris. Let us listen again, therefore to the Stabat Mater, and to music, all music. It swallows goddesses and strips them of necessity. (151-52)

Maternal suffering, bound as it is in the laboring, empathetic body, links us symbolically with death, for living entails acknowledging death as our inheritance. Contemplating the maternal body, the semiotic, bringing it to consciousness, is an ethical act in that it exposes the maternal base and orients children-read everyone-to reality, a reality that, though brutal, is made bearable by love. Kristeva's final emphasis on music is strategically brilliant and beautiful—music, Kristeva avers, may be associated with the semiotic, but, lest we forget the symbolic, the words are equally important. Perhaps singing them will bring the ethical imperative of herethics to both men and women. In this essay, Kristeva moves towards the ethical, suggesting at times ethics as inextricable from essential, corporeal humanness, and with that suggestion she recasts the psychic drives as less narcissistic.

Like Kristeva, Luce Irigaray identifies the severance of the mother and daughter bond as a danger of psychoanalysis as it has traditionally been conceptualized. Elisabeth Grosz explains that, in Irigaray's view, psychoanalysis is inherently detrimental to women in denying them a means through which to live in relationship:

$[\mathrm{P}]$ sychoanalysis does not allow a space for restructuring or reconceptualizing female relations, or reinventing a body-to-body and woman-to-woman relation with the mother. For Irigaray, this possibility can be concretized only by a multi-directional quest - the search for a history that has been rendered invisible by the refusal to accord women a name and place of their own; as well as the construction of a future which involves the painful process of giving up the mother as haven, refuge, or shelter in return for seeing her as a woman" (Jacques 182). 
The substitution of the idea and figure of the mother for the category "woman" is in part to blame for the prohibition on amiable female relations between mother and daughter. Irigaray describes how in desperation man appropriates woman to fulfill his desire to locate and recreate his "first and ultimate dwelling place[,] ... his prenatal home" (Ethics 11). Driven by that nostalgia-in relating to women and in building his life-man forecloses potentially ethical relationships. In this schematic, women are "designed" to contain the child and contain the man-however, they are given neither the recourse nor the knowledge to contain, to know, to hold the self. Here male restorative nostalgia directed at the mother is definitely insidious, as it forces women to follow a wellgrooved, socially-constructed path of regression.

Because doing so perpetuates a climate that works against mutual flourishing, Irigaray deems destructive reducing woman to the maternal. Irigaray asserts as integral to both men and women a relationship with the mother that acknowledges the debt we owe to her and concedes her separation from us. Mothers are beings in their own right, beings with identities that exceed that of mother. A particular violence inflicted by psychoanalysis and by sanctioned nostalgia blind to its desire to restore that which denies the mother's viability beyond her nurturing role is the erasure of a female genealogy, a genealogy that would be commodious enough to encompass and further female identification with the mother. This identification would, moreover, lead to enhanced recognition of mothers as others with whom women might establish relationships of equality. While denying maternal influence is unethical, recognizing the mother as a "you" in her own right is incumbent: 
Yet it is true that the child is always within us, and that we need you as we need parental guidance. Therefore you cannot be only you-father at the risk of depriving the child I am of the warmest and most vital childhood guidance-you-mommy. Once beyond the moment of intimacy with the child I am, it is towards the other that I should turn and, moreover, return trying not to impose on him or her any genealogical refuge of authority I may have. You, who are you? You are not nor ever will be mine. (I Love 119).

Like Kristeva, Irigaray calls for the development of a new "syntax, another 'grammar' of culture" (Sex 143). Irigaray's grammar would comprise "a transcendental which leaves them [mothers] free to embrace the maternal while giving them back their childhood at the same time. A transcendental ... that surrounds them and envelops them in their jouissance" (Ethics 69). An unspoken association of motherhood and femininity with self-effacement would be liberatingly absent.

This language would move toward love, an oft-taboo word in academia, a concept toward which Irigaray moves in her more recent writing. Most subversive (and most liberating) of Irigaray's claims is that one of love's manifestations is an "enveloping between mother and daughter, daughter and mother, among women, [that] must not become closure, enclosure while protecting the one 'for the other's sake' in a state of seduction or bondage that annihilates any possibility of subjecthood. Given that love of the same, within the same, is a form of innerness that can open to the other without loss of self or the other in the bottomlessness of an abyss" (Ethics 69). Key to Irigaray's vision of love is mutuality, mutual caring and commitment to the other's flourishing, and equal attention, care, and commitment to one's own flourishing. Approaching the other with a sense of omnipresent wonder - at an otherness that cannot be fully fathomed but nonetheless can be loved, embraced, and engaged. Mutuality demands a reverence for 
difference. The other is not for our use, not for our narcissistic fantasies, but is dignified and worthy of love in her uniqueness.

Nostalgic revelries of merging and wholeness have no place here, for within a self-other relationship, only rarely and briefly do we share a mediating space almost seamlessly. The vitality of relationship depends upon our integrity as individuals, respect for that which invigorates a sense of perpetual wonder. This wonder is directed toward the present: "The bridge, the stasis, the moment of in-stance? Where I am no longer in the past and not yet in the future. The point of passage between two closed worlds, two definite universes, two epochs, two others. A separation without a wound, awaiting or remembering, without despair or closing in on the self" (Ethics 75). Wonder inspires incarnated divinity, an ecstasy never asleep to the here and now that thrives in that perpetual though mitigated distance between two subjects instantiated by their desire for that which goes beyond mere selfishness. While Irigaray's concept of communion may appear to run counter to Boym's notion of "diasporic intimacy," it need not, for "diasporic intimacy" involves relations in the present between those who share profound experiences of loss. As Boym maintains, the subjects within the diasporic community are by no means interchangeable; they are drawn together through commonality. In both Irigaray's and Boym's worlds, identity is fluid, and this fluidity involves negotiations of pasts and presumed futures through engaging passionately in the glistening present.

Like Boym, Irigaray is no blind optimist. She recognizes wonder as "a mourning for the self as an autarchic entity; whether that mourning is triumphant or melancholy" (Ethics 75). Coming to terms with being bound in relationship to the other can lead to a sense of ecstasy, titillating freedom in connection, but it can also be experienced as a loss. 
It is as if the nostalgic inclination toward the mother has risen to the surface, except this time not as nostalgia but as a recognition of the impossibility of being without touching the other and being touched by her. Connection with the other through wonder is also, Irigaray asserts, the beginning of a new story, a birth, and this once more gestures towards an ideal of symbolic maternity stripped of its tendency to relegate the (m)other to she who exists solely to nurture me, to render me whole. Unpredictable in its scintillations, wonder is not a beacon of unceasing light. Its glimmering brilliance bespeaks perpetual striving for that which is unreachable, never-fully realized. It bespeaks fragmentation.

Irigaray's recent phenomenological turn is particularly fruitful, as it grants substantiality to human connection. Her latest studies are devoted to conceiving of ethical love, which, like Kristeva, she views as bound in considerations of the first relationship:

The "object" of wonder or attraction remaining impossible to delimit, impose, identify (which is not to say lacking identity or borders): the atmosphere, the sky, the sea, the sun. That which he designates as woman-eternity, an other who is sufficiently open, cosmic, so that he can keep on moving toward her. Not the eternal feminine of images and representation(s). But a mother-woman who keeps on unfolding herself outwardly while enveloping us? And toward whom he moves, without ever getting there, without distinguishing between inside and outside. Going again and again toward her within her? In a movement that precedes even desire? Which protects movement's lightness, its freedom, its continually new impulsion. Always for the first time. (Ethics 81)

The mystery of birth has evolved into a recognition of desire as continually new, for the desirer is propelled by an inclination toward she who is reborn in every moment. A dizzying swirling of sorts, vertiginous in its limitless horizons, fantastical relations with 
the mother are not static. For the desirer and the desired are always becoming, individually, and together.

Likewise, Irigaray's “Fecundity of the Caress" situates touch, specifically caress, as arousing empathy for the other and an infinite desire that is never consummated, never conquered: "As he caresses me, he bids me neither to disappear nor to forget but rather to remember the place where, for me, the most intimate life is held in reserve. Searching for what has not yet come into being for himself, he invites me to become what I have not yet become. To realize a birth that is still in the future. Plunging me back into the maternal womb and beyond that conception, awakening me to another birth—as a loving woman" (Ethics 187). In its singularity and irreducibility, the caress attests to the transcendental within the other that beckons toward our own transcendental. The caress awakens us from our slumber so as to reveal to us our divinity.

Much to many feminists' chagrin, throughout her discussion in this essay and in other essays in An Ethics of Sexual Difference, Irigaray discusses love and desire in terms of heterosexuality. In doing so she appears to interdict the plausibility of same-sex couples or, for that matter, same-sex friendships. Because Irigaray's project demands a recognition of a separate feminine sphere under penalty of an erasure of female points-ofview, in delineating ethical relationships Irigaray is compelled to project clearly what an ethical male-female relationship would look like. Recognizing her schematic as necessitating exemplification of the most notoriously inequitable relationship legitimates appropriating her model of ethical relations for understanding other relationships. Irigaray herself applies her methodology freely to mother-daughter relationships and their need to be conceptualized in an ethics of becoming. 
The saliency in Irigaray's writings of an appropriation of the language of birth and nurture for right relations with those beyond the mother-child dyad facilitates the endeavor to situate the maternal as a viable route through which to contemplate human relations that abolish no one's subjectivity but foster growth and fulfillment. She, like a number of the thinkers who serve as guides in this project, views the behaviors and emotions assumed to accompany motherhood as applicable to an ethic of flourishing in this world. Irigaray's theory of becoming is woven into the maternal, for it is rooted in the fact that "everything is always in movement, in a state of becoming. And the mediator of all of this is ... exemplarily ... love" (Ethics 21 ).

Both Kristeva and Irigaray are compelling in their emphasis on society's inability to talk cogently about the experience of motherhood from the viewpoint of the mother, and in their insistence upon acknowledging love as the defining characteristic of the maternal relationship. Jessica Benjamin proceeds in a similar direction in her advocacy of an intersubjective approach to understanding both child development and the experience of mothering. Most prominent in Benjamin's account is her refusal to conceptualize the mother-child, self-other relationship in terms of traditional objectrelations. Rather, she promotes a schematic founded on the principle that "the other must be recognized as another subject in order for the self to fully experience his or her subjectivity in the other's presence. This means that we have a need for recognition and that we have a capacity to recognize others in return, thus making mutual recognition possible" (Like 186). Benjamin transforms the psychoanalytic image of the baby into a being who is, from birth, a subject becoming aware of his or her own personhood and that of his or her nurturers. 
Benjamin rejects psychoanalytic claims of an early, undifferentiated motherinfant dyad, maintaining that in the beginning were two subjects. Her characterization of the child's first days is particularly powerful:

As she cradles her newborn child and looks into its eyes, the first-time mother says, 'I believe she knows me. You do know me, don't you? Yes you do.' As she croons to her baby in that soft, high-pitched repetitive voice (the 'infantilized' speech that scientists confirm is the universal baby talk), she attributes to her infant a knowledge beyond ordinary knowing. To the skeptical observer, this knowledge may appear to be no more than projection. For the mother, this peaceful moment after a feedingoften after a mounting storm of cries and body convulsions, her somewhat clumsy effort to get baby's mouth connected to the nipple, the gradual relaxation as baby begins to suck and milk begins to flow, and finally baby's alert attentive, yet enigmatic look - this moment is indeed one of recognition. (Bonds 13)

This extended passage exhibits Benjamin's occasionally earthy tone, which testifies that her psychoanalytic ideas are not mere rhetoric or jargon. She attempts to capture ordinary moments of motherhood in exemplifying her notion of intersubjectivity. Here she represents some of the bodily exchanges of the first days in the infant's life. Her descriptions are thorough because she hopes to establish that "in this early interaction, the mother can already identify the first signs of mutual recognition: 'I recognize you as my baby who recognizes $m e "(15)$. While this might seem a bit too sentimental, Benjamin's goal is not to provide nostalgic images of mothers and children. Rather, she refuses to admit the dangers of parenting without disclosing the existence of more tender moments. Hers is a story of how "the individual grows in and through the relationship to other subjects" (Bonds 20).

While psychoanalytic accounts of development typically follow the child's process of individuation, Benjamin brilliantly asserts that the trajectory is not so direct: 
[I]ntersubjective theory sees the relationship between self and other, with its tension between sameness and difference, as a continual exchange of influence. It focuses, not on a linear movement from oneness to separateness, but on the paradoxical balance between them. What we see in early infancy is not symbiosis, or complete undifferentiation, rather, an interest in externality alternating with absorption in internal rhythms; later there is alternation between the oneness of harmonious attunement and the "two-ness" of disengagement. (Bonds 50)

Attunement is not absolute, and certainly not permanent. In any intimate relationship, including that of mother and child, the perils of domination and subordination always loom. Balancing recognition of the other with wishing to merge with or control the other proves challenging. The intersubjective perspective does not invalidate the intrapsychic perspective; their coexistence renders the task of intersubjectivity as one interwoven with ethical responsibility. But it is not merely a matter of affirming the other. We need others to solidify our sense of independence. There lies the paradox: our realization of a healthy degree of independence is contingent upon the other's presence and active recognition. In turn, our active recognition of the other boosts her connectedness and independence.

Benjamin does not blindly hope for the best, but expounds on the degree to which the ideal of attunement is encumbered by a society that consigns women, mothers, and intimacy to the private sphere, to the home. Benjamin, like sociologists such as Tönnies and Simmel, cites modernity and its deification of rationality as implicated in the devaluation of relation:

[T] he principle of rationality which social theorists since Weber have seen as the hallmark of modernity - the rationality that reduces the social world to objects of exchange, calculation, and control-is in fact a male rationality. Rationalization, at the societal level, sets the stage for a form of domination that appears to be gender-neutral, indeed, to have no subject at all. Yet its logic dovetails with the oedipal denial of women's subjectivity, which reduces the other to object. The psychic repudiation of 
femininity, which includes the negation of dependency and mutual recognition, is homologous with the social banishment of nurturance and intersubjective relatedness to the private domestic world of women and children. The social separation of private and public spheres-long noted by feminists as the crucial form of the sexual division of labor and thus the social vehicle of gender domination-is patently linked to the split between the father of autonomy and the mother of dependence. (Bonds 184-84)

This brings us back to the concerns of Rita Felski and Luce Irigaray, the silencing of female voices through the relegation of women exclusively to the private sphere. As Benjamin brilliantly illustrates, "societal rationalization negates what is truly 'social' in social life" and hence proves detrimental to all" (Bonds 185). Women are called upon to be the scaffolding of the rugged individualism of modern culture, to remain at home at the beck and call of loved ones who need the affection, attention, and love that only a mother gives. It is society's dysfunction, Benjamin maintains, that leads to such a charged emphasis on mothers in the home: "The lack of support and responsibility in public life creates unremitting anxiety about being at the mercy of a heartless rationality. This is why the idea that women are needed in the home ... has once again become so popular, an enchanted vision of a maternal haven" (202). Benjamin's words here echo Felski's, but Benjamin's interest remains in remediating the unacceptable status quo through a change in the conceptualization of interpersonal relations and of what it means to cohabitate. Only through a paradigm change can relations centered on conflict be transformed into relations centered on flourishing.

\section{Flourishing and Natality}

In Becoming Divine: Towards a Feminist Philosophy of Religion, feminist theologian Grace Jantzen rejects the necrophilia that dominates both Christianity and Western thought, proposing instead modes of thinking that embrace vitality: 
But if religious discourse and the symbolic of which it is a part is a way of constructing human reality, a grand myth or set of myths that we live by (where 'myth' does not have 'truth' as it opposite), then restructuring that myth in ways that foster human dignity - perhaps in ways that enable us to become divine?-is of ultimate value. Nor should it be surprising that this might be 'a kind of philosophy nearer to literature than to science,' since it has been more characteristic of literature than of science to try to think otherwise, to provide alternative models of human becoming, to challenge largely utilitarian rationalism of the contemporary science world-view. (22)

Incorporating Irigaray's characterization of the Western (masculinized) symbolic, Jantzen argues as urgent the development of alternative ways of thinking, speaking, and acting in the world. She proposes instead a symbolic of natality, which, unlike the rationalistic symbolic, is not intent upon establishing black and white claims of truth. A symbolic of natality is about birth, creativity, and beginnings not yet conceived. A symbolic of natality is about becoming.

Jantzen's account of natality derives in part from that of Hannah Arendt, who celebrates the newness that birth introduces to the world and those of whom it is and will be comprised: "The miracle that saves the world, the realm of human affairs, from its normal, 'natural' ruin is ultimately the fact of natality, in which the faculty of action is ontologically rooted. Only the full experience of this capacity can bestow upon human affairs faith and hope .... It is this faith in and hope for the world that found perhaps its most glorious and most succinct expression in the few words with which the Gospels announced 'glad tidings': 'A child has been born to us'" (Arendt 247). Arendt's identification of newness as that which will enrich us, fulfill us, and better our world is keen. Writing after World War II as a German Jewish woman whose life was spared only because she fled, Arendt composed The Human Condition with an eye toward understanding the failures of political life past and present and imagining the political 
landscape of a better world. Arendt's appropriation and interpretation of the Christian story of Christ's birth confirms Jantzen's claim that natality and its attendant hope are already present in Western thought but have been repressed by what has become the masculine establishment.

Hope and possibility, the promises of birth. Birth reinvigorates awareness of life as opportunity, as perpetual newness. Yet, according to Jantzen, birth has been repressed by a masculinized attachment to salvation as an ideal and a rigid preoccupation with Truth rather than an openness to intricate, delicate webs of truths. An openness to the plurality of truths radically disturbs a model of identity as stable and static; through an incorporation of select concepts from Lacanian theory, Jantzen illustrates such openness as capacious enough to acknowledge identity as fluid. An ethic of natality encompasses creativity and imagination as means that enable a re-visioning of the world and of the self-in-relation.

Particularly telling in Jantzen's schematic is the inclusion of God in this flux of becoming - she conceives of the divine, and here she means the divine in its unlimited incarnations-as "the deepest and best of human [my emphases] desires (or at least what are taken to be such) which are projected as the divine horizon" (91). As Jantzen addresses in great depth in Becoming Divine, that human potential partakes of divinity challenges dualistic accounts of soul-body, secular-sacred, immanence-transcendence. The everyday is encompassed by divinity, and divinity consists, among other things, of the everyday, things and people thought to be unremarkable without the intervention of creativity and imagination. Most compelling in the context of the present study is the possibility of spirituality in interactions between "natals," newcomers to this world, and 
the fact that those interactions are colored by an awareness of their affiliation with an utmost significance defying designation. Interactions between self and other hold the possibility of ecstasy, an ecstasy that is of this world.

Jantzen locates desire as central to flourishing: "[D]esire and the imagination have been the repressed (female, maternal) basis for the masculine and necrophilic configuration of the philosophy of rationally justified beliefs, and ... this masculinist symbolic ... [may] be disrupted by a symbolic of natality which celebrates rather than represses its maternal and material foundations" (95). Natality entails an insatiable desire, desire proceeding not from a forbidden id or from a primal scar of separation, but from a love of one's world and its inhabitants: "[D]esire itself is reshaped by the face of the Other, shaped into a response that goes far beyond myself. It is not the name of a lack, but the release from self-enclosure, a joy, therefore, that is always in excess, and a desire not diminished in its fulfillment" (251). The appeal and applicability of the divine in this world is omnipresent; we need only embrace it. It entails justice and concern for other natals, love and responsibility for the world.

Desire for home and for the maternal takes on an entirely new significance in Jantzen's work. For the maternal signifies the reality that we are all born of woman and are all natals; the maternal reminds us of our connection with the possibility of beginnings. The maternal in this sense takes us home-not necessarily to the grounded, physical structure called home, but to imaginative spaces conducive to our thriving. These spaces do not suffocate: rather, they are places we know intimately, places of both solitude and connection. These beginnings are not located in an inaccessible past, but rather are available to us in every instant. Nostalgia for the mother, then, is transformed 
into a reminder of our beginnings that infuses us with the recognition that all of life's moments are new, that life is ripe with beginnings, perpetual beginning. Moreover, Jantzen seizes upon an idea of Hannah Arendt's that is particularly applicable to the autobiographical analysis of Virginia Woolf that will shortly follow: Story is fundamental to being human-everyone's life may be told as a unique story. No story is prescriptive. Beginnings proliferate; every moment is laden with the fruit that may be harvested for good.

Again exposing that which has been repressed by the necrophilic symbolic, Jantzen emphasizes the presence of a symbolic of flourishing in ancient Judeo-Christian texts, vegetal metaphors of prolific vine-like growth branching out multi-directionally, bursting with ripeness, heavy with fruit: "[T]here are many branches, in relation with one another as well as with the vine. The model of flourishing is one which assumes the interconnectedness of people, and indeed of the ecosystem: flourishing is impossible by oneself alone .... Moreover, that flourishing is not once-for-all, but is growth and process, never static. The model of flourishing is therefore a model of amor mundi, love of the world and care for all within it, to set over against competitive individualism" (165). The love here is of the world, not beyond this world; loving entails acting mindfully for the well-being of fellow natals and for the world in which each of us lives. While Jantzen's symbolic is conceived through the exercise of creativity, she insists that it is not merely a product of a fevered brain: the metaphors are already extant even in Christian sacred texts. Obscured by necrophilia, they have gone largely unrecognized. An ethic of natality and flourishing calls upon us to act ethically in this world. It is not only mindful of this world, but actively seeks to better it through the exercise of 
justice and love. Jantzen explicitly brings us full circle: she proposes "our awareness of our place in the web of life... [as] an antidote to the alienation that is so much a part of the technological culture of modernity, [the] worldlessness ... in which kinship is rejected and people see themselves as disconnected individuals" (151). The responsibility of love for the world is by no means exclusive to the mother, but she is a reminder of the nurture that comprises stewardship, an ideal to which we must all aspire. She is also a reminder of our dependence upon others for our well-being and survival, of how it is incumbent on each of us to care for our world. One might interpret the mother as an intermediary symbol borrowed from the traditional symbolic but molded to fit the needs and goals of a symbolic that is much more humane.

Virginia Woolf and Käthe Kollwitz contemplate natality as an alternative to the necrophilic focus of Western thought and action in the modern era. They consider maternity as legitimate nostalgic longing, and, in doing so, represent their engagement with natality, flourishing, and connection. The above discussion of Boym's The Future of Nostalgia prepares us for the possibility of legitimate desire for an (imagined) lost, ideal connection when that ideal is coupled with an acknowledgement of that desire as fanciful and when that desire propels one toward right action: caring for oneself, others, and the world. Reflective nostalgia, then, is all about active home-making as our mission. The "nostalgia" for motherhood that we witness in the work of Woolf and Kollwitz need not be read as normative nostalgia. Rather, it might be viewed as progressive in its contemplation of newness, a newness that necessitates moving beyond the blind, utopian ideal of becoming one with the lost other to acknowledging that the self 
and other in their uniqueness have the potential to enter into and recognize becoming-inrelation. Both Woolf's and Kollwitz's projects enact such an ideal.

The above discussion of Boym, Kristeva, Irigaray, Benjamin, and Jantzen should invite a reconsideration of Rita Felski's characterization of a nostalgic desire for the mother as necessarily unproductive and retrogressive. Recall the aforementioned anecdote of the World War I soldier crying desperately for his mother in the last moments of his life. This is perhaps an overly-charged moment on which to focus, but it does hone in on a desire for the past and a safe connection with the mother that is not unusual among nostalgics. Spattered with mud, body maimed and exceeding its boundaries, this man sought respite not in God, but in the human. One might not unreasonably attribute his desire to the absolute aloneness of death, but one need not cast his cry for the mother as narcissistic per se. Surely a vision of being held and cherished contrasted the bloody, anonymous trenches and comforted the man as he lay dying, surely his instincts are rooted in the intersubjective nature of human life. As his life ebbed, that is, he cried for connection. In this the most lonely of moments, in this the war-scarred terrain of modern Europe, he longed to go home.

When civilization's rubble stifles angelic voices, reactionary regression appears as a very tempting alternative. As we have seen in Rita Felski's, Luce Irigaray's, and Jessica Benjamin's critiques of Western culture, that might consist of vehement advocacy of loving mothers in warm homes nurturing children and awaiting anxiously the return of their beloved. However, Irigaray, Benjamin, and Jantzen provide an alternative vision in which what appears to be nostalgic and narrow may be expanded into something ethical and empowering. Theirs is an alternative narrative of homecoming. 


\section{CHAPTER III}

\section{INHABITING: VIRGINIA WOOLF AND THE ART OF HOME}

This intuition of mine-it is so instinctive that it seems given to me, not made by mehas certainly given its scale to my life ever since I saw the flower in the bed by the front door at St. Ives. If I were painting myself I should have to find some-rod, shall I saysomething that would stand for the conception. It proves that one's life is not confined to one's body and what one says and does; one is living all the time in relation to certain background rods or conceptions. Mine is that there is a pattern hid behind the cotton wool. And this conception affects me every day. I prove this, now, by spending the morning writing, when I might be walking, running a shop, or learning to do something that will be useful if war comes. I feel that by writing I am doing what is far more necessary than anything else. ${ }^{10}$

Virginia Woolf "A Sketch of the Past"

Virginia Woolf's intimate portrait of childhood and family life, "A Sketch of the Past" is nonetheless punctuated with references to the bombs and immanence of German invasions that threatened her present even as she immersed herself in her past. In The Gift, H.D. makes clear that her retreat into memories of childhood-and into reconfiguring creatively those memories-is precisely what salvaged her from the psychological rubble wrought by the bombings in London. While Woolf does not say as much, surely her autobiographical writing likewise functioned to stem the devastating effects of violence upon her already vulnerable psyche. In an entry from "A Sketch of the Past" dated June $8^{\text {th }} 1940$, Woolf invokes the violence of her time briefly: "The battle is at its crisis; every night the Germans fly over England; it comes closer to this house

${ }^{10} 72$. 
daily. If we are beaten then-however we solve that problem, and one solution is apparently suicide (so it was decided three nights ago in London among us)—book writing becomes doubtful. But I wish to go on, not to settle down in that dismal puddle" (100). Woolf then starts en medias res to discuss once more her past life, a past marred by pain and loss, but a life endowed nonetheless with meaning worth pursuing. As Woolf's writing makes clear, at its best, immersion in the past affirms the sanctity of the spirit. True to Grace Jantzen's call for an approach to living that embraces the world in its possibility rather than succumbs to an obsession with its fallenness, Woolf salvages impassioned life from the past to mitigate the devastation of the present. This, in turn, reflects and begets Woolf's proactive spirit that moves her to aspire to contribute not only to her own well-being, but to that of her world.

Woolf began "A Sketch of the Past" in April of 1939, months before Britain officially declared war against Germany, but the tension of the times was palpable. Hitler had already taken Czechoslovakia and had threatened Poland, and Italy had invaded Albania. In short, Europeans had a well-founded inkling that the atrocities experienced in World War I had not been completely vanquished. Their world would very likely be suspended in chaos once more, a chaos Woolf visits in a number of her novels from the 1920 's. In each of those novels, Woolf finds something redeeming-something beautiful - to clutch that mitigates some of the terror of war. In this autobiographical essay, Woolf unearths significance that serves the purpose of shoring up an increasingly fractured identity. The subject material she uses to do so is at times excruciating, yet the traumas of being sexually fondled by an elder half-brother, of losing her mother at the tender age of thirteen, of losing her half-sister Stella just two years later, and of existing 
with a temperamental father whose outbursts and neediness frequently rendered him puerile and domineering are outweighed by vivid sensory-rich memories that in retrospect prefigure and intertwine with her creative spirit. Virginia Woolf's memories took her home during a time when her adult home was being threatened.

Central to these memories are a few vital components that orient us to her conception of the terrain of her past. As indicated above, sensory detail is salient. Her account of her first memories serves as a case in point:

--I begin: the first memory.

This was of red and purple flowers on a black ground-my mother's dress; and she was sitting either in a train or in an omnibus, and I was on her lap. I therefore saw the flowers she was wearing very close; and can still see purple and red and blue, I think, against the black. Perhaps we were going to St. Ives; more probably, for from the light it must have been evening, we were coming back to London. But it is more convenient artistically to suppose that we were going to St. Ives, for that will lead to my other memory, which also seems to be my first memory, and in fact it is the most important of all my memories. If life has a base that it stands upon, if it is a bowl that one fills and fills and fills-then my bowl without a doubt stands upon this memory. It is of lying half asleep, half awake, in bed in the nursery at St. Ives. It is of hearing the waves breaking one, two, one, two, and sending a splash of water over the beach; and then breaking, one, two, one, two, behind a yellow blind. It is of hearing the blind draw its little acorn across the floor as the wind blew the blind out. It is of lying and hearing this splash and seeing this light, and feeling, it is almost impossible that I should be here; of feeling the purest ecstasy I can conceive. (64-65)

Profuse references to sight, touch, and sound dominate this passage. Woolf sees and asks us to see and feel viscerally a wholly-absorbing floral burst blossoming from the curves of her mother's body, an aura of fading light conducive to dreaming, splashing water, an oval, wooden blind pull. She hears the waves pulsing their timely beat, the sonorous voice of nature, the wind dragging a wooden knob on a string across the floor. And through all of this she feels the warmth of her mother's lap-it is from this vantage point 
that she begins her first memory, and it is no coincidence that the second, equally poignant memory occurs as she lies in bed soothed by the sound of the breaking waves that intuitively invoke the waters of the womb. Reflecting on "the intensity of this first impression," Woolf speaks of the effect of "lying in a grape and seeing through a film of semi-transparent yellow" (65). She attributes the magical aura of this moment to the relative shock of changing nurseries, for time at the Stephens' holiday home at St. Ives was wholly different from that in London. Here new impressions are rendered enhancing rather than dangerous because they are experienced in hindsight in the shadow of her mother's presence. Likewise, in an equally sensory-laden passage but a few paragraphs later, Woolf describes in terms of the womb an edenic garden at her family's holiday home in St. Ives. In these passages, she expresses her conviction that each memory is an ecstasy, a rapture, and it is as if recreating these memories in her essay transports her once again to a safe, insulated space-shelter from the constraints of time and human folly.

A keen awareness of place proves vital to Woolf's representation of memory. Woolf constructs place through sensory imagery such as that discussed above, but place transcends the sensory through its mere presence, its ineffable space. In The Poetics of Space, Gaston Bachelard speaks of "secret rooms, rooms that have disappeared, ... [as] abodes for an unforgettable past," and he proceeds to associate the soul with structures of our lost, beloved homes: "Not only our memories, but the things we have forgotten are 'housed.' Our soul is an abode. And by remembering 'houses' and 'rooms,' we learn to 'abide' within ourselves" (xxxvi-vii). As in the above description of the nursery and gardens of St. Ives, intimate, domestic spaces of a particular place prove fertile to the 
soul work that is imaginative creation and to thriving from within. For these spaces are rooted deeply in the ground in which they have been planted.

An art in itself, the act of inhabiting requires refined development, for "to curl up belongs to the phenomenology of the verb to inhabit, and only those who have learned to do so can inhabit with intensity" (xxxviii). It is this art of inhabiting intensely in the present that connects us most intimately to the spaces of our past-what results, it seems, is poetic reverie, always contingent upon our ability to merge with the domestic spaces in which we find ourselves, always contingent upon our own openness to the resultant affinity with the spaces of our imaginary life of the past. In an openness to the art of inhabiting, we inhabit simultaneously past and present. Bachelard explains:

In this remote region, memory and imagination remain associated, each one working for their mutual deepening. In the order of values, they both constitute a community of memory and image. Thus the house is not experienced from day to day only, on the thread of a narrative, or in the telling of our own story. Through dreams, the various dwelling-paces in our lives co-penetrate and retain the treasures of former days. And after we are in the new house, when memories of other places we have lived in come back to us, we travel to the land of Motionless Childhood, motionless the way all Immemorial things are. We live fixations, fixations of happiness. We comfort ourselves by reliving memories of protection. Something closed must retain our memories, while leaving them in their original value as images. Memories of the outside world will never have the same tonality as those of home and, by recalling those memories, we add to our store of dreams; we are never real historians, but always near poets, and our emotion is perhaps nothing but an expression of a poetry that was lost. (5-6)

One struggles not to quote the whole of Bachelard's text, which itself bears the mark of active imagination. Bracing the self against the agitations of the world requires an ability to suspend oneself in memory, which is itself always at root poetic. One might charge Bachelard's "Motionless Childhood" with insidious nostalgia and insensitivity to the present, but perhaps such a charge would be ill-founded. "Motionless Childhood" refers 
not to detachment from the present, but to a way of approaching that present that never isolates itself from ways of becoming in what are in retrospect perceived to be securer times. The house, says Bachelard, "allows one to dream in peace," and one cannot discount the fact that dreaming in peace may well lead to bountiful living in the present.

Woolf's recollections of childhood at Talland House are encapsulated by the most intimate and intense of inhabitation, inhabitation of the womb. Imagining the spaces that affected her first impressions of life, Woolf renders them aesthetically. Her vantage point is that of a child in utero:

If I were a painter I should paint these first impressions in pale yellow, silver, and green. There was the pale yellow blind, the green sea; and the silver of the passion flowers. I should make a picture that was globular; semi-transparent. I should make a picture of curved petals; of shells; of things that were semi-transparent; I should make curved shapes, showing the light through, but not giving a clear outline. Everything would be large and dim; and what was seen would at the same time be heard; sounds would come through this petal or leaf-sounds indistinguishable from sight. (66)

Here beauty is pondered from within a globed space, yet it is simultaneously the globed space that is being pondered. In that way, the womb in which she rests is both habitat and mirror, and that which she contemplates is her own act of inhabitation. Sights and sounds coalesce in a quintessential synesthesia of the womb; here visceral response to sound, to sight, arouses movement and a gaze outward, which results in senses so finely woven as to be indistinguishable. The adult Virginia is rocked gently in the waters of the womb as she sees and hears her world as if for the first time. The mother's body, then, carries Woolf to an intimate understanding of inhabitation in its best possible sense.

Sheltered by her mother's body, she is awakened to the beauty of love, and to the beauty of the woman who initiates her into the world of the aesthetic. 
Woolf's reflections circle around domesticity. Chapter II establishes that feminists are not without cause wary of nostalgia that roots itself in the domestic, yet given the ground we have traversed in our consideration of Woof's memory-work, dismissing domesticity as by nature deludingly regressive is hasty. Woolf's oneric flight into the past is neither mindless nor destructive, for the act of revivifying her own history endows Woolf with the sustenance she needs to withstand the perilous times at hand. Many feared that it was the past that bred modernity's seething, violent energies-and there is something to be said for that theory. As discussed in Chapter I, Modris Eksteins traces World War I to misguided community-building, aesthetic energies, but those are not at play in Woolf's case. Rather, the accessibility of previous experiences with domesticity equips her with the material needed for introspection and for a critical evaluation of aspects of the past that were particularly deleterious to her, her sisters, and her mother. Woolf's introspection encompasses a celebration of beauty and nurture, both figured in imagery of the maternal, yet she does not shy away from the darker materials of her making. That she is able to confront these discrepancies even while in the throes of nostalgia suggests that her longing might be rightfully characterized as "reflective nostalgia."

Finally, Woolf is acutely forthright in characterizing memory as partial, as necessarily devoid of some of the meaning and substance of the past that it desperately attempts to retrieve. She wonders why, for instance, can she recall the aforementioned moment in the nursery but have no recollection of her father throwing his naked young daughter playfully into the sea. She recognizes that most of our waking moments are experienced as if in a slumber: "As a child, then, my days, just as they do now, contained 
a large proportion of this cotton wool, this non-being. Week after week passed at St. Ives and nothing made any dint upon me. Then for no reason that I know about, there was a sudden shock; something happened so violently that I have remembered it all my life" (71). When she speaks of violence here, she is not so much speaking of tragedy, but rather of moments of emotional and sensory intensity. Among such "moments of being" are an experience fighting with Thoby in which young Virginia felt suddenly the weight of her participation in human sadism; her enduring impressions of that moment include standing there allowing her brother to beat her and a deep feeling of depression.

In a second, much more benign moment of being that likewise occurred at St. Ives, standing near a flower bed, staring at a vigorous plant with its profusion of leaves, she suddenly had the revelation that it was "the whole.... . [I]t seemed suddenly plain that the flower itself was a part of the earth; that a ring enclosed what was the flower; and that was the real flower; part earth; part flower" (71). Again, this memory is definitely domestic, set as it is in the family's garden space at St. Ives. Here a seemingly ordinary moment of the past is seized upon as a premonition of artistic sensibility, a heightened awareness of a cosmic order in which she participates. The cultivated flower bed, created for the sake of beauty, partakes of and is constituted by a deeper, primordial order, a natural order to which all life is connected. This is an apt metaphor for artistic creation, and for the creative memory-work in which Woolf engages in this essay. This was also an omen for Woolf; she claims to have recognized somewhat hazily even at the moment it transpired something of its significance to her future. 
Despite the fact that recollections of the past are generally shoddy and are only infrequently graced with these "moments of being," Woolf takes solace in revisiting the visceral, momentary shocks, for they lead her to a revelation of a larger order:

I feel that I have had a blow; but it is not, as I thought as a child, simply a blow from an enemy hidden behind the cotton wool of daily life; it is or will become a revelation of some order; it is a token of some real thing behind appearances; and I make it real by putting it into words. It is only by putting it into words that I make it whole; this wholeness means that it has lost its power to hurt me; it gives me, perhaps because by doing so I take away the pain, a great delight to put the severed parts together. Perhaps this is the strongest pleasure known to me. It is the rapture I get when in writing I seem to be discovering what belongs to what; making a scene come right; making a character come together. From this I reach what I might call a philosophy; at any rate it is a constant idea of mine; that behind the cotton wool is hidden a pattern; that we-I mean all human beings-are connected with this; that the whole world is a work of art; that we are parts of this work of art. Hamlet or a Beethoven quartet is the truth about this vast mass that we call the world. But there is no Shakespeare, there is no Beethoven; certainly and emphatically there is no God; we are the words; we are the music; we are the thing itself. (72)

Woolf roots what she terms her "intuition," her artistic sensibility that carries her closer to the truths of the world, in vivid moments recollected and rendered aesthetically. Memory, then, preserves her from falling into oblivion. It assures her when amidst inanity that meaning-enduring meaning, aesthetic meaning, definitively human meaning—serves as "scaffolding in the background" (73).

What she suggests, then, is that it is not objectively-rendered details that make the difference. Rather, what matters is connecting imaginatively with the pattern to which we already belong, of which humanity is an integral part. This is remarkably similar to Grace Jantzen's characterization of human flourishing as dependent on recognition of the connectivity that permeates everyday life and the infusion of life-giving creativity. Hence, the fact that Woolf admits that she cannot remember the precise details of the 
journey she was taking when she experienced that first pronounced memory of being held close by her mother who was wearing a floral dress is of little consequence. That "it is more convenient artistically to suppose that .... [she was] going to St. Ives" makes supposing so perfectly amenable to her cause, for it contributes to seeing the world in its aesthetic truth.

My evaluation of Woolf, then, supposes the domestic as central to imagination, to identity, and to constructions of the ideal, and it seeks to resuscitate it from its reputation as insidiously conservative. Home is a notion that must be questioned and re-questioned, that must be recognized as built on instability and flux, but it must not be razed. The idea of home suffuses its remembering architects with a sense of safety that allows them to move forward in the midst of profound doubt in the feasibility of the present-it is, in fact, erected in the very present it seeks to redeem. Moreover, a consolatory idea of present and past homes is needed to shore up an identity that one recognizes as precarious. Woolf likens her present identity to "a fish in a stream; deflected, held in place; but [she] cannot describe the stream" (80). Not without cause, she desperately needs to lean against a past that, while it is by no means over and done with, is better known than the present and is somewhat malleable in the face of the needs of the present.

"A Sketch of the Past" locates Woolf's idea of safety in her idea of her mother and the refuge her nurture could offer. As $A$ Room of One's Own attests, however, she was not naïve enough to assume that woman should be collapsed with the identity "mother"; she basks in the sensual beauty of the maternal while recognizing the mother as a woman. Throughout "A Sketch of the Past," memories are tinged with domesticity, and domesticity itself is inhabited by Julia Duckworth Stephen, even after her death. 
Pertinent to the above discussion of Bachelard's theory of place, Woolf characterizes her childhood as a "great Cathedral space," "a great hall ... with windows letting in strange lights; and murmurs and spaces of deep silence," at the center of which dwells her mother (79). While a cathedral, with its somber half-light, dank spaces, and domed vastness hardly seems to be compatible with the sheltering home described by Bachelard, there is something to be said for the aura imagining home in such a way conveys. Cold, solid, and damp, cathedrals at once reach nobly toward the heavens while preserving gravitas and depth. A cathedral space preserves historical solidity while allowing one to scale the spiraling towers of fancy. Much as Proust does in his characterization of the church at Combray, here Woolf endows her past with the colors of imagination. Moreover, she endows both that past and the present with connections with hitherto unrecognized generations. The term "Cathedral space" invokes retrospective solemnity that aligns her and her mother with now-hushed multitudes from the past.

This "Cathedral space" by its nature references religious tradition, but Woolf recasts that tradition to endow it with human experience of the pulsating divine that permeates the everyday world. Given her aversion to organized religion, the experience of the divine merges with her idea of the cotton wool, its hidden pattern, and its epiphanic moments of being. What we have, then, is a recasting of the domestic into a magical world replete with the angels of everyday life. It is in this manner that Woolf begins her search for Julia Stephen.

While Woolf's moments of being and their inseparability from her domestic life are compatible with Bachelard's sense of "Motionless Childhood"- that which is 
arrested in the moment and preserved as such eternally—it must be said that Woolf constructs this space as by no means static:

But somehow into that picture must be brought, too, the sense of movement and change. Nothing remained stable long. One must get the feeling of everything approaching and then disappearing, getting large, getting small, passing at different rates of speed past the little creature; one must get the feeling that made her press on, the little creature driven as she was by growth of her legs and arms, driven without her being able to stop it, or to change it, driven as a plant is driven up out of the earth, up until the stalk grows, the leaf grows, buds swell. That is what is indescribable, that is what makes all images too static, for no sooner has one said this was so, than it was past and altered. How immense must be the force of life which turns a baby, who can just distinguish a great blot of blue and purple on a black background, into the child who thirteen years later can feel all that I felt on May $5^{\text {th }} 1895$-now almost exactly to a day, fortyfour years ago- when my mother died. (79)

On the one hand, the child Virginia was the child rooted in the soil of her birth and in the moments of being to which she could cling, but on the other, because of the traumatic events that assailed her, the child Virginia was as a flower susceptible to the vicissitudes of the wind. Into this dwelling space she infuses something of the adult realization that the many-hued leaves all-too-quickly drift to the ground. Time passes. What was is no longer. Never an unadulterated, fanciful childhood, Woolf's beautiful childhood space is infused with pain as well as joy. A testament to the resilience of her imagination and its capacity to forge connections between what appears to be disparate, her home is imagined as vast yet bonded with the mother to whom she traces her own identity as a woman and as an artist. In thinking back through her mother, she finds herself as she exists in her childhood.

In "A Sketch of the Past," remote childhood, childhood as it might have continued to exist had Julia Stephen not died when her daughter was only thirteen, is embedded quite precisely in St. Ives, a locale that was inhabited by the Stephens exclusively when 
Julia was yet living. Throughout the essay, St. Ives is characterized as a retreat from the demands of the Victorian household exemplified by Hyde Park Gate. In large part this is so because it is most clearly identified with Woolf's lost mother, and, as such, its connections with the primal input of the senses is most pronounced. Much as she speaks of the womb as rudimentary to her being, she describes St. Ives in terms of the primitive:

The town was then much as it must have been in the sixteenth century, unknown, unvisited, a scramble of granite houses crusting the slope in the hollow under the Island. It must have been built for shelter; for a few fishermen, when Cornwall was more remote from England than Spain or Africa now. It was a steep little town. Many houses had a flight of steps, with a railing leading to the door. The walls were thick blocks of granite built to stand the sea storms. They were splashed with a wash the colour of Cornish cream; and their roughness was like the clot of cream. There was nothing mellow about them .... It [St. Ives] might have been built yesterday; or in the time of the Conqueror. It had no architecture; no arrangements. The market place was a jagged cobbled open place; the Church was on one side; built of granite, ageless, like the houses. (128)

A village from a bygone era, stark refuge from brutal weather, St. Ives represents fundamental shelter, unadorned, remarkable only in the fact that something so petrous could serve a hospitable purpose. Yet, it is this uncompromising purpose that is so fully served by this place, so much so that it exceeds its purpose and shelters the imagination, as well. One can imagine this abode as inspiring the adventurous spirit to find relics of the past buried among its sea-stripped stones. Woolf paints the place as virtually uninhabited, free from the meddling tourists who would eventually, Woolf tells us later, destroy its ambiance, its magic. It was the incursion of tourists a couple of years before her mother's death, in fact, that deterred Julia from wishing to continue the family's St. Ives holidays.

Associations with her mother would intuitively soften the Cornish coast's brutal, wind-battered exterior, and a softness of voice reverberates as Woolf describes the two or 
three acre gardens around Talland House and their accompanying, picturesque view of the bay. As described in "A Sketch of the Past," the cottage was situated in the midst of an impeccable garden that "formed itself into separate gardens, surrounded by thick escallonia hedges, whose leaves, pressed, gave out a very sweet smell ... [T]here was the coffee garden; the Fountain-a basin with a funnel that dripped, hedged in with damp evergreens; the cricket garden lawn; the Love Corner, under the greenhouse, where the purple jackmanii grew .... Then there was the kitchen garden; the strawberry beds; the pond where Willy Fisher sailed the little steamers he made" (128-29). An idyllic, enclosed little world that piques the senses-visual, olfactory, and, later, when Woolf invokes the click of the wooden gate leading to these gardens, aural-the grounds of Talland House are hardly rugged, but are cultivated for the purpose of inhabitation. Returning to Bachelard, here is a domicile graced with the potential for imaginative inhabitation. While Bachelard is speaking of the architecture of our homes when he speaks of space, the cozy spaces within, Woolf imagines space in Talland House as equivalent with its correspondent place, environs that are wholly different from those of London.

St. Ives as Woolf immerses herself in memories of it is inviolable. Woolf's descriptions are not unrelated to Grace Jantzen's concept of thriving in this world and her insistence that thriving is inseparable from and exemplified in nature. Flourishing, Jantzen claims, grows from an innate fertility within that is best exemplified by the proliferation of nature. Here Woolf and her family flourished in fecund gardens, which were, Woolf suggests, conducive to flights of imagination, flights still extant to the extent 
that they enable her to thrive in a dismal present. In turn, imaginative fervor colors her description of a view from a favorite post in the gardens, the Lookout place:

From the Lookout place one had then, a perfectly open view across the Bay .... It was a large Bay, many curved, edged with a slip of sand with green sand hills behind; and the curves flowed in and out to the two black rocks at one end of which stood the black and white tower of the Lighthouse; and at the other end, Hayle river made a blue vein across the sand, and stakes, on which always a gull sat, marked the channel into Hayle Harbour. This great flowing basin of water was always changing in colour; it was deep blue; emerald green; purple and then stormy grey and white crested. (129)

Even as she describes it, the water of which Woolf speaks sparkles and flows in audible tones, with one shade merging into another-it partakes of the imaginative possibility of reconfiguring the past and of allowing that reconfiguration to color the present. Here the curves of the Bay signify salutary maternal indeterminacy, meandering, gracing the disparate land it touches with the cool waters of aesthetic bliss. What is evident in this passage, then, is the maternal's connection with the imaginative, and with the imaginative immersion in the past that allows Woolf to redeem the present.

However, Woolf is not unremitting in her roseate sketches of imaginative bliss. Rather, she devotes a good bit of "A Sketch of the Past" to the less affirming aspects of her becoming. She discloses the violation of her body when she was very youngpresumably prepubescent, before her mother's death—by her half-brother George Duckworth, a violation that links her, she believes, with "thousands of ancestresses in the past" (69). In retrospect, Woolf recognizes in George's transgression a perennial violence perpetrated by scores of men upon countless women. This initial offense might be to blame for feelings of shame with which Woolf was steeped at Talland House when she gazed into the mirror, a shame she speculates might be related to the fact that she and 
Vanessa were something of tomboys at St. Ives who "played cricket, scrambled over rocks, climbed trees, and were said not to care for clothes" (68). This description of her childhood self endows us with a bit of insight into the joy she felt at St. Ives, a joy connected with opportunities for androgynous adventure. Nonetheless, Woolf speculates, this dread of the mirror seems more likely to be the manifestation of a dread-even a feeling of shame - regarding beauty and its connection with sexuality.

Later Woolf remembers a dream that haunted her-again involving the looking glass - in which, as she gazed at her reflection, gazing back from above her shoulder appeared the face of a beast. This later incident proved so powerful to her development that she struggles to discern whether it was dream or reality. These traumas at the mirror lead Woolf to reiterate that capturing a person's identity proves infinitely complicated, as even the person to whom incidents such as the above happen are oblivious to their import. It is telling that yet another looking glass episode occurred after her mother died: This time the looking glass was placed in her bedroom by George, in "the hope that ... [she] should look into it and learn to do ... [her] hair and take general care for ... [her] appearance" (122).

In memory, these traumatic aspects of Woolf's childhood are not separate from St. Ives, and nor are some of the blunt-force moments of being such as being pummeled by Thoby and hearing of an acquaintance's suicide and feeling it viscerally. However, the most malevolent aspects of the past remembered by Woolf are associated most acutely with the family's residence in London, Hyde Park Gate. Hyde Park Gate, as Woolf characterizes it, was a model of repressive Victorian society. At the helm of this pernicious society as it existed to Woolf were Leslie Stephen and George Duckworth, 
whose influences were felt primarily downstairs in the Victorian drawing room, for "[d]ownstairs was pure convention; upstairs was pure intellect" (157). The overseer of the coming out of the two marriageable Stephen daughters, George scrutinized them mercilessly for their gracefulness or lack thereof, for their adherence to Victorian ideals. As Woolf astutely puts it, "Society—upper middle class Victorian society-came into being when the lights went up. About seven thirty the pressure of the machine became emphatic .... Neck and arms had to be scrubbed, for we had to enter the drawing room at eight with bare arms, low neck, in evening dress. At seven thirty dress and hair overcame paint and Greek grammar. I would stand at George's Chippendale mirror trying to make myself not only tidy, but presentable" (150). She tells of one scarring instance in which she bashfully made her way downstairs in a new green dress to be inspected by George as if she were "a horse brought into a show ring"; this inspection ended with a brutally-disapproving George bellowing "Go and tear it up" (151).

Exacting, George followed Victorian decorum religiously, cruelly, and unthinkingly. For Virginia and Vanessa, the mores that permeated Hyde Park Gate rendered their house into a veritable prison in which the sisters' bodies and integrity were at stake. Leslie Stephen, it must be said "preserved the framework of 1860, [while] George filled in the framework with all kinds of minutely-teethed saws; and the machine into which [their] ... rebellious bodies were inserted in 1900 not only held [them] ... tight in its framework, but bit into [them] . . innumerable sharp teeth" (152). Here and throughout the essay Woolf offers a sharp critique of the patriarchal world she inhabited as she came of age, keenly illustrating the ways in which its social machinery humiliated her and stripped her of confidence. It is not surprising that she describes Hyde Park Gate 
as it existed even before her mother's death in terms of furniture and paintings, china, and silverware, in terms of material possessions rather than the capaciousness and natural amenities with which she associates St. Ives. Her description of Hyde Park Gate leaves little room for freedom of thought, cluttered as it is with the inane acquisitions and aspirations of upper-middle class life.

Enabled by this Victorian framework, the domineering impulsiveness of Leslie Stephen's "violent temper" raged against the remaining family after Julia Stephen's death. While Woolf was and remained as she wrote this essay somewhat enamored of her father, his intellectualism, "his honesty, his unworldliness, his lovableness, his perfect sincerity," she recognizes in her father a detrimental "godlike, yet childlike, standing in the family" that weighed heavily on those in its wake (110-111). She admits that her father possessed an innate charm, a presence by which she was awed, and she felt very strongly flattered when she recognized that he too was aware of an affinity between father and daughter. Woolf acknowledges these positive attributes of her father, trying to convince herself, it seems, that she is too captious in this account, emphasizing as she does "the tyrant father-the exacting, the violent, the histrionic, the demonstrative, the self-centered, the self-pitying, the deaf ..." father who weighed on her so even after his death. It is this father who rendered 22 Hyde Park Gate into a "cage," a hollow "shell" $(116,143)$. The next chapter, which focuses on To the Lighthouse, more completely analyzes Woolf's admittedly ambivalent relationship with her father and her father's ghost, both of whom haunt her memories of Hyde Park Gate.

In all fairness, Woolf notes that, for a few hours a day, Vanessa and Virginia were able to escape the strictures of the society that so repelled them: 
From ten to one Victorian society did not exert any pressure upon us. Vanessa ... made those minute pencil drawings of Greek statues which she brought home and fixed with a spray of odd smelling mixture; or painted a histrionic male model ... in oils. I read and wrote. For three hours we lived in the world we still inhabit. For at this moment (November 1940) she is painting at Charleston; and I am writing here in the garden room at Monks House. Nor would our clothes be different; the skirts a little shorter perhaps. My hair not much untidier then than now; and Vanessa in a blue cotton smock; as no doubt she is at the moment. (148)

The upstairs rooms in which the Stephen girls plied their crafts were, as Bachelard remarks about attic rooms, appropriately associated with flights of imagination, and it is these attic rooms with which Woolf touchingly aligns her present identity. Woolf fancies that, appearance-wise, the young Virginia was not really so different from the middleaged woman looking back upon her youth through writing, the art in which the youthful Virginia Stephen likewise took great pleasure. Moreover, imaginative, attic space at Hyde Park Gate is here not so far away really from the garden room at Monks house where she is composing "A Sketch of the Past," which is itself not far removed from the childhood gardens at St. Ives that were so foundational to the development of Woolf's artistic sensitivity. These domestic spaces foster her imagination even as she writes in 1939-1940. What, then, distinguishes amenable space from that which squelches?

Perhaps it is association. Confinement was the rule at Hyde Park Gate, where Woolf's and her siblings' lives were "tortured and fretted and made numb" between the hateful years 1897-1904, "the seven unhappy years" (136). Woolf delineates as the causes of such unhappiness not the deaths of her mother and her half-sister Stella Duckworth Hills, but "the damage that their deaths inflicted" (136). Hyde Park Gate is associated not only with Victorian society at its most crushing, but with lack, an absence of vitality. By "damage" Woolf seems to mean a rupture between a relatively safe and 
capacious past and one that was lived in the face of impinging doubt, fear, and awkwardness, in the face of claustrophobia. The past as represented by Victorianism is a plunge into backwardness Woolf is loathe to make, while the past as incarnated in the recollection of St. Ives is a past characterized not only with plentitude, but with creative freedom:

If there is any good (I doubt it) in these mutilations, it is that it sensitises. If to be aware of the insecurity of life, to remember something gone, to feel now and then, overwhelmingly, as I felt for father when he made no claim to it, a passionate fumbling fellowship - if it is a good thing to be aware of all of this at fifteen, sixteen, seventeen, by fits and starts-if, if, if--. But was it good? Would it not have been better ... to go on feeling, as at St. Ives, the rush and tumble of family life? To be family surrounded; to go on exploring and adventuring privately while all the while the family as a whole continued its prosaic, rumbling progress; would this not have been better than to have had that protection removed; to have been tumbled out of family shelter; to have it cracked and gashed; to have become critical and sceptical of the family-? (137)

Contrasting the oppressive family regime at Hyde Park Gate, family life at St. Ives was conducive to the daughter's exploration of self and world. In its liveliness, family life was invigorating, but not consuming. By contrast, in its rigid sterility, post-mortem Hyde Park Gate perpetuated violence upon its inhabitants. As a result, Woolf identifies those within the family who survived Julia and Stella's death—herself, her siblings, and even her father-with a failure to thrive, the cause of which might accurately be diagnosed as a lack of an enlivening spontaneity that she most closely identifies with her mother.

But who was Woolf's mother? While recollections of Talland House represent most fully Julia Duckworth Stephen's ties with nourishing the imaginative, self-soothing aspects of Woolf's becoming, these are but associations, not attributes. In attempting to capture those attributes, Woolf realizes her ability to do so as severely compromised: 
If one looks at her not as a child, of seven or eight, but as a woman now older than she was when she died, there is something to take hold of in that fact. She was not so rubbed out and featureless, not so dominated by the beauty of her own face, as she has since become-and inevitably. For what reality can remain real of a person who died forty-four years ago at the age of forty-nine, without leaving a book, a picture, or any piece of work-apart from the three children who now survive and the memory of her that remains in her minds. There is the memory; but there is nothing to check that memory by; nothing to bring it to ground with. (85)

"A Sketch of the Past" in many respects represents Woolf's search for her mother, a specter now here, now there, lacking substance, lacking reality. Woolf knowingly creates a search for a referent who is always gone, always phantasmal. Yet the search is not futile. Relations with the mother-even imagined relations with her-serve a healing purpose. Woolf recognizes that her mother was necessarily a "general presence rather than a particular person to a child of seven or eight," in part because she was tending to her charitable causes, raising eight children, and pacifying an infantile husband (83). One reason Julia Stephen is but a specter to her daughter is that "she was living on such an extended surface" that she had neither time nor energy to dote on any particular child (except, Woolf somewhat bitterly adds, Adrian). Woolf can only envision Julia amongst others, always surrounded, never alone.

And so she must imagine her mother, "the creator of that crowded merry world which spun so gaily in the centre of ... [her] childhood" (84). She must speculate on what she imagines was her mother's unparalleled happiness in her companionate marriage to Herbert Duckworth, taking her cue from what is left, the memory of her tinkling bracelets, the memory of lying alone, a young child longing for her mother. She must remember herself being "struck by the gravity of her face," the shape of her as she approached, eyes cast downward, on a particular day at St. Ives. She must imagine as she 
was before her marriages, the woman behind the photograph, a young woman at Little Holland House, “"a vision' . . , silent, with her plate of strawberries and cream" (87). In short, Woolf professes, "I dream; I make up pictures on a summer's afternoon" (87). This artistic sensibility is not antithetical to locating the essence of Julia Stephen, for it was Julia Stephen herself who counseled a young Virginia who was anxious for her mother's presence "to think of all the lovely things [she] could imagine. Rainbows and bells ...." (82).

Woolf traces her artistic temperament to her mother who prepared young Virginia for maternal absence by promoting storytelling as a substitute for presence. And while this was never enough to compensate for the profundity of loss, it did equip Woolf to dream her mother: "[I]f one could give a sense of my mother's personality one would have to be an artist. It would be as difficult to do that, as it should be done, as to paint a Cezanne" (85). And so Julia's memory was bequeathed to her sensitive, loving, creative daughter. Woolf comments that:

Those moments-in the nursery, on the road to the beach-can still be more real than the present moment .... I can reach a state where I seem to be watching things happen as if I were there. That is, I suppose, that my memory supplies what I had forgotten, so that it seems as if it were happening independently, though I am really making it happen. In certain favourable moods, memories- what one has forgotten-come to the top. Now if this is so, is it not possible-I often wonder-that things we have felt with great intensity have an existence independent of our minds; are in fact still in existence? (67)

In writing, in creating, Woolf revivified her mother and the little world that vanished with her, to the extent that we might almost believe the resurrection to be literal, we who imagine the Virginia Woolf who so tenderly imagined her mother. 


\section{CHAPTER IV}

\section{ASSEMBLING: MRS. RAMSAY AND THE ART OF CONNECTION}

For always . . . there was something incongruous to be worked into the harmony of her face. She clapped a deer-stalker's hat on her head; she ran across the lawn in galoshes to snatch a child from mischief. So that if it was her beauty merely that one thought of, one must remember the quivering thing, the living thing ...., and work it into the picture; or if one thought of her simply as a woman, one must endow her with some freak of idiosyncrasy — she did not like admiration-or suppose some latent desire to doff her royalty of form as if her beauty bored her.

Virginia Woolf To The Lighthouse ${ }^{11}$

In "A Sketch of the Past," Virginia Woolf identifies the process of writing To the Lighthouse as therapeutic in her struggle with her mother's death. As Woolf describes it, the memory work that was the process of composing To the Lighthouse lightened a burden Woolf had been carrying for some thirty years:

It is perfectly true that she [my mother] obsessed me, in spite of the fact that she died when I was thirteen, until I was forty-four. Then one day walking round Tavistock Square I made up, as I sometimes make up my books, To the Lighthouse; in a great, apparently involuntary, rush. One thing burst into another. Blowing bubbles out of a pipe gives the feeling of the rapid crowd of ideas and scenes which blew out of my mind, so that my lips seemed syllabling of their own accord as I walked. What blew the bubbles? Why then? I have no notion. But I wrote the book very quickly; and when it was written, I ceased to be obsessed by my mother. I no longer hear her voice. I do not see her.

I suppose that I did for myself what psycho-analysts do for their patients. I expressed some very long felt and deeply felt emotion. And in expressing it I explained it and then laid it to rest. (81)

${ }^{11} 29$. 
Given the fact that "A Sketch of the Past" might be accurately described as a quest for the essence of Julia Stephen, Woolf might seem to be overstating her case regarding the forgetting To the Lighthouse enabled. Nonetheless, if in the midst of this quest Woolf cites To the Lighthouse as momentous, it behooves us to take into account the image of the mother-and of the artist-that emerges in this text.

Created as she was in the image of Julia Stephen, Mrs. Ramsay is an incarnation of home. The keeper of the little world that the Ramsays and their guests inhabit, she oversees the quotidian and ensures it as conducive to the flourishing of its denizens. The novel's opening line-"Yes of course, if it's fine tomorrow .... But you'll have to be up with the lark"-situates her as a potential fulfiller of childhood reveries of Bachelardian proportions (3). An emotionally impressionable child, her son James beatifies this moment of possibility:

To her son these words conveyed an extraordinary joy, as if it were settled, the expedition were bound to take place, and the wonder to which he had looked forward, for years and years it seemed, was, after a night's darkness and a day's sail, within touch. Since he belonged, even at the age of six, to that great clan which cannot keep this feeling separate from that, but must let future prospects with their joys and sorrows, cloud what is actually at hand, since to such people even in the earliest childhood any turn in the wheel of sensation has the power to crystallise and transfix the moment upon which its gloom or radiance rests, James Ramsay, sitting on the floor cutting out pictures from the illustrated catalogue of the Army and Navy Stores, endowed the picture of a refrigerator, as his mother spoke, with heavenly bliss. It was fringed with joy. The wheelbarrow, the lawnmower, the sound of poplar trees, leaves whitening before rain, rooks cawing, brooms knocking, dresses rustlingall these were so coloured and distinguished in his mind that he had already his private code, his secret language. (3-4)

Contrasting the stark and stern presence that Mr. Ramsay makes throughout much of

"The Window," Woolf attributes to Mrs. Ramsay the creation of domestic space 
conducive to the sort of solitude Bachelard associates with reverie. James is of a more sensitive disposition than most, more sensitive to images, symbols, and to the sensory input of everyday life. In his attention to the quickening of the world and all that composes it, in his overt disdain for a father he experiences as far too severe, James might remind us of Virginia Woolf herself, who in imagining herself as a child attributes her creative becoming to the influence of her mother and contemplates the birth of artistic sensibility in terms of the maternal. It is fitting, then, that art is the medium through which Woolf rediscovers her own and her mother's identities, for art becomes Woolf's home in a world without her mother.

Immersed in creative reverie, Woolf sketches a daydream within a daydream, both of which are begotten in intimate spaces, Woolf's in Monk's House and in Talland House, and James's in the cottage in the Hebrides, itself a fictionalized construction of Talland House. Bachelard maintains reverie as a route to reimagining childhood, which enables a reinvigoration of spontaneity and poetic impressionability. To access the eternal yet buried childhood that exists within, one must become like a child again. Hence, to Bachelard, and to Woolf in both "A Sketch of the Past" and To the Lighthouse, art necessitates revisiting one's past. As will be discussed in the next chapter, in Lily's case this means returning both physically and emotionally to one's home, and in Woolf's it means trailing the vines of a sensitivity that first manifested itself when she was but a toddler. Bachelard explains that "reverie toward childhood returns us to the beauty of the first images," for children's worlds pivot on alluring sensory stimulation (Reverie 103). As elaborated in the previous chapter, in "A Sketch of the Past" Woolf remembers vividly from her childhood her mother's dress, a membrane that seemed rather like a 
grape, the visions of St. Ives, all of which return to memory so vividly because Woolf is able to access the bodily traces they left behind, traces that endure because they were created in a state of imaginative fervor. James mirrors his creator here. The elements that comprise his world quiver before him, glistening with life energy.

James's imagination is surely sustained by his mother's. Not only does she infuse him with the joys of the liminal fairytale world through her reading of "The Fisherman and his Wife," but she embodies creativity in how she approaches the real world, hardly a fairytale. In doing so, she imparts the wisdom that perception in large part determines the extent to which our lives are wondrous. In short, Mrs. Ramsay is in a perpetual state of awareness of the wonder of natality. She is able to render a perfectly dull errand into town into a "great expedition," an expedition that at once allows her to bathe in the sea air, reach out to a socially-inept Mr. Tansley, and administer to the needs of the less fortunate in the coastal town that is her home for a portion of her year. The vivaciousness with which she embarks upon her journey is communicated through the stimuli that catch her fancy and her responses to them. As Woolf describes Tansley and Mrs. Ramsay catching sight of a man hanging an advertisement for the circus, one can feel the breeze whipping about and the colorful energy that is a child's anticipation of the circus's arrival into her town: "The vast flapping sheet flattened itself out, and each shove of the brush revealed fresh legs, hoops, horses, glistening reds and blues, beautifully smooth, until half the wall was covered with the advertisement of a circus: a hundred horsemen, twenty performing seals, lions, tigers ... . 'Let us all go!' she cried” (11). Tunneling into her past, revisiting childhood ecstasy, Mrs. Ramsay learns that Mr. Tansley did not share 
such an ecstasy-he did not visit the circus as a child. Assessing her own emotion and weighing it against Tansley's, she creates something of a deeper connection with him.

Woolf's decision to build camaraderie between Mrs. Ramsay and Tansley is significant, for Tansley is the naysayer who threatens to shatter James's reverie of making his great expedition and whose nasty refrain "women can't write, women can't paint" interrupts To the Lighthouse's celebration of female imagination (197). Tansley's treatment of James, in fact, leads Mrs. Ramsay to cast him as an "odious little man"; nonetheless, beneath his contemptible behavior she recognizes something deserving of concern and respect. She recognizes his fragile humanness. While Mrs. Ramsay exhibits a somewhat insidious reverence toward young men, she recognizes in them a stultifying sterility; "they are poor as church mice" (6). She wishes for her daughters that they might "find a way out of it all. There might be some simpler way, some less laborious way" (6). Yet, for her own part, she intervenes.

Mrs. Ramsay loathes both Tansley's and Mr. Ramsay's insensitivity, for “[t]o pursue truth with such astonishing lack of consideration for other people's feelings, to rend the thin veils of civilisation so wantonly, so brutally, [is] . . to her so horrible an outrage of human decency" (32). Confronted with such a world view, she feels herself sullied by "the pelt of jagged hail, the drench of dirty water," yet she steps in to soften the harshness (32). Her great gift is to usher men into "the circle of life, warmed and soothed, ... [their] barrenness made fertile" (37). Her ability to do so is realized through her successful creation of a salutary domestic atmosphere, "all the rooms of the house made full of life--the drawing-room; behind the drawing-room the kitchen; above the kitchen the bedrooms; and beyond them the nurseries; they must be furnished, they must 
be filled with life" (37). Taking Tansley in as she does, she beckons him to join the human community outside of his world of "ugly academic jargon, that rattle[s] itself off so glibly" (12). Engaging him aesthetically on their little jaunt, a jaunt that extends the domestic beyond the walls of the Ramsay cottage, Mrs. Ramsay works a bit of a miracle.

The circus flyer certainly does not serve as the culmination of sensory bliss.

Rather, directly after viewing the poster, Mrs. Ramsay is enraptured by a sublime view of the bay:

Mrs. Ramsay could not help exclaiming, 'Oh, how beautiful!' For the great plateful of blue water was before her; the hoary Lighthouse, distant, austere, in the midst; and on the right, as far as the eye could see, fading and falling, in soft blue pleats, the green sand dunes with the wild flowing grasses on them, which always seemed to be running away into some moon country, uninhabited of men.

That was the view, she said, stopping, growing greyer-eyed, that her husband loved. (12-13)

Here rapture takes us more properly into place, into the world that is the natural world that cradles the novel, a natural world modeled on the one that so fed Woolf's childhood senses and continued to nourish her as she wrote. Place then ushers Mrs. Ramsay into a sacred consideration of her marriage, and, in doing so, fuses place, mutuality, domesticity, and art. For, immediately after contemplating that she and Mr. Ramsay share an affinity for this place, she catches sight of a derivative artist's painting in the latest fashion, which leads her to recall what she knows of the painting habits of her grandmother's friends. Here yet more connection is forged, Virginia Woolf's with her childhood, and Mrs. Ramsay's with her husband, her maternal past, and the places of her childhood.

As for Tansley, the intervention alters him, if only temporarily. His view of the world suddenly alters: "he was coming to see himself, and everything he had ever known 
gone crooked a little. It was awfully strange" (13). His intimacy with Mrs. Ramsay disturbs his sense of balance because this balance was molded to fit his lonely shape. In Teaching Beauty in DeLillo, Woolf, and Merrill, Jennifer Green-Lewis and Margaret Soltan describe "the experience of beauty ... as the disclosure of a radiant and exhilarating fit between the self and the world[,] ...[a] glimpse of an underlying coherence ... of a seemingly natural alliance between the self and the world at a time when an utter alienation between the self and the world is assumed" (44). This surely explains Tansley's liminal moment here. Touched by beauty, most notably Mrs. Ramsay's beauty that itself encompasses the natural world and the world of her making, Tansley is able to emerge gradually from the shell that is his sense of inferiority and isolation into space that is neither fully self nor fully other, but is inclusive of life in its manifold forms.

Admittedly, back at the cottage he reverts to the cynicism that characterizes Mr. Ramsay's coterie, but these moments with Mrs. Ramsay matter, for they disrupt the loneliness that shadows his interactions. Perhaps we might attribute the seemingly disjointed fact that after the war he delivers lectures on, of all things, love, to his time in the domestic world of Mrs. Ramsay's creation? That Mrs. Ramsay embraces him despite his flaws surely contributes to the fact that, as will be discussed in the next chapter, Tansley can spend a peaceful day with Lily and Mrs. Ramsay on the beach without resorting to his derogatory refrain regarding women's unsuitability for artistic creation. Playing ducks and drakes, skipping stones, Tansley becomes a child again, a child unfettered by the harshness that characterized his childhood, a childhood without circuses. 
At times, Mrs. Ramsay's imaginativeness manifests itself in the colorful art of exaggeration: "She could not help laughing at herself sometimes. She said, the other day, something about 'waves mountains high.' Yes, said Tansley, it was a little rough. 'Aren't you drenched to the skin?' she had said. 'Damp, not wet through,' said Mr. Tansley, pinching his sleeve, feeling his socks" (8). Mrs. Ramsay's hyperbole dismantles Mr. Tansley's and Mr. Ramsay's hierarchy of reason throughout To the Lighthouse, for, ultimately, it is her influence that endures, her legacy of reverie that inspires those left behind. Approaching the world through the lenses of unfettered emotion and creativity, Mrs. Ramsay conjures an embracing social order that facilitates its inhabitants' thriving, an expansive order that, emanating from Mrs. Ramsay as it does, envelops without suffocating.

Woolf bequeaths to her readers the gift of accessing Mrs. Ramsay's associative, non-dictatorial thinking, a gift accessible to them if they only suspend their own identities for a bit. We witness Mrs. Ramsay's thoughts jump from the fact that Tansley is "such a miserable specimen, .. . all humps and hollows," to her own embellishment of reality; to her children's thoughts of Tansley's deficiencies; to her children's private, attic spaces; to the differences we half-invent that only serve as barriers to understanding others; to social justice (7). Excerpted from a seemingly insignificant portion of the text, this trajectory of thought is telling, for it reveals how Mrs. Ramsay makes her way from brute fact to imagination, which ultimately leads her to empathy and a contemplation of social justice. Her way of thinking - and of acting —entails recognizing connections where others do not. 
Mrs. Ramsay's capacity to weave connections where none are evident is literalized in her knitting. Throughout "the Window," she knits a "reddish-brown stocking" intended for the lighthouse keeper's little child who suffers from tuberculosis. Busying her hands allows her to enter a state in which doing mirrors thinking, a state that links action, art, thought, and reaching beyond the bounds of her individual psyche. From Mrs. Ramsay's point of view, a main impetus for the much-anticipated journey to the lighthouse is delivering to the lighthouse keeper supplies that will render his lonely time keeping watch more bearable. Once more, Woolf intertwines creativity and love for the world:

If she finished it [the stocking] tonight, if they did go to the Lighthouse after all, it would be given to the Lighthouse keeper for his little boy, who was threatened with a tuberculous hip; together with a pile of old magazines, and some tobacco, indeed, whatever she could find lying about, not really wanted, but only littering the room, to give to those poor fellows, who must be bored to death sitting all day with nothing to do but polish the lamp and trim the wick and rake about on their scrap of garden something to amuse them. For how would you like to be shut a whole month at a time, and possibly more in stormy weather, upon a rock the size of a tennis lawn? she would ask; and to have no letters or newspapers, and to see nobody; if you were married, not to see your wife, not to know how your children were,--if they were ill, if they had fallen down and broken their legs or arms; to see the same dreary waves breaking week after week, and then a dreadful storm coming and the windows covered with spray, and the birds dashed against the lamp, and the whole place rocking, and not be able to put your nose out of doors for fear of being swept into sea? How would you like that? she asked, addressing herself particularly to her daughters. So she added, one must take them whatever comforts one can. (5)

Mrs. Ramsay models for her daughters how, when applied rightly, creativity betters the

lives of others. Entering what she imagines to be the consciousness of one less fortunate than herself, she suffers the brunt of the waves of loneliness and acts to mitigate the pain. One might argue that she understands the plight of the lighthouse keeper's confinement at 
sea because it mirrors her own confinement within the home, within domesticity, for Woolf does critique the extent to which Mrs. Ramsay has been prevented from doing all that she wishes to do, immersed as she is in the chores of keeping the hubbub of family life. Yet, though that critique is present, it does not outweigh impressions of Mrs. Ramsay's work as salutary. Her conception of what she might offer the world outside of the sphere of her family consists of becoming something of an "investigator, elucidating the social problem"-working to remedy situations that inhibit flourishing, particularly as they impact the domestic sphere (9). Mrs. Ramsay's rounds about town visiting the poor and ailing, it should be said, mirror those of Julia Duckworth Stephen, known as she was for her philanthropic, compassionate works, works that took her beyond her family home to her home in the larger community. ${ }^{12}$ Here Woolf merges her own memories of her mother's mission with aesthetics and aesthetics with addressing issues that plague society. Through doing so she not only pays homage to Julia Duckworth Stephen, but she awakens readers to art's ability to move its creators and its audience beyond the confines of their own limited perceptions, beyond individual identity. She encourages others to care, and reveals the act of doing so as inherently creative.

\section{Imagining Loss}

Mrs. Ramsay's most salient creative interventions occur on the individual level and strive to counter the antagonistic whisperings of death and loss that threaten to dominate even the most blessed life. Even as she scaffolds James's urgent longing to make a jaunt to the lighthouse, to experience adventure free from the strictures that limit a child's ability to pursue his fancies, she harbors the fearsome awareness that maturing

\footnotetext{
${ }^{12}$ Lee $97-98$.
} 
necessitates first-hand knowledge that living is equivalent to surrendering oneself to destructive forces beyond human control:

Oh, but she never wanted James to grow a day older! or Cam either. These two she would have liked to keep for ever just as they were, demons of wickedness, angels of delight, never to see them grown up into longlegged monsters. Nothing made up for the loss. When she just now read to James, 'and there were numbers of soldiers with kettledrums and trumpets,' and his eyes darkened, she thought, why should they grow up, and lose all that? He was the most gifted, the most sensitive of her children. But all, she thought, were full of promise .... Why, she asked, pressing her chin on James's head, should they grow up so fast? Why should they go to school? She would have liked always to have had a baby. She was happiest carrying one in her arms. Then people might say she was tyrannical, domineering, masterful, if they chose; she did not mind. And, touching his hair with her lips, she thought, he will never be so happy again, but stopped herself, remembering how it angered her husband that she should say that. Still, it was true. They were happier now than they would ever be again. (59-60)

Mrs. Ramsay is not simply blindly nostalgic for the carefree days of childhood—she knows firsthand the trials adults must face: "There were the eternal problems: suffering; death; the poor. There was always a woman dying of cancer even here. And yet she had said to all these children, You shall go through it all. To eight people she had said relentlessly that" (60). We learn in "Time Passes" that her children are destined for the premature losses of their mother and two of their siblings, and for the erosion of faith in human goodness and the gnawing sense of homelessness that, as discussed in Chapter I, necessarily accompanied World War I. Weighing these facts against Mrs. Ramsay's near premonition here makes her children's resultant haggardness all the more poignant. Woolf's autobiography attests that the violent ripping of these innocent children from what Woolf affectionately refers to in "A Sketch of the Past" as "the rush and tumble of family life" will be almost more than they can bear. Mrs. Ramsay's trepidation is wellfounded. 
Yet, her regret is not based solely on her conviction that "this thing called life [is] terrible, hostile, and quick to pounce on you if you gave it chance" (60). Rather, she loathes that reality will set in, that the imaginative grounds her children trample will be plowed over and will inevitably be replaced by the necessity of facing brute reality, a reality that too often debilitates those who confront it by defying their visions and dreams. Between the ellipses in the above quotation, Mrs. Ramsay takes a few moments to relish her children's gifts, Prue's patience and beauty; Andrew's mathematical aptitude; Nancy's and Roger's wildness that leads them to romp about the countryside; Rose's artistic inclinations; and, while she does not entirely approve, Jasper's current rage for shooting birds. She is alert to the simple beauty of childhood felicity:

A tenpenny tea set made Cam happy for days. She heard them stamping and crowing on the floor above her head the moment they woke. They came bustling along the passage. Then the door sprang open and in they came, fresh as roses, staring, wide awake, as if this coming into the diningroom after breakfast, which they did every day of their lives, was a positive event to them, and so on, with one things after another, all day long, until she went up to say good-night to them, and found them netted in their cots like birds among cherries and raspberries, still making up stories about some little bit of rubbish—something they had heard, something they had picked up in the garden. They had their little treasures. (59)

Immune to hierarchical modes of approaching the world, to adult cynicism, her children live zealously, hungry for the moment they are in, hungry for the moments yet to come. And, not unlike their mother, they tell tales when they find themselves reeling from the hustle and bustle of their bountiful days, tales of the treasures they have accumulated during their waking hours. Mrs. Ramsay laments the fact that childlike spontaneity inevitably gives way to rigidity, for what is rigidity if not the antithesis of living fully? 
A testament to Mrs. Ramsay's influence that will enable her children to thrive beyond childhood proper is the brooding Nancy's creative encounter with the depths of the tidal pool. Nancy is brooding, it should be said, over the spectacle of the rituals of courtship as exemplified by Paul and Minta, rituals that she intuits will impose limits on her friend Minta's boundless spirit. This is not altogether unduly cynical, given that Minta shortly thereafter loses her grandmother's brooch, given that Woolf includes the incident of Minta's lost jewel to illustrate that the movement from childhood into a prescriptive adulthood does threaten to unravel--temporarily anyway-that which was intricately wound. Nancy attempts to stem her anxiety regarding the knowledge that this path has been ordained for her through engaging in a bit of play:

Nancy waded out to her own rocks and searched her own pools and let that couple look after themselves. She crouched low down and touched the smooth rubber-like sea anenomes, who were stuck like lumps of jelly to the side of the rock. Brooding, she changed the pool into the sea, and made the minnows into sharks and whales, and cast vast clouds over this tiny world by holding her hand against the sun, and so brought darkness and desolation, like God himself, to millions of ignorant and innocent creatures, and then took her hand away suddenly and let the sun stream down .... And then, letting her eyes slide imperceptibly above the pool and rest on that wavering line of sea and sky, on the tree trunks which the smoke of steamers made waver upon the horizon, she became with all that power sweeping savagely in and inevitably withdrawing, hypnotised, and the two senses of that vastness and this tininess (the pool had diminished again) flowering within it made her feel that she was bound hand and foot and unable to move by the intensity of feelings which reduced her own body, her own life, and the lives of all the people in the world, forever, to nothingness. (75-6)

Acting out her rage upon a world of her own creation, Nancy imagines herself as God damning his world with his presence and blessing it with his absence. Nietzschean in its disdain of Christianity, this might well represent Virginia Woolf's conviction that organized religion inflicts damage upon those in its grasp. Also productive is reading this 
passage as Woolf's take on World War I, with the slaughter of the innocents as proof of religion's culpability in the violence that infests the world. In the world of To the Lighthouse, this foreshadows the loss that is to come, the war that battles to destroy the fragile goodness of human connection. Try as she may to conceive a world in which she might control her own destiny, Nancy is overpowered and continues to brood. This is indeed an indictment of civilization, but not of the creative endeavors imposed to make it more palatable. Nancy's imaginative powers are not such that she can prevent the storms to come, but perhaps they will endow her with the vision to revive hope in the tempest's wake. And these gifts she possesses most assuredly have been bequeathed to her by her mother.

One of the most beautiful scenes in the novel occurs after the dinner party when Mrs. Ramsay visits the nursery to look in on her youngest children. Frenzied, unable to sleep, James and Cam argue over the "horrid skull" nailed to the nursery wall. Enamored of it, James insists that it must not be touched, while Cam fears it. A symbol of death that foreshadows what is in store for the children in the not-so-distant future, the skull is displayed prominently in part to pose the question with which Mr. Ramsay is obsessed: "What endures?" Skillfully and lovingly, Mrs. Ramsay models the act of creation as a means to assuage death's sting:

[S] he quickly took her own shawl off and wound it round the skull, round and round and round, and then she came back to Cam and laid her head almost flat on the pillow beside Cam's and said how lovely it looked now; how the fairies would love it; it was like a bird's nest; it was like a beautiful mountain such as she had seen abroad, with valleys and flowers and bells ringing and birds singing and little goats and antelopes and ... She could see the words echoing as she spoke them rhythmically in Cam's mind, and Cam was repeating after her how it was like a mountain, a bird's nest, a garden, and there were little antelopes, and her eyes were 
opening and shutting, and Mrs. Ramsay went on speaking still more monotonously, and more rhythmically and more nonsensically, how she must shut her eyes and go to sleep and dream of mountains and valleys and stars falling and parrots and antelopes and gardens, and everything lovely .... (114-15)

A recasting of the stories Julia Stephen advised young Virginia to dream up when she struggled to sleep without her mother's presence, the story Mrs. Ramsay relates to Cam is a trace of Julia Stephen through which Woolf avows that art matters, stories endure, stories are presence. Moreover, Mrs. Ramsay prescribes art as a means to cope with loss, absence, and mortality, imagination as a treatment for fear, which again instantiates this as autobiographical. Julia Stephen endowed her daughter with this ethics of creation, which, in turn, her daughter bestows upon her readers.

The above story might be categorized as what Julia Kristeva refers to as the semiotic, partaking as it does of the tones and rhythms of language without absolute regard for the words' denotations. Woolf suggests art as inextricable from maternity and maternal heritage, situating herself within the bounds of maternity and establishing herself as a creator of domesticity and consolation. Art becomes as a home to those who truly inhabit it. Mrs. Ramsay's stories live on in Cam, who, for her part, retains something of her childhood sprightliness when she is older and restructures the culminating trip to the lighthouse at the end of the novel into a treasure-bound adventure. Cam's association of this consequential journey with a quest is sagacious, for it facilitates rediscovery of her mother's warmth and often indiscernible tenderness of her father.

Not only does Mrs. Ramsay's story survive for Cam's reclamation at the end of the novel, but her scarf remains in "Time Passes" to remind us that, despite her physical absence, she is very present in soul and memory, and it anticipates how her legacy will 
shape the whole of the last section of the novel, the whole of life. Even Mrs. Ramsay's

leave-taking of the nursery after she lulls Cam to sleep is heavy with significance,

simultaneous defeat and triumph, as she responds with regret and sadness to the drowsy

James' last words to her:

Would they go to the Lighthouse tomorrow? No, not tomorrow, she said, but soon, she promised him; the next fine day. He was very good. He lay down. She covered him up. But he would never forget, she knew, and she felt angry with Charles Tansley, with her husband, and with herself, for she had raised his hopes. Then feeling for her shawl and remembering that she had wrapped it round the boar's head skull, she got up, and pulled the window down another inch or two, and heard the wind, and got a breath of the perfectly indifferent chill night air and murmured good-night to Mildred and left the room and let the tongue of the door slowly lengthen in the lock and went out. (116)

Lamenting that this disappointment will contribute to the diminishment of James's carefree innocence, Mrs. Ramsay admits to herself that she has been overpowered, by her husband, by Tansley, by her own optimism and imaginative abandon, by nature itself. Moreover, she recognizes her own role in this travesty. To atone, as a gesture of hope, she self-consciously leaves a bit of herself behind. Her green shawl symbolizes fertility and eternal life, self-perpetuating presence. In the wake of the emptiness and loss that is

"Time Passes," her shawl remains, "wav[ing] gently, sway[ing] aimlessly", translucently obscuring death's ugliness, proclaiming life was here, life is here, love remains.

\section{Making Connections}

Through Mrs. Ramsay, Woolf celebrates the joys of vitality, a vitality that expresses itself in an urge to create that overshadows the necrophilia of which Grace Jantzen speaks in Becoming Divine. Mrs. Ramsay's creativity shines brilliantly throughout the novel in the forms of her ministrations to others, her fanciful stories, and her knitting. Mrs. Ramsay's knitting, an act that at once symbolizes her role within the 
community of those who inhabit the novel, the ethical impulse of her creativity, and the thoughts that pulse through her being as she navigates her world, is brought to metaphorical fruition in the novel's dinner party scene. Like Clarissa Dalloway, Mrs. Ramsay gives to her world through bringing together those from disparate walks. The dinner party urges those who inhabit her place and time to suspend their separateness and solitude, to immerse themselves in creativity through mutuality.

A true mutual encounter encompasses everyday spontaneity, demanding as it does that each respective party relinquish a portion of his or her self-serving habits to engage with the other at the threshold of identity. Neither fully immersed in the self nor fully consumed by the other, each participant in the encounter experiences something of the wonder of the world through firsthand exposure to other ways of seeing and becoming. As is exemplified in the connection between Mr. Tanslay and Mrs. Ramsay described above, true mutuality results in salutary bewilderment that disturbs both preconceptions and self-contained stability. Certainly this is what happens at times during Mrs. Ramsay's dinner party, but, as Woolf makes clear, one can never depend upon mutuality's constancy, as to do so would be to lose spontaneity and relapse into the limitations of habit.

Intent upon engaging everyone in the divine paradox of planned togetherness, Mrs. Ramsay involves two of her children, Rose and Jasper, in her dressing rituals. That Jasper is said to offer her an opal necklace and Rose is said to offer a gold one is of particular import, for it reveals that, through her gesture of involving her children, Mrs. Ramsay communicates to them that their participation in the evening is valued. Woolf is not merely trifling with details here-she is positing childhood and maternal creativities 
as intersecting. The children's choice of jewelry becomes an aesthetic choice, in Rose's case in particular, as she is later constructed as a bit of an artist herself through Mrs. Ramsay's enamored reflection on her daughter's artfully-arranged fruit bowl. Here aesthetics intertwine with something greater, however. Woolf reveals creativity as befitting the spectrum of the manifestations of reciprocal love between mother and child:

But she let them take their time to choose; she let Rose, particularly, take up this then that, and hold her jewels against the black dress, for this little ceremony of choosing jewels, which was gone through every night, was what Rose liked best, she knew. She had some hidden reason of her own for attaching great importance to this choosing what her mother was to wear. What was the reason, Mrs. Ramsay wondered, standing still to let her clasp the necklace she had chosen, divining, through her own past, some deep, some buried, some quite speechless feeling that one had for one's mother at Rose's age. Like all feelings felt for oneself, Mrs. Ramsay thought, it made one sad. It was so inadequate, what one could give in return; and what Rose felt was quite out of proportion to anything she actually was. And Rose would grow up; and Rose would suffer, she supposed, with these deep feelings .... (81)

In adorning her mother, Rose works with her feelings of idealization, just as Woolf does in "A Sketch of the Past" and in To the Lighthouse. In both cases, daughters render tangible their adoration. Yet, as Mrs. Ramsay reflects on her daughter's earnestness in this "little ceremony," she becomes somewhat sad, sad that her daughter cannot at this moment know her as well as she knows her daughter, sad that she will inevitably disappoint the young being who thinks so highly of her. To the returning reader-and to Woolf herself - this sadness is also bound in a premonition of death. In attributing such a premonition to Mrs. Ramsay, Woolf expresses her own regret over her relationship with her mother who was so swiftly taken from her, and she imagines her mother's sadness upon having to leave so soon. 
Woolf then takes an unprecedented turn. She reveals something of Mrs. Ramsay's experience of being a child and of being mothered. As Rose clasps her mother's necklace, Mrs. Ramsay arrives at a sort of epiphany: Rose, it seems, is following in her mother's footsteps. Mrs. Ramsay was a child who idealized her mother. Reflection brings Mrs. Ramsay into contact with her childhood self, with her mother, and with the daughter with whom she identifies so deeply. Is this not likewise Woolf's autobiographical reflection? Woolf casts herself as the adoring child, remembering what this idealization was like, an idealization that was only just beginning to be worked through as Woolf wrote To the Lighthouse. For Woolf lost the mother she idealized when she was only thirteen, when she was not so much older than Rose. Woolf also casts herself as her own mother, contemplating the inevitability of distance, the fact that this sacred relationship is not inviolable. Woolf dreams herself into the position of divining her mother's feelings for her, sobered, perhaps, by the recognition that all mother-child relationships are on some level distant, that the only way to bridge distance is to halfcreate. Mrs. Ramsay's thoughts are eerily prophetic. She does put her own daughter in the position of suffering and confusion; she does leave her daughter motherless. Ultimately, only creative memory remains to trace the impression that is the mother's legacy.

In the midst of the aforementioned reflections is Woolf's reflection on her role as artist, on what the artist contributes to her world, on art's inflection on the mother-child relationship, and on the extent to which through creating art one nurtures. In the scene discussed above, Rose luxuriates in the process of creating a beautiful image of her mother, much as Woolf does in her novel. Rose is the daughter-child enamored of her 
mother's brilliance, and it pains Mrs. Ramsay that she knows but is unable to communicate to her daughter that much of that brilliance is idealization. In humble thanksgiving, Rose creates an offering to communicate her love for a mother who so assiduously weaves connections that matter. In doing so, she perpetuates the cycle of giving.

Despite Mrs. Ramsay's periodic feelings of intimidation in the face of an impersonal world, Woolf constructs the maternal figure as never abandoning her faith in the possibility of humanity's capacity to connect. Hence, she assembles her friends and family—her little community—in a commitment to enabling such unity. Again, given Woolf's avowal of the novel's maternal context, reading the text in terms of Julia Duckworth Stephen proves enlightening. In imagining her mother, the creator of the world that was her childhood, Woolf endows her with a good dose of idealism, yet that idealism is not naïve. Rather, Mrs. Ramsay is cautiously and intermittently hopeful, for existential anxiety adulterates that hope. At the dinner party's inception, for example, Mrs. Ramsay's mind teems with existential questions and pessimistic assessments of her surroundings and her role in the scheme of things:

But what have I done with my life? ... They had that-Paul Rayley and Minta Doyle-she, only this—an infinitely long table and plates and knives .... She has a sense of being past everything, through everything, out of everything, as she helped the soup, as if there was an eddy-thereand one could be in it, or one could be out of it, and she was out of it. It's all come to an end, she thought, while they came in one after another .... Raising her eyebrows at the discrepancy - that was what she was thinking, this was what she was doing - ladling the soup - she felt, more and more strongly, outside the eddy; or as if a shade had fallen, and, robbed of colour, she saw things truly. The room (she looked round it) was very shabby. There was no beauty anywhere .... Nothing seemed to have merged. They all sat separate. And the whole of the effort of merging and flowing and creating rested on her. (83) 
Alienated from her surroundings and from those she has assembled, she retreats within herself because she senses incompatibility between her intentions and reality. Observing her situation from afar, as it were, an alienated Mrs. Ramsay finds herself out of place, the world she hoped to inhabit vacuous. Though many bodies are present, they fail to harmonize. Home is unheimlich, devoid of beauty and devoid of the emotion that would affirm it as shelter.

Not only is Mrs. Ramsay homeless at this asynchronous juncture, but, if read in terms of what happened to the world Virginia inhabited after her mother died, she has become a daughter without a mother. This scene anticipates the inhospitable aura that will characterize the next congregation some ten years later, a congregation that is found lacking because its domestic artist is absent. For the present, however, recognizing the necessity of remediating "the sterility of men" if all are to thrive, Mrs. Ramsay vivifies herself so that she might set things right. The metaphor Woolf employs to characterize Mrs. Ramsay's role here supports this moment as foreshadowing death, for she must "giv[e] herself a little shake that one gives a watch that has stopped, the old familiar pulse began beating, as the watch begins ticking-one, two, three, one, two, three. And so on and so on, she repeated, listening to it, sheltering and fostering the still feeble pulse as one might guard a weak flame with a newspaper" (83). Perhaps Lily's theory that a life of giving without reciprocity wearies Mrs. Ramsay is keen, for Mrs. Ramsay has been weakened.

For a moment, in fact, Woolf suggests surrendering as a distinct possibility through comparing Mrs. Ramsay to "a sailor [who] not without weariness sees the wind fill his sail and yet hardly wants to be off again and thinks how, had the ship sunk, he 
would have whirled round and round and found rest on the floor of the sea" (84). Mrs. Ramsay's fading is also likened to death through Lily's perception of her "drifting off into that strange no-man's land where to follow people is impossible and yet their going inflicts such a chill on those who watch them that they always try at least to follow them with their eyes as one follows a fading ship until the sails have sunk beneath the horizon" (84). Despite the lure of death, of eternal rest—something Lily apparently understandsMrs. Ramsay chooses life, not only her own life, but the lives of those she guards, the very ones who wear her down. We know that in her darkest hours Virginia Woolf was seduced by death; she proclaims here, however, as she did so many times through living and creating, that she must live, for without love, without art, so dark and feeble is the world, so sterile. Through her living artistry, Mrs. Ramsay nurtures others, and, at least as importantly, she nurtures herself.

Yet, the merging Mrs. Ramsay aspires to flounders into near non-existence for much of the evening; we are made privy to this through Woolf's narrative style that carries us into the characters' lonely pessimism. For her part, Lily loses herself in irritable consideration of Mrs. Ramsay's flaws of misjudging and projecting misguided pity and of Mr. Tansley's brutishness. Mr. Tansley, in turn, falls into self-pity and selfdoubt, wishing to retreat to the safety of his room to be alone with his books. Mr. Bankes is struck by the monotony of the Ramsays' domestic rhythms:

But it was not worth it for him. Looking at his hand he thought that if he had been alone dinner would have been almost over now; he would have been free to work. Yes, he thought, it is a terrible waste of time.... How trifling it all is, how boring it all is ... compared with the other thingwork .... What a waste of time it all was to be sure! Yet, he thought, she is one of my oldest friends. I am by way of being devoted to her .... Yet now, at this moment her presence meant absolutely nothing to him: her beauty meant nothing to him; her sitting with her little boy at the 
window-nothing, nothing .... The truth was that he did not enjoy family life. It was in this sort of state that one asked oneself, What does one live for? Why, one asked oneself, does one take these pains for the human race to go on? Is it so desirable? Are we attractive as a species? Not so very .... Foolish questions, vain questions, questions one never asked if occupied. Is human life that? One never had time to think about it. But here he was asking himself that sort of question because Mrs. Ramsay was giving orders to servants, and also because it had struck him ... that friendships, even the best of them, are frail things. One drifts apart. (89)

A profusion of doubts flood Mr. Bankes' mind. As with Tansley, the chaotic energies that circulate at any such gathering unnerve him. In juxtaposing the two men's anxieties, Woolf suggests masculine aversion to a domesticity that it cannot direct but that it needs nonetheless. The passage involving Mr. Tansley depicts his feeling of emasculation when Lily pokes fun at him, and this with Mr. Bankes associates impotence and an inability to connect, "rigid[ity] and barren[ness]"(89). In both Bankes' and Tansley's cases, work is a means of avoiding the more difficult aspects of life, ones that cannot be tamed. Mrs. Ramsay, it must be said, also wrestles with such existential questions and doubt—she too has only just doubted her purpose and has been shaken by the precariousness of friendship. Yet, Mrs. Ramsay perseveres, in large part because she believes in the cause. Her perseverance, in turn, penetrates the doubters among her group and inspires them to do the same.

Although she renounces domesticity as a path suited for her, Lily Briscoe likewise takes up the banner of civility, and, while she feels somewhat treacherous to herself for doing so, reaches out to the detestable man who has pelted her so often with insults. Throughout this section, then, a barrage of distress storms the party, yet, it is mitigated by a willingness to risk one's sense of personal propriety for the sake of compromise and, 
ultimately, human intercourse. Lily recognizes that human relations demand stepping outside of one's comfort zone, into the light of mutual responsibility:

There is a code of behavior, she knew, whose seventh article ... says that on occasions such as the sort it behooves the woman, whatever her occupation may be, to go to the help of the young man opposite so that he may expose and relieve the thigh bones, the ribs of his vanity ....; as indeed it is their duty, she reflected, in her old maidenly fairness, to help us, suppose the Tube were to burst into flames. Then, she thought, I should certainly expect Mr. Tansley to get me out. But how would it be, she thought, if neither of us did either of these things? (91)

Here Woolf advocates a middle ground, not a life of servitude, but an openness to witnessing another's weakness and stepping in to ease some of the burden. Woolf's forthrightness is commendable, for nostalgic though she is for her mother's presence, she is unwilling to embrace unquestioningly the domesticity of which she sees Julia Stephen representative. Nor is she willing to discard it. Rather, she exposes the beneficent potential of domesticity in the process of critiquing the extent to which it is detrimental. Lily's ambivalence towards domesticity will be thoroughly elaborated in the next chapter.

A presence that has been largely ignored in this study, Mr. Ramsay plays a pivotal role in all sections of the novel as a figure against whom the vicissitudes of domesticity are reflected. Like Leslie Stephen, Mr. Ramsay is too often puerile and domineering, and, as such, he weighs heavily upon his wife. It is she who must soothe her husband back into calmness a good bit of the time: he tends to work himself into a dither. Stella Duckworth and Vanessa and Virginia Stephen were themselves trampled by such a temperamental presence after their mother died; in experimentally working out the dynamics of Mr. and Mrs. Ramsay's marriage, Woolf is working through the confluence of relations that contributed to her making. With his perpetual "someone had blundered," Mr. Ramsay stands as the epitome of captious masculinity, and, through exploring in 
depth the source of his will to dominate, Woolf reveals the perils of clinging fast to a positivism in decline. ${ }^{13}$ For Mr. Ramsay is often quite the pathetic figure, shivering and quivering as he does, bursting out desperately with lines from Tennyson's "The Charge of the Light Brigade." And, while he needs Mrs. Ramsay desperately to quell his bitter temper and his anxiety, he is at times enraged by her refusal to submit to the gods of probability and logic. Consequently, he lords over his wife to squelch the fears that such a rebellion against proper reason provokes.

Yet, we should not simply discard him. Debating his character, Lily Briscoe and William Bankes acknowledge his flaws but cannot ignore his virtues. Alongside Lily's and William's credible assessments of Mr. Ramsay, Mrs. Ramsay is depicted as loving him despite his tyrannies, despite his egoism, though to these flaws she is certainly not blind. When confronted with one of his bouts with doubt provoked by his fear of failure and uselessness, Mrs. Ramsay "assure[s] him, beyond the shadow of a doubt, by her laugh, her poise, her competence (as a nurse carrying a light across a dark room assures a fractious child), that it [is] real; the house [is] full; the garden blowing. If he put implicit faith in her, nothing should hurt him" (38). While mothering this grown man exhausts Mrs. Ramsay physically and emotionally, the music that he and she make together even in such a charged scene sustains her: "there throbbed through her, like the pulse in a spring which has expanded to its full width and now gently ceases to beat, the rapture of successful creation. Every throb of this pulse seemed, as he walked away, to enclose her and her husband, and to give each that solace which two different notes, one high, one

\footnotetext{
${ }^{13}$ Steven Kern explains that "a number of thinkers and artists ... rebelled against the sweeping, and at times blind, faith that the nineteenth century had had in the value of the historical approach to all living processes, especially the human" (61). By and large this historical thrust hinged on the idea of history as progressive, an idea that was shattered with the onset of World War I.
} 
low, struck together, seem to give each other as they combine" (39). This transaction in which Mrs. Ramsay must employ her emotional intelligence to create an atmosphere of calm for her agitated husband is creative, even orgasmic, and, while it is not comprised of ceaseless pleasure, it is realistic. Any relationship of depth is at times marked by bad behavior, just as it comprised of moments of joyful reconciliation. Mr. Ramsay's unruliness surely cannot be sanctioned; yet, chemistry, affection, and underlying respect between husband and wife are present. Mrs. Ramsay is not completely overpowered. She wields her sword in subtle but swift ways, and we suppose Woolf imagines her mother doing the same. Still the daughter, Woolf seats herself at the table of the subsequent dinner party, to observe, to partake of her parents' relationship, to partake of the beauty and the ugliness of which it is comprised.

Tugged by the undertow of dissonance that pervades the gathering, Mrs. Ramsay looks to her husband to intervene: "One word, she said to herself. For if he said a thing, it would make all the difference. He went to the heart of things. He cared about fisherman and their wages. He could not sleep for thinking of them .... Then, realising that it was because she admired him so much that she was waiting for him to speak, she felt as if someone were praising her husband to her and their marriage, and she glowed all over ...." (95). Once again Woolf notes the ineluctable ebb and flow of human relations and the complexities of individual identities, for though Mrs. Ramsay at times in "The Window" thinks her husband savage in his cruel disregard for others, his heart-felt sympathy for the less fortunate, a quality not unlike that of hers that leads her to seek to remedy circumstances afflicting those less fortunate than herself, attracts her. A real 
difference here, it should be recognized, is that Mrs. Ramsay acts, whereas Mr. Ramsay perseverates, yet the core value of love for those who inhabit the world unites them.

Evaluating both parents' legacies, Woolf delicately probes her mother's and father's strengths and weaknesses, never forgetting that they were human in their foibles. Woolf is true to her mission of sketching human nature and human relations as necessarily imperfect, unpredictable and unstable, yet not altogether disagreeable. Basking in the warmth of Mr. Ramsay's goodness, Mrs. Ramsay steals a glance at her husband, yet there he is again, "screwing his face up, ... scowling and frowning, ... flushing with anger. What on earth was it about? she wondered. What could be the matter? Only that poor old Augustus should be beginning his soup over again. $\mathrm{He}$ loathed people eating when he had finished" (95). Just when she thinks she has been recovered from the depths of anomie, Mrs. Ramsay is flailed by her husband's rigidity. Mr. Ramsay once more proves himself to be something of a tyrant who seethes when deprived of the illusion that he controls the realm of this domestic kingdom. Bracing herself, sensing "that in a moment something violent would explode," Mrs. Ramsay is surprised to find that her husband halts in midstream (95). While this is hardly to be celebrated as an exemplar of marital unity, the moments that follow are exemplary, for, tumultuous though they may be, they represent an aversion of danger through the triumph of mutuality. Mr. and Mrs. Ramsay demonstrate resilience and a capacity to carry on, qualities that are rooted in mutual understanding.

Gazing at each other from opposite ends of the long table, husband and wife discuss the incident as if telepathically, Mr. Ramsay begging her take notice that he held his temper at bay despite his disdain for the circumstances, Mrs. Ramsay scolding him for 
allowing such a minor incident to carry him to the brink of fury. Neither speaks, yet "each know[s] exactly what the other [feels]" (96). This instance of unity within discord sets the scene right, stabilizes the community, though no words are uttered, though we have no indication that anyone besides husband and wife have sensed the moment of reconciliation. Deflecting attention from her husband's near loss of temper, Mrs. Ramsay commands "Light the candles," Rose and Roger rise to do so, and an everyday wonder is sparked, a brilliant sense of becoming together in an imperfect world:

Now all the candles were lit up, and the faces on both sides of the table were brought nearer by the candlelight, and composed, as they had not been in the twilight, into a party round a table, for the night was now shut off by panes of glass, which, far from giving any accurate view of the outside world, rippled it so strangely that here, inside the room, seemed to be order and dry land; there, outside, a reflection in which things wavered and vanished, waterily. Some change at once went through them all, as if this had really happened and they were all conscious of making a party together in a hollow, on an island; had their common cause against the fluidity out there. (97)

In the universe of To the Lighthouse, this moment occurs before the onset of the First World War; collective violence has not yet cast a pall on the reverence accorded an act of unity. Modris Eksteins argues that the heightened collectivity of the summer before the war proved such reverence potentially insidious, but Woolf does not make such a suggestion here. Rather, she posits aestheticized domesticity, a vigilant ethics of shared responsibility, as a remedy to the evils of war, as potentially preventative. For war occurs in the world of To the Lighthouse in the context of an absence of cohabitation, an absence of the beauty of togetherness that marks this scene. Given the loving image she limns of her mother in "A Sketch of the Past," surely Woolf is imagining her mother as present in this scene, directing her daughter to light the candles against the darkness that has been, against the darkness to come. 
It is not only candlelight that brings into focus the shared humanity inherent in the moment-at the center of the table, at the center of it all, lies Rose's art, her arrangement of fruit:

Thus brought up suddenly into the light it seemed possessed of great size and depth, was like a world in which one could take one's staff and climb hills, she [Mrs. Ramsay] thought, and go down into valleys, and to her pleasure (for it brought them into sympathy momentarily) she saw that Augustus too feasted his eyes on the same plate of fruit, plunged in, broke off a bloom there, a tassel here, and returned, after feasting, to his hive. That was his way of looking, different from hers. But looking together united them. (97)

Homage to the power of imagination to unite disparate--even conflicting — personalities, this passage takes the reader first into Mrs. Ramsay's and then into Mr. Carmichael's experience of aesthetic immersion. True to the élan vital that animates her, Mrs. Ramsay imagines herself roaming about the countryside, breathing in her expansive surroundings, contemplating her world, much as Mr. Ramsay rambled about in his younger days, much as the young Stephens did at St. Ives. And then, another miracle. Into Mrs. Ramsay's reverie wanders Mr. Carmichael, who has likewise taken an aesthetic plunge into the sphere of Rose's creation. Mrs. Ramsay's "way of looking" entails an erasure of the boundaries that inhibit roaming freely; Mr. Carmichael's is likened to feasting gingerly on art's sensory pleasures. That art not only accommodates multiple perspectives, multiple ways of becoming in the world, but also unites those it engages, is nothing short of miraculous.

This puts Rose, then, in the position of playing the part of her mother, albeit differently from Mrs. Ramsay. At her mother's behest, Rose lights the candles that soften hearts and minds, but her work of art illuminates possibility as much as the tapers do, as much as her mother does. Woolf commemorates her mother through Rose, and she 
aligns herself with the artist-mother. Virginia Woolf is Mrs. Ramsay beholding with enamored eyes the miracle of a daughter's gift; Virginia Woolf is Julia Stephen looking fondly upon her daughter in whom she is well pleased. Yet, Woolf is also Rose; she is the daughter looking at a mother who leaves her in awe. To commemorate Julia Stephen's life is to celebrate her own, to engage in the world creatively, and to write a book in which the image of mother and daughter endure.

Infused by her own abundance, by the act of creation, Mrs. Ramsay reflects that this moment will endure, this will outlive all that is ephemeral:

Everything seemed possible. Everything seemed right. Just now. . just now she had reached security; she hovered like a hawk suspended; like a flag floated in an element of joy which filled every nerve of her body fully and sweetly, not noisily, solemnly rather, for it arose, she thought, looking at them all eating here, from husband and children and friends; all of which rising in this profound stillness ... seemed now for no special reason to stay there like a smoke, like a fume rising upwards, holding them safe together. It partook, she felt, . . of eternity; . . . there is a coherence of things, a stability; something, she meant is immune from change, and shines out (she glanced at the window with its ripple of reflected lights) in the face of the flowing, the fleeting, the spectral, like a ruby; ... Of such moments, she thought, the thing is made that endures. (104-105)

Mrs. Ramsay takes sustenance from the communion she has brought into becoming, and this-participating in and witnessing the breaking of bread together-strengthens her. A sacredness lingers about the table, a sacredness that Woolf further emphasizes as Mrs. Ramsay gazes out into the dark through windows that reflect the brilliant, dancing flames and she considers that the voices around her sound as if they are voices reverberating in a Roman Catholic cathedral. As Woolf came of age in an England that converted to Protestantism in the $16^{\text {th }}$ century, her choice to specify Catholicism here is momentous. It contributes an historical gravitas that at once solemnizes the occasion and renders it 
progressive; human divinity supplants that advocated by the foundations of Western

Christianity. Reading Woolf's comparison of the relatively humble cottage and cathedral intertextually is fruitful, for, as discussed in the previous chapter, Woolf likened her childhood to a great Cathedral reigned over by her mother. With its sanctification of the web of connections Mrs. Ramsay weaves, this section of the novel in particular is a hymn to Julia Stephen.

\section{Sustaining}

The above analysis explores Mrs. Ramsay's gift to others, an intricately-woven web of human connection. Yet we must also consider what sustains Mrs. Ramsay, for to fail to do so would be to fall into what Irigaray, Benjamin, and Jantzen warn is unethical, casting the mother as the source of our sustenance without reflecting on her and her needs outside of the role of mother. Never seizing Julia Stephen's nurture as sufficient in itself, Virginia Woolf questions in To the Lighthouse what lay beneath her mother's gracious beauty. Imbibing the essences of her own creative labors is a source of Mrs. Ramsay's flourishing, though it is not only in reaching out to others that she achieves depth.

As her reflections on the losses entailed in coming of age illustrate, Mrs. Ramsay possesses something of a melancholy disposition, a disposition that she generally suppresses but that is present nonetheless. This depressive tendency emerges, for instance, when she muses that the sea is as a mother who rocks gently her agitated children, though its lulling cadences are in reality harbingers of death:

[T]he monotonous fall of the waves on the beach ... [that] for the most part beat a measured and soothing tattoo to her thoughts and seemed consolingly to repeat over and over again the words of some cradle song, murmured by nature, 'I am guarding you-I am your support,' $\ldots$ at other times suddenly and unexpectedly, especially when her mind raised itself slightly from the task actually in hand, had no such kindly meaning, 
but like a ghostly roll of the drums remorselessly beat the measure of life, made one think of the destruction of the island and its engulfment in the sea, and warned her whose day had slipped past in one quick doing after another that is was all ephemeral as a rainbow. (15-16)

This passage proves especially poignant when considered in light of both Woolf's and Mrs. Ramsay's exuberant experiences of the sea. "A Sketch of the Past"-written long after To the Lighthouse, it has been noted-tells of the wonders of St. Ives and the particularly intoxicating view from the Lookout Place. This text might be considered a eulogy to Julia Stephen written with a backward gaze toward To the Lighthouse as the novel that facilitated Woolf's ability to come to terms with her mother's legacy and death. As such, references in her autobiographical essay to the Lookout Place with its aerial view of the bay might be read intertextually. In both texts, the sea is inextricable from the deaths that the cycles of nature portend; both texts work to make sense of the death of childhood precipitated by the untimely death of Julia Stephen. In these works the sea comes to be known as a remnant from a world that has been lost, a remnant that proclaims in its undulations the inevitability of mortality, proclaims through its rises and falls the brevity of happiness. Woolf returns to St. Ives-the site of her childhood reveries - as she dreams her aesthetic vision that is an affirmation of life and a mourning that all of this should have to end. Like Woolf, Mrs. Ramsay does not view the life she so loves simplistically, but rather recognizes and resigns herself to its bittersweet depth.

Mrs. Ramsay's interior depth is communicated through Woolf's stream-ofconsciousness narrative technique, a technique that grants the reader access to the nonlinear thoughts that wind about in human consciousness. However, we are not only accessing fictional characters' minds when we immerse ourselves in a work of art. As Jennifer Green-Lewis and Margaret Soltan convincingly argue, through art we become 
intimate with others' thoughts and modes of beings, in this case with Woolf's, with what she imagines of her mother's, and with others who share with us the experience of immersing themselves in the universe that is To the Lighthouse. In respect for her mother, Woolf imagines her mother's imaginings through Mrs. Ramsay, and doing so is an ethical act of acknowledging another's being. We are blessed to be but a fine strand in this cosmic lacework.

Given that Mrs. Ramsay is indeed the creator of the childhood world of her children, and given that she, like Julia Stephen, was known for her kindnesses to others, Woolf attributes to Mrs. Ramsay a good dose of exhaustion: she often feels that she is "nothing but a sponge sopped full of human emotions" (32). To recuperate, Mrs. Ramsay retreats into a solitude comprised of a paradoxical mindful mindlessness:

She could be herself, by herself. And that was what now she often felt the need of - to think; well, not even to think. To be silent; to be alone. All the being and doing, expansive, glittering, vocal, evaporated; and one shrunk, with a sense of solemnity, to being oneself, a wedge-shaped core of darkness, something invisible to others. Although she continued to knit, and sat upright, it was thus that she felt herself; and this self having shed its attachments was free for the strangest adventures. When life sank down for a moment, the range of experience seemed limitless .... Her horizon seemed to her limitless. There were all the places she had not seen; the Indian plains; she felt herself pushing aside the thick leather curtain of a church in Rome. This core of darkness could go anywhere, for no one saw it. They could not stop it .... There was freedom, there was peace, there was, most welcome of all, a summoning together, a resting on a platform of stability. Not as oneself did one find rest, ever, in her experience (she accomplished here something dexterous with her needles) but as a wedge of darkness. Losing personality, one lost the fret, the hurry, the stir; and there rose to her lips always some exclamation of triumph over life when things came together in this peace, this rest, this eternity. (62-63)

Reflective of Bachelard's characterization of domestic intimacy as conducive to reverie, Mrs. Ramsay's withdrawal into a space of solitude allows her to dream outside of the 
confines of established identity and its accompanying roles. In this place and time, Mrs. Ramsay engages intensively in becoming, and becoming in this sense carries her aloft into worlds untraveled, into places and times not yet conceived. In visiting the Indian plains Woolf undertakes a pilgrimage to the site her mother's birth. Mrs. Ramsay is both mother and child meeting in an improbable space and time of the past, revisiting the birth of creativity.

Here is the absence of fragmentation, a centripetal merging not unlike the moments of unity at the dinner party. Though her hands are still acting, her mind is still. Woolf's portrait of the compatibility of these seemingly contradictory states-movement and stillness-is consistent with what many knitters have long recognized, what Bernadette Murphy terms "the Zen of knitting." Murphy writes in Zen and the Art of Knitting that knitting promotes a meditative mindset: A "tentative process," "knitting reflects the complexities of human life. As metaphor for understanding the web of unity connecting all life, and as a practice that puts one in touch with the simultaneous fragility and strength of life, knitting is both expansive and fertile" (vii). Mrs. Ramsay creates herself in the process of creating for another; this simple act enhances proximity between her, the lighthouse keeper, and his son. Simultaneity of action and inaction suggests the distance that may be traversed in such stillness, the multivalent productivity inherent in what others might deem merely materially productive. Mrs. Ramsay participates in the timeless-in terming Mrs. Ramsay's state of reverie "eternal," Woolf connects with intuited aspects of her mother that live on in her beloved daughter.

Yet another symbol of Mrs. Ramsay's profundity, the lighthouse is interwoven with her meditative state: 
$[\mathrm{P}]$ ausing there she looked out to meet that stroke of the Lighthouse the long steady stroke, the last of the three, which was her stroke, for watching them in this mood always at this hour one could not help attaching oneself to one thing especially of the things one saw; and this thing the long steady stroke, was her stroke. Often she found herself sitting and looking, sitting and looking with her work in her hands until she became the thing she looked at - that light for example. And it would lift up on it some little phrase or other which had been lying in her mind like that'Children don't forget, children don't forget' - which she would repeat and begin adding to it, It will end, it will end, she said, It will come, it will come .... She looked up over her knitting and met the third stroke and it seemed to her like her own eyes meeting her own eyes, searching as she alone could search into her mind and heart, purifying out of existence that lie, any lie. She praised herself in praising the light, without vanity, for she was stern, she was searching, she was beautiful like that light. (63)

Affirming an idea that Woolf articulates in both Mrs. Dalloway and $A$ Sketch of the Past, that an essence of oneself attaches eternally to the places with which one has been most intimately acquainted, Mrs. Ramsay becomes the light that outlives her body. Her reiteration of lulling words—here "Children don't forget"-proves self-soothing, constituting the very meditative state that conceives them. Charged with maternal import, the words Mrs. Ramsay utters are literally about how children experience their world and are in part semiotic, for their rhythm as much as their message is a lullaby to their creator.

While the connotative and denotative content is not necessarily of primary importance to the meditative state, in Woolf's case it is of utmost significance. "Children don't forget, children don't forget" may well be the mantra of To the Lighthouse, which embodies the Bachelardian reality that childhood endures even in those who are grown, as do the living relics of the mother. The reliquary that is Woolf's novel, then, is itself the expression of the unity of phenomena, not the least of which are the daughter and the mother in their past and present states, in their imaginative, eternal becoming. This unity 
is not a unity of a collapsed subject and object; rather, the paradoxical oneness that is birthed is inclusive of finely-yoked identities whose infinitesimal fissures are comprised of wondrous interconnections.

The lighthouse light, which is "steady, ... pitiless, ... remorseless, which [is] so much her, yet so little her," illumines the multidimensionality of existence (65). It gestures toward nature's beauty and the beauty of the soul, yet it is unsympathetic to a humanity aching with mortality. This does not diminish Mrs. Ramsay's exhilaration, however. Gazing at the lighthouse light,

hypnotized, as if it were stroking with its silver fingers some sealed vessel in her brain whose bursting would flood her with delight, she had known happiness, exquisite happiness, intense happiness, and it silvered the rough waves a little more brightly, as if daylight faded, and the blue went out of the sea and it rolled in waves of pure lemon which curved and swelled and broke upon the beach and the ecstasy burst in her eyes and waves of pure delight raced over the floor of her mind and she felt, It is enough! It is enough! (65)

Enraptured in her attunement with becoming, Mrs. Ramsay experiences a transcendence of self in which the waves of the sea betoken the colors of imagination, their undulations and breakers stimulating her inmost being. Pulsing with intensity, this rapture, like the incident of communion with her husband described above, is orgasmic. The sexual dimension of reverie situates dreaming as foundational, primal, fundamentally human. Through this passage Woolf affirms the cycles of life and death and their resonances; in doing so she affirms her mother's short life and her mother's relationship with the world and the beings inhabiting it. Once more, Woolf is both mother and child here: Mrs. Ramsay is the mother preparing for her own death by embracing the world, and she is the daughter reconciling herself to the cessation of the relationship with her mother's corporeal self. Woolf honors Julia Stephen as mother and creator, honors herself as 
daughter and artist, and, through doing so, shepherds her readers into a shared sense of becoming in the world. In turn, Woolf shepherds herself into the genealogy of the strong women who birthed her.

It is of tremendous import that we as readers are not the only ones attuned to the existence of Mrs. Ramsay's interiority. While Mr. Ramsay is unable to access the content of Mrs. Ramsay's consciousness, he does intuit the existence of elements in his wife that are not available to him. Through Mr. Ramsay's attentiveness to his wife's integrity, Woolf lovingly sketches a softer profile of his character, a side that diverges from his worship of brute reality and follows the fluttering that lies below that which is manifest. His recognition aligns him with his wife, for as he gazes into the hedge that surrounds and protects the seat of this insulated world, he realizes that he is unable to do the same for her. In this moment in which he sees the greenery in "its intricacy, its darkness," he perceives something of the unfathomability of the world and of those who inhabit it (64). He becomes less rigid; he becomes more human.

Witnessing his helplessness and sensing that his will to dominate has been subdued, Mrs. Ramsay reaches out in love: "And again he would have passed her without a word had she not, at that very moment given him of her own free will what she knew he would never ask, and called to him and taken the green shawl off the picture frame, and gone to him. For he wished, she knew, to protect her" (65). This need not be read as a solidification of gender roles: both spouses meet at the thresholds of their identities in an effort to understand and relate to each other. Given the tenor of Mrs. Ramsay's thoughts, given that this scene is but a step on the path toward embracing her own death, Mr. Ramsay's desire to protect her is quite keen. Mrs. Ramsay's act of love 
likewise springs from an impulse to shelter. She offers him her arm because she cannot spare him the pain of mortality. Perhaps this is death-defying. The memory of this act of love surely does something to stem Mr. Ramsay's fear of being forgotten.

\section{Continuing}

The last scenes of "The Window" in many senses rehearse the death and loneliness yet to come. This is particularly the case in our last moments with Mrs. Ramsay, the author of the world of this first section of the novel who has included us in her creative universe: "With her foot on the threshold she waited a moment longer in a scene which was vanishing even as she looked, and then, as she moved and took Minta's arm and left the room, it changed, it shaped itself differently; it had become, she knew, giving one last look at it over her shoulder, already the past" (111). The poignancy of this scene deepens when interpreted biographically. Virginia Woolf endows Mrs. Ramsay with a premonition that all is to end, that the panoply that is life, with its radiance and with its moments of being, of becoming, is in a real sense ephemeral. There is a melancholy air to this leave-taking of moments of wondrous communion. At the threshold of present and past, Mrs. Ramsay recognizes the miracle of life, transient though it may be. The beneficiary of a transcendental awareness bequeathed to her by her daughter, Mrs. Ramsay is from this moment forward in the present as present and in the present as past and can grasp more fully humanity's—and her own—plight.

Sorrowful though it may be, humanity's lot is not altogether tragic. For Virginia Woolf suggests through Mrs. Ramsay that mortality is not final, after all; the past—and, hence, the present-continues:

So she righted herself after the shock of the event, and quite unconsciously and incongruously, used the branches of the elm tree outside to help her to 
stabilise her position. Her world was changing: they were still. The event had given her a sense of movement. All must be in order. She must get that right and that right, she thought, insensibly approving of the dignity of the trees' stillness, and now of the superb upward rise ... of the elm braches as the wind raised them .... Yes, that was done then, accomplished; and as with all things done, became solemn. Now one thought of it, cleared of chatter and emotion, it seemed always to have been, only was shown now and so being shown, struck everything into stability. They would, she thought, going on again, however long they lived, come back to this night; this moon; this wind; this house: and to her too. It flattered her, where she was most susceptible of flattery, to think how, wound about in their hearts, however long they lived she would be woven; and this, and this, and this .... (113)

Reeling from the ebb and flow of the evening, the waves of stability that come and so quickly give way to movement, Mrs. Ramsay recognizes something of the eternal in communion that was and will continue to be. The very concept of endurance presupposes that something else will pass, a sparkling remnant will lodge itself in memory though much of the rest will disappear. This jewel, which Woolf likens to a ruby in an earlier passage, promises to lure the party's descendants back so that they might stroke its loveliness. Still quivering in her own brilliance, anything but fossilized, Mrs. Ramsay will continue to comfort those who need her and will grant them the strength to carry on. For the connections she has so brilliantly woven between friend, son, daughter, and husband will not unravel-in sharing her capacity to connect, she has ensured not only her own continuance, but the continuance of the possibility of an infinite network of connections. The web of life is ongoing, comprised as it is of those who are and have been. An intimate proximity of present and past, all is in order.

Solaced by the sense of "that community of feeling with other people which emotion gives as if the walls of partition had become so thin that practically ... it was all one stream, and chairs, tables, maps, were hers, were theirs, it did not matter whose," she 
finds peace (113-14). The portion of "The Window" that recounts what remains of the evening after the party has dispersed—our last moments with Mrs. Ramsay—moves slowly. She lingers about the hallways as if breathing her world one last time. As she climbs the stairs to the nursery, she takes an affectionate look at "the sofa on the landing (her mother's); at the rocking chair (her father's); at the map of the Hebrides," at peace with past and present, comforted by her conviction of the connectivity of the whole of life (113).

As Mrs. Ramsay descends the stairs after having quelled the ruckus in the nursery, still slow, still thoughtful, taking in the yellow harvest moon through the staircase window, Prue spies her and is suddenly struck with a paroxysm of awe and reverence. Mrs. Ramsay as the incarnation of beauty, wisdom, and artistry imbues Prue with a sense of childlike reverie, which, in turn, inspires a bit of a return to childhood in Mrs. Ramsay herself:

'That's my mother,' thought Prue .... That is the thing itself, she felt, as if there were only one person like that in the world; her mother. And, from having been quite grown up, a moment before, talking with the others, she became a child again ... And thinking what a chance it was for Minta and Paul and Lily to see her, and feeling what an extraordinary stroke of fortune it was for her, to have her, and how she would never grow up and never leave home, she said, like a child, 'We thought of going down to the beach to watch the waves.' Instantly, for no reason at all, Mrs. Ramsay became like a girl of twenty, full of gaiety. A mood of revelry suddenly took possession of her. Of course they must go; of course they must go, she cried, laughing; and running down the last three or four steps quickly, she began turning from one to the other... (116).

While psychoanalytic or feminist critics might cast this moment of Prue's as a plunge into the abyss of nostalgia, given Bachelard's description of childhood as ripe with dreams, this never leaving home might be interpreted as never completely abandoning 
childhood enchantment. As we have seen, Mrs. Ramsay's approach to her world embodies this childlike enthrallment. Witnessing in her daughter the joie de vivre with which she has hoped to endow her children, witnessing an undermining of the gloomy view that childhood is the happiest time, witnessing something of herself in Prue, Mrs. Ramsay quickens her step and thinks to go down to the beach herself. Woolf limns these last moments as foreshadowing Mrs. Ramsay's and Prue's deaths, but she does not limn these characters as faltering. Rather, they maintain their life force. Yet, prophetess that she is, Mrs. Ramsay stops herself from making her jaunt to the beach. She suddenly realizes what she already knows. Something holds her back. This something happens to be the something with which her grieving children and husband will struggle mightily. And so she resumes her creeping pace, imbibing the aura of her home, drawn to her husband who needs her as she does him.

Woolf affirms her parentage in ending "The Window" with the love of husband and wife, mother and father. As Mrs. Ramsay moves into the room that her husband occupies, she is vaguely aware that she "want[s] something more, though she did not know, could not think of what it was that she wanted" (117). She resumes her knitting, murmuring all the while that last refrain from the conclusion of the marvel of the evening, "And all the lives we ever lived/And all the lives to be, Are full of trees and changing leaves," and then immerses herself in a book of poetry, feeling "that she [is] climbing backwards, upwards, showing her way up under petals that curved over her" (119). Poetry has become an imaginative refuge, lost as she is in its resonances without regard for the proper meaning of that which she reads, lost in the semiotic. Moving deeper into a trancelike sleep within waking, lost in poetic reveries, Mrs. Ramsay 
"climb[s] up those branches, this way and that, laying hands on one flower and then another .... How satisfying! How restful! [And] then there it [is], suddenly entire; she [holds] it in her hands, beautiful and reasonable, clear and complete, the essence sucked out of life and held rounded here-the sonnet" (121). Her preparations for a death she does not consciously anticipate are pleasing to her, cleansing, and though her husband witnesses her peace, he vows not to disturb it.

Emerging from the cocoon of her reverie, she is drawn to her husband, desires desperately that he should speak. For she desires intimacy. And slowly, surely, "through the crepuscular walls of their intimacy, for they were drawing together, involuntarily, coming side by side, quite close, she could feel his mind like a raised hand shadowing her mind" (123). Though she never speaks it aloud, he recognizes that her mind has suddenly taken a turn toward pessimism, and she hopes that his reproving voice should counter it. United in thought, united in their wills to fight darker imaginings through clinging to their steadfast love, the scene-and the section—ends with an unspoken expression of the love that bolsters both. Though her stocking will not be finished tonight, will not be finished ever, this does not amount to defeat. Her love for the world will continue to guide, continue to uphold. The unity that characterizes the conclusion of "The Lighthouse" affirms that Mrs. Ramsay's connections are outside of ravaging time, outside of finitude. This affirmation of spousal love affirms a continuance of Mrs. Ramsay's presence.

Through this act of writing, Woolf achieves her own sense of peace. Dreaming her mother's peace, enacting the continuity of past and present, makes it so. Finding peace is so central a component of To the Lighthouse, in fact, that the remainder of the 
novel might be read as a quest towards that end. But, as Lily testifies in "The Lighthouse" section, serenity comes not in resigning oneself to loss, but in doing something with it, refashioning it so as to refashion oneself and the world into a salutary, commemorative embodiment of what has been and is being lost. Through fashioning life-affirming beauty that counters destructive forces even as it acknowledges them, Woolf created her own home, a home worthy of inhabitation. Modeling this home on the childhood home fashioned by Julia Duckworth Stephen, Woolf protects both from devastation. 


\section{CHAPTER V}

\section{REMEMBERING: LILY AND THE ART OF RETURN}

Lily stepped back to get her canvas-so-into perspective. It was an odd road to be walking, this of painting. Out and out one went, further and further, until at last one seemed to be on a narrow plank, perfectly alone, over the sea. And as she dipped into the blue paint, she dipped too into the past there. Now Mrs. Ramsay got up, she remembered. It was time to go back to the house-time for luncheon. And they all walked up from the beach together....

Virginia Woolf To the Lighthouse ${ }^{14}$

As the previous chapter alludes to briefly, a particularly momentous bit of connection contingent upon Mrs. Ramsay's presence occurs as Lily Briscoe and Charles Tansley play a game of ducks and drakes on a peaceful day at the beach with Mrs. Ramsay. This bit of play at once illuminates Mrs. Ramsay's benign influence on those around her and the extent to which such influences persevere. Surrounded by Mrs. Ramsay's presence, Tansley loses something of his nastiness, casting aside his derision of women in general and of Lily in particular. He becomes a boy once more, alive to the miracle of the stones' momentary lightness, to their ability to glide-though only briefly—upon the water's glassy surface before sinking and being carried off by the roaring waves. It is not only Tansley who benefits from this game-Lily's mental reenactment of this scene in "The Lighthouse" ultimately allows her to journey toward peace and inspiration.

${ }^{14} 172$. 
Having returned to her studio on the Ramsay lawn, Lily struggles to maintain the vision and momentum to continue to create the picture she leaves quite unfinished in "The Window." No sooner has she fallen into the rhythm of her first strokes than she is beset by memories of Tansley's jeering "women can't paint, can't write" (159). Much to her credit, she is able to counter negative memories with the more resonant ripples of the day at the beach with Mrs. Ramsay and Tansley:

But after all, she reflected, there was the scene on the beach. One must remember that. It was a windy morning. They had all gone down to the beach. Mrs. Ramsay sat down and wrote letters by a rock. She wrote and wrote. 'Oh,' she said, looking up at something floating in the sea, 'is it a lobster pot? Is it an upturned boat?' She was so shortsighted that she could not see, and then Charles Tansley became as nice as can be. He began playing ducks and drakes. They chose little flat black stones and sent them skipping over the waves. Every now and then Mrs. Ramsay looked up over her spectacles and laughed at them. What they said she could not remember, but only she and Charles throwing stones and getting on very well all of a sudden and Mrs. Ramsay watching them. She was highly conscious of that. Mrs. Ramsay, she thought, stepping back and screwing up her eyes .... When she thought of herself and Charles throwing ducks and drakes and of the whole scene on the beach, it seemed to depend somehow upon Mrs. Ramsay sitting under the rock, with a pad on her knee, writing letters .... But what a power was in the human soul! She thought. That woman sitting there writing under the rock resolved everything into simplicity; made these angers, irritations fall off like old rags; she brought together this and that and then this, and so made out of that miserable silliness and spite (she and Charles squabbling, sparring, had been silly and spiteful) something - this scene on the beach for example, this moment of friendship and liking - which survived after all these years complete, so that she dipped into it to re-fashion her memory of him, and there it stayed in the mind affecting one almost like a work of art. (159-160)

As Lily imagines her, Mrs. Ramsay is rather like an earthbound goddess, witnessing the virtue of her creation, struck by the conviction that, "behold, it was very good." And Lily is not oblivious to being observed; she is "highly conscious" and quite pleased, it seems, to be an active participant in creation, to be a source of joy for the creator. Quoting 
extensively here captures the simplicity of the moment remembered. This is a most humble image, an image that may without violence be reduced to basking in elements that are amongst nature's most benevolent and allowing such an immersion to color one's relations with others. Endeavoring as ever to connect with others, with her correspondents and with Lily and Tansley, Mrs. Ramsay appropriates the moment in good faith, as do Lily and Tansley, engaged as they are in amicable play.

As an artist, Lily is inspired by the artistry that fosters this everyday miracle. Her reflection on her mentor's capacity to knit together seemingly disparate forces and personalities is a testament to the extent to which Mrs. Ramsay's genius is truly remarkable, truly salutary. Mrs. Ramsay's mere presence rescues Tansley and Lily—if only briefly - from their petty rivalry, yet the breath of this everyday miracle endures to warm Lily some ten years later. Rather than fall prey to Tansley's misogyny, Lily “dips into" this remembered day of serenity to recast her vision of him. Recognizing that harboring resentment would impede her ability to thrive, to create, Lily seizes upon the positive and renders Tansley much less hateful. Thriving here is inextricable from art, living inextricable from creation: Woolf characterizes Mrs. Ramsay's gifts as definitively artistic; Lily's life is enriched by Mrs. Ramsay's connective artistry; the artistry of an isolated moment in the past swells into the present to endow Lily with the strength and skill to refashion a negative into a positive; and this, in turn, allows Lily to move forward in her endeavor to resolve the issues of her painting - and her psychethat have plagued her these ten years.

Art, then, is not an effete palliative prescribed by those disconnected from the "real" world. As this brief episode illustrates, art is not simply something begotten of 
inks and paints. Rather, art is a way of approaching the world. The artistic-minded recognize connection in their world where none is evident, and they act accordingly. In Mrs. Ramsay's case this means doing to enable others to arrive at such recognition, and in Lily's this means developing an aesthetic vision that is at once complex enough to acknowledge disparity and simple enough to affirm the connective fibers of life that proliferate despite this disparity. Lily's art, it seems, aims to work out personal, cultural, and ontological demons, while Mrs. Ramsay's is much more earthy. As Woolf's novel testifies through its very existence, and through the fact that it is our present topic of discussion, creative endeavors such as these are not inconsequential.

As it depends heavily on imagination, Mrs. Ramsay's facility for promoting others' thriving may be understood productively through the paradigm of flourishing described by Grace Jantzen as elaborated in Becoming Divine. As Jantzen explains, a symbolic of natality relies heavily on imagination and creativity, demanding that we strive to internalize that "the weaving of the web of life which each person enters in virtue of our natality means that we are connected with all other persons, female and male[,] ... . [that] this connectedness with all others, while allowing for great diversity, can therefore be recognized as the material basis of ethical responsiveness" (150-51). In Mrs. Ramsay we witness such a worldview, for her creativity facilitates recognition of connection and consequent action as potential remedies to situations that fail to further others' flourishing. Mrs. Ramsay's continuing influence on Lily supports the contention that acting mindfully in regard for others' well-being transcends time and space; though she is no longer living in "The Lighthouse" portion of the novel, her creative legacy continues to nourish. Mrs. Ramsay's creative approach to relations between those who 
do not particularly care for one another stimulates the production of more artful action that embodies in its conception and fabric an underlying weave of connectivity.

The game of ducks and drakes encapsulates the novel's preoccupation with ripples from the past that ever-so-subtly resonate in the novel's final section, for this childhood pleasure is, at least in part, about the stones' uncanny resistance to complete oblivion. Not only do the stones skim the water's surface, but they are stirred about in the water's frothy agitations. And while they are ultimately carried away by the tides, they are not completely lost. For, unexpectedly, unceremoniously, they wash up on another shore to be found by another wanderer in search of her share of the sea's bounty. The ripples of Lily's, Tansley's, and Mrs. Ramsay's day on the beach very profoundly shape Lily's imaginings in "The Lighthouse," surrounding her when she is most in need of something to alleviate her misgivings. They initiate her into the legion of the Mrs. Ramsays of the world who recognize and seek to scaffold human connection.

Affirmation and exemplification of the intricate veining that binds one to another is To the Lighthouse's most insistent triumph. Criticism of male chauvinism and the "sterility of men," as Mrs. Ramsay so aptly conceives of it, is certainly a salient aspect of the novel, yet Woolf criticizes divisive approaches to the world. Rather, through Mrs. Ramsay and through Lily's recollections of Mrs. Ramsay, Woolf advocates recognizing commonalities rather than perseverating on difference. Through highlighting the ripples that are initiated in "The Window" and reverberate in "The Lighthouse," Woolf parallels a conception of the past undulating in the present and an insistence upon humanity's capacity to connect. Her inclusion of the waves of the past swelling into the present represents Woolf's artistry at its best, for the reader herself participates in this microcosm 
of time's workings-immersed in the experience of reading the novel, carried on the delicate surface of its ripples, she experiences for herself the aesthetics of time and is beset with the pain of nostalgia with which those left behind contend.

Given that Julia Stephen played so pivotal a role in Woolf's psychological and artistic development, and given that Woolf cites the writing of To the Lighthouse as the process through which she belatedly came to terms with the premature loss of her mother, it is intuitive that Woolf wrote herself into the grieving daughters of the novel. For Lily and Cam are artists-Lily traditionally so, and Cam, much as her mother, through embracing life as an adventure on which continually to embark anew--whose development hinges on their experiences of a mother's enduring presence despite physical absence. Likewise, both vacillate between resentment for and admiration of the father, much as Woolf did as a child and continued to do even as she wrote To the Lighthouse and, much later, "A Sketch of the Past."

Lily's journey home is the focus of "The Lighthouse," for, as we were party to her consciousness quite extensively in the novel's first section, we are compelled to compare and contrast her engagement with the world during each period. While Edward Casey emphasizes that disillusionment and alienation characterize the pilgrim's homecoming, Woolf is careful to limn Lily's relationship to home in the first section of the novel as equally tentative. In identifying with Lily, Woolf imagines herself as an adult child living in her mother's shadow, and rather than completely romanticizing the relationship between mother and child, Woolf depicts it as ambivalent.

Woolf's project of writing autobiography represents immersing herself in the idea of the grown daughter's relationship with the mother, yet here the only way to do so is to 
take a headlong plunge into the past. In "The Lighthouse," Woolf identifies with Lily, Cam, and James in their struggle to flourish in a world devoid of their mother's physical presence. In "The Window," on the other hand, she writes herself in the fictional Lily to try on the role of daughter to a living mother, to imagine that Julia Stephen had lived into her daughter Virginia's adulthood. Woolf dexterously acts the part of not only the children but also the mother, demonstrating her commitment to discover as best as she can the many dimensions of identity. Woolf's project demands a vertiginous mingling of past, present, even future, to the extent that arranging time's intricate lacework becomes an act that is by nature artful. Woolf's belief in art's power to resonate in a broken world demands such radical re-conceptualizations of identity and time.

\section{"So much depends . . . upon distance"}

Returning to the Ramsays' some ten years after her earlier inhabitation, Lily is mesmerized by the place she once more inhabits, though no means comfortably:

She looked round for some one who was not there, for Mrs. Ramsay, presumably .... Then, being tired, her mind still rising and falling with the sea, the taste and smell that places have after long absence possessing her, the candles wavering in her eyes, she had lost herself and gone under. It was a wonderful night, starlit; the waves sounded as they went upstairs; the moon surprised them, enormous, pale, as they passed the staircase window. She had slept at once. (149)

After its period of vacancy, the cottage is once more alive with inhabitation. Dancing as they did at the dinner party, flames gesture toward the inextinuishable energy of connection. Imbibing the beauty of place, the rhythms of the sea and the light of the moon, Lily might now very well be a reincarnated Mrs. Ramsay, who, near the end of "The Window," which turns out to be near the end of her life, regards the moon as she descends the staircase from the nursery to see off her children and her young guests who

\footnotetext{
${ }^{15}$ Woolf, To the Lighthouse 191.
} 
are embarking on a nighttime adventure to the seashore. The window signifies in both cases a merging of home and place. Affirming home's gracious gift of a solitude conducive to imagination, the sheltered gazer communes with both internal and external worlds.

In "The Window" and "The Lighthouse," the moon lights a late-September night, a bittersweet harbinger of falling leaves and of skeletal branches. Yet, the September moon is, as Woolf specifies in both "The Window" and "Time Passes," a harvest moon, associated with the fruits of the changing seasons, the bounty of time's passage. In "The Window" section of the novel, as Mrs. Ramsay makes her descent to her death and as time ravages the ailing cottage, there is nonetheless a hope about it. For Mrs. Ramsay recognizes that memories of connection under this moon on this night will make something permanent of the evening. The moon, that is, gestures towards the eternal. This hope comes to fruition in "The Lighthouse" section as Lily ascends the staircase to her sleeping quarters for the night and gazes at the same light that illumined her predecessor. Though her journey to peace is arduous, it begins with this, her conscious return to the past. Lily's return is an ascension, for, paradoxically, tunneling into the past here is a gesture toward the present and future, an emergence into the light. The moon only gestures toward the next day's fruits-surviving the day will prove a true labor.

Despite Lily's auspicious return, "Time Passes" concludes with a middle-aged Lily Briscoe waking with a start. Having slept the night in the bedroom that she inhabited some ten years before when the Ramsay cottage was bustling with life, life that this section of To the Lighthouse so poignantly illustrates has left only traces, Lily "sit[s] bolt upright" (143). She wakes to the remembered reality that Mrs. Ramsay, Prue, and 
Andrew, all of whom "The Window" represents as destined to flourish and to contribute to others' flourishing, are no longer living. The house is but a frame of what it once was, devoid of the vivifying presence that was Mrs. Ramsay, and of promise, a promise typified by the lighthouse trip that was so desired by young James but was caustically denied him: "The house was left; the house was deserted. It was left like a shell on a sandhill to fill with dry salt grains now that life had left it. The long night seemed to have set in the trifling airs, nibbling, the clammy breaths, fumbling, seemed to have triumphed" (137). Yet, life returns, first in the earthy forms of Mrs. McNab and Mrs. Bast, who restore the house to a state yet again inhabitable by humans, and then in the return of Lily, Mr. Carmichael, Mr. Ramsay, Nancy, Cam, and James.

Lily wrestles with alienation upon her homecoming in large part because the home to which she returns is not the home she left. Edward Casey explains the "fragility of being-in-place," with a descent into alienation from that which we call home always looming: "Entire cultures can become profoundly averse to the places they inhabit, feeling atopic and displaced within their own implacement. If Freud and Heidegger are correct, this dis-implacement, or 'dysplacement' as it could also be called, is endemic to the human condition in its ineluctable 'uncanniness'; Unheimlichkeit, not-being-at-home, is intrinsic to habitation itself" (34). Imperiled by the abyss of unheimlichkeit, Lily comes to consciousness after a night of what were presumably uneasy dreams: "She clutched at her blankets as a faller clutches at the turf on the edge of a cliff. Her eyes opened wide. Here she was again, she thought" (143). Waking with a start, exhibiting a reflex akin to the infant's Moro reflex, Lily must orient herself so as not to fall into oblivion, into non-being. This passage is somewhat reminiscent of Marcel's waking into 
a sense of no-place in Proust's Swann's Way; to find their becoming, both Lily and Marcel must first find their situatedness in place. Woolf's inclusion of Lily's sense of unheimlichkeit is of personal and cultural import-Woolf's own homelessness was generated not only by the loss of her mother, but by the cultural turmoil that led to and was perpetuated by World War I.

This uncanniness recalls an episode from Woolf's own life related in Hermione Lee's biography of Woolf. Lee characterizes To the Lighthouse as a ghost story that "reenacts, over twenty years later, the ghostly feelings of the young, orphaned Stephens going back to Talland House in 1905, in its return to a Victorian past, and in its echoes of Victorian pastoral elegy" (476). No longer their literal home, Talland House nonetheless incited in the Stephen siblings recollections of becoming-at-home, a life no longer extant except in the memories of the outcast returning to the site of experienced plentitude. In both novel and life, true inhabitation entails more than simply space and place; the act of inhabiting together, cohabitation, renders home compelling. With the absence of Mrs. Ramsay and of Julia Stephen, whom Lily and Woolf most closely identify with the idea of home, home as it is first known is uninhabitable. It no longer exists in its original form.

Casey elaborates on the hazards of the pilgrim's return:

In ending a journey in homecoming, I get to where I have been alreadyan extant or previous home- but I now experience it as if it were a new place. This new/old place seems to present itself to me this time for the first time .... The issue is how we can come to such a disparate perception of what is unquestionably the same place. The basis for the disparity is twofold. First, a given home-place is always sufficiently ambiguous to accommodate a radical revision of its appearance and significance as we reencounter it. Part of the very meaning of 'home' is that it is able to give rise to quite divergent perceptions and significations. A home can be experienced at one time as perfectly amicable, at another 
time as hostile; yet it remains one and the same place through these vicissitudes and not just despite them .... Second, the journey that has intervened between my leaving home in the first place and the present moment of return has led me to other experiences in other places, thereby tempting me to regard a given place, and most notably a home-place, as quite different from what I first took it to be. I know it for the first time upon return in that I am now sensitive to aspects unappreciated when I was first living there. The home-place I knew then was not the whole, or even the essence, of the place to which I now return. It is as if I had to leave my home to become acquainted with a more capacious world, which in turn allows me to grasp more of the home to which I return. (294)

Casey's complication of the notion of home illuminates the futility of approaching home through the lens of Boym's restorative nostalgia—a restoration of home as it is imagined to have first existed is both impossible and inadvisable. Casey reveals negotiating the interrelation of present and past as inherent to return, and through doing so convincingly makes the case for the return—if it may be regarded such-as bound in reconstruction that critically assesses the past and refashions the idea of home, even the past home, to conform to present realities and needs. As To the Lighthouse so brilliantly illustrates through Lily's introspection in both "The Window," the novel's first world, and "The Lighthouse," the first world revisited through the lens of the third, the multifaceted nature of home is an engagement in the irresolute complexities of identity. Lily cannot know fully, in either section of the novel, what home is, the degree to which it is salutary, the degree to which it is insidious. Such knowledge is denied the dweller. Through its tripartite structure, Woolf's novel illuminates the extent to which time, and the journey that we embark upon with ourselves and others through time, de-stabilizes any consolation of absolute return.

Advocating a critical approach to nostalgia that acknowledges it as incorporating both personal and cultural elements, Boym asserts that, "[a]t first glance, nostalgia is a 
longing for a place, but actually it is a yearning for a different time- - the slower rhythms of our dreams. In a broader sense, nostalgia is rebellion against the modern idea of time, the time of history and progress. The nostalgic desires to obliterate history and turn it into private or collective mythology, to revisit time like space, refusing to surrender to the irreversibility of time that plagues the human condition" (xv). Woolf's project in To the Lighthouse and "A Sketch of the Past" indeed "goes beyond individual psychology," for though Woolf's experience of loss and consequent nostalgia were very much bound in the personal traumas of her childhood, those traumas were experienced and understood within a culture defined by loss (Boym xv). Woolf's dream of re-inhabiting a prelapsarian St. Ives conflates childhood innocence, domestic plentitude, and a world unscathed by humanity's self-mutilation. To the Lighthouse collapses personal and cultural contingencies to posit a self-consciously artificial divide between the then and the now, tempting the reader-as it tempts Lily—to wallow in restorative nostalgia upon being denied a desired return.

\section{"What does it mean then, what can it all mean?"16}

While the impossibility of returning home is by nature unsettling, to the creative mind it can be invigorating, as it apparently was to many modernists. Boym brands such modernists "off-modernists":

There is in fact a tradition of critical reflection on the modern condition that incorporates nostalgia, which I will call off-modern. The adverb off confuses our sense of direction; it makes us explore sideshadows and back alleys rather than the straight road of progress; it allows us to take a detour from the deterministic narrative of twentieth-century history. Offmodernism offered a critique of both the modern fascination with newness and no less modern reinvention of tradition. In the off-modern tradition, reflection and longing, estrangement and affection go together. Moreover, for some twentieth-century off-modernists who came from eccentric

\footnotetext{
${ }^{16}$ Woolf, To the Lighthouse 145.
} 
traditions, ... as well as for many displaced people from all over the world, creative rethinking of nostalgia was not merely an artistic device but a strategy of survival, a way of making sense of the impossibility of homecoming. (xvi-xvii)

This description fits a great many modernist authors: Joyce, Eliot, Faulkner, and Woolf, to name but a few. In considering the implications of time's passage, our responses to that passage, and the acceleration of time that is modernity, off-modernists deal in the perils and triumphs of modernity, the losses inherent in what has been called progress. This tradition (as paradoxical as it may be to call a critique of tradition by the very term against which it is to an extent rebelling) most acutely probes subjectivity, perceived ways of becoming, so as to make meaning out of that which could prove devastating. For the artist living in modernity, creation becomes a process through which to make sense of personal and cultural history, a mode of re-assembling differently that which has been fragmented in order to salvage oneself and one's relation to her world.

In casting homecoming as an aesthetic challenge, Lily reveals that this is so in her case:

("Alone" she heard him say, "Perished" she heard him say) and like everything else this strange morning the words became symbols, wrote themselves all over the grey-green walls. If only she could put them together, she felt, write them in some sentence, then she would have got at the truth of things. Old Mr. Carmichael came padding softly in, fetched his coffee, took his cup and made off to sit in the sun. The extraordinary unreality was frightening; but it was also exciting. Going to the Lighthouse. But what does one send to the Lighthouse? Perished. Alone. The grey-green light on the wall opposite. The empty places. Such were some of the parts, but how to bring them together? (147)

Here we have a portrait of the creative mind enthralled by the evasive interconnectedness of the world in its manifold shapes, past and present. Lily's enthrallment is spurred by a sense of terror-of unheimlichkeit--that can only be navigated imaginatively, for the evaporation of the known demands the spontaneous development of new ways of relating 
to place, to others, and to oneself, which, in turn, demands a reconsideration of a past that may have seemed relatively stable. Here Lily feels—as Woolf apparently did-that exploring the symbols of the mysterious world she inhabits has the potential to lead to a more invigorated, attuned experience of it. As the fact that she alternately finds the possibility of the emptiness both captivating and disconcerting attests, the homelessness that accompanies revisiting home is by no means unadulterated inspiration.

Casey's insistence that "[a] home can be experienced at one time as perfectly amicable, at another time as hostile" captures the root of Lily's struggles in "The Lighthouse" portion of Woolf's novel (294). Indeed, in order to arrive at a juncture hospitable to a realization of adequate significance to constitute a vision, Lily must hold in suspension the contradictions that linger in her consciousness. The most salient of these contradictions revolve around the experience of home as both animate and inanimate, the degree to which place is enlivened by inhabitation past and present and the degree to which it shrivels when human life abandons it. This question looms in readers' minds as they are dragged forcefully from the vivacious cottage of "The Window" to a corpse-like cottage in "Time Passes":

So with the house empty and the doors locked and the mattresses rolled round, those stray airs, advance guards of great armies, blustered in, brushed bare boards, nibbled and fanned, met nothing in bedroom or drawing-room that wholly resisted them but only hangings that flapped, wood that creaked, the bare legs of tables, saucepans and china already furred, tarnished cracked. What people had shed and left-a pair of shoes, a shooting cap, some faded skirts and coats in wardrobes - those alone kept the human shape and in the emptiness indicated how once they were filled and animated; how once hands were busy with hooks and buttons; how once the looking-glass had held a face; had held a world hollowed out in which a figure turned, a hand flashed the door opened, in came children rushing and tumbling; and went out again. Now, day after day, light turned, like a flower reflected in water, its sharp image on the wall opposite. Only the shadows of the trees, flourishing in the wind, made 
obeisance on the wall, and for a moment dared the pool in which light reflected itself; or birds, flying made a soft spot flutter slowly across the bedroom floor. (128-29)

Ripples from the past here are poignant—one cannot read of this miniature of the cosmic force of decay without considering the night when the home was most alive with Mrs. Ramsay's denizens dining together, Mrs. Ramsay's young children taking such care to dress their mother for the evening, and Mrs. Ramsay gazing into the mirror and lamenting that she is "[s]habby and worn out" (42). Much as the human form recedes with age, the cottage has fallen into disrepair with the disappearance of its inhabitants. Yet, this substantial decay likewise proves to be a voluble echo from the past; in "The Window" Mrs. Ramsay considered the shabbiness of the cottage, the wallpaper faded and peeling, the furniture decrepit. As Mrs. Ramsay recognized, however, the fact that this space brings joy to those who occupy it redeems such shabbiness. In "Time Passes," the cottage houses no such occupants.

Most touching here are the reverent allusions to the articles of clothing the Ramsays left behind, limp without a form to animate them, tangible reminders that the "rushing and tumbling" of life has come and gone. Gone are the shadows that accompany human movement, though the trees' shadows on the wall recall Mrs. Ramsay's story of Mary and Joseph, the fiery rooks who live in the trees outside the cottage. Echoing here is Mrs. Ramsay's humorous description of Joseph as "a disreputable old bird[,] . . . like some seedy old gentleman in a top hat she had seen playing the horn in front of a public house" (80). The shadows of birds that appear in the desolate season of disinhabitation-shadows that, not insignificantly, invoke the "exquisite scimitar shapes" of the rooks' wings, "the movement of [which] ... beating 
out, out, out[,] ... was one of the loveliest of all to her"--again attribute life to a form devoid of the life it once sustained (80). To describe the cottage as empty would be mistaken.

While the narrating presence of "Time Passes" goes out of its way to paint the cottage as much changed by the withdrawal of human presence, the palimpsestic qualities of material, emotive, and cognitive memories infuse it with a renewed life of its own. Of utmost profundity is the shawl that Mrs. Ramsay placed in the nursery in "The Window" dancing gently in the wind in the vacant house. Professing the continued presence of Mrs. Ramsay's spirit, the potency of her legacy, this remnant of her creativity continues to mitigate the force of death's sting. While no one save the reader and Mrs. McNab witness its presence, it revivifies Mrs. Ramsay, nonetheless. Asserting Mrs. Ramsay's abiding presence, this token of Mrs. Ramsay's creativity comforts the reader still in shock from Woolf's parenthetical announcement of Mrs. Ramsay's and Prue's deaths. For Mrs. McNab, the shawl coincides with memories of Mrs. Ramsay's kindnesses and charisma. An equally vivifying presence, the lighthouse light with which Mrs. Ramsay in her core of darkness so completely identified lovingly caresses the vacant rooms of "Time Passes." Signifying Mrs. Ramsay's enduring presence, the lighthouse light is particularly potent in its insistence that human love can infuse even that which is inanimate. Surely the process of writing about the lost world of her beloved St. Ives and of her mother was profoundly spiritual for Virginia Woolf; surely it was an act of love.

Returning home for the reader proves to be unheimlich, but not without hope that something of its original vitality yet exists. Reverberations of the time before what is cast as a primal loss occupy the cottage in its most hollow hours, but the reader is not merely 
greeted by memories of what has been. In spite of the tragedy of the Ramsay family deaths and of the devastation of World War I, life continues to proliferate:

The long night seemed to have set in; the trifling airs, nibbling, the clammy breaths, fumbling, seemed to have triumphed. The saucepan had rusted and the mat decayed. Toads had nosed their way in. Idly, aimlessly, the swaying shawl swung to and fro. A thistle thrust itself between the tiles in the larder. The swallows nested in the drawing-room; the floor was strewn with straw; the plaster fell in shovelfuls; rafters were laid bare; rats carried off this and that to gnaw behind the wainscots. Tortoise-shell butterflies burst from the chrysalis and pattered their life out on the window-pane. Poppies sowed themselves among the dahlias; the lawn waved with long grass; giant artichokes towered among the roses; a fringed carnation flowered among the cabbages; while the gentle tapping of a weed at the window had become, on winters' nights, a drumming from sturdy trees and thorned briars which made the whole room green in summer....

What power could now prevent the fertility, the insensibility of nature? (137-38)

Clearly, crumbling walls and the degradation of living space imply a lack of soulful presence. The rusty kitchenware is a sad reminder of better times, when the house was aflutter with the energy of the dinner party, that moment of magical stability within the flux of time when bread was broken together, the doormat degrading with disuse reminiscent of the pitter patter of feet on a mission, of Mrs. Ramsay traipsing about and of the "wild villain ... Cam dashing" in and out much to the chagrin of her exasperated mother. Yet, Woolf paints a not altogether pessimistic picture of the house without human inhabitants. Plant and animal life thrive--both inside and outside the cottage. Though a house overrun by "the insensibility of nature" is not ideal for human habitation, the life force dominates. Woolf could have chosen to characterize the Ramsay home devoid of human presence as aridly desolate, but she did not. Quite the contrary, life abounds. The gardens do not wither; they hybridize. Nature's stubborn resilience proves reassuring. The cottage is overrun by lusty nature that stakes its claim in what has been 
left behind by those who came before, and while the question of whether it will ever again be suitable for human habitation is very real, the fact that nature takes root somehow proves consoling. Life does not, will not, retreat. It builds upon leavings, and, doing so, dislodges their finality.

While visions of untamed nature's spontaneous fervor may not color Lily's vision of life at the holiday home post-Mrs. Ramsay, they do color the reader's in the process of preparing her to recognize the echoes with which Lily wrestles throughout the third section of the novel. The poignancy of Lily's struggles is magnified in the context of an awareness of the life that has passed and that which has blossomed. After her startled waking, Lily is in a stupor, without recourse for understanding her own relation to this place to which she has returned, without a sense of meaning. Questioning herself"What does it mean then, what can it all mean?"-is but a means "to cover the blankness of her mind," for she has woken into a world she does not recognize (145). Lily finds herself out of place, much as Mrs. Ramsay did at the start of the dinner party ten years earlier.

As she comes to a sense of where she has awakened, she finds it alienating, "extraordinarily queer," without a form of life with which she can identify:

Sitting alone ... among the clean cups at the long table, she felt cut off from other people, and able only to go on watching, asking, wondering. The house, the place, the morning, all seemed strangers to her. She had no attachment here, she felt, no relations with it, anything might happen, and whatever did happen, a step outside, a voice calling ..., was a question, as if the link that usually bound things together had been cut, and they floated up here, down there, off, anyhow. How aimless it was, how chaotic, how unreal it was, she thought, looking at her empty coffee cup. Mrs. Ramsay dead; Andrew killed; Prue dead too-repeat it as she might, it roused no feeling in her. And we all get together in a house like this on a morning like this, she said, looking out the window. It was a beautiful still day. (146) 
What is lacking, this passage makes clear, is the human element that renders space into a home place. While it appears to in the previous evening's echoes of the dinner party, the home as described here affords nothing of warmth or connection-in the wake of the Ramsay deaths it is as if the house has shed much of what animated it. Lily is numb; the house is experienced as barren; and the ties that bind fellow inhabitants are entirely lacking. This is consistent with Casey's description of the disorientation of placelessness.

The experiences surrounding Lily's displacement and re-implacement are quite dramatic. Nonetheless, Casey maintains that:

[i]f we are to get back into place..., we must take our time. A retarded movement back, a motion in ritardando, is prescribed ... . The habitus ensconced in re-inhabitation signifies just such slowed-down speed: the need for the gradual re-acquisition of the right habits, the sedimentation of the appropriate habitudes, the growth of effective habituations. All of these latter are matters of memory, and of body memory in particular. For it is the remembering body that, concluding a time-consuming but timely and well-timed journey, brings us back into place. (297)

"The Lighthouse" follows Lily's gradual and wrenching reacquisition of a habitus that will enable her to thrive. Lily must negotiate the paradoxical coexistence of alienation and belonging through remembering what it was to feel and to recognize connectedness. This is equivalent to restoring her sensitivity to the place-ness of place, which is only possible through reassuming the habits of becoming she learned through her relationship with Mrs. Ramsay. This is very complicated, as all negotiations involving home inevitably are; finding a sense of belonging within a space that is not wholly one's own entails reorganizing one's boundaries of self. This struggle, it seems, is a foregone conclusion, not only because the experience of journeying necessitates a continual redefinition of values such that she who begins the journey is not the same as she who 
returns, but also because from the beginning Lily is a thoughtful, unconventional soul who rejects much of what domesticity has to offer. Lily's art proves a viable means through which she can find herself in the past and in the present, for through it she refashions home to be more accommodating to her independence and values, values that are inextricable from Mrs. Ramsay's influence. Through her artistic labors of exploring connections between ideas of and experiences of home, creativity, and connectivity, Lily identifies with a notion of home that does not compromise her authenticity.

\section{"But this is what I see; this is what I see."17}

To the Lighthouse was an intensely personal endeavor for Woolf. Written in response to a pressing emotional need to confront the loss of her mother and hence of her innocence, to address consequent grief, and to probe the origins and trajectory of her own artistic identity, this novel might productively be categorized as a variety of Künstlerroman. According to Aranzazu Usandizaga's "Gender and Genre: The Genres of Modernism," at the end of the nineteenth and beginning of the twentieth centuries, in a generalized and often tentative way, women writers of different western cultures slowly appropriate, transform and eventually transgress the genres both of the Bildungs and the Künstlerroman by experimenting with them in their need for self-definition and self-representation. These genres become the arena in which they play out their desire for selfknowledge and self-construction, so that the sad lament of the male artist who stresses his alienation from the world and the world's misunderstanding of his art, gradually becomes the joyful cry of feminine self-recognition and self-assertion. (110)

While Lily is clearly not an author in the literal sense of the word, her artistic struggles are Woolf's own. Woolf is a character in her own novel, just as Lily is an author in the sense that she labors to write her identity through an aesthetic medium. To the Lighthouse indeed traces in Lily feelings of alienation and being misunderstood,

${ }^{17}$ Woolf, To the Lighthouse 19. 
however, per Usandizaga's claims, ultimately a cry of triumph issues from Lily's onerous journey of introspection, artistic risk, and confrontation with modernity.

Lily's negotiation of the past in the context of her growth as an artist is central. Although she is hardly a youth in the novel's opening section, the novel unquestionably traces her development as a creative soul. Applying a cultural-historical lens proves illuminative here. Given the general historical timeline of the novel, Lily's growth into a more confidently independent artist and woman is a process informed by massive World War. While only Andrew dies from wartime violence, the deaths of Mrs. Ramsay and Prue and the abandonment of the cottage for a good many years are consonant with the massive destruction of war. To the Lighthouse portrays the obliteration of a way of life and a way of thinking about the world through placing it in the context of family and its fulfillment of the primal need for connection with others. To find her way, Lily must search for a mode of connecting with others and with her past that perseveres despite historical and personal contingencies. Contrast this with Stephen Dedalus who believes his stature as artist demands "silence, exile, and cunning," and the distinguishing characteristics of the female Künstlerroman become all the more salient. As Woolf illustrates through To the Lighthouse, the female model of the Künstlerroman is much more apt to situate connection as fundamental to coming into one's own as an artist.

That Woolf should choose to depict a protagonist who is in her thirties and early forties and still developing is consistent with the approach to life that Woolf advocates, an approach that embraces the imaginativeness and curiosity of childhood as central to experiencing the world in its manifold colors. It also suggests that she conceives of both herself and her mother-and their legacies-as eternally in process. Hence we have Mrs. 
Ramsay bounding across the yard in a deerstalker's cap corresponding with the sprightly little Cam dashing about, both of which correspond with the older Ramsay children's nighttime jaunt to the beach to watch the waves. What all of the above scenarios share is a joie de vivre that cannot be squelched, a liveliness that thrives on interacting with the quickening flux that is the world.

At times the emptiness of the house in "Time Passes" and "The Lighthouse" chillingly suggests that this joie de vivre has forever withdrawn, that the collapse of a more benign world threatens to obliterate the lingering comforts of what was perceived to be a meaningful past. Enter Lily. Though her muse speaks to her primarily when she is outside the literal walls of the home, that muse — enduring memory—is never separate from the architectural reality of home. Lily resembles Woolf in embracing the grounds of the cottage home as equally constitutive of the home-place and hence equally implicated in home's allure, but as explained in "A Sketch of the Past" through Woolf's early sensory memories of the nursery at St. Ives, the physical structure of home need not be read as comprised of claustrophobic walls.

However, that which generates her art simultaneously hinders it. To find her art entails finding herself in the moment of creation, but doing so is impeded by piercing grief and confusion. Creating art at this point in her life demands revisiting the place that is her muse and addressing the question of what to do when the person behind the place has forever vanished:

Mrs. Ramsay had given. Giving, giving, giving, she had died—and had left all this. Really, she was angry with Mrs. Ramsay. With the brush slightly trembling in her fingers she looked at the hedge, the step, the wall. It was all Mrs. Ramsay's doing. She was dead. Here was Lily, at fortyfour, wasting her time, unable to do a thing, standing there, playing at painting, playing at the one thing one did not play at, and it was all Mrs. 
Ramsay's fault. She was dead. The step where she used to sit was empty. She was dead.

But why repeat this over and over again? Why be always trying to bring up some feeling she had not got? There was a kind of blasphemy in it. It was all dry: all withered: all spent. They ought not have asked her; she ought not to have come. One can't waste one's time at forty-four, she thought. She hated playing at painting. A brush, the one dependable thing in a world of strife, ruin, chaos - that one should not play with .... (149150)

While Lily believes herself incapable of mustering even a remnant of her former feeling for Mrs. Ramsay, believes that a return to the place of inspiration is futile, as the final section of the novel proceeds it becomes clearer that Lily's apparent detachment is in reality a symptom of the depth of her grief. Hoping that putting Mrs. Ramsay's absence into stark, unadorned terms will render the truth somehow comprehensible, Lily repeats "she [is] dead." Returning to that primal place that is the instant of inspiration is uncanny, not only because Lily's journey has intervened, but because that primal place as she once knew it could no longer exist even should Lily be the same person she was those ten years ago. She struggles throughout "The Lighthouse" with what to make of herself, her art, and her feelings when it seems that the genius of the place has retreated.

Yet, even in "The Window," Lily's self-assessment was neither simple nor confident, and her self-doubt regarding her art appeared to be linked inextricably with her conflicting feelings toward Mrs. Ramsay in particular and domesticity in general. From the beginning of our introduction to Lily, her painting is contingent upon Mrs. Ramsaythe window of the section title refers to, among other things, the window through which Lily looks to study the forms of mother and child. Lily made her entrance, as it were, through the consciousness of Mrs. Ramsay, who, gazing out of her sheltered solitude, considered what an endearing, independent soul Lily is. Watching Lily roused Mrs. 
Ramsay into the remembrance that she must remain still--she was sitting for Lily's portrait. Looking at Mrs. Ramsay looking at Lily, we were asked to identify with both, to recognize the emptiness and fullness of each respective woman's existence.

A threshold, the window allows us to look out of our own consciousnesses, to escape our isolation, to inhabit the consciousness of another. It calls upon us to delay judgment. These properties of the threshold correlate with Mrs. Ramsay's empathetic approach to inhabiting her world—as she contemplated her connections with the natural world that surrounds her, she remained insulated by sheltering space. Equivalent to a boundary between self and other, the glass is transparent but nonetheless protects each party from being known completely. Irigaray asserts the idea of the threshold as central to coming to know the other ethically, for only through the establishment of such neutral openings can we forge relationships free of domination and appropriation:

On the borders of our own dwelling, thresholds will prepare a meeting with the other: thresholds on the horizon of a world allowing us to leave it and to welcome the other, thresholds also on the border of oneself, if it is possible to distinguish the two .... Trusting in the contribution that the otherness of the other will provide us with, agreeing to receive until we become changed, without for all that renouncing ourselves-that is what a threshold must give us access to. Opening a welcome through working out an appropriateness to ourselves, through a gathering within ourselves. (Sharing 9)

Mrs. Ramsay's example encourages Lily to construct thresholds that enable her to look beyond the flaws of both Charles Tansley and Mr. Ramsay, to recognize their humanness. Through the establishment of such thresholds, the petty conflicts that characterize relations between the sexes in To the Lighthouse fall away and true connection founded on an appreciation of the other in her or his otherness is enabled. At times the threshold ideal falls short, for example when Mr. Ramsay dominates his wife and Lily in his 
demand for sympathy, when Lily is filled with a self-consuming desire to become one with Mrs. Ramsay, and when Mrs. Ramsay verges on being domineering in her rage for marriage. Despite these failures of the model, however, Woolf retains faith in the capacity for human connection, a faith that people can break free from their selfabsorption. This faith colors relations within the novel and those Woolf remembers so tenderly through it.

The window, it should be said, also represents framing the impossible, Mrs. Ramsay and James in their animated humanness, the world that is the novel's first section, the world with which the reader becomes so enamored through entering it though she remains sheltered in her solitude. Capturing life in its contradictions, symmetry, and caprice is a fundamental goal of Lily's art. Like Mrs. Ramsay, Lily seeks to capture something of the living moment, to engrave its fluttering in perpetuity, which is, like desire itself, by nature paradoxical. The same may be said for Woolf's designs for To the Lighthouse. Woolf illustrates in "The Window" the fluctuation that is living through Lily's alternation between love of Mrs. Ramsay as domestic goddess and rejection of Mrs. Ramsay's conformity to a standard of female subservience.

This is most salient in the context of Lily's struggle to find her voice as an artist:

It was in that moment's flight between the picture and her canvas that the demons set on her who often brought her to the verge of tears and made this passage from conception to work as dreadful as any down a dark passage for a child. Such she often felt herself-struggling against terrific odds to maintain her courage; to say: "But this is what I see; this is what I see," and so to clasp some miserable remnant of her vision to her breast, which a thousand forces did their best to pluck from her. And it was then too, in that chill and windy way, as she began to paint, that there forced themselves upon her other things, her own inadequacy, her insignificance, keeping house for her father off the Brompton Road, and had much ado to control her impulse to fling herself (thank Heaven she had always resisted so far) at Mrs. Ramsay's knee and say to her-but what could one say to 
her? "I'm in love with you?" No, that was not true. "I'm in love with this all," waving her hand at the hedge, at the house, at the children. It was absurd, it was impossible. (19)

As she embarks upon her quest for an aesthetic that will allow her to express herself genuinely, Lily is beset with self-doubt. Though she understands that her independence endows her with artistic vision and the time and space to paint, she simultaneously fears that it renders her barren.

Woolf likens Lily's situation to that of an infant struggling to make her way from her enclosure in the maternal body to comparative freedom in the extra-uterine world. Here the metaphor of birth is entirely apropos, for not only is Lily searching for relative independence of vision, but, like a child being birthed, she is dependent upon maternal intervention. Birth is a cooperative endeavor, as is all becoming. Counterbalancing the urge for independence is an urge to connect with she who is a symbol of connection, the Ur-Mother of the world that is To the Lighthouse. It is telling that Woolf does not identify Lily's biological mother: this only compounds her longing for communion with the life force. Yet, Lily's desire is insidiously linked with a fear of "insignificance," a fear that it is only through traversing the path of motherhood and domesticity that one makes her mark. Indeed, this world of the Ramsays' making seductively presents itself as the heart of becoming - Lily must strain mightily to integrate into her vision an acceptance of domesticity and art as equally bound in the connective energies that sustain life.

Childless, Virginia Woolf mourned her lack of participation in the web of biological reproduction, even as she recognized this lack as constitutive of a practical freedom that endowed her with conditions conducive to being an artist. Hermione Lee 
explains that Leonard, Vanessa, and Virginia's doctors conspired to ensure that "Virginia's maternity was decided for her" (330). For, while they vacillated on whether motherhood may or may not be advisable for a woman suffering as Virginia did with intermittent mental illness, ultimately the fear of both hereditary insanity and Virginia's precariousness prevailed. Lee explains Woolf's fraught conception of the idea of her own motherhood:

What is known is that she liked and was good at talking to children (there are many witnesses to this), that she bitterly regretted not having them; and that she never consoled herself with the belief that her books were a substitute or an equivalent. These feelings would surface whenever she was depressed. In her deepest plunges into 'melancholy' or a sense of failure, she always uttered the words 'children': 'It's having no children,' it's 'a desire for children.' Though she knew that childlessness left her open to, or created, other kinds of relationships and other sorts of work ... ., that perception did not lessen 'the horror that sometimes overcomes me.' (329)

It is important here to recognize that, while feminist theorists sometimes label Woolf's assessment of motherhood as entirely disempowering in part because it is decreed by the patriarchal establishment as the proper vocation of women, in Woolf's case this establishment--perhaps not altogether injudiciously-denied the desirability of the role for one in her situation. The circumstances surrounding Woolf's childlessness, along with her complex conceptions of what constitutes purpose and meaning, necessitate a more nuanced reading of her view of maternity.

That Woolf appears to have genuinely enjoyed the company of children in general and her sister Vanessa's sons and daughter in particular is not insignificant. One might attribute her fascination with children to her sense that, as Mrs. Ramsay articulates so well, childhood imagination is sublime. Biographical contingencies as well as her association of childhood with relative imaginative bliss render her depictions of 
motherhood more ambiguous, in part because her own loyalties were likely divided. Given that Woolf wrote herself into the motherless artist, Lily's simultaneous desire and disdain for a Mrs. Ramsay-Julia Stephen-inspired domesticity proves more understandable, if no less complex. Lily, like Woolf, appreciates the beauty of a creativity-haloed realm of family, but she is nonetheless wary of the potentially deleterious effects plunging headlong into such an ideal would entail and seeks rather desperately to convince herself of the merit of her independence. While Lily is by no means facing a decree that has denied her suitability for motherhood, her engagement with the issue of domesticity by definition takes on the issue of mothering. Lily wonders how she can contribute to the inextinguishable force of human connectivity if she finds it inadvisable to literalize it through biological reproduction, the culturally-sanctioned epitome of this force.

Lily's struggle with the expectation that women should marry is of course bound in her relationship with Mrs. Ramsay, for, always the matchmaker, Mrs. Ramsay advocates this above all else. While we glean from Mrs. Ramsay's introspection in "The Window" that her opinion of her own marriage is not entirely positive, she forces it on others in the fear that without it the mold of human connection will shatter. Though Mrs. Ramsay's delicately-wrought world exists before the advent of World War I, it would not be remiss to situate her anxieties in modernity in general as elaborated in the first chapter of the present study. We might certainly situate Woolf's nostalgic relationship with the "great Cathedral space that was childhood" accordingly. Woolf was by no means reactionary, but writing To the Lighthouse after the cataclysm of the Great War surely tinged her memories of the childhood she knew before her mother's death. Lily's 
ambivalence concerning marriage and her periodic seduction by the lure of union with another is imbricated in the milieu of modernity, as well, despite the fact that the setting of the novel appears to be a world away from civilization proper. Lily's unconventional art and the charged subjectivity with which she approaches it attest to the fact that she is not immune to the upheavals in thought flooding the West.

After the War, in the blur that is the world of "The Lighthouse," Lily's contention with Mrs. Ramsay's approach to human relations intensifies, perhaps in part due to the fractures with which everyone living in the Twenties was afflicted. Lily Briscoe is grieving the loss of a comparatively benign home, and, most notably, the matriarch of the threshold that is "The Window." Though Woolf was by no means writing allegory, the broadest of the afflictions with which Lily toils individually were simultaneously felt culturally during the period in which "The Lighthouse" takes place, and during the period in which Woolf composed the novel. Interpreted broadly, the home Lily is mourning is the cradle of civilization that offers the promise of indefinite sustenance and stability. As such, it may be conceptualized through the maternal, that which affirms the child's thriving and that which advocates the conviction that all will be well for those in the mother's care.

As the material in the first chapter of this study expounds through its discussion of such thinkers as Nietzsche and Arnold, well before the First World War such consolatory images of the cultural edifice were beginning to crumble. We might sense their encroaching fissures in Lily's synchronous desire for and rejection of the realm of perceived abundance in "The Window," her recognition of its dubious foundations. "The Lighthouse" witnesses Lily's development of a sensibility that allows her to alleviate 
much of the tension that surrounds her relationship with the ideal of domesticity as the primary means of connection, her grief over the loss of the maternal figure in her life, and her self-doubt, all of which-in Lily's case—are inextricable from the post-World War I milieu. Lily answers Woolf's call for a woman of a new generation, a generation that believes more profoundly in art's rehabilitative potential and works diligently and soulfully to express that conviction.

One might read in Lily's discomfort with and disdain for Mrs. Ramsay's legacy Woolf's own anger at Julia Stephen's untimely passing and its ramifications on the Stephen and Duckworth children. Lily is angry that Mrs. Ramsay's tendency to dote on her ill-behaved husband ultimately leaves him to tyrannize Lily in his rage for sympathy. In this, Lily resembles Julia's children, Stella, Vanessa, and Virginia in particular, who, as Woolf relates in both "Reminiscences" and "A Sketch of the Past," were left to pacify a tyrannously demanding Leslie Stephen desperately searching for meaning and companionship after his wife's passing. The Duckworth-Stephen children are likewise epitomized in the remaining Ramsay children who are left to brave the buffets of their father's coercion and puerility after the death of their mother. This, Lily realizes, "was tragedy -not the palls, dust, and the shroud; but children coerced, their spirits subdued" (149). Given the crushing circumstances surrounding her own experience with domesticity in her childhood, it is no wonder that Woolf's novel exudes palpable anxiety concerning its implications.

It is simultaneously fruitful to consider the cultural dimensions of Woolf's biographical contingencies, for, rather uncannily, her familial woes echoed those afflicting a culture in a state of revolution. In particular, as Virginia and Vanessa set out 
to break from the sometimes-dysfunctional domestic precedent established by their parents that became increasingly evident after Julia Stephen's death, so progressive forces in Western culture writhed with the birthing pangs of modern feminism. Shattering the mold was not unadulterated liberation for those afloat in the deluge of change, even those desiring such change. Woolf's novel testifies to this, as does the sisters' affiliation with the Bloomsbury Group. For the Bloomsbury Group did not seek to obliterate domesticity altogether, but to remake it in the group's own image.

Bloomsbury's domesticity entailed a break from Edwardian propriety—a lack of dressing for dinner, visitors coming and going unannounced, unencumbered and overt sexualitybut it preserved the idea of home in its conception of setting up a household. The Omega Workshops, for example, was definitively home-bound, even as it endeavored to alter that home. Woolf and her Bloomsbury comrades prudently retained the elements of the past they deemed preservative of sanity. ${ }^{18}$

Despite the fact that Lily is thoroughly discomfited by Mr. Ramsay's leonine disposition "seeking whom he could devour," she recognizes his loneliness, a loneliness both specific to him in his loss of his wife and his children and to a world mired in collective loss:

But now he had nobody to talk to about that table, or his boots, or his knots .... And then, she recalled, there was that sudden revivification, that sudden flare (when she praised his boots), that sudden recovery of vitality and interest in ordinary human things, which too passed and changed (for he was always changing, and hid nothing) into that other final phase which was new to her, and had, she owned, made herself ashamed of her own irritability, when it seemed as if he had shed worries and ambitions, and the hope of sympathy and the desire for praise, had entered some other region, was drawn on, as if by curiosity, in dumb colloquy, whether with himself or another, at the head of that little

\footnotetext{
${ }^{18}$ See Christopher Reed, Bloomsbury Rooms: Modernism, Subculture, and Domesticity.
} 
procession out of one's range. An extraordinary face. The gate banged. (156)

Empathetically, Lily perceives Mr. Ramsay's basic human needs, companionship and a diversion from the depths of grief and alienation begotten of death. While Lily is initially "ashamed of herself" for praising his boots cheerfully "when he had shown her his bleeding hands, his lacerated heart, and asked her to pity them," her gesture is powerful, both for giver and recipient (154). For a moment, Mr. Ramsay ceases to define himself in terms of his loss, but instead recognizes himself in terms of what he has. While gloating over his boots and the knots he so ably ties may seem ridiculously trivial, it does, as Lily intuits, represent a healthy interest in the everyday, something to which modernists such as Woolf were acutely sensitive.

Lily's intervention here is not unlike that of Mrs. Ramsay in her dealings with the socially-inept Charles Tansley and Lily's own determination at the dinner party that she should intervene in his insecurity despite her aversion to him. Lily's acceptance of Mr. Ramsay in his imperfection affirms the epiphany she experiences at the dinner party that "nevertheless, ... it was almost impossible to dislike any one if one looked at them. She liked ... [Tansley's] eyes; they were blue, deep set, frightening” (85). These ripples once more affirm the endurance of Mrs. Ramsay's spirit of wonder at the world's bounty in its many guises. It is noteworthy that this passage also affirms the continued existence of Woolf's childhood, sensory memory of time spent at her holiday home in St Ives. In "A Sketch of the Past," she notes the sound of the gate as one of her lasting memories of this place. That this incident that concludes with the clang of the gate carries Lily to an immersion in her art illustrates touchingly Woolf's conviction of memory's centrality in artistic sensibility. 


\section{"One line placed on the canvas committed her to innumerable risks"19}

This sudden flash of liking for Mr. Ramsay confirms Lily's earlier epiphany regarding the positive humanity within even the most unpleasant of specimens and leads directly into her moment of becoming that is spurred by her immersion in and embodiment of the act of creation:

The great revelation perhaps never did come. Instead there were little daily miracles, illuminations, matches struck unexpectedly in the dark; here was one. This, that, and the other; herself and Charles Tansley and the breaking wave; Mrs. Ramsay bringing them together; Mrs. Ramsay saying 'Life stand still here'; Mrs. Ramsay making of the moment something permanent (as in another sphere Lily herself tried to make of the moment something permanent)-this was the nature of a revelation. In the midst of chaos there was shape; this eternal passing and flowing (she looked at the clouds going and the leaves shaking) was struck into stability. Life stand still here, Mrs. Ramsay said. 'Mrs. Ramsay! Mrs. Ramsay!' she repeated. She owed it all to her. (161)

Once again, Woolf emphasizes keen attention to the everyday as fundamental to embracing the miracle of life, which aligns her with many a modernist who seized upon the seemingly common as rife with significance and depth. Recognizing that here lies the beauty of Mrs. Ramsay's art, her gift of eternalizing moments of connective significance, Lily echoes Mrs. Ramsay's own sense of consolation after the dinner party, when, intuiting her numbered days, she takes comfort in the fact that this magical time "seemed always to have been, only was shown now and so being shown, struck everything into stability" (113). Lily's intuition connects her with Mrs. Ramsay's intuition, which confirms this as a true moment of being, a true instance when consciousness beholds something of the truth "that behind the cotton wool is hidden a pattern; that we-... all human beings - are connected with this; that the whole world is a work of art; that we are parts of this work of art" ("Sketch" 72). All of this is to suggest that not only are Woolf's

\footnotetext{
${ }^{19}$ Woolf, To the Lighthouse 157.
} 
moments of being inextricable from the skein of the past, which is itself very much bound in her spectral experience of the mother, but the immanent presence that was and is Julia Stephen impressed her daughter with rather esoteric knowledge of the intricate lacing of becoming, which is revealed through that which appears to be most simple. And to possess even an inkling of this knowledge is to be a visionary.

While at its quintessence Mrs. Ramsay's dinner party leads its congregants to a moment when "they were all conscious of making a party together in a hollow, on an island; had their common cause against the fluidity out there," it is not without risk for its creator (97). So it is with Lily's art. Following Mrs. Ramsay's example, in "exchang[ing] the fluidity of life for the concentration of painting," Lily, like Mrs. Ramsay, is battered by her share of doubt. It is telling that Lily likens the artist at her most vulnerable, when she is scaling the infinite possibilities of creating, to life before biological conception: "[S]he had a few moments of nakedness when she seemed like an unborn soul, a soul reft of body, hesitating on some windy pinnacle and exposed without protection to all blasts of doubt" (158). While it is ultimately creativity's limitless possibility that liberates Lily, before she embarks upon creation, the comforts of the known-restrictive though they can be-prove seductive. Moreover, true to Woolf's embrace of the body as essential to experiencing her world, and to creating and experiencing art, she endows Lily with a healthy appreciation of bodily perceptionvulnerability here is associated with an absence of embodiment, with the deprivation of not being birthed into human corporeality, which is by nature dependent upon physical connection with the mother. Before she musters her confidence, Lily loses the vital connection between body and mind, a severance that can only be repaired through 
reestablishing the sacredness of the interrelationship. This reparation is necessary if Lily is to return to a state of belonging resembling that with which she was blessed-if only ephemerally—during her first inhabitation of the Ramsays' cottage.

Casey's characterization of reinhabitation as necessarily gradual applies equally to what one might call artistic homecoming, for to be receptive to home's sonority one must gradually resume the habits of body and mind that will allow a return to experiencing sensorially the ambience of place. As Casey avows, "it is the remembering body that, concluding a time-consuming but well-timed journey, brings us back into place" (297). In "The Lighthouse," Lily must determine slowly what home means in the incarnation of both her current identity and the place to which she has returned, how to take on the habit of existing there as if naturally, and how the return will inform the subject and the execution of her art. At times after Mrs. Ramsay's death, the throes of desperate grief over having lost the home of her (relative) youth nearly debilitate Lily, for though this grief forges a consonance of body and mind, both body and mind remain in a state that inhibits acting in the present:

It was one's body feeling, not one's mind. The physical sensations that went with the bare look of the steps had become suddenly extremely unpleasant. To want and not to have, sent all up her body a hardness, a hollowness, a strain. And then to want and not to have-to want and want—how that wrung the heart, and wrung it again and again! Oh, Mrs. Ramsay! she called out silently, to that essence which sat by the boat, that abstract one made of her, that woman in grey, as if to abuse her for having gone, and then having gone, come back again. It had seemed so safe, thinking of her. Ghost, air, nothingness, a thing you could play with easily and safely at any time of day or night, she had been that, and then suddenly she put her hand out and wrung the heart thus. Suddenly, the empty drawing-room steps, the frill of the chair inside, the puppy tumbling on the terrace, the whole wave and whisper of the garden became like curves and arabesques flourishing round a centre of complete emptiness. (178-79) 
Though Lily justifies her distress through denial, body and mind are indeed interacting to communicate to her the terror of loss and death, the threat of nothingness. Lily's state of anxious arousal is not merely corporeal—body and mind respond in kind to the stress of confronting the current incarnation of home as comparatively devoid of presence. Rather than falling prey to romanticizing the past, both Lily and the reader must keep close at hand the fact that Lily experienced only instants of feeling fully "at home" at the Ramsays' in the "benign" past, only instants of the moments of being that Woolf so lauds. Somehow she must take from these moments and a concurrent acknowledgement of moments not touched by epiphany a relatively-unified revelation. In "The Window," Lily was smitten by the implausible ideal of becoming one with her subject, which equates to a desire to merge with the object of her aesthetic and emotive affections, Mrs. Ramsay. Lying her head on Mrs. Ramsay's lap, laughing hysterically in confused emotion, Lily desperately sought release from the loneliness and alienation that are the plight of humanity, a plight most acutely perceived by the artist and the thinker:

[S] he imagined how in the chambers of the mind and heart of the woman who was, physically, touching her, were stood, like the treasures in the tombs of kings, tablets bearing sacred inscriptions, which, if one could spell them out, would teach one everything, but they would never be offered openly, never made public. What art was there, known to love or cunning, by which one pressed through into those secret chambers? What device for becoming, like waters poured into one jar, inextricably the same, one with the object adored? Could the body achieve, or the mind, subtly mingling in the intricate passages of the brain? or the heart? Could loving, as people called it, make her and Mrs. Ramsay one? for it was not knowledge but unity that she desired, not inscriptions on tablets, nothing that could be written in any language known to men, but intimacy itself, which is knowledge.... (51) 
Desiring something of the comfort, assurance, and unity of the mother-child dyad, Lily positioned herself as an infant, her body resting on she who had been designated mother. Far from the insidious desire for the mother of which Irigaray speaks, a controlling desire that reduces the mother exclusively to her mothering role, Lily's desire is to understand Mrs. Ramsay as a woman, to imbibe her essence, to experience what she imagines to be ideal mutuality, which in this case is best exemplified, as Irigaray describes in "The Fecundity of the Caress," in bodily embrace. These longings shape her artistic leanings, for, like Woolf's, and like Mrs. Ramsay's, Lily's art enhances her interaction with her world, just as her embodied experience of the world shapes her art. Perhaps Lily's art incorporates the sensations of her brief semiotic encounter with Mrs. Ramsay, and perhaps her urge to create springs from an unfulfilled desire for more such interaction.

As Irigaray explains, however, one's ideal of mutuality must be tweaked to recognize and take joy in the fact that the other is never fully knowable, never one's possession. For, if it is to be ethical, a relationship must seek to consume neither the other nor the self, and this unavoidably leaves each party prey to her resident loneliness. Recognizing that "one ... ranged the wastes of the air over the countries of the world alone," Lily is never able to penetrate the essence of Mrs. Ramsay (51). A challenge faced by a great many characters in To the Lighthouse, loneliness in its many manifestations reveals that behind the beauty and energy of living amongst the Ramsays lingers the innate, haunting desolation that is a dimension of being human. The liberating, creative solitude facilitated by home can transform unpredictably into hollowness. 
And so it is that in order to create, Lily must confront both the exhilaration and loneliness of love, of the past, of becoming in place. Poised to paint, uncertain where to begin, she faces her canvas after having seen off Mr. Ramsay and his children:

So they're gone, she thought, sighing with relief and disappointment. Her sympathy seemed to be cast back on her, like a bramble sprung across her face. She felt curiously divided, as if one part of her were drawn out there - it was a still day, hazy; the Lighthouse looked this morning at an immense distance; the other had fixed itself doggedly, solidly, here on the lawn. She saw her canvas as if it had floated up and placed itself white and uncompromising directly before her. It seemed to rebuke her with its cold stare for all this hurry and agitation; this folly and waste of emotion; it drastically recalled her and spread through her mind first a peace, as her disorderly sensations ... trooped off the field; and then, emptiness. She looked blankly at the canvas, with its uncompromising white stare; from the canvas to the garden. There was something .... she remembered in the relations of those lines cutting across, slicing down, and in the mass of the hedge with its green cave of blues and browns, which had stayed in her mind; which had tied a knot in her mind so that at odds and ends of time, involuntarily, as she walked along the Brompton Road, as she brushed her hair, she found herself painting that picture, passing her eye over it, and untying the knot in imagination. But there was all the difference in the world between this planning airily away from the canvas, and actually taking her brush and making the first mark. (156-57)

"[S]o they're gone." Mr. Ramsay, Cam, and James. Mrs. Ramsay, Prue, and Andrew.

Only Lily and Mr. Carmichael remain, and Lily finds herself divided between the lush

verdure of the present in its exhilarating, frightening possibility and the stark stoniness of a past that was once so verdant.

As her sympathies dash out to her past and its representatives-the Ramsay family on their journey of reparation, the lighthouse that in being a beacon is a symbol of Mrs. Ramsay's brilliance and in its starkness proclaims her incontrovertible absenceLily is drawn back to her canvas, to utter emptiness, an emptiness that beckons substance. Though a specter of aesthetic meaning plagued her during the interstitial ten years that divided becoming-at-home and reinhabitation, the blank canvas can only be filled in the 
present, upon this return. As has been reiterated throughout this chapter in its references to Casey and to Woolf's art as autobiographical, the past's ripples that wash over the present implicate themselves in any present endeavor, for the present is never fully present but is by nature awash in the past. Yet this moment must be seized as the moment to act, to reconcile moments of seeming incongruity. This moment renders she who is called upon to act vulnerable to uncertainty, and, potentially, to utter nihilism. But Woolf repeatedly affirms belief in creation as self-constituting meaning. Epiphanous by nature, creation blesses Lily, though it is, as has been demonstrated, not undemanding. For, while her art is engaged firmly in the quotidian, Lily is pulled from the intercourse of everyday life to muse on the deeper, subtler chords of life's symphony and to express her revelations on the canvas, swept up by her visions and the manifold truths they communicate:

Here she was again, she thought, stepping back to look at it, drawn out of gossip, out of living, out of community with people into the presence of this formidable ancient enemy of hers-this other thing, this truth, this reality, which suddenly laid hands on her, emerged stark at the back of appearances and commanded her attention. She was half unwilling, half reluctant. Why always be drawn out and haled away? Why not left in peace, to talk to Mr. Carmichael on the lawn? It was an exacting form of intercourse anyhow. Other worshipful objects were content with worship; men, women, God, all let one kneel prostrate; but this form ... roused one to perpetual combat, challenged one to a fight in which one was bound to be worsted. (158)

Significantly more introverted than Mrs. Ramsay's, Lily's art often disengages her from community, demanding as it does extended contemplation and meditation. A testament to its contemplative, meditative nature, her painting does not reach material form until the end of the novel, which puts its gestation at nearly ten years. Mrs. Ramsay's art, on the other hand, might be deemed more immediate, in that it proceeds from her desire to 
further human community and the thriving of that community and manifests itself in perceivable, timely action that frequently yields an early, evident harvest. In the above passage, Lily appears to desire what she has not been granted: a more extroverted artistic inclination that would usher her into relation rather than separating her from participating in it fully.

Despite these misgivings, the act of creation eventually draws her into the folds of belonging with those with whom she has cohabitated, for "as she lost consciousness of outer things, and her name and her personality and her appearance, and whether Mr. Carmichael was there or not, her mind kept throwing up from its depths, scenes, and names, and sayings, and memories and ideas, like a fountain spurting over that glaring, hideously difficult white space, while she modelled it with greens and blues" (159). Lily's sense of belonging, it seems, happens in retrospect, when she processes that which she has seen and done, when she has contemplated and can communicate aesthetically its significance. Her gift, then, ostracizes her in the short term, in that her artistic sensibility frequently takes precedence over spontaneous enjoyment, but the act of creation firmly and permanently situates her within human community. Ultimately, Lily realizes, "'you' and 'I' and 'she' pass and vanish; nothing stays; all changes; but not words, not paint ... . One might say, even of this scrawl, not of that actual picture, perhaps, but of what is attempted, that it "remained for ever"" (179). Indeed, as "The Lighthouse" demonstrates so poignantly, Mrs. Ramsay's attempts at creating of the moment "something ... immune from change, [that $\ldots$ shines out ... in the face of the flowing, the fleeting, the spectral, like a ruby[,]" endure to grace an uncertain present, and in doing so inspire Lily to mottle them according to her own vision (105). 
In "A Sketch of the Past," Woolf describes childhood as a "great Cathedral space" imbued with her mother's presence. It is not coincidental, then, that as Lily finds herself finally able to communicate her vision, she "felt as if a door had opened, and one went in and stood gazing silently about in a high cathedral-like place, very dark, very solemn. Shouts came from a world far away" (171). Lily cannot know that at least some of the shouts the reader hears are those of Mrs. Ramsay's thoughts at the dinner party that liken the increasing harmony amongst her guests with "voices at a service in a cathedral" (110). Lily's vision, like Mrs. Ramsay's, partakes of the mystery of communion between subjectivities, of its gravitas, intuits something of human connection's timelessness, echoing as it does with voices from the past engaged in the same holy, human ritual that is connecting with others. We witness this firsthand as Mrs. Ramsay's unexpressed convictions regarding meaning flow through Lily's consciousness.

Lily's vision goes further, however, for she is returning home, and, as such, she is endowed with arcane knowledge accessible only after she has gone and embarked on her pilgrimage home:

So much depends, then thought Lily Briscoe, looking at the sea which had scarcely a stain on it, which was so soft that the sails and the clouds seemed set in its blue, so much depends, she thought, upon distance: whether people are near us or far from us; for her feeling for Mr. Ramsay changed as he sailed further and further across the bay. It seemed to be elongated, stretched out; he seemed to become more and more remote.... It was all in keeping with this silence, this emptiness, and the unreality of the early morning hour. It was a way things had sometimes, she thought, lingering for a moment and looking at the long glittering windows and the plume of blue smoke: they became unreal. So coming back from a journey, or after an illness, before habits had spread themselves across the surface, one felt the same unreality, which was so startling; felt something emerge. Life was most vivid then. One could be at one's ease .... One need not speak at all. One glided, one shook one's sails (there was a good deal of movement in the bay, boats were starting off) between things, beyond things. Empty it was not, but full to the brim. She seemed to be 
standing up to the lips in some substance, to move and float and sink in it, yes, for these waters were unfathomably deep. Into them had spilled so many lives. The Ramsays'; the children's; and all sorts of waifs and strays of things besides. A washer-woman with her basket; a rook; a red-hot poker; the purples and grey-greens of flowers: some common feeling held the whole. (191-92)

Journeying endows Lily with perspective, as only departure and subsequent return can. Moving about as a stranger, Lily is granted insight into unrecognized dimensions of the place she has come to re-inhabit. An unreality hangs about the return, a sense of being strangely separate from that which was so intimate, a sense of separateness from the self who felt such intimacy. It is this, Lily recognizes, that affords her the ability to see the unseen. As she navigates this unfamiliar, familiar place, she finds herself immersed in all that made and continues to make this home. Wading in memory, wading in the spiritual leavings of the Ramsay marriage, of childhood innocence, of what seemed to be everyday trivialities, of nature, of life and death, Lily has her vision.

Ineffable though it may be, this vision includes an awareness of ephemerality, an awareness of love as transcending the ephemeral, an awareness of the eternal benevolence of art begotten of love. For, "[l]ove had a thousand shapes" (192). Though Lily and Mrs. Ramsay differ in their creative process and products, they are united in valuing human connection and the intricate fibers of becoming that unite all that exists, and in their recognition that living artfully translates to a perpetual commitment to creation and re-creation. 


\section{CHAPTER VI}

\section{MOTHERING THE LIVING}

"I imagine the following sculpture as utterly beautiful: a pregnant woman chiseled out of stone. The immobility. restraint, introspection. The arms and hands dangling heavily, the head lowered, all attention directed inward. And the whole thing in heavy, heavy stone. Title: Pregnancy."

Käthe Kollwitz, September 1, $1911^{20}$

Like Virginia Woolf, Käthe Kollwitz endured World War I, and like Virginia Woolf she experienced but did not live to see the end of World War II. While Woolf fictionalizes the setting of her mother's death to correspond with the havoc wrought by World War I in To the Lighthouse, Kollwitz's quest to portray the worst horrors of the First World War does not demand fictionalization: Kollwitz's youngest son Peter died in October of 1914 , less than a month after he enlisted in the German army. For the remainder of Kollwitz's artistic career, she created in the name of her son Peter; her World War I and post-World War I work is defined by this catastrophic loss. Kollwitz's art, like Woolf's, may be understood in part as a means of confronting and attempting to make something of loss, which both artists explore through the figure of the mother. Like Woolf, Kollwitz probes the ramifications of a severed mother and child bond and ties this severance to the cultural-historical period in which she lives. However, because Kollwitz was a mother who suffered the death of her son at the hands of a sadistic

${ }^{20} 59$. 
cultural war machine rather than the daughter of a mother who died from naturallycontracted illness, her oeuvre is very differently tinged from that of Woolf's.

From the beginning of her artistic career, well before World War I, Kollwitz was fascinated by the plight of the desperate, specifically that of the proletariat. Her Weavers (Ein Weberaufstand) and Peasant War (Bauernkrieg) cycles attest to this, as do her postWorld War I indictments of the interrelated effects of war and poverty. As she discloses in both her diary and in a short memoir she presented to her eldest son Hans on his thirtieth birthday, she was drawn to representing the working class in her art because she saw in them an innate, tragic beauty, whereas exemplifications of joy did not elicit from her such artistic fervor. Her proximity to the working class in both her childhood and married life facilitated her ease with and understanding of this population. As the wife of a doctor whose patients consisted primarily of the working poor, Kollwitz was intimately acquainted with the working class.

Given the biographical contingencies pertaining to her son Peter cited above, one might be tempted to attribute Kollwitz's interest in the primal relationship of mother and child to her son Peter's death, yet a number of her pre-World War I representations evidence an acute interest in that relationship. This may be due to the fact that she witnessed through her husband's practice compromised living conditions that took a toll on child mortality, and that, as she relates in her diaries, the women in working class families often bore the brunt of their husbands' violence, a violence begotten of disempowerment. Hence, her pre-World War I mothers that are surely inspired by the proletariat life in which she took great compassionate and artistic interest are by 
definition disempowered, incapable of nurturing themselves and the children they so tenderly love. They are, like the social world in which they existed, broken.

Yet, a number of her early depictions of the mother-child dyad are not overtly associated with the proletariat population. These are more primal in nature, the most notable of which are Pietà (fig. 1) and Woman with Dead Child (Frau mit totem Kind) (fig. 2), both finished in 1903, and Woman and Death (Tod und Frau) (fig. 3), completed in 1910. Appropriating Christian iconography, Kollwitz's Pietà renders secular mother and child relations rife with unparalleled depth of emotion and frightening vulnerability, with precarious physical and psychological symbiosis that threatens continually to unravel due to uncontrollable external and internal forces. Featureless, the hunched mother in Pietà knows nothing but the cold, still body of the child she embraces in vain, her muscled arms and supporting hand impotent to imbue him with life. Pressed to her son's still chest, she listens desperately for the beat of a heart once synchronized with hers that pulses no more. No Virgin Mary, the mother in Pietà is nonetheless sacred in her maternal sorrow.

More disturbing, and more potent, Woman with Dead Child pictures a mother physically consumed by the lifeless body of her son, with rough, etched lines that gesture simultaneously toward the gashes the loss of a child inflicts upon the mother left behind and the impossibility of making something positive of such a loss. Here the mother presses her mouth to her child as if she wishes to consume him, to taste his life once more as if they have not been ripped asunder, as if her child has not fallen into a world that doomed him to premature death. Bodily boundaries of mother and child are to some extent collapsed, most notably near the child's heart and near his neck in which the 
mother burrows. As Elizabeth Prelinger explains, critics are largely unified in interpreting this image in light of its reception by Kollwitz's intimate friend of sixty years, Beate Bonus-Jeep, who characterizes it thus:

A mother, animal-like, naked, the light-colored corpse of her dead child between her thigh bones and arms, seeks with her eyes, with her lips, with her breath, to swallow back into herself the disappearing life that once belonged to her womb. When I saw the sheet, by chance we had not heard from each other for a long while. In the exhibition I suddenly found myself in front of the etching and turned quickly out of the room in order to compose myself: 'Can something have happened to little Peter that she could make something so dreadful?' No! It was pure passion itself, the force, sleeping contained in the mother animal, that yielding itself to the eye, is fixed here by Käthe Kollwitz, someone to whom it is given to reach beneath the ultimate veils. (qtd. in Prelinger 42)

Bonus-Jeep's articulate description of what her friend-"Schmidt," as she affectionately called her-is doing here captures the inarticulable rawness of the pain of losing a child, a pain so universal as to be animalistic. As Prelinger interprets the above passage, '[Jeep's] characterization of the figure as 'mother animal' strips away in words, as Kollwitz stripped away in this image, any vestige of 'civilized' or rational mourning. In the bestial pathos of the motif, Kollwitz laid bare the savage force of the deepest of human emotions" (43). Indeed, it is fitting that both mother and child are naked, bare, and that the mother especially is featureless, dramatically more so than the mother in Pietà.

Prelinger aptly suggests Kollwitz's image is influenced by Edvard Munch's iconographic Vampire (fig. 4); if this is indeed the case, it says much about Kollwitz's view of the emotional and corporeal passion of maternity, a passion that defies the rational, that defies words, a passion that at its most heightened can be identityconsuming. Virginia Woolf reveals the irresistibility of maternal longing as equally 
poignant in the daughter's desire for the lost mother, as does Kollwitz in her account of the distant mother of her childhood. Though Kollwitz created this image well before Peter fell in war, here her creativity is fed by an anticipatory loss that, as will be revealed below, she experienced through empathizing with her bereaved mother and through remembering her childhood longing. At times, both Woolf's and Kollwitz's creativity is bound in a desire for connection with a mother-child dyad that had been fractured by death.

As disconcerting as Woman with Dead Child is the derivation of the image as Kollwitz explains it in a letter to Beate Jeep-Bonus's husband, Arthur Bonus: "When he [Peter] was seven years old and I was doing the etching Mother with Dead Child, I drew myself in the mirror while holding him in my arm. The pose was quite a strain, and I let out a groan. Then he said consolingly in his high little voice: 'Don't worry, Mother, it will be beautiful, too"' (Kollwitz 164). ${ }^{21}$ Acknowledgement of the practicality of using one's son as a model aside, one has to wonder what led Kollwitz to be willing to identify so clearly her own mothering with childhood death. It is difficult not to interpret this work as uncannily foreshadowing what would become Peter's fate some eleven years later. As will be discussed, Kollwitz wrestled torturously with the idea of sacrifice after Peter's death in 1914, which may be legitimately traceable to the rhetoric of war as beatified sacrifice and motherhood as the haloed means through which that sacrifice could be exacted, a rhetoric that proliferated throughout Europe during the World War I era.

\footnotetext{
${ }^{21}$ The German "Frau" may be translated "Woman" or "Wife." While Kollwitz's Frau mit totem Kind is alternately translated Woman with Dead Child and Mother with Dead Child, I use the former translation, as do a number of my sources.
} 
Ann Taylor Allen explains in Feminism and Motherhood in Germany, 1800-1914 that even before the advent of war, discourses of motherhood as "women's service to society" were rampant (11). Feminist circles of all stripes embraced motherhood as a rallying cry, in part because it was an institution that furthered their interests in female empowerment:

[T] he maternal ethic, developed into a concept of public motherhood, called into question the antithesis between public and private worlds that was fundamental to nineteenth-century culture. This connection between home and world provided the basis of a claim to female power, which at first was conceived as primarily cultural and pedagogical and later as political. Feminists thus often questioned conventional (that is, maleidentified) structures of political discourse that placed the family outside politics. They asserted the underlying connections between private and public concerns .... A central metaphor, recurring throughout the writings of feminists throughout this period [1890's-1914], was that of society as family, or 'great social household' (3).

Given the prominence of maternal discourses incorporating the above interests, and given that, as Allen states elsewhere, “'motherhood' became a metaphorical trope signaling a distinctively female claim to rights based on women's service to society," Kollwitz's foray into the maternal might be more understandable. Moreover, the years during which Kollwitz created the above-referenced works were frenzied with concern over a declining population, which, coupled with the rising nationalism of the time that carried with it the natural trajectory of war, inevitably led to a focalization on the role of mother as vital to preserving the Germanic race. Was Kollwitz's concern for the poor mothers with whom she came into contact combined with the heightened nationalism in the air significant enough to lead her to associate maternity and death so absolutely?

Regina Schulte and Danielle Knafo, among others, attribute Kollwitz's obsession with the bereaved mother to her own experience of being mothered by a woman who lost 
three of her children to death and "became distant and reserved as a result of these deaths - unavailable - an emotionally-dead mother" (Knafo 24). Indeed, the autobiographical writing Kollwitz presented to Hans details the extent to which Kollwitz experienced her mother through the lens of bereavement: she speculates that "it must have been ... [my mother's] years of suffering which gave her for ever after the remote air of a madonna" (Kollwitz 18). Of lasting poignancy to Kollwitz is her memory of the death of her youngest sibling, Benjamin, who lived through infancy only to succumb "like the firstborn" to meningitis when he was only a year old (Kollwitz 19). Not only does Kollwitz merge her brother's illness and death and her mother's "determination not to cry before all of us" despite her anxiety and suffering, but she remembers vividly the announcement of her brother's passing coming just as she was making a sacrifice to Venus via a temple she had built with her blocks (Kollwitz 19). That coincidence, Kollwitz relates, led young Käthe to assume that she was to blame for her younger brother's death, that God was exacting vengeance for her disbelief.

In her memoir, Kollwitz recounts her childhood awareness of her mother's overwhelming grief that led to an emotional death of sorts-lack of a sanctioned outlet for the expression of such incisive grief left Katharina Schmidt incapable of embracing her living children, and, as the above passage indicates, at times Käthe blamed herself for her mother's distance. In reality, the prohibition of demonstrative mourning in the Schmidt household likely sprung from the stoic Protestantism that pervaded the family due to the abiding presence of Kollwitz's Grandfather Rupp, a renowned, progressive Protestant minister whose creed imbued in him a detached resignation to life as 
transitory. Kollwitz narrates the aftermath of Benjamin's death and the lack of a means

for a young girl such as herself to discuss openly the family's loss:

Then I saw little Benjamin lying on the bed in the front room and looking so white and pretty that I thought: If we only open his eyes, maybe he will come alive after all. But I did not dare to ask Mother to open the baby's eyes and see whether everything would not turn out all right. I don't know whether I dared to touch the little dead body myself.

Konrad and I were in the big front room. Konrad stood at the door to the smaller room where the body lay. This door opened and Grandfather Rupp came out. This is the first conscious memory I have of him. He had been inside looking at little Benjamin. When he came out, he noticed Konrad and spoke gravely to him-saying, as I recall it, something like, 'Do you see now, how fleeting everything is?' They were the earnest words of a minister .... To me, what Grandfather said sounded cruel and unloving.

Then I remember Grandfather speaking at the bier, and then Father and, I suppose, Grandfather and friends of the family drove together down to Koenigstor to the Free Congregation's cemetery. Mother stood at the window and watched the hearse depart. I loved her terribly, but did not go to her. (20)

Young Käthe was stung quite early with first-hand knowledge of life's frailty; denied an outlet to express her confused response to the tragedy at hand; and alienated from a mother with whom she longed to communicate mutual sorrow. Käthe's childhood experiences with her mother were in their very essence heavy with silence, and with desire. Maternal grief and a social world inhospitable to grieving resulted in a disruption of the mutuality that Jessica Benjamin explains as implicit in the mother-child dyad. To young Käthe, mothering was tantamount to exclusion from participation in what matters, exclusion from the procession to Benjamin's grave, exclusion from a world in which to acknowledge one's pain is recognized as legitimate and curative, exclusion from a sustained, open relationship with one's adoring children. Exclusion from becoming. Kollwitz's Woman and Death bears a close resemblance to this dysfunctional childhood world, for in it the mother is without will strong enough to resist the seduction of death, 
though her child clings desperately to her, imploring her to remain in this world,

imploring her to mother the living. Käthe's childhood was one in which innocence was sullied almost at conception with the stain of an awareness of mortality and humanity's inability to speak about that mortality meaningfully. Young Käthe Schimdt's notion of home was unheimlich.

It is telling that immediately following the story of her experience of Benjamin's death Kollwitz elaborates on her separation anxiety that revolved around her relationship with her mother:

In those days my love for my mother was tender and solicitous. I was always afraid she would come to some harm. If she were bathing, even if it were only in the tub, I feared she might drown. Once I stood at the window watching for Mother to come back, for it was time. I saw her walking down the other side of the street, but she did not glance over at our house. With that distant look of hers, she continued calmly down Koenigstrasse. Once again I felt the oppressive fear in my heart that she might get lost and never find her way back to us. Then I became afraid Mother might go mad. But above all I feared the grief I would endure if Mother and Father should die. Sometimes this fear was so dreadful that I wished they were already dead, so that it would all lie behind me. (20)

Again, for Käthe, to be at home was to be subject to predatory fears of the absence of home- as she relates it, even the beginning of her life story is marred by threat and regret. Käthe imagined herself responsible for looking after her mother, somehow guilty for the lack of closeness between them. Clearly relations with her mother as she remembered them were inseparable from an abiding fear of the transitory nature of security, of life itself. Like young Virginia Woolf and Marcel in Swann's Way, Käthe fretted over the possibility of her mother's disappearance, which once more links the passion for creating art and the maternal, specifically with desire for the absent mother. Particularly significant here is the image of Katharina Schmidt that Kollwitz sets before 
us, a withdrawn wanderer disconnected from the life in which she found herself living, disconnected from an abiding sense of home. It is no wonder, then, that young Käthe worried about her mother's sanity. In turn, from an early age Käthe herself was prone to chronic stomach aches, crying spells, tantrums, nightmares, and nervous fits, all of which, it seems, were related to her own recognition of the unheimlich within the heimlich, especially as embodied in figure of Katharina Schmidt.

Kollwitz's memory of her childhood home and its attendant nurture was punctured by emotional and material emptiness, evaporative promise, insecurity, and guilt. Benjamin's death and her mother's consequent strained composure occurred at the second of Kollwitz's physical homes, a home the Schmidt family moved into when Käthe was nine. However, Kollwitz likewise relates earlier, less oppressive memories: "I dimly remember a room in which I was doing pen drawings, but what I recall most distinctly are the yards and gardens. By passing through a front garden we came to a large yard that extended down to the Pregel River. There the flat brick barges docked and the bricks were unloaded in the yard and so piled that there were hollow places in which we played house" (15). Though Kollwitz renders hers in less sensoriallyprovocative terms, Kollwitz's and Woolf's first memories are not altogether dissimilar. Both remember Bachelardian spaces amenable to creative reverie, and both express a kinship with the gardens of their childhood. Yet, Kollwitz's benign first memories are inseparable from a recollection consonant with her later childhood experience of her brother's death. For, along the banks of the river where she played lay a "raft for rinsing laundry," where, much to Käthe's horror, the body of a child washed ashore. This primary memory remains so vivid for Kollwitz that as she writes she can "still see the 
terrifying hearse and coffin" (15). Though Kollwitz does not take her reaction to this tragedy to a level of awareness that would constitute a Woolfian moment of being, the sense that the young Käthe learned something of the way of all flesh through witnessing the death procession for this innocent child is undeniable. To a greater extent than Woolf's, Käthe's first memories as she articulates them are infused with death's immanence.

Notably absent from Kollwitz's earliest recollections of her first home is the presence of her mother:

I do not remember Mother at all from that time. She was there, and that was good. We children grew up in the atmosphere she created. Before Konrad's birth Mother had lost two children. There is a picture of her holding on her lap her first child, which was named Julius after my grandfather. This was the 'firstborn child, the holy child,' and she had lost it, as well as the one born after it. Looking at that picture you can see that she was truly Julius Rupp's daughter and would never let herself give way completely to grief.... Mother was never a close friend and good comrade to us. But we always loved her; for all the respect we had for our parents, we loved them, too. (18-19)

While Kollwitz acknowledges her indebtedness to her mother for bringing into being the sphere of her childhood, attempts to lay hands upon actual memories of time with her mother fall short. More resonant to her is a photograph taken long before her fifth child, Käthe, was born. For her "holy child," as Kollwitz imagines him, Katharina was surely much more accessible; he came into being before her mothering was branded with death.

If there is nostalgia woven into Kollwitz's experience of being mothered, it is this: she looks back to the photograph of her mother and imagines happiness, fulfillment. Her nostalgia is an impossibility, a longing to be born before she was, a longing to grace her mother with life-affirming presence. As it stands, however, Käthe is unable to regard her mother without regarding the gaping wound of death and loss, the pain that marred her 
childhood and rendered her mother a phantom. She enters the world of this photograph through connecting with something she does recognize - a trace in her mother's countenance of the emotional austerity with which she is so familiar. Reminiscent of Roland Barthes in his touching account of being pierced with emotion when finally discovering a photograph that spoke the essence of his mother among the many as he sorted through her collection after her death, Kollwitz must find this trace of the mother she knew before she is able to arrive at an epiphany that will prove salutary both to her own identity and to the one she grants her distant mother.

The struggle with an inability to remember the mother resonates powerfully in Woolf, as well, though Julia Stephen's absence was for the most part due to her death in Virginia's early adolescence. As Woolf relates in "A Sketch of the Past," however, she struggles to remember her living mother in part because Julia Stephen was likewise a "madonna," somewhat inaccessible, perhaps due to her private grief over the death of her first husband Herbert Duckworth years before Virginia was born. Indeed, both "Reminiscences" and "A Sketch of the Past" speak longingly of a Julia Stephen happy beyond measure. It is striking that in "A Sketch of the Past," Woolf, like Kollwitz, looks to a photograph to try to recover this elusive happiness:

Little Holland House was her world then. But what was that world like? I think of it as a summer afternoon world. To my thinking Little Holland House is an old white country house, standing in a large garden. Long windows open onto the lawn. Through them comes a stream of ladies in crinolines and little straw hats; they are attended by gentlemen in peg-top trousers and whiskers. The date is around 1860. It is a hot summer day. Tea tables with great bowls of strawberries and cream are scattered about the lawn. They are 'presided over' by some of the six lovely sisters; who do not wear crinolines, but are robed in splendid Venetian draperies; they sit enthroned, and talk with foreign emphatic gestures-my mother too gesticulated, throwing her hands out-to the eminent men ...; rulers of India, statesmen, poets, painters. My mother comes out of the window 
wearing that striped silk dress buttoned to the throat with a flowing skirt that appears in the photograph. She is of course 'a vision' as they used to say; and there she stands, silent, with her plate of strawberries and cream . ... How easy it is to fill in the picture with set pieces that I have gathered from memoirs .... But if I turn to my mother, how difficult it is to single her out as she really was; to imagine what she was thinking, to put a single sentence into her mouth! I dream; I make up pictures of a summer's afternoon. (87)

Because Woolf's mother is dead and has been since Virginia was thirteen, her search for the essence of Julia Stephen falls far shorter than does that of Käthe Kollwitz. Even Woolf's memory of the photograph is sketchy-it captures Julia Stephen's fairy tale dress, her beauty, but not Julia Stephen herself. As Woolf relates in To the Lighthouse, to be hypnotized by beauty is to be blind to the most integral aspects of the person being pondered. Though Kollwitz's memory of her mother in childhood is likewise sketchy, she is more attuned to her mother's distance than Woolf is to hers, in part because Kollwitz's mother is yet living as she writes, and even this inability to remember, Kollwitz determines, speaks to Katharina Schmidt's personality and to her ways of relating to her children.

The biographical contingencies disclosed above legitimize interpreting Kollwitz's early mother and child images as imbricated in her childhood relationship with her own mother, and in her memories of that relationship. Through Pietà and through Mother with Dead Child, she is surely empathizing with her mother of many sorrows, attempting to understand the phantom who inhabited her youth. Taking on Katharina's sorrows as if they are her own, Kollwitz remediates her bond with her mother, creating a sense of unity where none was present. Her commitment to bearing her mother's burden also amounts to mothering herself, facilitating as it does a deeper recognition of the source of distance in the mother-child dyad and affirming that neither the mother nor the living daughter is 
to blame. Yet this artistic role-playing is not as benign as it may seem-mending the relationship necessitated Kollwitz trying on the role of the dead child. In order to feel loved she needed to die. Likewise, sketching and etching these prints as a literal mother, Kollwitz was compelled to consider the child in her arms, the model for her sketches, as a deceased child, to cast herself as bereft of her son, Peter. The raw poignancy of Pietà and Mother with Dead Child suggests the experience of creation as physically and mentally wrenching, as does the violent sensuality of the child struggling for the mother's life in

\section{Woman and Death.}

Woman and Death captures the torment born of being a child to a woman whose constant companion was death; in the struggling child Kollwitz surely limns her childhood self so prone to nervous fits, so consumed with unspeakable fear. The macabre eroticism of this etching speaks to the twisted sense of sexuality Katharina communicated to young Käthe through her reticence. Confused by her sexuality, constantly falling in love with one or another boy or girl, man or woman, Käthe sought reassurance and understanding through confiding in her mother:

I was plunged into those states of longing for I knew not what which torment a child at puberty. I felt the lack of any real friendship with mother more distinctly than ever before. The moral tone of our upbringing was such that-ignorant as I was of the scientific view of human nature-I inevitably felt guilty about my condition. I needed to confide in my mother, to confess to her. Since I could not conceive of lying to my mother, or even of being disobedient, I decided to give my mother a daily report on what I had done and felt that day. I imagined that her sharing the knowledge would be a help to me. But she said nothing at all, and so I too soon fell silent. (23)

And so the adult Käthe imagines her mother drawn more toward non-being than to being, imagines in her the association of sensuality with death instead of with life-giving energy. Doing so surely carries Kollwitz back to insecure adolescent sexuality, but in retrospect 
she is able to affirm herself through recognizing her mother's circumstantial pathology. Through the act of creation, Kollwitz is able to narrate both her own and her mother's stories, stories in which the narrator is not captious, but empathetic.

In her adulthood, Kollwitz was likewise able to achieve a physical closeness with her mother, this time in the role of caretaker; the dementia-stricken Katharina Schmidt lived with the Kollwitz family in her later years. In a fitting diary entry written in December of 1919, most likely before she composed her autobiography, Kollwitz writes of touching evidence that helps to amend her conception of their relationship: "There are days when Mother sleeps most of the time, murmuring softly in her dreams and daydreaming when she is awake. Always about children. Sometimes full of care that they will not come home. But mostly the scenes she sees are very pleasant. The children sleeping in their room. Then she wants to go to wake them, and comes back wondering: where are they? It is really so sweet to see how the dreams and visions and fantasies of so old a mother always return to her children. So after all they were the strongest emotion in her life" (95). After all Käthe was loved, is loved, though it took a loss of memory to carry Katharina Schmidt to a place where she could bask in the life of her children, could bask in their becoming. This is admittedly belated, though somehow it comforts Kollwitz, who as she writes this has been grieving the loss of Peter for some five years. In the background of Schmidt's "sweet" dream, however, lies the specter of fear and loss--worry that the children will not return home, an inability to find the children who are supposed to be sleeping peacefully in their beds. At this point the rawness of Kollwitz's grief left her watching her own mother for an inkling of the long term wages of loss. Perhaps Kollwitz interpreted her mother's anxiety regarding the 
whereabouts of her children as such because she wished to witness in her mother a healing that would envelop her, as well.

It is important to acknowledge that, recording her autobiography in 1922 or so (in his forward Hans Kollwitz indicates that he does not remember the date precisely), Kollwitz molded her childhood story—consciously or unconsciously—in the form of her recent loss. After Peter's death, she was hypersensitive to the ways in which maternity and death all too often overlap. To what extent are Kollwitz's memories of her mother colored by her own loss of Peter some eight years before? To what extent does her inability to recall her mother's presence reflect her own experience of the incontrovertible separation of mother and child that was confirmed in the most tragic of circumstances, the death of Peter? Certainly we might link the profundity of her empathy to her sense of living her mother's legacy in this way. These questions are intrinsically unanswerable. Whatever the case, Kollwitz's story of her childhood is surely shaped by the fact that she inevitably writes as a bereaved mother. What remains incontrovertible, however, is the fact that Pietà, Mother with Dead Child, and Woman and Death precede Kollwitz's identity as a grieving mother. The associations of maternity and death as reflected in these prints could not have proceeded from the loss she experienced in 1914.

However, to view Kollwitz's conception of motherhood as unadulteratedly bleak would be myopic. Her pre-war diaries tell a far less pessimistic story. Taken as a whole, Kollwitz's diary reflects a thoughtful, introspective woman endeavoring to understand the evolution of herself and her relation to her changing world. That she so often contemplates how her roles as mother and artist intertwine establishes their interrelatedness as important to her worldview. In contrast to the aloofness with which 
she associates her mother in her autobiography, in the diaries Kollwitz aligns her own mothering with pleasure and with artistic productivity.

In April of 1910, Kollwitz writes that she has of late dreamt a series of nostalgic dreams: "I repeatedly dream that I again have a little baby, and I feel all the old tenderness again-or rather more than that, for all the feelings in a dream are intensified. What I have in these dreams is an inexpressibly sweet, lovely, physical feeling. First it was Peter who lay asleep, and when I uncovered him it was a very small baby exuding the warm bodily fragrance of babies" (53). Wholly absent from Kollwitz's reverie are the concerns that plagued Katharina Schmidt. What is most salient is the physical, sensorial pleasure mothering an infant entails. As she expresses it, embodied motherhood is the stuff of which sweet dreams are made. And perhaps sweet dreams make for inspired art.

Kollwitz's diaries posit a strong correlation between maternal sensuality and artistic production. As Rosemary Betterton argues in An Intimate Distance: Women, Artists, and the Body, this is in marked contrast to predominant discourses of the period "in which artistic production and motherhood were defined as mutually incompatible" (41). The sway of such discourses is evident in the fact that Kollwitz's art school colleagues and her own father feared her engagement to Karl Kollwitz would jeopardize her artistic promise. Kollwitz's journal from April 1910, the journal of an artist and mother, suggests otherwise:

I am gradually approaching the period in my life when work comes first. When both the boys went away for Easter, I hardly did anything but work. Worked, slept, ate and went for short walks. But above all I worked. And yet I wonder whether the 'blessing' is not missing from such work. No longer diverted by other emotions, I work the way a cow grazes; but Heller once said that such calm is death. Perhaps in reality I 'accomplish' 
little more. The hands work and work, and the head imagines it is producing God knows what; and yet formerly, in my so wretchedly limited working time, I was more productive because I was more sensual; I lived as a human being must live, passionately interested in everything .... Potency, potency is diminishing. (53)

Undermining the assumption that addressing the needs of others necessarily detracts from the female artist's ability to create, Kollwitz asserts that the physical and emotional work of raising children infused her with passion, and, in doing so, proved vital to soulful creation. The busyness of mothering exposed her to a broad range of circumstances, relations, and emotions to which she responded passionately, and this generalized passion necessarily found expression aesthetically. Maternal intimacy gifted her and her children. Kollwitz confesses a fear that increasing distance between her and her children will negatively impact her art, that creation will somehow suffer from the sterility she associates with an empty nest.

Kollwitz was clearly not entirely at peace with the changes involving her own and her children's aging. Does increased autonomy equate to soulless art? Does middle age drain the artist of vitality? She voices these fears again in an entry dated New Year's, 1912-1913:

My impression of Hans is that he does not always find in me what he seeks. He is moving forward swiftly and I am not. Does he feel that I am getting old? Am I perceptively aging? I do not know. Sometimes I feel almost paralyzed, at other times buoyant. Sometimes I stop believing in my working, and that is bad .... Now I feel myself vulnerable; sometimes I am a prey to despair. And I am too much upset by the young people with their different point of view. If I had great strength within myself they would hardly trouble me, but now I feel that my work has no echo, feel as if I have been tossed into the scrapheap. And so I have. All that one can do is put on blinkers and plod along by oneself, paying no attention to anything else. I've worked almost exclusively in sculpture this year. I don't know whether I will get anywhere. If not, what then? (60) 
Kollwitz's anxieties here clearly relate to her perception of her art as old-fashioned, a concern that was, in fact, keen—many critics are still reluctant to categorize her work as modernist, in large part because of its realist bent. As this entry reveals, her fear of obsolescence coincides with her boys' increasing independence and the potential decrease in connectivity such independence entails. This was a period in which Kollwitz was also likely entering menopause, a stage of life that demanded that she take account of where she had been, a stage that demanded that she plot her course, a life stage that called upon her to make a new start (Kearns 123).

Despite her anxieties, witnessing her children's birth into adulthood and the possibility inherent in their maturation simultaneously nurtured Kollwitz's hope for the future, theirs and her own. In a passage from September of 1913, she imagines that the historical period in which she is creating, a period "when all the old values are being overthrown," might allow her to "begin anew, unencumbered by any technique, simply newborn" (61). While she eventually dismisses this hope as too idealistic, comparing herself to a newborn at a juncture when her sons were on the verge of adulthood suggests her association of her own growth with her sons'. Kollwitz suggests, that is, that the process of mothering her children has been one of her own becoming, as well, that their emergence into the world correlates with hers.

In addition to her recognition of the potential horizons of growth that Hans' and Peters' comings of age brought to the forefront, Kollwitz was sensitive to the fact that, on a practical level, their independence would allow her to immerse herself more fully in her art. In an April 1910 entry, she expresses enthusiasm toward her "darling boys ... growing more independent," communicating not merely a peace with, but exhilaration 
regarding her children coming into their own: "I can already see the time when they will break loose from me, and at the moment I look forward to it without sorrow. For then they will be mature enough for a life wholly their own, and I shall still be young enough for my own life" (54). Kollwitz was able to study art in Paris and Italy for extended periods while her young children stayed behind in Berlin, but she recognizes this juncture as ushering in more extensive and consistent freedom to focus intensely on her art. Moreover, she anticipates a future in which she will be able to look at her grown children and be well-pleased, pleased that they are flourishing, pleased that she is flourishing, proud of the fruits to which her mothering has given and continues to give birth. In the years preceding the war, Kollwitz was consumed by a sense that this was the end of an era, an end of years of intensive mothering, a time of reckoning. Her pre-war diaries are an arena in which she works through concerns about what lies ahead in her art, in her relationship with her children, and in her personal growth.

Vowing to devote the creative energies that had been directed toward her children to her art, Kollwitz extols both mothering and artistic creation as affirmative, and interconnected, as the following reflection from New Year's Day, 1912 attests: “Are not the ties with the boys also growing slacker? I almost think so. For the last third of life there remains only work. It alone is always stimulating, rejuvenating, exciting and satisfying. This year I have made excellent progress in sculpture" (59). It is no coincidence that one of the sculptures she envisions is "a pregnant woman chiseled out of stone. The immobility, restraint, introspection. The arms and hands dangling heavily, the head lowered, all attention directed inward. And the whole thing in heavy, heavy stone. Title: Pregnancy" (59). Kollwitz conjoins the maternal body and the creative 
mind, conceiving as an appropriate medium heavy stone to signify the ways in which both are foundational to becoming. Her artistic growth is inspired by her literal motherhood, the becoming of those she shepherded into maturity. Her relationship with her children at this juncture has become one in which they nurture her in return, especially as she considers the miracle of connectivity she brought into being. This lens into the miraculous is one Woolf can only imagine her own mother experiencing, which she does through writing herself into both Mrs. Ramsay and Lily in To the Lighthouse. A letter to Hans written on July 8, 1912 emphasizes Kollwitz's continuing commitment to her grown child and her uncertainty regarding how to carry out that commitment:

I hope this letter will reach you by my birthday. It is strange to be alone with Father on this day-this is the first time that's happened since you were born .... But I am not sad, although when I realize the changes that have taken place I become thoughtful. How fast the time has gone by, really, from the days when you were still a baby and belonged to me. Now it is very different. But let me say again, Hans, I am not complaining about it. The goal of parents, after all, is to make their children independent. The love between parents and children does not cease, never ceases, but everything changes and takes on new forms. If you would rather not have me share in what you are experiencing at this time, I completely respect that wish .... I have just seen so many things in life go awry and turn out unhappily; and often the unjustified feeling comes over me that even a grown child is still a child to be guided. That is nonsense, of course. One must have confidence in one's child .... And I do have confidence, my boy. (140)

In later years, it was surely difficult for Kollwitz to avoid connecting these difficulties mothering her children through their processes of increasing separation from her with the mass statement of humanity's disconnection from each other that soon befell Europe, soon befell her beloved home. The trepidation evident here is, she would soon discover, well-founded. 
"The frightful insanity—the youth of Europe hurling themselves at one another."22

It is sadly ironic that just two months before the war, in a diary entry dated simply June 1914, Kollwitz expresses an ennui, a discomfiture, "the desire to get away, just to have things different and to live my own life. Just not to go on in the humdrum traditional style" (62). Only two months later life as she knew it would be shattered, and the idea of "humdrum traditional" was but a dream. Her journal for August 1, 1914 represents succinctly what would be her predominant artistic and personal struggle for the rest of her years - an assertion of the day's infamy, the word "War" sprawls across the page (Friedrichsmeyer 206). Given the humanistic values evident in her pre-World-War I oeuvre and diaries, it comes as little surprise that among her first reflections on war is an affirmation of human connection despite the consuming violence: "August 27, 1914: In the heroic stiffness of these times of war, when our feelings are screwed to an unnatural pitch, it is like a touch of heavenly music, like sweet, lamenting murmurs of peace, to read that French soldiers spare and actually help wounded Germans, that in the franc-tireur villages German soldiers write on the walls of houses such notices as: Be considerate! An old woman lives here.-These people were kind to me.-Old people only.-Woman in childbed.-And so on" (62). Like the Christmas Truce of 1914 that would occur later that year, the incidents Kollwitz relates here confirm the substantiality of human goodness, an underlying weave of human connection, and this heartens her. These moments of good will provide the illusion that perhaps the war will not be so brutal. But Kollwitz was not so naïve as to believe that such kindnesses would forestall or overshadow the horrors to come.

\footnotetext{
${ }^{22}$ From Kollwitz's diary dated 11 October 1916 (74).
} 
While Kollwitz is best known for protesting war through her art, as Regina Schulte maintains, "[i]n 1914, Kollwitz, like most Germans, accepted the war as a defensive struggle for national survival. Like many artists who volunteered or were drawn into the war, she had expected the greatness of the experience to enlarge her vision and find expression in her art. And like many other women, she was committed to the concept of sacrifice for a higher ideal, a concept to which she returns again and again in her diary" (95). This assessment of Kollwitz proves consistent with Modris Eksteins' classification of the energies that rallied support for the Great War as aesthetic in nature. According to Eksteins, "[i]n early August Germans wallow in what appear to them to be the genuine synthesis of past and future, eternity embodied in the moment, and the resolution of all domestic strife - party versus party, class against class, sect against sect, church in conflict with the state. Life has achieved transcendence. It has become aestheticized. Life has become a Wagnerian Gesamtkunstwerk in which material concerns and all mundane matters ... are surpassed by a spiritual life force" (62).

Even a humanitarian such as Käthe Kollwitz found herself implicated in the zeal of such nationalism. This sets her apart from Virginia Woolf, who was consistently opposed to war. After Peter died, Kollwitz feared that rejecting that nationalism was tantamount to rejecting Peter, who believed so zealously in the cause that he saw fit to offer his life for it. The evolution of Kollwitz's perspective on war and its inflections upon her relationship with Peter remain the predominant subjects of her art, diaries, and published letters from 1914 onward. At least in her diaries and letters from the war years, that perspective is not uniformly pacifist. 
In an entry dated 10 August 1914, Kollwitz explains heeding the call for strong

German mothers to offer their sons to the sacred mission of the State:

Karl: 'The fatherland does not need you yet, otherwise you would have been called already.' Peter, more quietly, but firmly: 'The fatherland does not need my year yet, but it needs me.' He keeps turning to me with silent, pleading looks, begging me to intercede for him. Finally, he says, 'Mother, when you embraced me, you said 'Don't think me a coward, we are ready.' I stand up, Peter follows me, we stand at the door and embrace and kiss and I ask Karl on Peter's behalf.-This singular hour. This sacrifice he forced out of me and which we forced out of Karl. (qtd. in Schulte $194^{23}$ )

As Schulte rightly surmises, it was not only Peter who was swept up in religious fervor for sacrifice for the Fatherland: Käthe Kollwitz was a reluctant but willing participant in the ritual of offering up her son, a ritual she conceptualized in terms of the sacred, so much so that she worked to convince her pacifistic husband of the worthiness of the cause. Schulte illustrates persuasively that Kollwitz's diaries reveal that for an extended period she conceived of the first World War in terms of a holy sacrifice of Germany's youth for a greater ideal, that of the triumph of the spirit of the State. Yet, the diaries are not consistently romantic: coexisting with descriptions that imbue the young men's service to the state with hallowedness are stark assessments of the war as inhumane, as boding ill for individuals, for their families, for the State, for humanity itself.

In a keen assessment of the purpose and content of Kollwitz's diary, Sara Friedrichsmeyer maintains that it guided Kollwitz's growth from a patriotic woman who succumbs to a sense of duty for her homeland, to one who questions the war critically, to the mother and artist who avows pacifism as the only ethical route to personal and

\footnotetext{
${ }^{23}$ Kollwitz's complete diaries - published in German as Die Tagebücher and edited by Jutta BohnkeKollwitz-have yet to be published in English. Schulte's article-originally published in German-cites the Bohnke-Kollwitz German diaries. The English edition of Kollwitz's diaries, edited by Hans Kollwitz, contains only excerpts.
} 
collective freedom. As Friedrichsmeyer explains, however, Kollwitz's journals are by no means marked by linearity - they represent her shifting and often contradictory thoughts regarding the war to which her son sacrificed himself with her blessing. The process of writing, then, played a very literal and central role in Kollwitz's becoming, her evolution into a committed pacifist who channels her artistic gift to better her world:

That her diary offered an outlet she required and depended on is clear: its importance to her emotionally as a method of controlling grief and intellectually as a forum of working out her attitude to war can be discerned not only from the content, but also from the length and frequency of the entries through the war years. Of the ten books she wrote between 1908 and 1943, one entire volume is devoted to the first eight months of 1916. But there was more to the diary's appeal. Kollwitz had a Protestant sense of life as a gift to be used or, negatively expressed, of life as an obligation. She communicates to the reader a lingering fear of not living up to her potential, of not performing her duty. The journal ... offered her a chance to validate her life and affirm herself in her various roles-including those of woman, mother, wife, daughter, sister, friend, and artist. (Friedrichsmeyer 212)

The act of writing, then, was not merely therapeutic in the face of devastating personal and cultural loss: It contributed to her ability to construct herself in the image of an ethical agent who worked to shape her world into a home conducive to the flourishing of its inhabitants. This aligns her with Woolf, whose writing was a means of personal growth that rendered her more capable of and committed to revealing both the inadequacies of her world and the sorts of presences that might remedy them.

As with Woolf, it is not only the fact that Kollwitz wrote that made the difference; the form in which the writing was completed is amenable to personal growth and a reevaluation of personal commitments. As Friedrichsmeyer explains,

the relatively unrestricted genre allowed her the freedom to deal with problems from many different perspectives and as often as she desired; over a period of years it allowed her through stylistic experiments and thematic digressions to relive the past and spiral into the future as 
necessary. With its emphasis on process instead of goal, the diary also assured the continuity and sense of involvement she required .... Above all, as she pushed to understand her own feelings and integrate them with what she knew intellectually to be true, her writing helped her develop confidence in her own thinking. (213)

Theoretically, the diary genre is more forthright than, say, a memoir written for an audience other than the self, for the diary represents the self-writing-for-the-self. Inauthenticity is still a distinct possibility and likely creeps into even the most earnest of writings due to the "natural" human urge to paint the self as noble to convince that self of its worthiness. One can imagine a bereaved diarist such as Kollwitz appropriating the diary for the sake of presenting a laudatory vision of war in order to convince herself that the cause to which she bequeathed her son was indeed just. Yet Kollwitz's diary appears not to be sullied with such inauthenticity. Though, as cited above, the sacrifice motif appears consistently in the first years of the war, it is counterbalanced by Kollwitz's salient doubts that call into question the motif's validity. The many perspectives discernible in Kollwitz's diary and the fact that hers is not a straightforward trajectory suggest it as an arena in which she participates in an anguished battle with her own thoughts and changing perspectives.

As she came to terms with the advent of a war she was inclined to support, Kollwitz was beset with doubts proceeding from a pained conscience regarding the tolls it would take on human relations, as is clear in the second half of the August $27^{\text {th }}, 1914$ entry referenced above:

A piece by Gabriele Reuter in the Tag on the tasks of women today. She spoke of the joy of sacrificing - a phrase that struck me hard. Where do all the women who have watched so carefully over the lives of their beloved ones get the heroism to send them to face the cannon? I am afraid that this soaring of the spirit will be followed by the blackest despair and dejection. The task is to bear it not only during these few weeks, but for a 
long time - in dreary November as well, and also when spring comes again, in March, the month of young men who wanted to live and are dead. That will be much harder. Those who now have only small children ... seem to be so fortunate. For us, whose sons are going, the vital thread is snapped. (62)

Though at this point in her journals she generally succumbs to the ideology of sacrificial heroism, here it is clear that Kollwitz is under no illusions regarding the violence it will perpetrate upon individual families, and upon the procreative longings that sustain life. As she so aptly puts it, "the vital thread is snapped," the ties of connectivity severed. Reading this in retrospect, Kollwitz likely felt that she betrayed the voice of the humanitarian who speaks so loudly and clearly here, betrayed the son she seems to intuit will lose his life. Indeed, as predicted, her November was exceedingly dreary, and her spirit did not soar. That this prophetically dire entry should appear amidst a flurry of entries that communicate sympathy for the cause reveals the freedom from adhering to a foolish consistency that the diary genre afforded Kollwitz. Almost certainly she looked back nostalgically to this period when her son was yet living and her assessments of the war were not so laden with loss. Surely she wept that her voice of justice was muffled by an internalized, virulent nationalism.

Kollwitz's entry from September 30,1914 is especially suited for illustrating her uncensored contradictions appearing even within the same entry: "In such times it seems so stupid that the boys must go to war. The whole thing is so ghastly and insane.

Occasionally there comes the foolish thought: how can they possibly take part in such madness? And at once the cold shower: they must, must! All is leveled by death; down with all the youth! Then one is ready to despair. Only one state of mind makes it all bearable: to receive the sacrifice into one's will. But how to maintain such a state?" (63) 
Wavering between outrage regarding its inhumanity and the guilty conviction that she too should be willing to sacrifice for her homeland, Kollwitz struggles to determine her duty - to her son, to her country, to the spirit of the age, to her conscience. Though the first bit of the above passage appears to be adamant in its anti-war stance, she turns the tables and affirms the necessity of that which seems "ghastly and insane." Even after the "musts," Kollwitz reverts to a reiteration of the destruction of Germany's youth, only to swerve once more to the sacred ideal of sacrifice. Her final question-"But how to maintain such a state"-captures keenly the artist grappling with her conscience. Such grappling represents the diary fulfilling its most lofty purpose-bringing into contact the everyday self with the highest self. And, in Kollwitz's case, this highest self is very much bound in her identity as mother. The soul work that is journaling eventually led her to adopt the Goethean mantra "seed for the planting must not be ground," which she devoted the best parts of her aesthetic energies to promoting for the remainder of her life. Through the diaries, she came to conceive of herself as "the bearer and cultivator of a grain of seed-corn," the fulfiller of Peter's legacy (64). For, Peter was killed in action on 22 October 1914. 


\section{CHAPTER VII}

\section{MOTHERING THE DEAD}

Can I affirm the sudden cutting off of a man's life on earth and the possibility that this experience-his death-enriches my life? It seems to me one does not talk like that when one's children die.

Käthe Kollwitz, August 12, $1916^{24}$

The diaries not only prove indispensable in charting Kollwitz's fluctuating regard for the war effort, but they also offer insight into the art that she undertook in response to the war and the death of her son. Like Woolf, Kollwitz found art a viable means through which to grieve and seek peace, and, like Woolf's, Kollwitz's attempts to reconstitute herself in the face of such grievous losses entail exploring the intersections of maternity, human connectivity, and home. Though Kollwitz was never able to resolve the loss of her son, creating The Mourning Parents (Trauernden Eltern) (fig. 14) and the War (Krieg) cycle (fig. 5-11) played a vital role in her attempts to trudge through the grieving process and her success in appropriating her grief for social action. The creation of these works that are essentially about war's capacity to destroy what is fundamental to human flourishing — family and home-called upon Kollwitz to engage in extensive reflection on a personal and cultural level, reflection that ultimately led her to recognize resolution as both impossible and unethical. Kollwitz herself expresses it succinctly in a letter

2472. 
written to a friend of Peter's-Erich Krems, who would be killed shortly thereafter-in early December 1914: "There is in our lives a wound which will never heal. Nor should it. To give birth to a child, to raise him, and after eighteen precious years to see his talents developing, to see what rich fruit the tree will bear-and then to have it cut short . ..! I have in mind a sculpture in honor of Peter. That is one goal for living" (144). Art critics in general agree in viewing the War series and The Mourning Parents as expressions of cultural and personal grief and a transposition of that grief into social action. As Louis A. Gamino contends in his consideration of Kollwitz's work as therapeutic in her struggle with grief, the death of a child constitutes a loss so profound and unnatural that the healing process is frequently prolonged to the extent that it is never complete. Gamino argues from a clinical perspective that "epidemiological evidence has indicated that the pain of bereavement, especially parental bereavement, lasts longer than many professionals have realized and may last a lifetime. In this context, Kollwitz's ongoing struggle to accommodate her grief appears normative rather than pathologic" (281). After Peter's death, melancholia is omnipresent in Kollwitz's writings and art, and it is melancholia's presence that renders her works agents of social change.

Kollwitz's art exemplifies what Patricia Rae terms "resistant mourning," a refusal to subscribe to the ideology of successful mourning as "severing all ties with the lost beloved" (16). As Rae explains in her introduction to Modernism and Mourning, "[a]t the heart of what has been called a 'depathologizing' of melancholia, a movement whose recommendations extend to struggles with the loss of places, abstractions, and ideals, even the 'the past' as a broad abstraction, has been a sense that such 'work' amounts to a forgetting of, or an abdication of responsibility for, what has been lost, and that this 
amnesia has been too often demanded and paid in the interests of preserving the status $q u o^{\prime \prime}(18)$. Losing her son was no mean deprivation to be swept swiftly under the rug in the name of psychological healing and a will to move forward — such amnemonic healing would be inauthentic and demeaning to her memory of Peter and to her own motherhood. In a tragic reversal of roles, Kollwitz was ordained to carry her son's seed, to disseminate his legacy. The sustainability of his legacy demands continued acknowledgement of the pain inflicted upon the family by the ideology of sacrifice in the name of the nation, a paradoxical illumination of that legacy as severely compromised by the unforgiveable murder of its rightful progenitor. As the essays in Modernism and Mourning attest, Kollwitz's inability to complete the cycle is not idiosyncratic, but is instead a cultural phenomenon in the wake of unprecedented mass European warfare. In this way, some modernist art-with Kollwitz's as exemplar-might be deemed ethical in conception and effect. Kollwitz rendered her private, maternal grief public, and, in doing so, encouraged her world - and ours- to be more attuned to the inhumanity inherent in nationalism.

What follows is a chronological consideration of Kollwitz's The Mourning Parents and War series. Such an approach enables a nuanced exploration of her grieving process, her view of war, and her mindset as it influenced and was influenced by her art. Because the gestation period for The Mourning Parents was over seventeen years (October 1914-July 1932), and because the seven woodcuts in the War series were completed during a period of approximately two years within those seventeen (19221923), analysis of these respective works will not be as tidy as might be desired. To understand The Mourning Parents and War best necessitates conceptualizing them as 
Kollwitz's conversations with her own grief, and this demands, in turn, immersion in the chronology of her diaries.

In November 1914, less than a month after Peter's death, Käthe Kollwitz wrote to thank her friend Frau Schroeder and her daughter Dora for their gift of a shawl to the young soldier and to relate news of her dear child's death. She articulates her loss in terms that invoke his infancy, in terms of the fragility of the child who came into the world needing to be sheltered from life's chill: "Your pretty shawl will no longer be able to warm our boy. He lies dead under the earth.... We thank God that he was so gently taken before the carnage" (143). Unable to warm the son she brought into the world, she takes solace in the fact that he was taken gently, rocked as it were to his death rather than ripped violently. Her perspective on losing her youngest child reflects her need to believe that he was nurtured even in his death, the extent to which, although she consigned him to the State, she still views him as a child in need of care. If it had been heeded, this instinctive regard for nurture and well-being as infinitely more valuable than heroism would have dissuaded her from prioritizing the amorphous spirit of the State over the individual life.

Kollwitz's first diary reference to Peter's death appears a little over a month later, on December 1, in the form of a plan for a memorial to him: "It must stand on the heights of [Mount] Schildhorn, looking over the Havel [River]. To be finished and dedicated on a glorious summer day. Schoolchildren of the community singing, 'On the way to pray.' The monument would have Peter's form, lying stretched out, the father at the head, the mother at the feet. It would be to commemorate the sacrifice of all the young volunteers. It is a wonderful goal, and no one has more right than I to make this memorial" (63). As 
this passage attests, at its inception, Kollwitz's vision for Peter's memorial is very much steeped in the ideology of heroic sacrifice. This is particularly evident in the pageantry Kollwitz dreams up for the dedication-processing children proclaiming in song the sacredness of the occasion, the solemnity of the cause, the glories of this beautiful day. Imagining a monument erected on high that includes a mother and father standing to affirm that their son was sacrificed for the greater good of the collective home, she proclaims that their parentage extends beyond their blood kin to encompass the singing children who testify that this sacrifice was made for them, for all.

Here Kollwitz invokes a traditional communal celebration affecting and affected by nationalistic unity, and in doing so exposes appeals to nationalism as pivoting on the desire to redeem a perilous history. In Kollwitz's vision, Peter is the exemplar of the worthy son who lives and dies to save his country and in so doing renders his own death redemptive, infinitely meaningful. In light of the misgivings she voices in earlier entries, it is clear that at this point Kollwitz seeks desperately belief in the dignity of her son's death. Such belief demands validation of the cause. Kollwitz struggles to envision this sacrifice effecting a return to simplicity, a return to innocence, soon recognizing her restorative nostalgia as what it is-a desperate, flawed attempt to recover what she can never recover, her son in his childhood bliss. Though when Kollwitz finished her monument to Peter nearly two decades later it would be installed at the Belgian cemetery where her son was buried, at this point in the grieving process a cemetery played no part in her vision. At this point, that is, Kollwitz's conception of Peter's memorial pivots on her denial of the finality of death. The hope she exudes here is nationalistic-she 
imagines the nation's becoming as ensuring the continued becoming of the heroes who gave their lives for the cause.

An entry dated December 9, 1914 amends the fantasy somewhat. In this manifestation, instead of focusing on the pageantry of the day, Kollwitz attends to the appearance of her aestheticized son: "My boy! On your memorial I want to have your figure on top, above The Mourning Parents. You will lie outstretched, holding out your hands in answer to the call for sacrifice: 'Here I am.' Your eyes—perhaps—open wide, so that you see the blue sky above you, and the clouds and birds. Your mouth smiling. And at your breast the pink I gave you" (63). Again lauding Peter's willingness to submit himself body and soul to Germany, Kollwitz romanticizes the result of his devotion, imagines him taking joy in his aesthetic rebirth. As she pictures him here, in death Peter is not maimed but beatified. Imbibing the beauty of nature, at one with his unsullied homeland, he lies peacefully. And the flower given to him by his mother as he departed for war lies blooming upon his breast, a testament to his immortality, the immortality of the cause for which he gave his life, the permanence of home and of the mother-child dyad that symbolizes that home.

When Kollwitz reached the stage of working physically on Peter's monumentcertainly by April 1915-she conceived of it as an "offering." The process of molding this "offering" did much to further the grieving process and to alter her perspective on her son's death (64). The act of taking the clay in her hands, the sensuality of sculpting, carried her closer to a truth that mirrored her humanitarian leanings. Read through the lens of Irigaray's "The Fecundity of the Caress," in caressing the clay Kollwitz became enamored of the other in her own right, the other within the self of the mother she was 
sculpting. Doing so, without resorting to inauthentic mastery, she recognized her sorrow more deeply, a sorrow that would eventually enable the realization that nothing could justify the destruction of the life of the other that had emanated from her.

In an entry from April 27, 1915, she indicates that the project deviated from her expectations as she continued to work the clay: "I am working on the offering. I had to-it was an absolute compulsion—change everything. The figure bent under my hands of itself, as if obeying its own will-bent over forward. Now it is no longer the erect woman it had been. She bows forward and holds out her child in deepest humility" (64). At this point it is not clear to Kollwitz why the mother bowed as if of her own volitionhere she attributes it to humility in the face of sacred, sacrificial duty. Eventually, however, many years later, Kollwitz found the mother's posture to be attributable to a leaden grief, a mother's and a culture's. Only the creative process could provoke so deep a confrontation with the truth of her own and her world's irresolvable loss.

In a moving diary entry dated July 15,1915 , Kollwitz describes her creativity in its highest form as prayerful, with prayer as inseparable from her bond with Peter:

It is said that prayer ought to be a coming to rest in God, a sense of uniting with the divine will. If that is so, then I am-sometimes-praying when I remember Peter. The need to kneel down and let him pour through, through me. Feel myself altogether one with him. It is a different love from the love in which one weeps and longs and grieves. When I love him in that way I do not pray. But when I feel him in the way which I want to make outwardly visible in my work, then I am praying. That is also why the parents on the pedestal are kneeling as they carry their dead son. And are wholly in meditation, and in him. (64).

When infused with the spirit of Peter, with the vitality of past, creation constitutes ecstasy. At this point, Kollwitz has not yet converted herself wholly to what is to become her adamant anti-war stance, yet she does associate Peter-infused creativity with a 
participation in divinity. Her writing from only two months later confirms that she is nearing an epiphany in her increasingly self-conscious search for her life's divine purpose: "Humanity's goal goes beyond the first stage of happiness-elimination of poverty, disease and so on-and also beyond the complete development of the forces within itself. The goal is to develop divinity, spirituality" (66). Kollwitz's view of divinity is similar to that of Grace Jantzen-for both, becoming divine demands a commitment to recognizing one's connection with and caring for the world and those within it. As Kollwitz's diaries progress, she gradually begins to recognize that her route to divinity is to be paved with her artistic renderings of the terrors war inflicts upon the living, which will require her to relinquish her validation of the war as sacred cause.

By November 1915, Kollwitz has for the most part jettisoned the romantic language of sacrifice. Renewing her commitment to being a worthy heir, she is coming closer to identifying that this worthiness will be enacted through opposition: "Again I feel quite distinctly that it is not proper for me to lament over the war. Certainly I know what it is like. But I may not complain. No one may for whom the dearest person in the world has gone, as Peter went .... It is right for us to weep for our loved ones, but we must be worthy heirs. We may also be against the war. We may work-must help work - so that this one will be the last. But I must stop giving way to this type of personal grief" (66). Chastising herself for self-serving lamentation, Kollwitz nonetheless expresses a conviction of opposition as legitimate-if it is undertaken for the betterment of the whole. Here she marshals the same logic that led her to deem incumbent sending Peter off to war-the logic of collective health as necessarily eclipsing that of the individual-to support her increasing pacifism. 
Finding a mode of rejecting a cause for which her son zealously gave his life was emotionally-excruciating, for it demanded that she not only face her loss but also face her culpability in that loss. Kollwitz articulates in her diaries in the following two months that she is coming to acknowledge the reality that nothing can compensate for the loss of her irreplaceable son: "December 1915 ... What was important was this particular form which grew. This unique person, this human being who could live only once. What continues is spirit in itself, but yet not Peter's spirit. Peter's spirit was inseparable from his body. That is why for me there is no consolation at all in the thought of immortality" (66). This realization undermines her idealization of sacrifice and nourishes her commitment to the preservation of life. As Sara Ruddick maintains, preservative love is a fundamental component of maternal practice. While Peter is lost, Kollwitz holds tightly to the precepts of her maternal practice and comes to acknowledge them as more faithful to her relationship with Peter than the allegiance to sacrifice that entered their lives so late in that relationship. Her goal as a mother was to nurture her children's becoming in relation to herself, to others, and to their world. To her devastation, she was recognizing sacrificial heroism as it was playing out in Germany as counteracting such a goal.

Fumbling for an inkling of personal growth that will mitigate her sense of loss, Kollwitz formulates something of a New Year's resolution on January 2, 1916: "The narrowness in me-that is the worst. To extend, expand, become something higher-that is what one asks of oneself. To remain the same person one was before fate struck-this must not be. Transformation through a single act of will has not come about. Therefore it must take place slowly" (67). Confirming that she is holding true to her promise, that 
she is emerging from the stupor of grief to a more active form of bereavement, a good number of diary entries from the first few months of 1916 concern her participation in the art world. Increasingly, Kollwitz conceptualizes art as a viable, ethical response to her profound grief, one through which she can touch the lives of the everyday person struggling to make sense of a world in which cohabitants engage actively in the destruction of themselves and of their collective home. While Woolf's To the Lighthouse does not constitute so brazen an act of social activism, Woolf, like Kollwitz, reaches out from within the darkness of personal grief to fashion a better world through art. Woolf does so through projecting a positive vision of a world attuned to connectivity, whereas Kollwitz invokes this salubrious world through revealing its opposite, a world that profanes human relations.

As Kollwitz laments in her diaries, her ability to move forward in the realization of her divinity continued to be compromised by debilitating grief. Though she is approaching the recognition that a suffering world needs her art, she is unable to accommodate because her pain continues to isolate her from the will necessary to carry on in the name of her son and her world. On January 17, 1916, she reiterates the fear that the diminishment of her mothering responsibilities renders her barren, a fear that recurs in a number of her diaries from 1916:

Where are my children now? What is left to their mother? One boy to the right and one to the left, my right son and my left son, as they called themselves. One dead and one so far away, and I cannot help him, cannot give to him out of myself. All has changed forever. Changed, and I am impoverished. My whole life as a mother is really behind me now. I often have a terrible longing to have it back again - to have children, my boys, one to the right and one to the left; to dance with them as formerly when spring arrived and Peter came with flowers and we danced a springtime dance. (67) 
Taken in the contexts of her pre-war association of mothering with creativity, her association of her boys' development with her own, and her fear that a diminishment of the sensual tasks of mothering will jeopardize her ability to create passionately, these misgivings sprung from a sense of helplessness in the face of a world that holds no regard for human flourishing, a world that prohibits sustained relations. As so many of her War woodcuts reflect, Kollwitz pictures war's savage disregard for humanity's need to nurture and be nurtured through the iconic mother and child relationship. With Peter dead and Hans distant both physically and emotionally, Kollwitz faced firsthand an inability to nurture those she called her own. She longed for the life-affirming energies of a foundational domesticity. She longed to celebrate with her boys the fecundity of becoming rather than mourn with them the destruction that shadowed their existence. In a letter to Hans written on January 16,1916 , one day earlier than the above entry, Kollwitz expresses her fear that he has fallen into one of his depressions. Gently chastising him for leaving her with "short rations with letters," she discloses her means of being near to her children in their absence, passing her time in what was once Peter's room:

I am growing more and more fond of sitting here with Peter, where it is so quiet and shut off. After I have opened the old desk and placed the lamp on the hinged top, the three compartments confront me. In the four small drawers to the left are all the pictures of you boys .... In the center open compartment is a picture of the two of you as children. You must have been about seven at the time, Peter about three. You are standing arm in arm, and you are bigger than your brother.- - Here is also a picture of Peter before his departure. Along the back wall of this compartment there is just room enough for another picture. A fine Bellini now stands there: the lamentation over Christ. When I look up I must look at this picture; it makes a lasting impression. But I intend to change it, to place other pictures there too. (147-48) 
As Regina Schulte explains, Peter's room "became the shrine of a cult of the dead which in turn became an element of everyday life in the Kollwitz house. Every act in this room acquired a sacral dimension, for 'his room was holy' .... In 'Peter's room' time appeared suspended to Kollwitz, having come to a standstill in the past" (197). By Schulte's logic, the presence of the aforementioned Bellini Lamentation (fig. 12) was not coincidental—in her diaries, Kollwitz repeatedly associates her fallen son and Christ. Peter's room held an aura of an imagined holiness emanating from his heroic sacrifice; it follows that Kollwitz's retreat there represents a denial of the reality of the circumstances that robbed her son of life. Schulte's thesis is well-founded and well-supported, but a sense of the quotidian lingers about the above entry to suggest increasing detachment from the rhetoric of sacrifice toward which she had been so prone.

While Kollwitz speaks of Bellini's Lamentation, she also expresses her intention "to change it," presumably to replace it with pictures of her sons' childhoods. Here Kollwitz does not speak as a mother of a Christ child, but as an everyday mother reflecting on time's passage as she looks upon the still portraits of her young children, children who are young no longer. Kollwitz is a mother lamenting that freedom and innocence are ephemeral for all, even for those we seek to protect. There is indeed a sense of the sacred that lingers in this scene, but that sacredness is not rooted in the ideology of sacrificial heroism. Rather, the sacred as it is manifest here lies in Kollwitz's view of human connection as sacred, of a mother's everyday relationship with her children as perpetually holy. This is certainly consonant with Grace Jantzen's focus on the miraculous connectivity that characterizes even the most mundane lives. 
While, as discussed in the previous chapter, Kollwitz's confrontation with her mother's portrait brought a sense of healing and resolution, her confrontations with images of her sons in their childhood offered nothing of the sort. This lack of consolation likely lay in the fact that the portraits of her boys in their youth carried with them a sort of horror, a horror of time passing, of time having passed, and of their loving mother being powerless to intervene. Roland Barthes explains that in its assurance of a death to come, every photograph is tragic:

[T] he punctum is: he is going to die. I read at the same time: This will be and this has been; I observe with horror an anterior future of which death is the stake. By giving me the absolute past of the pose (aorist), the photograph tells me death in the future. What pricks me is the discovery of this equivalence. In front of the photograph of my mother as a child, I tell myself: she is going to die: I shudder, like Winnicott's psychotic patient, over a catastrophe which has already occurred. Whether or not the subject is already dead, every photograph is this catastrophe. (96)

Surely Kollwitz was struck by the incongruities of her present and the present of her young children in the photograph, of her hopes for Hans and Peter and the fact that Peter had fallen in war and Hans had brushed against gruesome death time and time again in his work in the ambulance corps. How disparate are the dreams of the young mother for her sons and the reality in which they found themselves. On one level, then, the photographs exude innocence and hope, yet on another, they exude the travesty of innocence and possibility betrayed, an inevitable travesty even in the absence of war. All she could do - and she did, according to her diary for April 18, 1916-was dream the old dream of mothering a baby once more: "I was holding the tiny infant in my arms and I had a feeling of great bliss as I thought that I could go on always holding it in my arms. It would be one year old and then only two, and I would not have to give it away" (69). This is a dream with which Mrs. Ramsay would sympathize, reminiscent of the 
restorative nostalgia Woolf attributes to her own mother, though surely Kollwitz's nostalgia begotten of the loss of her son is very different from any sort of nostalgia Julia Stephen could have experienced. Woolf's characterization of her mother's nostalgia for her children's babyhoods is surely colored by the fact that Woolf longed for her own infancy, a time when mother and child were together and secure. The security Kollwitz desired, on the other hand, was lodged in her idea of her children's infancies as antithetical to death.

The months of July, August, September, and October 1916 for Kollwitz were marked by depression and doubt, but also by increasing firmness of conviction. Feeling "older and feebler," "parched," empty, and disenchanted with the idea that war can further growth of any sort, she continued her work for Peter but labored over what that work should represent. Immersed in the pain of loss, she strove to commune with Peter through her art, but to no avail:

August 22, 1916 Made a drawing: the mother letting her dead son slide into her arms. I might make a hundred such drawings and yet I do not get any closer to him. I am seeking him. As if I had to find him in the work. And yet everything I can do is so childishly feeble and inadequate. I feel obscurely that I could throw off this inadequacy, that Peter is somewhere in the work and I might find him. And at the same time I have the feeling that I can no longer do it. I am too shattered, weakened, drained by tears . ... I no longer have the strength to live what is written. (72)

Woefully bereft, Kollwitz sought to create her child as if for a second time, to reassemble him imaginatively, to rebirth him through rendering him artistically. Her words here resonate horror, futility, terror, the search for a beloved child who is never to be found.

While in this entry Kollwitz indicates her tentative acceptance of the precept that to create art the artist must be capable of stepping outside of her lived experience, she finds this to be an impossibility, determining that her art must reflect the love of "a 
mother who will not give up her sorrow" (72). While it is dominated by frustrated anxiety, this passage speaks to Kollwitz's progress in envisioning a fitting memorial for Peter's memory. Despite artistic creeds that state otherwise, Kollwitz recognized that her art must be infused with visceral terror and desperation, with the maternal sorrow that consumes her. The drawing she speaks of above, the drawing of a mother cradling her dead son that she hoped would bridge the distance between her and Peter, is founded upon an impossibility: catching her dead son would do nothing to mitigate the sting of death, would do nothing to put her into deeper communion with him. For she cannot comfort him as she did when he was an infant in her arms. He would be insensible to such love. In the process of discovering the implausibility of her previous conceptions for the monument, Kollwitz was losing faith in the idea of redemptive sacrifice-Peter seemed "far, far in the distance" (73).

Bereft, both Woolf and Kollwitz sought to recreate what had been lost, which Woolf was able to do somewhat satisfactorily. Perhaps this is because Woolf's memory of her mother was so dim that she could scarcely remember time spent together. Julia Stephen died before her young daughter had developed a sense of what comprises a close relationship; it was always incumbent upon a mature Woolf to half-create who her mother was and who they were together. "A Sketch of the Past" reveals that, as Woolf remembers them, even her earliest times with her mother were infused with imagination. Physical proximity was rare. Julia Stephen was known best to Woolf as the creator of the sphere that was her childhood. By contrast, Kollwitz remembers vividly bringing her son into the world and engaging in long-term practices that Sara Ruddick classifies as maternal: practices that entail preservation, nurture, and socialization (61). In short, 
losing a child is very different from losing a parent; losing a child disrupts the expected generational trajectory and leaves the parent with memory upon memory of expectation. Kollwitz could not half-create her son because she knew him intimately and participated in his development even until he made his last decision, a decision that she sanctioned. It is this last decision that consumed Kollwitz in her quest to carry out Peter's legacy, a legacy he should have been actively preparing himself.

Increasingly, Kollwitz forced herself to confront her "contradictory position on the war," begotten of her love for her son who died for a cause he deemed noble:

August 27, 1916 ... My untenably contradictory position on the war. How did I come to it? Because Peter sacrificed his life. What I saw so clearly then and what I wanted to preserve in my work now seems to be once more so dubious. I think I can keep Peter only if I do not let anyone take away from me what he taught me then. Now the war has been going on for two years and five million young men are dead, and more than that number again are miserable, their lives wrecked. Is there anything at all that can justify that?" (73)

As the humanitarian inclinations for which she is best remembered in the art world began to dismantle the self-preservative defenses she had erected for the sake of sanity, Kollwitz was assaulted with questions that could only lead her to a decisively pacifistic stance:

October 11,1916 ... This frightful insanity-the youth of Europe hurling themselves at one another ....

Peter, Erich, Richard, all have subordinated their lives to the idea of patriotism. The English, Russian and French young men have done the same. The consequence has been this terrible killing, and the impoverishment of Europe. Then shall we say that the youth in all these countries have been cheated? Has their capacity for sacrifice been exploited in order to bring on the war? Where are the guilty? Are there any? Or is everyone cheated? Has it been a case of mass madness? And when and how will the awaking take place....

The abyss has not closed. It has swallowed up millions, and it still gapes wide. And Europe, all Europe, is still like Rome, sacrificing its finest and most precious treasure- but the sacrifice has no effect. 
Is it a breach of faith with you, Peter, if I can now see only madness in the war? Peter, you died believing. Was that also true of Erich, Walter, Meir, Gottfried, Richard Noll? Or had they come to their senses and were they nevertheless forced to leap into the abyss? Was force involved? Or did they want to? Were they forced? (74)

The willingness to ask these questions, it seems, provoked the epiphany that had been germinating since the advent of the war: World War I and the nationalistic ideology that promoted it constitute an unforgiveable betrayal. For war, she concludes in a March 19, 1918 journal, is no better than a "slaughterhouse .... And Peter would still be living had it not been for this terrible betrayal. Peter and millions, many millions of other boys. All betrayed. That is why I cannot be calm. Within me all is upheaval, turmoil ... All is turbulence" (88).

Surely this turbulence was in part induced by guilt, guilt that she condoned and even played an active role in the collective betrayal. Near the end of October 1918, just days before the armistice, Kollwitz found the courage to denounce the war publically, in the form of a letter written to the Social Democratic newspaper Vorwaerts in response to poet Richard Dehmel's Sole Salvation, a manifesto calling for more able-bodied men to volunteer for the all-but-defunct German army. After exposing as a travesty calling upon young men to offer "their bare young lives," Kollwitz ends her letter with the mantra she adopted when Peter fell: "'Seed for the planting must not be ground" (89). This mantra inspired Kollwitz for the rest of her artistic career, a career devoted to the memory of her son.

In February of 1917, after working for a bit on the father for the memorial, Kollwitz was moved to have a look at the sculptural figure of Peter that she would eventually abandon for good. She had left the head of the sculpture covered, perhaps to 
spare her eyes the sight of the all-too-brute reality of her son sculpted in lifeless plaster. In the journal entry in which she describes the private unveiling, she speaks of what she saw in terms of her fixation on her children's infancies, again expressing nostalgia for the all-too-brief period in which she was able to shelter them: "Before I left I removed the cloths covering Peter's head. The head is turned to one side. The blanket still lay over the body. Emerging out of the wholly wrapped-up figure, his head looked utterly beautiful, with his serious, devout smile. Perhaps I shall do the work so that the entire body is wrapped in a blanket and only the head left free" (77). Swaddled, this Peter is safe from harm, warm, contented, secure. Yet, the swaddling symbolism that invokes the newborn nestled in blankets that shield him from the cold and from his own reflexive terror simultaneously gestures toward the cerements of burial.

Sculpting her representation of Peter carried Kollwitz to an intimate understanding of the most frightening irony of living to which the terrified infant seems to be periodically attuned - to be born is to be ushered into death. As Barthes astutely reveals the photograph to be a premonition of death, so Kollwitz reveals the state of the newborn to be the same. While Kollwitz was surely drawn to the idea of a blanketed Peter in her desire to recapture and preserve the early moments of his life that were not overtly shrouded in death, moments ripe with becoming, she ultimately was unable to do so. For she recognized in the primal helplessness of infancy a figuration of the existential helplessness of humankind, a dark view of life that was surely induced by the death that enshrouded her world. Kollwitz began to see what she longed to preserve as an impossibility, which is surely one reason she eventually deemed unfit including the image of Peter in the monument to be installed in the cemetery at Roggevelde. 
Only a few days after her consideration of a blanketed Peter, Kollwitz set about shaping the mother. Her description of that work in her diary from February 9, 1917 proves particularly illuminative of the extent to which rendering the mother in threedimensional form was true soul work for her, the grieving mother on whom her sculpture is modeled. Of particular import is the physicality entailed in attempting to set the figure right. That she was compelled to saw off the head and place it "experimentally in an entirely different position" is telling—surely the act of dismembering this reproduction of herself was an excruciating evaluation of her own mindset regarding Peter's death, her role in his life, and the extent to which his life was taken in vain. The severed head is also emblematic of the tolls pervasive death took on her psyche and the psyches of the millions bound in its coils. Kollwitz's subsequent comments about this process of reconstituting the mother suggest an intuitive awareness that the transformation would be lengthy because it is infinitely more than simply working with clay: "Possibly what I said will come about-that by continuing to work on the plaster I shall be able to raise myself above the average in one spot first and then, sticking to that, gradually pull up the other parts of the work. Climbing like a snail, creeping, taking the tiniest steps, but at least going upward" (77). Rendering the mother functioned to guide her in pulling herself out of the dregs of depression toward a more proactive appropriation of her grief, an appropriation that allowed her to reach outward even in the midst of an irresistible urge to withdraw.

Kollwitz's battle with loss continued to devastate her during the teens and twenties, yet her characteristic humanitarianism shines through even the darkest periods. This humanitarianism manifested itself in her deep concern for the working class that she 
translated into works of art, in her concern that her art be accessible to the "average spectator," in her insistence that "art for the average spectator need not be shallow," and in her determination to continue to create in order to "help the ascent of man" $(68,81)$. The War series is a culmination of her appropriation of the shards begotten of loss to create something of enduring meaning for humanity, a disturbingly poignant exploration of how the destructive drives of nationalism poison the most wholesome of human relations. Likewise, The Mourning Parents was designed to stem the hemorrhaging sorrow that afflicted nearly every German family in one way or another. Her offering to Peter was created not only with Peter in mind, but with the countless young boys who lost their futures. In the life she led outside of her art studio, these humanistic energies were directed toward Hans, his wife, and his children, as well as toward Peter's surviving friends who found themselves disoriented and without direction in a war-torn world. To these young men Kollwitz became something of a surrogate mother, a role she assumed most devoutly, for, as she expresses to Hans in a letter dated September 1916, "It seems to me nowadays that the most important task for someone who is aging is to spread love and warmth wherever possible. Life is so terribly hard now" (151).

Kollwitz did not deem sharing her maternity with those in need as mere obligation - as has been demonstrated, this aspect of her personality functioned as an expression of her creativity. In February of 1917, still in the throes of relatively raw grief, she related in her diary a most romantic daydream of what, at its best, her old age might consist:

At some pretty place nearby - say, Ferch-Karl and I will have a cottage with a garden, a small potato field, at least one dog. We will work in the garden and each of us will go about his own pursuits. Karl will do scientific research and I, as far as I am still able, small sculptures and 
drawings. Above all we will live in nature and will have with us a few children whom we will take from the city for the whole long summer. City children. They will go to the village school and play about in the open, learn to swim, to row, and so on. If they could be our own grandchildren-how wonderful that would be. But if not, then strangers' children .... Faithful old Lina would take care of the household; some nice girl — we know many of them - would be in charge of the children. Four or five children, I think. That would be a lovely life. (79)

Kollwitz's dream of her ideal future restores what she believed to be the fundamental beauties molested by war-the simplicity of a bucolic life, companionship, the freedom to pursue one's interests leisurely, the innocent joys of childhood. Hers is a dream of a world without war, of a world in which one need not be constantly projected into a reality of shelling and gunfire. Hers is an idyllic world of yesteryear, the sphere of her children's carefree childhoods unencumbered by predatory reality. Hers is a Bachelardian paradise. Were it not Kollwitz relating this utopic fantasy, one might accuse her of insidious amnesia. She should not be chastised, however, for her restorative nostalgia for an unscathed home, a home, a childhood, of which she had never seen the likes. Indeed, Kollwitz's daydream is not without an insistent devotion to nurturing others, for she conceives of her ideal existence as one in which she is provided with the opportunity to continue to exercise her humanitarian energies—only without desperation. These energies are, for lack of a better word, maternal, as is evidenced in the ubiquitous mothers and children in the War woodcuts, in the behaviors she exhibited toward others, in the monument she sought to create for Peter, and in her fantasy.

In Kollwitz's early conception of Peter's memorial in which the young children's procession to its dedication symbolizes her and Karl's surrogate parenthood, Peter lies above the parents, which, as is suggested above, signifies an allegiance to the ideal of sacrificial heroism. By July 1917, however, Kollwitz speaks of a relief carved with the 
images of only the parents to be installed at the site of Peter's grave. Eventually this relief evolved into The Mourning Parents. As she articulates it, she came to this vision of the monument when Karl expressed a desire for a gravestone for Peter. After considering the relief of the parents as suiting the purpose, she "realized that this relief would be appropriate for the whole cemetery. It belongs up front at the entrance. A square stone, a relief cut into the face. Life size. Below or above it: Here lies German youth. Or: Here lie Germany's finest young men. Or: Here lie the youthful dead. Or simply: Here lie the young. It seems to me I must carry this out. God grant I keep my health until it is done for Peter and the others" (82-83). Evincing Kollwitz's recognition of the transformative power of translating her private grief into something that will speak to and for silenced others, this change in conception illuminates her healing process as bound in her love for her world.

Each possibility for the inscription emphasizes the travesty of lives cut woefully short. While the first two are Germany-specific, with the second bordering on potential support for sacrificial heroism, depending on how one interprets it, the latter two proclaim the travesty of the correlation of death and youth. The last, it seems, is the most poignant, as it speaks in bare terms what the war has wrought—innocence, beauty, and possibility have been consigned to the realm of the dead, their vitality snuffed. They lie in the ground in a state of decomposition. The term "young" is significantly more inclusive than "youth," "young men," and "youthful dead." The young are comprised of girls and boys whose ages span infancy to early adulthood. And the life-size parentsread Karl and Käthe--who survey the cemetery become the parents of all the young whose lives and innocence have been betrayed. These parents who are all parents assume 
the cares of the world, though they can do nothing to ameliorate them except remain there as testaments to loss. Even this requires the intervention of the mother, the artist.

After contemplating and experimenting with the memorial for a good five years, a frustrated Kollwitz abandoned it in June 1919:

With what firm faith I set to work, and now I am stopping. As I stood up on the scaffold beside Peter and saw his sweet, smiling face, his air of devotion, and then thought of all the time I had worked, of all the love and aspiration, all the tears that are frozen into that work, I promised him again: I will come back, I shall do this work for you, for you and the others. It is only postponed. But the promise no longer has its old intensity....

As I kissed Peter's face and bade good-bye to the work, I thought of Germany. For Germany's cause was his cause, and Germany's cause is lost now as my work is lost. No, not really lost. If I am permitted to live and see Peter's work done and done well, commemorating him and his friends in some beautiful place- then perhaps that will signify that Germany too has passed out of the most difficult time. (93)

Her motivation in ceasing her work on the memorial is somewhat opaque. Jay Winter suggests that The Mourning Parents was so long in the making because, as a member of the older generation, Kollwitz faced her own culpability for "failure to find a better way, . .. failure to prevent the madness of war from cutting short his life" (Great War 391). The unforgiveable ramifications of such an error demand an apology on a level that is inconceivable-perhaps aborting the project for a good many years was necessary to allow her to ruminate on what would constitute a fitting, if not adequate, apology for her implication in conspiring in a world that could come to World War. Her initial allegiance to the rhetoric of sacrifice for the nation certainly suggests Winter's argument as keen, as does the soul-searching that fills her diary. Even outside the context of War, a parent who loses a child to death inevitably suffers guilt because the unnatural has happenedthe parent has outlived the being entrusted her for preservation. 
Kollwitz was mentally exhausted from all that had transpired in the previous five years. How was she to express the gravity of her loss without trivializing it? Her inability to proceed reflects ambivalence toward closing this chapter in her life, the sense that finishing this "offering" would somehow constitute amnesia—precisely the opposite of how she intended her memorial to function. Ironically, the process in which she engaged passionately for those five years, the goal of which was to create an aesthetic object that would testify to the emptiness begotten of war, threatened to diminish both personal and collective anguish in its final, material form, threatened to hasten forgetting. Kollwitz astutely surmised the forgetting implicit in relegating Peter to an historical site, that completion threatened to be synonymous with betrayal. The idea of the forgetting inherent in the monument's short term role as means to healing proved terrifying, for healing implies letting go. Though unscathed by guilt, Woolf likewise suggests that healing inevitably entails forgetting. In "A Sketch of the Past," when Woolf proclaims the process of writing To the Lighthouse therapeutic, she cites as evidence the fact that intrusive memories of her mother no longer plague her. Of course, the fact that Woolf was still finding her mother through the process of writing "A Sketch of the Past" affirms that she had not let go, that, if healing is forgetting, then she had not healed.

Kollwitz's struggle with the ethics of memory was symptomatic of her time, and ours: inauthenticity of memory is intrinsic to modernity. In Realms of Memory, Pierre Nora exposes modernity as "a turning point in which a sense of rupture with the past is inextricably bound up with a sense that a rift has occurred in memory. But that rift has stirred memory sufficiently to raise the question of its embodiment: there are sites, lieux de memoire, in which a residual sense of continuity remains. Lieux de memoire exist 
because there are no longer any milieux de memoire, settings in which memory is a real part of everyday experience" (1). As discussed in the first chapter in reference to Durkheim, Tönnies, Simmel, and Weber, modernity's dismantling of communal tradition and ritual resulted in a pandemic of alienation. In a cultural climate such as Kollwitz's, where communal and familial ties had been worn by an interpenetration of an accelerated pace of living and the cataclysm of war, memory was severely compromised. Despite the fact that the European powers entered the war with the supposed agenda of protecting age-old values, obliterative warfare was an exponential expansion of what had already been at play-an erosion of traditional communal values in favor of mechanization and acceleration. From its inception, this erosion necessarily preyed upon memory, and what had been authentic became formulaic.

As Nora explains, the 'acceleration of history' ... brings us face to face with the enormous distance that separates real memory-the kind of inviolate social memory that primitive and archaic societies embodied, and whose secret died with them-from history, which is how modern societies organize a past they are condemned to forget because they are driven by change; the distance between an integrated memory, all-powerful, sweeping, un-self-conscious, and inherently present-minded-a memory without a past that eternally recycles heritage, relegating ancestral yesterdays to the undifferentiated time of heroes, inceptions, and myth - and our form of memory, which is nothing but history, a matter of sifting and sorting. (2)

Kollwitz's nostalgia for Hans's and Peter's childhoods was nostalgia for a society and home in which the maternal values of love, nurture, and connectivity triumph, a world much like the world that Mrs. Ramsay attempts to create in To the Lighthouse. Aware of what was at stake, aware that solidifying Peter would be but a counterproductive attempt to eternalize him, Kollwitz was perplexed. If Nora's theory holds, committing Peter to stone would be equivalent to committing him to a realm of inauthentic historicist 
commodification. Kollwitz's challenge was to balance what she perceived to be personal and collective emotional needs with the awareness that doing her part to fulfill those needs would necessarily render Peter more distant. Ultimately, of course, it is not the sculptural rendition of Peter that stands in the cemetery where Peter's remains are buried. It is the rendition of his parents who abide there to testify to the ineffable. Embodying the parents in stone communicates something wholly different from appropriating the lost child for such a form.

While Kollwitz claimed to have abandoned her "big work" in June 1919, such a claim was self-critically overstated, for all of the work she undertook between 1914 and 1931 served to subsidize what would become The Mourning Parents. In November 1917, she indicates that she has executed innovative sketches for the cemetery relief of the parents. However, her intent to create a relief was soon eclipsed by her investment in depicting the subject matter to the best possible effect. In an entry from November 7 , she expresses her conundrum: "It must not be realistic, and yet it cannot be anything but the human form we know. Inventing a form as Krauskopf does is impossible for me; I am no expressionist in that sense. So there remains for me only the familiar human form, but it must be thoroughly distilled" (85). Though she does not articulate it here, this sketch and the same subject executed in sculptural and graphic media have everything to do with her memorial to Peter, for she seeks to capture in these parents "simplicity in feeling, but ... the totality of grief," something that will characterize The Mourning Parents memorial (87). Kollwitz's commitment to extracting all but the essential qualities of parents in mourning reflects a desire to universalize the image, which makes it, among other things, amenable to her goal of speaking to the ordinary person. This 
universalization is also notable in its defiance of nationalism-Kollwitz seeks to capture not simply grieving German parents, but all parents in the throes of a grief begotten of war. Kollwitz's imperative to communicate parental grief was symptomatic of a more expansive vision that eventually became a reality-the War graphic cycle of 1922-1923.

War was executed in woodcut form in 1922-23, though Kollwitz was contemplating its individual images as early as 1914:

[1918] I have jumped ... into a work which probably since 1914 has been hanging heavy in my mind .... Until now there are only drawings. Shown them to no one. Drawn with tears. Besides the fact that I had not thought about making prints in the next years, there are two other reasons why I always put off the plan. First, the fear of what has been experienced so deeply, to get over the feelings from those years, and then the feeling of the tediousness of studio work, compared to life, this life and death. (Käthe Kollwitz Museum Koln)

Confirming that one factor in Kollwitz's temporary discontinuation of the memorial was the sense that completing the project is equivalent to forgetting, here Kollwitz communicates the conviction that studio work might paradoxically detach her from the crisis at hand. In 1918, however, Kollwitz faced her fears to her personal benefit and to the benefit of her world.

Completing War as a cycle enabled her to plumb the depths of a broad spectrum of psychological and social dysfunction induced by World War I. The cycle format was not innovative - since the late-nineteenth century, German artists had found it a viable means to study thoroughly subjects of enhanced cultural import. Indeed, a number of other German war cycles were created during the period when Kollwitz executed hers (Prelinger 56). Kollwitz's, however, is distinctive among these cycles. Elizabeth Prelinger maintains that 'Kollwitz' work is unique because it includes no scenes of combat or of material devastation. Rather, it presents the phenomenon of war entirely 
from the perspective of the home front, of mothers and children in particular, and may in a sense be interpreted as a study of the notion of sacrifice" (57). Coming into the public eye years after the war officially ended, the cycle exposes war as continuing to maim Europe through permanently insinuating itself into individual psyches, individual families, into the very notion of home.

Arguing that Kollwitz's moral testimony has been too often minimized by readings that reduce her to "a sorrowing woman who found consolation in-and offers consolation through - her art," Ingrid Sharp situates Kollwitz as a moral witness whose contribution to our understanding of World War I is invaluable (101). She explains that Kollwitz's unique perspective on the war has been devalued because hers is not a message from the battlefield, and that such devaluation skews our understanding of the comprehensive effects of war:

Our cultural memory of World War I is shaped to a great extent by artistic and literary representation in which personal testimony occupies a central place. It therefore matters a great deal if key pieces of the mosaic are omitted, misread, overlooked, or suppressed, or if anachronistic layers of interpretations and assumptions obscure the freshness and authenticity of what the artist is struggling to convey. If these cultural representations are limited to the combat experience of - and often by and for-'the men who were there,' we are left with a distorted and partial understanding of the experience and significance of war-what it was, how it felt, and how it affected those who experienced it. (102)

Reducing Kollwitz to a conveyer of private pain obscures her as a prophetic, incisive voice whose exposure of enduring violence "at home" is at least as vital as voices from the center of military action. In particular, Sharp compares Kollwitz's reception to that of Otto Dix, whose The War (Der War) cycle of 1923-24 is deemed the epitome of authentic anti-war testimony because it is based upon Dix's experience in the line of fire. Kollwitz's universalization of private pain opens the pages on a hushed 
subject - the permanent effects of war on those who are christened "non-heroic"women and children. Failure to recognize her account as integral to the mosaic of World War I testimony is a failure to acknowledge that though the perils of war may seem most pronounced on the battlefield, they penetrate at least as deeply "at home."

In these woodcuts Kollwitz transposes the emotional rawness of her private pain to a collaboration with fellow sufferers that communicates shared pain. Begotten of a primary wound, Kollwitz's War reaches from within the shattered self to garner community from others mired in an all-too-human predicament that threatens to sever one from another. In this way, War is multivalent, simultaneously a universal account of suffering and a variegated stroke of tragedy that mitigates isolation through being observed (and created). It is a sobering insistence upon the perpetuity of the pain of war, a prophetic warning. Yet it is also an affirmation of meaning, conveyed through the representation of meaning, of becoming, in a state of violation. Only the facts that Kollwitz was able to create these images from within the abyss and that they are and were shared with others exudes hope.

In contrast to Woolf's To the Lighthouse and "A Sketch of the Past," Kollwitz's War-like her primal images Pietà, Mother with Dead Child, and Woman and Death-is denuded of place, lacking consolatory mooring. War's figures inhabit featureless foregrounds that assert the desperation of their positions. In each of the cycle's images except The Sacrifice (Das Opfer) (fig. 5) and The Volunteers (Die Freiwilligen) (fig. 6), the figures' desperation is reinforced by a lack of distinguishable background. These victims simply are. Elizabeth Prelinger maintains that War's simplicity furthers Kollwitz's ability to speak a universal language: "Everything is expression, gesture, and 
iconic form. In keeping with her wish that the series should travel the world with its message, Kollwitz adopted a stark black and white language of signs that would be universally understood. They are unencumbered by particulars that would restrict them to a specific time or place" (59). Through the utter starkness of the reality exuded in the cycle, Kollwitz communicates that these casualties of war are without a home. While the diaries frequently invoke a common weave uniting belonging in space and time, motherhood, and creativity, this multi-faceted strength is entirely absent in War-here home is conjured only through the representation of what it is not, and the strength of maternity, when present, is begotten of desperation. While all of War's images except The Volunteers pivot on the mother-child relationship as foundational, the relationship is disturbed, dire-neither mother nor child thrive in the homeless state. Through the portrayal of dysfunctional mother-child relations, Kollwitz effectively captures the deeply-rooted physical and emotional traumas that afflicted nearly every European family during and after the war.

Erin Hogan explains the woodcut form as acutely suited to War's subject matter, as "a natural medium to depict these two expressive subjects [death and war]. Woodcut is perhaps the most physical and basic of the print technique; images are formed by literally gouging a block of wood, incising the block with line and planes. Forms can be drastically simplified to the point of abstraction, and if a unity of form is desired, it is easily accomplished as the forms are initially of the same piece" (Heller et al. 58). The physicality entailed in preparing the woodcut for a psychologically-wrenching project such as War is more fitting than the processes of lithography or etching; perhaps Kollwitz experienced gouging the wood as something akin to striking back at the destructive 
forces that brought a culture to its knees in agony, to allowing herself to experience visceral fury and to excise that fury constructively. Kollwitz found etched and lithographed versions of the War prints lacking, failing to communicate the rawness she wished to portray. Through the woodcut medium Kollwitz is able to accomplish just what her diaries indicate she seeks—unadulterated "expression" (98).

The first two images from War, The Sacrifice (fig. 5) and The Volunteers (fig. 6), serve to contextualize the five images that follow, illustrating the precursors to the afflictions chronicled in The Parents (Die Eltern) (fig. 7); The Widow, I (Die Witwe I) (fig. 8); The Widow, II (Die Witwe II) (fig. 9); The Mothers (Die Mütter) (fig. 10); and The People (Das Volk) (fig. 11). These initial sheets illuminate what Kollwitz herself was prey to at the onset of war-the seductive lure of the ideology of sacrificial heroism discussed earlier. In The Sacrifice, a mother reluctantly but willingly offers her child to the cause, a cause she has been conditioned to understand as haloed in sacredness. A rainbow of light illumines the bodies of mother and child, yet something fundamentally discordant inhabits a scene in which the mother raises her infant to be subsumed by that which has been extoled as sacred while she lovingly cradles him in the crook of her arm. Incapable of holding up his own head in conscious acquiescence, the child depends upon his mother, here literalized in the fact that the mother supports her newborn's neck. Sleeping contentedly in the fetal position, the newborn lies in a simulation of the maternal womb, unaware of the cause for which he has been destined. Like the ball turret gunner of Randall Jarrell's poem, he will soon fall from his "mothers' sleep into the State." Previously sheltered in a protective cloak that has been disturbed by the bellicosity of the land in which she and her child make their home, the mother is 
vulnerable, naked, blinded by an irresistible, piercing light that purports to be a force for good. Masklike, her face reflects both the fact that she has been inculcated with the lie and the sorrow that she feels nonetheless. Her worry-scarred visage appears to be caving in to expose the state to which she and her son will be reduced-literal and metaphysical death.

The Volunteers (fig. 6) proceeds directly from The Sacrifice, with the helpless infant now a helpless young man swept up in a mass procession to war, which is, the skeleton leading the procession makes clear, a procession to death. Significantly broadened, the illumined halo of sacrifice is present though tenuous, suggesting that though the perils of sacrifice are now becoming visible, those destined as victims are helpless to resist the juggernaut that propels them. As the central figure, the now-grown infant from The Sacrifice directs the viewer's gaze toward him, and, as in the first image, he remains incapable of supporting his own head. Bent backward, this soldier's neck appears to be broken, rendered brittle by the unwholesome environment in which he has come of age that has denied the development of creativity and of the will to dissent. Shards of light that seem representative of holiness in The Sacrifice connote fire in The Volunteers. Rough-stroked brightness fans the figures as they proceed-the frenzy of nationalism has been converted to encompassing conflagration.

Only the figure behind the grown young man at the center resists, crying out in pain, in prescience of what is to come. Expressing hope in the midst of this mass blindness, Kollwitz features prominently the supportive hands of comrades who seek to bolster him. As Antonina Gove insightfully demonstrates, however, "[i]n the context of death and grief, as Kollwitz draws and sculpts them, hands, which often are the 
instruments of human action and creativity as well as of love and intimacy in touching and holding, are seen as objects of empty helplessness and mute suffering" (165). Our hero is sleeping, already dead to the world before his seed has been sown. But perhaps he is vaguely aware that his brothers are reaching out in love in these last hours, incapable though they are of resisting the course of events.

A mother whose impressionability led her to offer her son in the name of the triumph of the State, Kollwitz identified with the vulnerable mother of The Sacrifice who bequeathed vulnerability to her son. Given the numerous references in her diaries and letters to Peter as infant, surely Peter is the literal and figurative infant in both The Sacrifice and The Volunteers. What follows in the cycle are variations on the theme, explorations of how the ideal of heroic sacrifice in action occludes primary relationships, most notably that of mother and child. Through this visual narrative Kollwitz is able to transform her disenfranchised hands that are not unlike those in many of her images into life-dispensing organs of social justice, though this necessarily entails the omission of images of maternal bliss.

Among the most self-reflective of Kollwitz's images, The Parents (fig. 7) not only pictures parental sorrow, but it represents Kollwitz's attempt to comprehend the permanent impact of grief upon those who unwittingly relinquish their child to a treacherous cause. As is discussed extensively above, the task of representing her subjectivity such that it constitutes an offering to the absent child was anything but straightforward for Kollwitz. Anguished reflections on the theme throughout her diaries speak to how essential it was to understanding herself as the mother of a deceased son and to formulating a path for her life that would allow her to engage her wounded self in 
a cause that would remediate both that self and the world that inflicted the wound.

Through The Parents, she posits exposing parental powerlessness in the wake of death as an essential form of truth-telling, for though she diligently and soulfully created in the name of Peter to promote peace through War, Kollwitz was under no illusions concerning the regenerative capacity of her art and works to portray that insistently through these images. Not even the most concentrated of creative endeavors can bring back her lost son or achieve satisfactory reparation, though they can, she was convinced, further the establishment of a world order in which the desire for such reparation is obsolete, a world in which sons and daughters are no longer incorporated into a grand betrayal.

In this woodcut, the identity of neither father nor mother is distinguishable-grief has rubbed identifying characteristics bare. Each has become the sorrow that they share, and in that they are united. Though the lines that comprise each figure intersect to the extent that personal boundaries merge at times, the fact remains that sorrow isolates each from the other. The father does support the hunched mother in the crook of his arm -not unlike the mother does for the son in The Sacrifice-but her curved posture indicates that she is turned inward, that her reality is the interior void, the sorrow of having lost. Like the son in the previous two images, the mother is too weak to support her own head; her helplessness has induced in her a regression into veritable infancy. It is too late to ameliorate her son's circumstances, too late to protect him.

Suggesting both metaphorical amputation and the extraneousness of that which is fundamental to contributing to one's own, others', and the world's well-being, the nurturing hands of motherhood have been severed from visibility, her instruments of creativity paralyzed. As for the oversized, protective hands of the father, they are 
engaged somewhat futilely in the attempt to support his inconsolable spouse and to stanch the grief in which he himself is drowning. His hands shield his eyes from the existence of a world in which the child no longer exists, a reality neither father nor mother can quite face directly. The Parents poignantly illustrates the aloneness within togetherness that is parental grief and offers the only consolation suitable-the consolation of a shared but not identical burden.

This work likewise probes the effect of mutual loss on Kollwitz's own marriage. Throughout the diaries, Kollwitz expresses awe in the face of Karl's "stock of love and kindness [which] is inexhaustible" (61). She praises her husband's capacity for goodness, his love for his patients, their love for him, his foundational innocence that enables him to live joyously. Yet, she also expresses her deep-seated conviction that they will never reach what Karl believed to be the "sole worthwhile goal of . . long living together-[growing] together in the deepest intimacy" (59). All of her work on The Parents and the memorial to Peter incorporates her contemplation of the effect of grief on their marital relationship, and indeed it was through grief that she felt they achieved an enhanced level of mutuality. She took comfort in the fact that Karl stood steadfastly by her side, that though her transaction with life was much more topsy-turvy, they shared something foundational.

A touching letter to Karl on their silver wedding anniversary in 1916 captures best her sense of their relationship:

When we married, we took a leap in the dark. We were not building upon a firm foundation, or at least one firmly believed in. There were grave contradictions in my own feelings. Mother, who realized all that and was often worried, once said to me: 'You will never be without Karl's love.' That has been true. I have never been without your love, and because of it we are now so firmly linked after twenty-five years .... I thank you for 
all you have given me out of your love and kindness. The tree of our marriage has grown slowly, somewhat crookedly, often with difficulty. But it has not perished. The slender seedling has become a tree after all, and it is healthy at the core. It bore two lovely, supremely beautiful fruits . ...

I am thankful to the fate which gave us our children and in them such inexpressible happiness.

If Hans is let live, we shall be able to see his further development, and perhaps we may expect children of his. If he too is taken, then all the sunlight that out of him lighted, warmed and made everything golden will be smothered; but we shall still hold tight to one another's hands to the end, and remain heart to heart.

Your Kaethe. (70-71)

Refraining from sentimentality, Kollwitz's account of love and marriage acknowledges the difficulty of straining for an ideal of enduring intimacy. Despite marital trials, the profundity of Karl's love and their shared sense of joy in their children united them. That joy was all the more poignant after Peter's death, the beauty, rendered bittersweet, all the more evident after having lost it, which is, after all, something Kollwitz strove to communicate in her studies of The Parents and The Mourning Parents. As will be demonstrated in the culminating discussion of The Mourning Parents, Käthe and Karl achieved the epitome of their closeness only in standing at Peter's burial site, contemplating themselves in their mutual but separate grief, a grief that is rendered more intrinsically lonely in The Mourning Parents than in the woodcut The Parents.

It is the absence of marital support that Kollwitz considers in War's next two images, The Widow, I (fig. 8) and The Widow, II (fig. 9). In representing the bereaved wife, she deviates from first-hand experience to inhabit the psyche of one experiencing a different sort of grief from hers, grief over the loss of the father of one's unborn child. Given her description of her own marriage, one might conjecture that Kollwitz conceived of spousal grief in terms of the loss of a companion with whom to create a home, the loss 
of a helpmate to offer material and emotional support in the grievous times of which life is inevitably comprised. Of particular importance in the first image of The Widow is the woman's suggested pregnancy that situates her not only as a bereaved wife, but also as a mother whose child will be born into a world of death and violence. Enshrouded in a black mourning garment that obscures her body, the widow, like the baby in The Sacrifice, the soldier in The Volunteers, and the mother in The Parents, is weakened by the weight of such a world-her head, like that of the others, droops. Kollwitz's signature oversized hands dominate this picture, protecting the widow's heart and the womb in which her unborn child is as of yet shielded from the outside. Despite her commitment to nurture, this child is already doomed for a premature fall into life's dark reality - the thickened, black lines of the mother's face foreshadow an early death. The ideal of creative maternity that inhabits Kollwitz's journals is obstructed in this woman's existence- - hers is a reality in which war widows are without support, without companionship, without a means of thriving. The becoming of which both pregnancy and infancy are symbolic is destined for violation.

As was foretold in the previous image, the woman in The Widow, II is dead. Along with its precursor, this woodcut exemplifies the social commentary for which Kollwitz is best known. This mother did not die from grief alone, but from a combination of grief and a complete lack of hope that society would be conducive to her and her child's flourishing. Darkness weighs heavily in this scene: the black background merges with black in the foreground to assert the impossibility of escaping the abyss into which the living fall. Indeed, the deceased woman's body is integrated into the darkness to the extent that one cannot distinguish her from her bleak surroundings. What results is 
a pervasive sense of fragmentation and distortion—a seemingly-severed head, disfigured arms, a body in an unnatural posture, and the familiar broken neck of the first five $\mathrm{War}$ images. Draped over the mother's breast, the child lies peacefully in an eternal sleep where being parted from the protective mother need never be faced. Both have died a common death, the only positive element of the widow's existence. Her protective hands, it seems, patted the child until the end.

In contrast to The Parents, The Widow, I, and The Widow, II, The Mothers (fig. 10) represents safety in numbers. Here the mass deification of sacrifice has been transformed into a formidable fortress of determined mothers uniting to protect the vulnerable. The lack of distinguishable bodily boundaries communicates the truth Kollwitz wished to relay, the value of affiliation inherent in maternal practice as preservative. Affiliation is such in this group that, while four children appear to be visible, the viewer remains uncertain of both their number and the mother to whom each child "belongs." Through The Mothers, Kollwitz exhorts that only non-exclusive, consciously-engaged connectivity such as this promises to dismantle the pervasive culture of death. In that way, this image in particular resonates with the universalizing simplicity of the War cycle through which Kollwitz seeks to build connection that undermines chauvinistic loyalties. The sheet's dominant darkness is disturbed only by faces and hands that ensure the solidarity of those committed to the preservation of life, and by the ends of what might be taken as a bright white scarf at the center that invoke an invisible but substantial band binding each to each. This central brightness communicates hope, though this hope is admittedly precarious. 
The whiteness might also be interpreted as the garment of the center-most child, in which case exposure gestures toward a purity soon to be violated. Their frightened gazes scanning the shared circumference vigilantly in the determination to stave off stalking predators, the mothers are reduced to atavistic defensiveness. Their children, in turn, lack the carefree innocence ideally accorded the young; terrified, they cling to their mothers while peeking out at the antagonistic world that lies beyond the protective bodies that surround them. While Kollwitz's signature hands are rendered somewhat impotent in the cycle's other sheets, in The Mothers they actively protect, actively nurture, actively reinforce to ensure that the circle remains unbroken. Undertaken in the direst of circumstances, this concert of nurture must not cease for an instant. So adamant was Kollwitz in the veracity of this image that she reworked it in sculptural form some fifteen years later, when the energies of war were once more fomenting. Entitled Tower of Mothers (fig. 13), it brings to fruition the woodcut medium's "sculptural nature," and, through doing so, enhances The Mothers verisimilitude (Prelinger 63).

The last of the War sheets, The People (fig. 11) is inhabited by a swath of society reduced to terror, rage, and anxiety. Like the children in the previous sheet who gaze uneasily upon the world that surrounds them, three of the figures in this image stare ahead in frightened anticipation of what lies ahead. Once more Kollwitz speaks eloquently the language of iconography - the people in this woodcut are little more than skulls endowed with emotion. They are everymen and everywomen stripped of their humanity. Particularly disturbing is a face to the central figure's left; unsexed, lupine, this being seems to have lost his or her bearings, seems to be on the brink of attacking his or her own. Meanwhile, the figure to the right of the central figure covers his mouth in 
desperation, barely able to suppress the screams and sobs that threaten to issue forth. The people, then, have been terrorized by war, and as their present affords them little nurture, little hope, the future remains bleak.

However, the central figure, the figure toward whom viewers' eyes are drawn, tells a different story. With her Kollwitzian visage, she is a model of stoicism, a model of resolve, staring confidently at what lies ahead in apparent determination to confront boldly all that threatens. Looking out from her black robe is the inquisitive face of a child, who, unlike those surrounding her, exhibits relative calm. For shielding this child is a Kollwitzian hand offering assurance of unswerving protection. Most notable in the image is the contrast-between the people who are lost and the mother and the child she is protecting. Through this maternal icon Kollwitz proposes a force that will work to heal the wounds, a fierce force who will face unafraid the darkness and demons that advance upon her. The fact that Kollwitz endows this figure with her own face reflects her belief in the artist as capable of nurturing the dying society back to health, her alignment of maternity, art, and becoming. In both The People and The Mothers, Kollwitz promotes maternal strength and poise to counter the deadly poisons of war and alienation. Never absent from her considerations of ideal motherhood, creativity is likewise lauded as a route to liberation, for the mother will fight the powers of mass annihilation through taking what comes her way, one obstacle at a time, and modeling her responses on what she perceives to be necessary. To combat dehumanization, she will mother.

Such is the conclusion Kollwitz comes to in her quest for meaning that will remediate the darkness of the period in which she lives. Her determination to create art that resonates with everyday victims, and the fruition of this determination, the War 
cycle, attest to her conviction that the artist plays an active, vital role in forming a world in which, using Grace Jantzen's terminology, "natals" flourish. Though Kollwitz's most recognized prints are peopled by mothers and their children, natals are not confined to the jeopardized young who inhabit her works. Rather, to Kollwitz, natality encompasses all-infants and children, men and women, mothers and fathers. Kollwitz's The Mothers and The People posit connectivity and nurture as the foundations of a healthy world and argue explicitly that if these core values were reverenced as they should be, war would not exist. Kollwitz insists, that is, upon the deprivatization of mothering practices as incumbent if the world is to be inhabitable-her matriarchal ideal demands from everyone an embodiment of mothering.

Despite the recognition afforded her visionary War series, Kollwitz continued to be haunted by the well of emptiness that occupied her and countless European families in the wake of the First World War. Struggling to comprehend the void, she returned to her work on the memorial in 1924, plagued by her as of yet unresolved commitment to create a meaningful legacy for Peter in the form of a monument, plagued by her uncertainty regarding how to mother the dead. On January 11, 1924, Kollwitz writes that in "accidentally uncover[ing] the head of the mother on the fireplace," she looked upon the sculptural work for the monument for the first time in years (106). Rejuvenated by her recent artistic productivity and critical acclaim, and by the joy granted her by her three grandchildren, Peter, Jutta, and Joerdis, Kollwitz finally felt herself ready to embark upon the completion of her beloved sculptural work.

Attributing a necessary change in conception to the fact that she is in physical decline - though she was only fifty-seven and would live for another twenty-one years- 
she contemplates a monument picturing only the parents. Not even a remnant of her adherence to the ideology of heroism is present - the War series, it seems, proved effectively purgative. The absence of a physical representation of Peter in the memorial evidences her retreat from her former romanticism — the mental and physical labor involved in the creation of War clearly allowed her to excise a good many of her psychological demons. War constitutes Kollwitz's journey of understanding her own view of war, her culpability in her son's death, and the forces she believed will prevent a recurrence of such horror, such loss. Though War had proven significantly therapeutic, returning to the monument confirmed for Kollwitz that her introspective journey was just beginning. An excerpt from Kollwitz's diary from January 11, 1924 illustrates convincingly the role of journaling in her artistic and healing processes as she sought a worthy form for Peter's memorial:

I have the idea of a large entrance gate to the cemetery in Roggevelde. To either side, on the right and the left, kneel the parents. Larger than life size. Above this the text: Here lie the finest of Germany's youth. Or: Here lies the flower of youth. The figures would be conceived as figures in high relief. Simpler and more cohesive than they are now. They let visitors pass through them. Or perhaps not relief. But very much larger than life. In that case the figures must affect contour. Or without gates. Only the blocklike figures, Egyptian in size, between which the visitors would pass. Perhaps that would be the really beautiful way. The words, 'Here lie the finest of Germany's youth,' could be cut into the floor between the figures. That would bring out the tremendous gravity of it. (106-107)

Illustrative of the diary genre as conducive to straining with ideas of psychological depth, Kollwitz's contemplative creativity comes to life on the page. The entry is remarkable in demonstrating her deliberate quest for a form suiting the task: she ponders relief, then three-dimensional sculpture, the presence of a gate, then the lack of a gate, an inscription above the figures, then an inscription in the floor. Though she does not expand on them 
here, it is quite clear that her design choices do not merely pivot on practicality, but are driven by the psychological necessity of expressing effectively the inextricability of personal grief and that of the larger culture's, the ineffability of mourning. Above all, Kollwitz wished to honor Peter through speaking his absence.

A memorial gate would require visitors to pass through the auspices of the prayerful Kollwitz parents, who in their outward-facing posture appear to be one with their bereft world. Because the parents' larger-than-life size insinuates a capacity to absorb the grief of others, entering the cemetery would signify being ushered formally into the human community of the grieving, and into healing. Already Kollwitz expresses tentative doubt that the relief would communicate adequately the multidimensionality of suffering: dismissing the relief form almost as soon as she has introduced it, she envisions large statuary parents. Unlike the parents in her War cycle, the parents in both conceptions of the memorial described above are separated by space that is more demonstrative of the loneliness of grief than the separateness within togetherness depicted in The Parents woodcut. In addition to signifying distance, this literal gap between mother and father alludes to what is not there, and through doing so expresses permanent scarring. The parents can never replace the infinitely irreplaceable child. Their relationship will always bear the burden of the child who is no longer living. The penetration of that space by fellow sufferers insinuates them in the pain, asks them to occupy the space the lost child would have, to empathize with other bereaved. This pilgrimage, in turn, engages pilgrims in a physical enactment of their own psychological pain. 
Noticeably absent from the above considerations is reference to the parents' spatial relation to the young men's graves. This betrays a detachment from the corporeal reality of death, a paradoxical distance begotten of silence. An entry from October 13, 1925 , nearly two years later, attests that Kollwitz came to deem the parents' proximity to the graves an essential element of the memorial design, and, fittingly, in this entry she articulates that she is "with Peter only when ... plans for the soldiers' cemetery in Roggevelde are stirring again" (110). By this point she has transplanted the sculptural parents from the cemetery entrance to the midst of the graves themselves, bringing them into closer accord with the reality of death. Here she plans for the mother "to kneel and look out over the multitude of the graves. The unhappy woman spreads out her arms over all her sons. The father kneeling too. He has his hands clasped in his lap" (110). In a strong statement of the difference between maternal and paternal grief, Kollwitz casts the all-seeing mother as continuing to nurture the deceased, as actively protectant, while the father remains quietly numb. Given her commitment to remediating a fallen world, Kollwitz's characterization of the mother as lovingly mothering countless young men is understandable, despite the logical truth that this tender gesture cannot resurrect the youthful dead. Here Kollwitz professes faith in her art, faith in maternal love, and faith in the tapestry of their interwoven threads.

Meanwhile, Kollwitz's trials in relating-and discovering - what she wished to capture continued. In March of 1926, she worked on a depiction of the mother similar to that of the previous October, this time representing the mother as transcending her grief, "kneeling, leaning forward, hands laid one on the other below the face in an attitude full of life, head tilted slightly backward. With her eyes she embraces all the graves, smiles 
gently, loves them all" (111). This strangely optimistic take on the ability to conquer grief, and death, was short-lived, for as if of its own volition, the mother fell to the ground and was destroyed when in the process of being honed. Initially agitated, Kollwitz was shortly moved to interpret the accident as providential. While the loving mother is appropriate to the degree that she symbolizes Kollwitz's fierce commitment to remembering not only her son but the other war dead through her art, her sense of calm constitutes a denial of the permanent ramifications of what had transpired, of the degree to which Kollwitz and other survivors cannot transition gracefully to a world deprived of their loved ones.

In 1928 and 1929, she worked more mindfully on incorporating her own identity into the mother, for though it seems intuitive that she had been modeling this mother on herself and her grief, it was not until April 1928 that "the scales fell from ... [her] eyes" and she realized that she should base the sculptural mother's head on her own (116). This is surely a sign of her increasing ability to distance herself from her pain enough to engage in meaningful introspection. It is telling, however, that in the intervals when Kollwitz was not engaged in shaping the mother, she kept her covered. On a practical level, this prevented damage from undue exposure to the elements, but on a psychological level it suggests the continued rawness of a grief that if faced on a daily basis would prove debilitating. For to gaze continually as if in a mirror at a maimed self necessitates identifying more fully with the permanence of absence and the degree to which it inflicts an eternal loss of innocence.

In 1926, Kollwitz wrote a letter to Hans and his family from Mariakerke-Ostende, in Flanders, very near where Peter had fallen. Though it seems inconceivable, for the 
first time she and Karl were visiting Peter's grave. While the town itself was disfigured by "traces of war," by Belgian and German trenches colloquially called "the bowels of death" and by shellholes, Roggevelde was surrounded only by fields, appropriately removed from the hustle and bustle of everyday life, appropriately effecting an air of "solitude" (166). So unassuming was the German cemetery that the Kollwitzes initially passed it by, its entrance merely "an opening in the hedge that surrounds the entire field. It was blocked by barbed wire" (165). Within the cemetery the setting was equally anonymous, with relatively few large white crosses that had fallen over in ruin, a massive number of small yellow crosses marked with only a number, and undifferentiated mounds of "naked, yellow soil" (165). Käthe and Karl cut some wild roses for their son, laid them near his cross, and acknowledged to themselves that "[a]ll that is left of him lies there in a row-grave" $(165)$.

The terms in which Kollwitz describes the experience of being present in the place solidifying Peter's absence are remarkably unemotional and certainly without an imposition of justificatory meaning. The only beauty in the scene is the serenity of its remoteness, and the fact that "[h]ere and there relatives have planted flowers, mostly wild roses, which are lovely because they cover and arch over the grave and reach out to the adjoining graves which no one tends, for to the right and left at least half the graves bear the inscription allemande inconnu" (165). This is the only life attributable to the scene, an affirmation of the immortality of connectivity.

This visit to Roggevelde furthered Kollwitz's completion of the memorial, allowing her to visualize the cemetery as she planned the specifics of the monument, and encouraging her to witness her own stake in the arid soil, the soil that was now home to 
Peter, Peter forever dead, and she forever a bereaved mother. It was after this visit that Kollwitz had the epiphany regarding shaping the mother's visage as her own, which inevitably entailed recognizing this place of death as home to her, as well.

In April 1930, as the figures neared completion, Kollwitz indicates that the fact that she is almost finished with The Mourning Parents agitates her, that finishing is somewhat unheimlich, for this sculptural process has become her reality, her home, the overarching goal toward which she has been aspiring for nearly two decades.

Completion on some level signifies a letting go, partial forgetting, and Kollwitz has finally arrived at a place that requires her to do so. In 1931, she exhibited plaster casts of The Mourning Parents at the Berlin Academy Exhibition. After so many years of anguished, solitary labor, Kollwitz's private world emerged into the public eye. She met this milestone with mixed emotions:

This is a great divide, a highly significant period. For years I worked on them in utter silence, showed them to no one, scarcely even to Karl and Hans; now I am opening the doors wide so that as many people as possible may see them. A big step which troubles and excites me; but it has also made me very happy because of the unanimous acclaim of my fellow artists. These past weeks have been very strenuous. But now that the works are delivered to the world, I am calmer. In June I will start on the finishing touches. In the fall-Peter,-I shall bring it to you. (119)

This was a turning point that demanded that Kollwitz retreat somewhat from the singularity of her pain through acknowledging it as collective. This was a juncture at which Kollwitz was forced to reinvent herself, and this entailed calling for something of a moratorium on immersing herself so fully in the identity of a mother isolated and debilitated by grief. Projecting a vehement indictment of militarization through her War prints of the 1920's, Kollwitz had already taken the step of appropriating her pain for the abolishment of suffering, and she would continue to do so. But giving birth to herself as 
a three-dimensional aesthetic object signifies something more. Her suffering immortalized for her own good and the good of others, Kollwitz freed herself to engage more fully with the living.

Käthe and Karl Kollwitz drove to what Käthe experienced as a changed Roggevelde cemetery on Saturday, July 23, 1932. It seemed smaller, contained larger crosses than before, and looked "more monotonous than it did" (121). The rows had been straightened, a stone wall had been erected in which mosses now grew, and what had been arid, yellow soil had grown into lawn. Only three of the graves were marked with roses, with Peter's being one of those. The cemetery was by no means beautifulKollwitz expresses disdain for prettify[ing] with flowers ... mass death of all these young men" as the British and Belgians do (122). "A war cemetery," Kollwitz maintains, "ought to be somber" (122).

On Sunday, The Mourning Parents was painstakingly installed at the head of Roggevelde, with the plan for "crosses in front and all around them like a flock" (121). These grieving parents were erected such that they are meant to do the impossible: shepherd the innocent even in death. A testament to the fact that the youthful dead were loved, that they are still loved, that their presence and legacies are forever missed, The Mourning Parents remains to comfort the dead by affirming these truths should they awake and fear themselves forgotten. No longer a smiling mother reaching her enveloping arms above her countless sons, the mother gazes downward, her empty arms embracing her own body to offer comfort to her broken self, for the dead who reside here can no longer grace her loving arms. The father likewise gazes downward, for, due to the lay of the land, the workers installing the monument were unable to achieve the effect of 
the father watching over the flock. Like the mother, he embraces himself, separated from his son, separated from his wife, by the hand of this mortal pain.

In the end, the right way of carrying on for Peter was to create-yes-but also to represent emptiness, the space between parents that a child's death inflicts, the chasm in the home that was purportedly unified. On the cultural level, this speaks to the ways in which the homeland was now devoid of the vivifying presence that was its youth.

Woolf represents this space, as well, in the emptiness that is the cottage stoop, in the starkness that characterizes human presence in "The Lighthouse" section of her novel. And yet the vision Lily arrives at in To the Lighthouse, the vision Virginia Woolf achieves, is an optimistic vision of the undergirding fabric of connectivity. For To the Lighthouse is a novel of growth, whereas Kollwitz's is an expression of insatiable yearning for the renewal of a fledgling drained of vitality. Despite her affirmation of connectivity through the creation and installation of a public monument in a cemetery for the war dead, ultimately the message that the monument projects is "Never Again."

Reflecting on her time in Belgium nearly two months later, Kollwitz describes as her "loveliest memory" gazing at The Mourning Parents, gazing at herself, from the vantage point of Peter's grave: "[E]verything was alive and wholly felt. I stood before the woman, looked at her-my own face-and I wept and stroked her cheeks. Karl stood close behind me-I did not even realize it. I heard him whisper, 'Yes, yes.' How close we were to one another then" (122). It surely was a comfort to feel themselves present at the site of their dead son's interment, for their perpetual presence there as sources of comfort and lessons in loss allowed them to continue in the land of the living. In order to progress in her journey toward healing, Käthe Kollwitz deemed it necessary to declare 
herself a citizen of two homes, one in a then-present-day Berlin, and one in a timeless Roggevelde in Belgium.

When Peter's remains, along with those of his fallen German comrades, were moved to the nearby war cemetery of Vladslo some two decades later, The Mourning Parents traveled with them. If one visits the cemetery on a rainy day, she can claim herself a witness to the parents' fresh tears. 


\section{CONCLUSION}

\section{TO NURTURE AND TO BE NURTURED}

Virginia Woolf and Käthe Kollwitz spoke to a culture in urgent need of reparation, a culture defined by the loss of consolatory ways of understanding the world and humanity's relationship to it. Both artists' most extreme struggles challenged their conceptions of home. In their darkest hours, Woolf and Kollwitz felt as if they had no home. In this, their experiences typify modern homelessness. Violating the very idea of connectivity, modernity threatened to undermine faith in becoming, the promises of home.

The autobiographical nature of Virginia Woolf's and Kollwitz's art testifies to their ability to speak to a grieving world and to speak to it with empathy. Though they lived in a culture that devalued mutuality, both artists demonstrated a commitment to it through the act of creation, through their ability to translate their own pain into a consideration of others. Acting creatively to better the world is life-bestowing, and as such constitutes a commitment to natality, a reverence for the newness that is ever reshaping our world. Woolf's and Kollwitz's aesthetic universes are governed by an overarching principle of connectivity that asserts interrelationship as fundamental to flourishing. Their aesthetics interweave nostalgic desire, maternity, and creativity to suggest that any attempt to speak to human need must honor these coexistent, foundational human drives. As Woolf's To the Lighthouse and "A Sketch of the Past" 
and Kollwitz's War cycle and Mourning Parents attest, this coalescence is not merely of aesthetic import. Through their keen attunement to connection (and to its lack), these works illuminate our experiences of the world as pivoting on interrelationship and relationship as bound in an ongoing, creative appropriation of desire.

If, as this project has sought to establish, motherhood is aligned with mutuality, then the disintegration of community that was so rampant during the late- nineteenth and early-twentieth centuries might be understood as a pervasive sense of mother-loss. In retrospect, Woolf understood her mother's death as occasioning her own fall from innocence, as evicting her from the safety and security of the home of her fondest dreams. Through her memory work, Woolf is able to affirm both the continuance of Julia Stephen's spirit and the creative legacy she bequeathed to her daughter. Though her mother is irretrievable, Woolf demonstrates that she carries on the maternal legacy through aestheticizing the most poignant beauty in everyday life, a beauty that Woolf explains in terms of a recognition that "behind the cotton wool is hidden a pattern." This recognition is exemplified in the affiliation inherent in the mother-child dyad. Woolf's writing process and the worlds of her creation offered her solace that made bearable her sense of bereavement and demonstrate to the grieving the beauty, hope, and creativity of connectivity.

Communicating this truth, a truth afforded her through her experience of being nurtured and through the cultivation of her artistic gift, provided Woolf and continues to provide her readers with the capacity to trace Julia Stephen's thread in the weave. This exposure affirms natality: the weave continues to grow and new life, aesthetic and otherwise, is conceived through exposure to the ever-evolving pattern. Recognition of 
the pattern and its boundless expansion furthers human flourishing - those who are granted but a glimpse of its intricacy are enabled to ensure its continued viability. The place of childhood that Woolf conjures in "A Sketch of the Past" and To the Lighthouse, which is a place of changing tides, exemplifies connectivity and reverence for natality at their finest. Woolf's reconstruction of St. Ives is a nostalgic reverie to be sure, but the nostalgia that nourishes her and her readers is reflective. She is able through her writing to celebrate the most benign elements of her childhood in the process of critiquing those elements that were detrimental.

Because she dealt in aesthetic realities, because in writing she assembled what would become her own legacy, Woolf was able to fashion a vision in which life outshines death, a vision in which modeling right relations does something to mitigate that which is deleterious to human flourishing. Woolf created a home in which possibility is not foreclosed, and she demonstrated her commitment to such an ideal through working and reworking memories that she identifies in her art as in process, always becoming, always bound in desire for the other. Woolf spoke to a culture in mourning, a culture acutely aware of its demise, and that which had the potential to soothe mourners and direct their energies toward living played an inspirational role in counteracting obsession with the ubiquity of death. Her emphasis on connectivity might be read as a missal of hope for a fallen world. Woolf discovered her home through the construction of a beauty affirmative of the pattern behind the cotton wool that unites each to each, each to her world, each to generations past. Finding her way creatively allowed her to soothe her grief, to contribute to her own and others' flourishing, and to express 
her longing for wholeness and her desire for home And all the while it carried her into closer proximity to her mother.

Though nostalgia, maternity, and creativity are likewise interwoven in Kollwitz's aesthetic, she speaks from a different vantage point, that of a mother in mourning. In doing so she reveals that the longing of the homeless modern likewise manifests itself in a desire to nurture others, a sorrowful desire to create a home worthy of the natals who people her existence. This strain of modern desire emanates from a yearning to redeem the past, a desire that the creation of such a home should be retroactive, should awaken the youthful dead. Kollwitz sought to do the impossible: to create a benign home capable of facilitating her fallen son's flourishing. Woolf likewise envisioned creating a home, but, in fashioning her aesthetic home, she identified as a daughter-artist rather than a mother-artist. She looked to rediscover the psychologically-salubrious place of her childhood, whereas Kollwitz longed to create a psychologically-salubrious place worthy of childhood. Given Kollwitz's experiences as a child, surely her pre-war acts of creativity and home-fashioning were psychologically expedient. Her post-war endeavors were endlessly more so. After her son's death, she battled shame and guilt because she had succumbed to the ideology of nationalistic unity that was so very antithetical to the preservative love at the core of her maternity. Her self-prescribed penance and cure, never sufficient, never complete, was an immersion in the creation of a life-giving aesthetic undertaken to heal the self and the world. It was to her infinite sadness that Peter could not fall under the auspices of such healing.

As Kollwitz's journals attest, she conceived of creating art and mothering as intertwined, so much so that she feared the diminishment of intensive mothering to be 
detrimental to her artistic potency. The pre-war journals written during her sons' adolescence and early adulthood actively engage the past as a repository of memories that enrich the present. In these journals, she articulates a vision of home that unites maternity, creativity, and nostalgia for her children's babyhoods and the mutuality and possibility inherent there. By dismantling the possibility Kollwitz had so painstakingly cultivated for her son, Peter's untimely death threatened her worldview and her capacity to remain a creative, life-giving force in the present. Her process of healing, her agonized search for a path to traverse in the interest of life, entailed creatively extracting from her well of grief the love, possibility, and reverence she had nourished as she mothered and engaged in the artistic process.

In the name of healing, in the name of her art, in the name of remediating her world, Kollwitz tunneled back to a home pregnant with meaning, the home she cultivated as a mother, and created something of a palimpsest incorporating present deprivation and past becoming. Her grief-wrought works proclaim the association of past and present, such that the figures in War and The Mourning Parents simultaneously project despair and hope. Her woodcuts are devoid of place, the figures that people them reduced to near nothingness. Mothers and children are in abject pain, are without agency, and are incapable of flourishing. Their worlds are dire. Yet the mere presence of mothers and children, the presence of their desperate love, invokes hope. The absence of place and space conducive to childhood imagination gestures toward the possibility of a fullness of place, plentitude, the vitality of childhood. Kollwitz's is a message of "If only," an invocation to herself and others to erect a world worthy of inhabitation. 
Through her artistic process and through her art, Kollwitz continued to work toward such a universe. Tragically, she would witness another war within her lifetime, World War II, which brought further personal tragedy. Her grandson, Peter, named after his uncle, was killed in action on September 22, 1942, and her home, the home in which her sons had been born, was destroyed by bombing on November 23, 1943 (Kollwitz 9). When Käthe Kollwitz died on April 22, 1945, World War II was in its last stages.

The Mourning Parents that now reside in the Vladso cemetery warn that her goal of peace has not come to fruition. Kollwitz suggests beauty in representing the mourning for a loss of beauty and possibility, and through doing so she embodies beauty and becoming, a paradoxical faith that materializes in The Mourning Parents. The Mourning Parents still plead, "If only ...." The world continues to desacralize natality and its attendant becoming, but possibility abounds.

Virginia Woolf and Käthe Kollwitz testify to the dual human desires to nurture and to be nurtured, drives that need not be mutually exclusive. They illuminate that these foundational desires so salient in the mother -child dyad are the very desires that might be channeled to rehabilitate the world. If only one attends to their common thread. 


\section{REFERENCES}

Albright, Daniel. "Virginia Woolf as Autobiographer." The Kenyon Review 6.4 (1984): 1-17. JSTOR. Web. 02 July 2012.

Allen, Ann Taylor. Feminism and Motherhood in Germany, 1800-1914. Rutgers, NJ: Rutgers UP, 1991. Print.

Arendt, Hannah. The Human Condition. 1958. Chicago: U of Chicago P, 1998. Print. Arnold, Matthew. "Dover Beach." The Norton Anthology of English Literature: Major Authors. $6^{\text {th }}$ ed. Ed. M. H. Abrams. New York: Norton, 1996. 2059-2060. Print.

Bachelard, Gaston. The Poetics of Reverie. 1961. Trans. Daniel Russell. Boston: Beacon, 1971. Print.

---. The Poetics of Space. 1958. Trans. Maria Jolas. Boston: Beacon, 1994. Print.

Barthes, Roland. Camera Lucida: Reflections on Photography. Trans. Richard Howard. New York: Hill, 1981. Print.

Beer, Gillian. Darwin's Plots: Evolutionary Narrative in Darwin, George Eliot, and Nineteenth-Century Fiction. London: Ark, 1985. Print.

Bellini, Giovanni. Lamentation Over the Body of Christ. 1500. wikipaintings.org.

Benjamin, Jessica. The Bonds of Love: Psychoanalysis, Feminism, and the Problem of Domination. New York: Pantheon, 1988. Print.

Benjamin, Walter. "On the Concept of History." Illuminations: Essays and Reflections. 
1940. Ed. Hannah Arendt. Trans. Harry Zohn. New York: Harcourt, 1968. 253-264. Print.

---. "Berlin Chronicle." 1932. Selected Writings, Vol. 2, part 2. 1931-1934. Ed.

Michael Jennings, et. al. Cambridge, MA: Harvard UP, 1999. Print.

Berger, Peter, Brigitte Berger, and Hansfried Kellner. The Homeless Mind:

Modernization and Consciousness. New York: Vintage, 1974. Print.

Bergson, Henri. Time and Free Will: An Essay on the Immediate Data of Consciousness.

Trans. F. L. Pogson. 1889. New York: Harper, 1960. Print.

Betterton, Rosemary. An Intimate Distance: Women, Artists, and the Body. New York: Routledge UP, 1996. Print.

Boym, Svetlana. The Future of Nostalgia. New York: Basic, 2001. Print.

Caramagno, Thomas C. The Flight of the Mind: Virginia Woolf's Art and ManicDepressive Illness. Berkeley: U of California P, 1992. Print.

Carter, Mia. "History's Child: Virginia Woolf, Heritage, and Historical Consciousness." Alif: Journal of Comparative Poetics 27 (2007): 68-95. JSTOR. Web. 02 July 2012.

Casey, Edward. Getting Back into Place: Toward a Renewed Understanding of the Place World. Bloomington, IN: Indiana UP, 1993. Print.

DeSalvo, Louise. Virginia Woolf: The Impact of Childhood Sexual Abuse on Her Life and Work. Boston: Beacon, 1989. Print.

Detloff, Madelyn. The Persistence of Modernism: Loss and Mourning in the Twentieth Century. Cambridge, UK: Cambridge UP, 2009. Print.

Eksteins, Modris. Rites of Spring: The Great War and the Birth of the Modern Age. 
New York: Houghton, 1989. Print.

Eliot, Thomas Stearns. "East Coker." 1940. The Complete Poems and Plays: 19091950. New York: Harcourt, 1971. 123-129. Print.

--.. "The Wasteland." 1922. The Complete Poems and Plays: 1909-1950. New York: Harcourt, 1971. 37-55. Print.

Faulkner, William. Absalom!, Absalom!. 1936. New York: Vintage, 1990. Print.

---. Light in August. 1932. New York: Vintage, 1990. Print.

---. The Sound and the Fury. 1929. New York: Vintage, 1990. Print.

Felski, Rita. The Gender of Modernity. Cambridge, MA: Harvard UP, 1995. Print.

Freud, Sigmund. Civilization and Its Discontents. 1930. Trans. James Strachey. New York: Norton, 1961. Print.

---. "The Uncanny." 1919. The Uncanny. Trans. David McLintock. New York:

Penguin, 2003. Print.

Friedrichsmeyer, Sara. “'Seeds for the Sewing': The Diary of Käthe Kollwitz.” Arms and the Woman: War, Gender, and Literary Representation. Ed. Helen M. Cooper, Adrienne Auslander Munich, and Susan Merrill Squier. Chapel Hill: U of North Carolina P, 1989. 205-224. Print.

Fussell, Paul. The Great War and Modern Memory. Oxford: Oxford UP, 1975. Print. Gamino, Louis A. "A Study in Grief: The Life and Art of Kaethe Kollwitz." Grief and the Healing Arts: Creativity as Therapy. Ed. Sandra L. Bertman. Amityville, NY: Baywood, 1999. 277-288. Print.

Gilloch, Graeme. Myth and Metropolis: Walter Benjamin and the City. Cambridge, UK: Polity, 1988. Print. 
Gove, Antonina Filonov. "The Modernist Poetics of Grief in the Wartime Works of Tsvetaeva, Filonov, and Kollwitz." Russian Narrative and Visual Art: Varieties and Seeing. Ed. Roger Anderson and Paul Debreczeny. Gainesville, FL: UP of Florida, 1994. 148-72. Print.

Green-Lewis, Jennifer and Margaret Soltan. Teaching Beauty in DeLillo, Woolf, and Merrill. New York: Palgrave, 2008. Print.

Grosz, Elizabeth. Jacques Lacan: A Feminist Introduction. New York: Routledge, 1990. Print.

Heidegger, Martin. Being and Time. Trans. Joan Stambaugh. New York: SUNY, 2008.

Heller, Reinhold, et al. Stark Impressions: Graphic Production in Germany, 1919-1933. Evanston, IL: Northwestern UP, 1993. Print.

Henke, Suzette and David Eberly, eds. Virginia Woolf and Trauma: Embodied Texts. New York: Pace UP, 2007. Print.

Irigaray, Luce. An Ethics of Sexual Difference. 1984. Trans. Carolyn Burke and Gillian C. Gill. Ithaca: Cornell UP, 2003. Print.

-.-. I Love to You: Sketch for a Felicity Within History. 1990. Trans. Alison Martin. New York: Routledge, 1996. Print.

---. This Sex Which Is Not One. 1977. Trans. Catherine Porter. Ithaca: Cornell UP, 1985. Print.

---. Sharing the World. New York: Continuum, 2008. Print.

James, William. The Principles of Philosophy, vol. 1. The Stream of Consciousness. 1890. New York: Cosimo, 2007. Print. Jantzen, Grace. Becoming Divine: Towards A Feminist Philosophy of Religion. 
Bloomington, IN: Indiana UP, 1999. Print.

Jarrell, Randall. "The Death of the Ball Turret Gunner." 1945. The Norton Anthology of Modern Poetry. $2^{\text {nd }}$ ed. Ed. Richard Ellmann and Robert O'Clair. New York: Norton, 1988. 902. Print.

Joyce, James. A Portrait of the Artist as a Young Man. 1916. Ed. Chester G. Anderson. New York: Viking, 1968. Print.

--. Ulysses. 1922. New York: Random House, 1934. Print.

Käthe Kollwitz Museum Koln. Web. 15 July 2012.

Kearns, Martha. Käthe Kollwitz: Woman and Artist. New York: The Feminist P at CUNY, 1993. Print.

Kern, Stephen. The Culture of Time and Space 1880-1918. Cambridge, MA: Harvard UP, 1983. Print.

Knafo, Danielle. In Her Own Image: Women's Self-Representation in Art. Madison, WI: Fairleigh Dickinson UP, 2009. Print.

Kollwitz, Käthe. The Diary and Letters of Kaethe Kollwitz. Ed. Hans Kollwitz. Trans. Richard and Clara Winston. Evanston, IL: Northwestern UP, 1988. Print. ---. The Mothers (Die Mütter). 1922-1923. wikipaintings.org 28 November 2012. ---. The Mourning Parents. 1914-1932. plough.com 28 November 2012.

---. The Parents (Die Eldern). 1922-1923. wikipaintings.org 28 November 2012.

---. The People (Das Volk). 1922-1923. wikipaintings.org 28 November 2012.

---. Pietà. 1903. thornscompose.com 28 November 2012.

---. The Sacrifice (Das Opfer). 1922-1923. wikipaintings.org 28 November 2012.

---. Tower of Mothers. 1937. Käthe Kollwitz. Ed. Elizabeth Prelinger. New Haven: 
Yale UP, 1992. Print.

---. The Volunteers (Die Freiwiigen). 1922-1923. wikipaintings.org

---. The Widow, I (Die Witwe, I). 1922-1923. webs.wichita.edu

---. The Widow, II (Die Witwe, II). 1922-1923. sorornex.tumblr.com

---. Woman and Death (Tod und Frau). 1910. wikipaintings.org

---. Woman with Dead Child (Frau mit Totem Kind). 1903. wikipaintings.org

Kristeva, Julia. "Motherhood Today." Colloque Gypsy V. Paris, France. October 2005. http://www.kristeva.fr/motherhood.html. Web. 24 November 2012.

--.. "Stabat Mater." Trans. Arthur Goldhammer. 1976. Poetics Today 6.1/2 (1985): 133-52. JSTOR. Web. 6 June 2011.

LaCapra, Dominick. Emile Durkheim: Sociologist and Philosopher. Ithaca: Cornell UP, 1972. Print.

Lackey, Michael. "Anti-Philosophicalism nd Virginia Woolf's Critique of Philosophy." Journal of Modern Literature 29.4 (2006): 76-98. JSTOR. Web. 02 March 2012.

Lee, Hermione. Virginia Woolf. New York: Knopf, 1997. Print.

Levenson, Michael. "Introduction." The Cambridge Companion to Modernism. Ed. Michael Levenson. Cambridge: Cambridge UP, 1999. 1-8. Print.

McIntire, Gabrielle. Modernism, Memory, and Desire: T.S. Eliot and Virginia Woolf. New York: Cambridge UP, 2008. Print.

Mepham, John. "Mourning and Modernism." Virginia Woolf: New Critical Essays. Ed. Patricia Clements and Isobel Grundy. London: Vision, 1983. 137-56. Print. Murphy, Bernadette. Zen and the Art of Knitting: Exploring the Links Between Knitting, 
Spirituality, and Creativity. Avon, MA: Adams, 2002. Print.

Nietzsche, Friedrich. The Gay Science. 1882. Trans. Thomas Common. New York: Dover, 2006. Print.

---. Thus Spake Zarathustra: A Book for All and None. 1891. Trans. Thomas Common. New York: MacMillan, 1911. Print.

Nisbet, Robert. The Sociological Tradition. New York: Basic Books, 1966. Print. Nora, Pierre. Realms of Memory: Rethinking the French Past, vol. 1. Ed. Lawrence D. Kritzman. Trans. Arthur Goldhammer. 1984. New York: Columbia UP, 1996. Print.

Pals, Daniel. Seven Theories of Religion. New York: Oxford UP, 1996. Print.

Prelinger, Elizabeth. "Kollwitz Reconsidered." Käthe Kollwitz. Ed. Elizabeth Prelinger. New Haven: Yale UP, 1992. Print.

Proust, Marcel. Swann's Way. Trans. C. K. Scott Moncrieff. New York: Barnes and Noble, 2005. Print.

Rae, Patricia. Modernism and Mourning. Lewisburg, PA: Bucknell UP, 2007. Print.

Reed, Christopher. Bloomsbury Rooms: Modernism, Subculture, and Domesticity. New Haven: Yale UP, 2004. Print.

Ruddick, Sara. Maternal Thinking: Toward a Politics of Peace. Boston: Beacon, 1989. Print.

Scott, Bonnie Kime. Refiguring Modernism, vol. 2.: Postmodern Feminist Readings of Woolf, West, and Barnes. Bloomington, IN: Indiana UP, 1995. Print.

Sharp, Ingrid. "Käthe Kollwitz's Witness to War: Gender, Authority, and Reception." Women in German Yearbook 27 (2011): 87-107. JSTOR. Web. 6 May 2012. 
Sherman, David. "A Plot Unraveling into Ethics: Woolf, Levinas, and Time Passes." Woolf Studies Annual 13 (2007): 159-179. Print.

Shulte, Regina. “Käthe Kollwitz's Sacrifice.” Trans. Pamela Selwyn. History Workshop Journal 41 (1996): 193-221. JSTOR. Web. 6 May 2012.

Simmel, Georg. On Individuality and Social Forms. "The Metropolis and Mental Life." 1903. 324-339. Ed. Donald N. Levine. Chicago: Chicago UP, 1971. Print.

Smythe, Karen. "Virginia Woolf's Elegiac Enterprise." NOVEL: A Forum on Fiction. 26.1 (1992): 64-79. JSTOR. Web. 11 September 2012.

Sultan, Stanley. Eliot, Joyce, and Company. Oxford: Oxford UP, 1990. Print.

Tönnies, Ferdinand. Community and Civil Society. 1887. Trans. Jose Harris and Margaret Hollis. Ed. Jose Harris. Cambridge: Cambridge UP, 2001. Print. Usandizaga, Aranzazu. "Gender and Genre: The Genres of Modernism." Modernity, Modernism, Post-Modernism. Ed. Manuel Barbeito. Santiago de Compostela, Spain: U of Santiago de Compostela P, 2000. 107-133. Print.

Van der Kolk, Bessel, Alexander C. McFarlane, and Lars Weiseth, ed. Traumatic

Stress: The Effects of Overwhelming Experience on Mind, Body, and Society. New York: Guildford, 1996. Print.

Weber, Max. The Protestant Ethic and the Spirit of Capitalism. 1905. The Protestant Ethic and the Spirit of Capitalism and Other Writings. Trans. Peter Baehr and Gordon C. Wells. New York: Penguin, 2002. 1-201. Print.

Winks, Robin and Joan Neuberger. Europe and the Making of Modernity: 1815-1914. New York: Oxford UP, 2005. Print.

Winter, Jay. Sites of Memory, Sites of Mourning: The Great War in European Cultural 
History. Cambridge: Cambridge UP, 1995. Print.

Winter, Jay and Blaine Baggett. The Great War and the Shaping of the $20^{\text {th }}$ Century. New York: Penguin, 1996. Print.

Woolf, Virginia. The Diary of Virginia Woolf. Vol. 3: 1925-1930. Ed. Anne Olivier Bell and Andrew McNeillie. New York: Harcourt, 1981. Print.

---. Mrs. Dalloway. 1925. New York: Harcourt, 2005. Print.

---. To the Lighthouse. 1927. New York: Harcourt, 1989. Print.

World War I in Color. Dir. Jonathan Martin, II. Narr. Kenneth Branaugh. Capital

Entertainment, 2005. DVD.

Young- Bruehl, Elisabeth. Introduction. Freud on Women: A Reader. Ed. Elisabeth Young-Bruehl. New York: WW Norton, 1990. 3-47. Print. 


\section{APPENDIX}

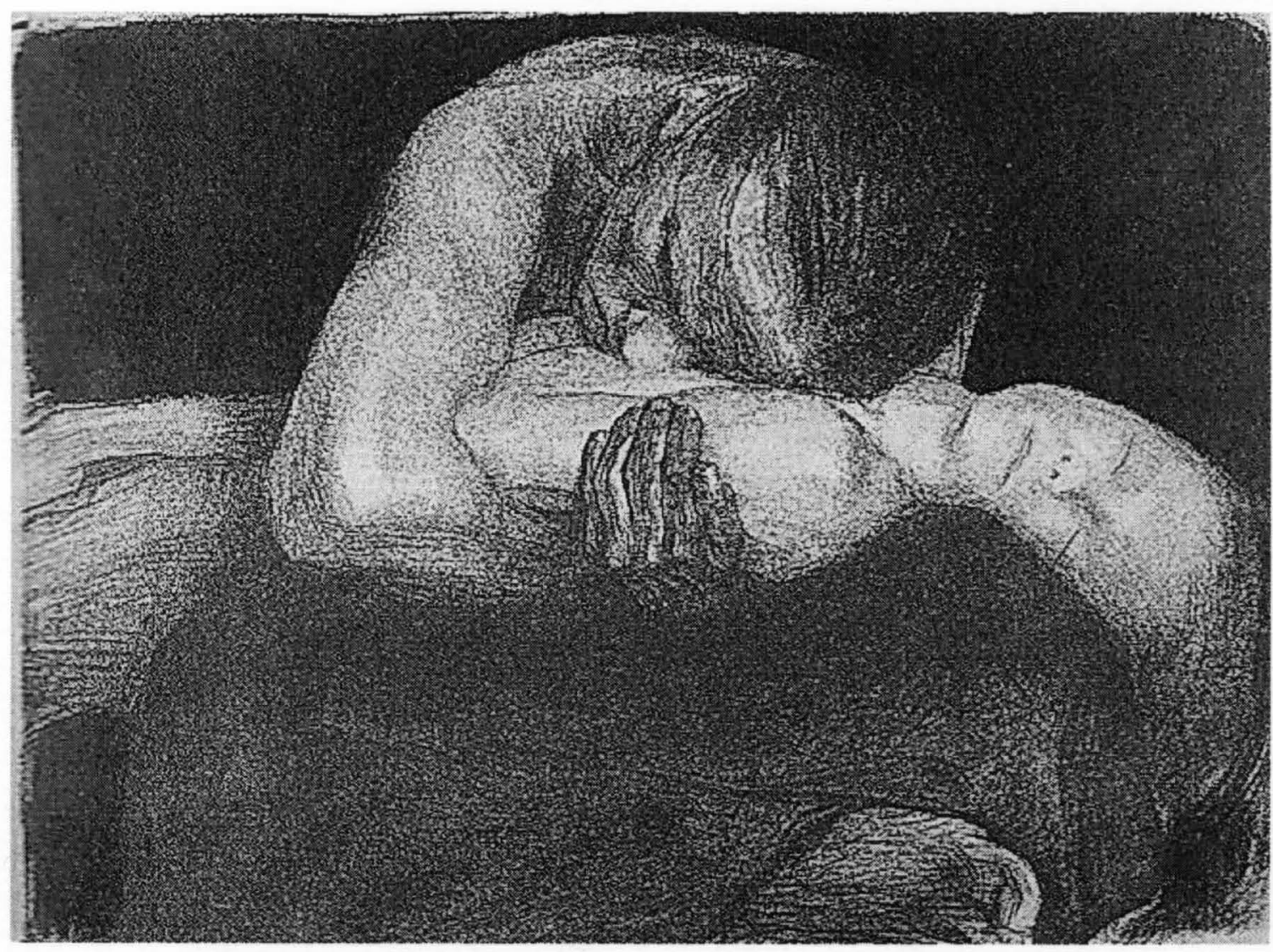

Figure 1: Pietá (Kollwitz, 1903)

$<$ thornscompose.com> 


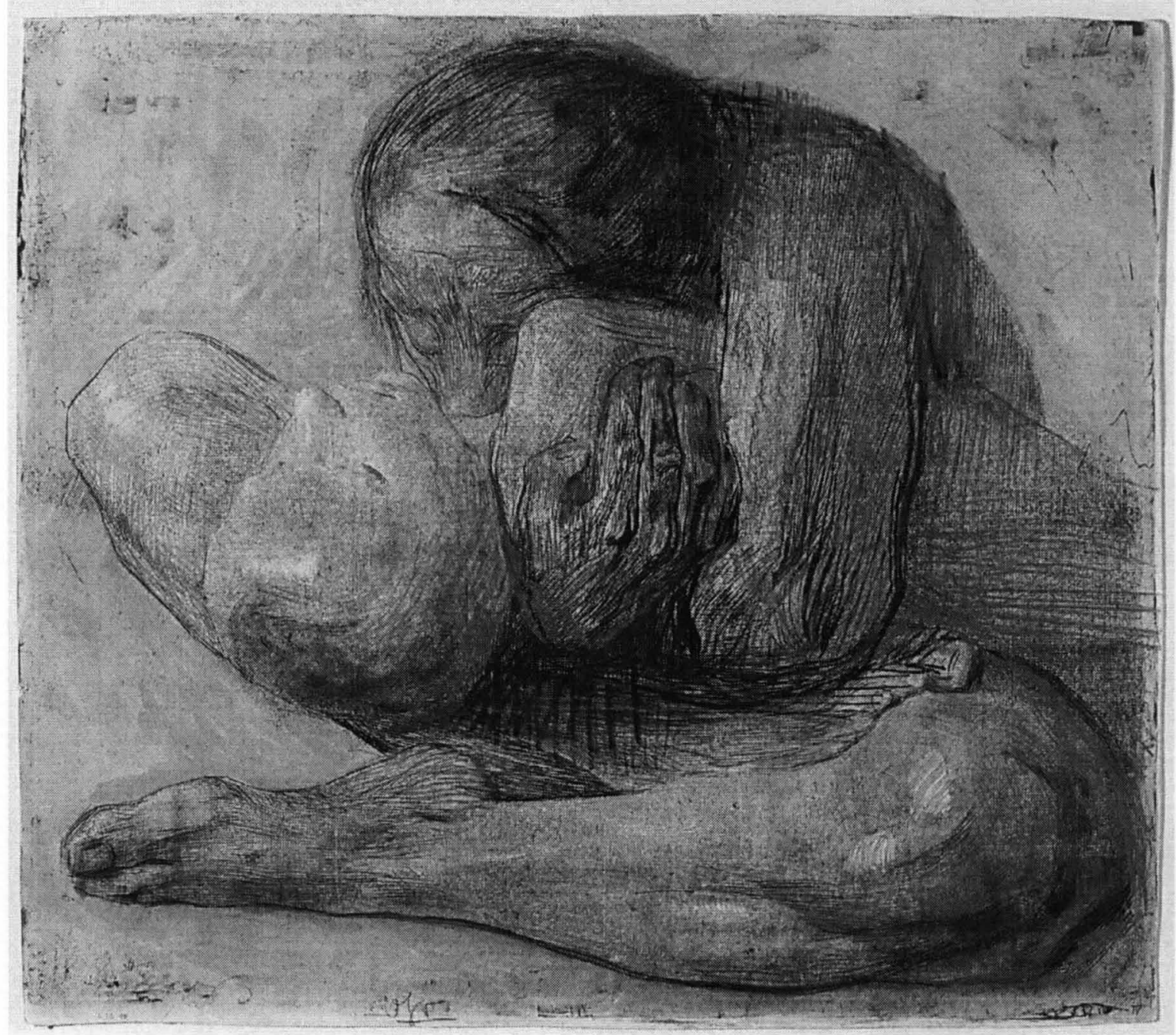

Figure 2: Woman With Dead Child (Frau mit Totem Kind) (Kollwitz, 1903)

<wikipaintings.org $>$ 


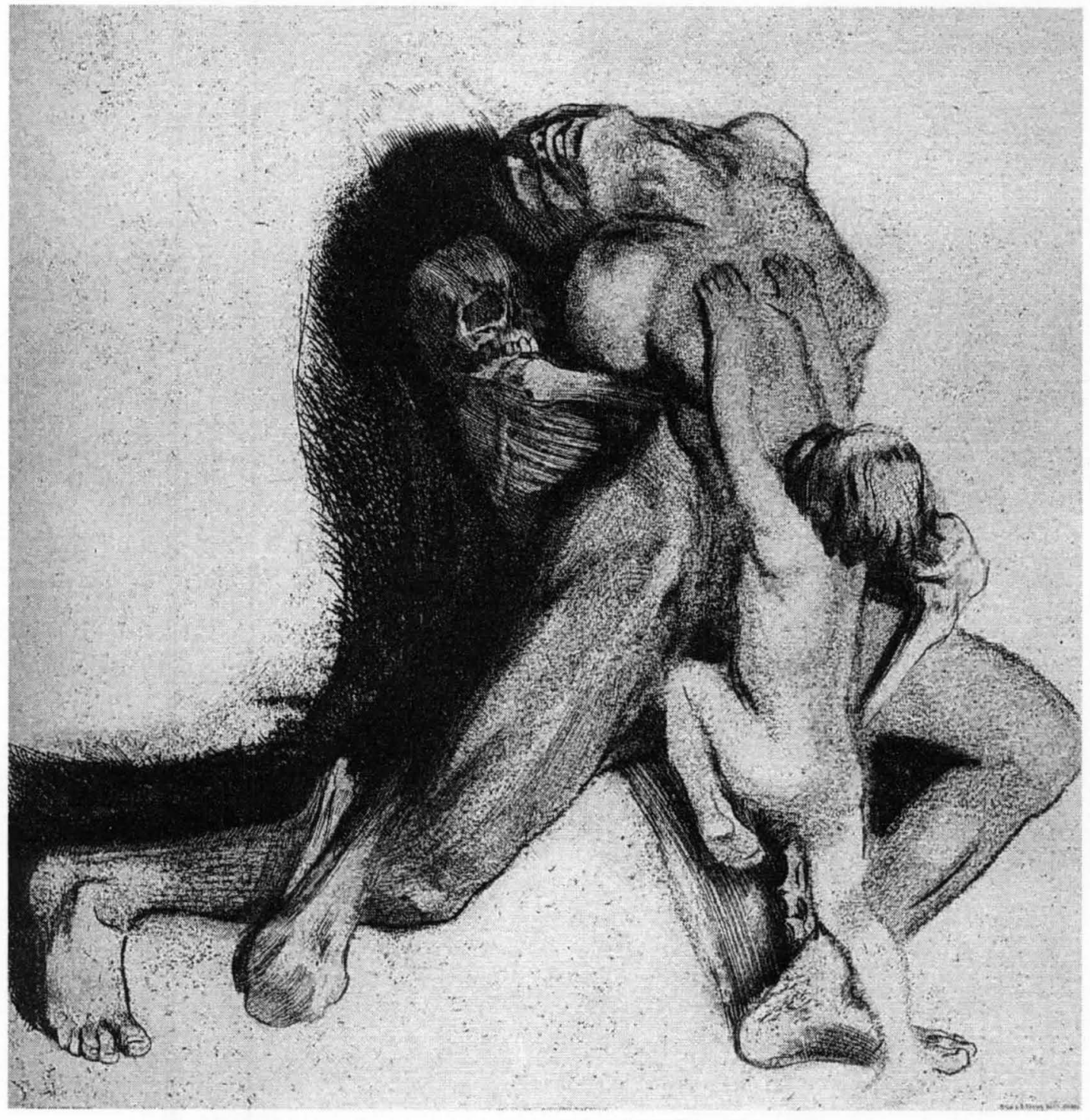

Figure 3: Woman and Death (Tod und Frau) (Kollwitz, 1910)

<wikipaintings.org $>$ 


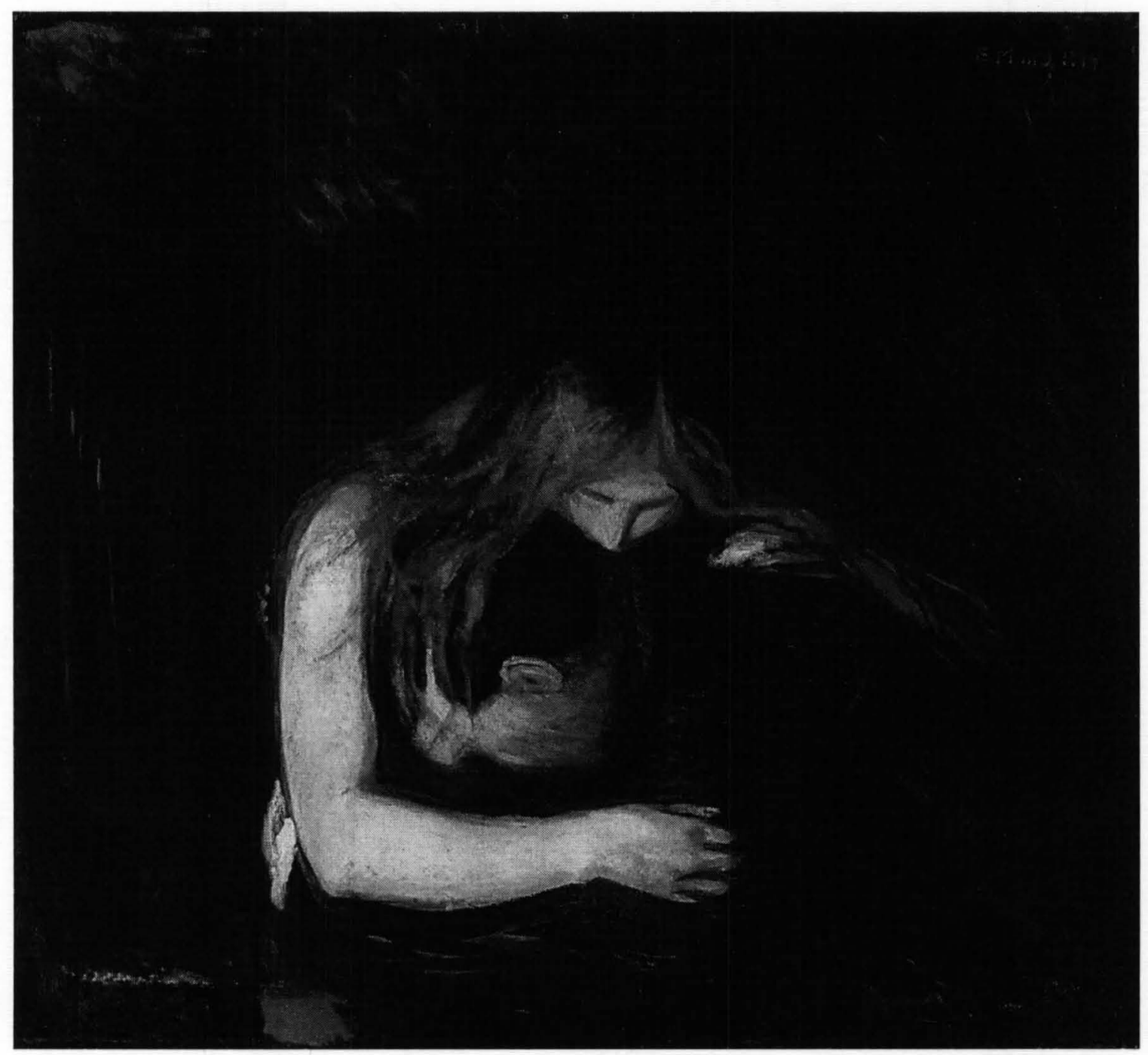

Figure 4: Vampire (Edward Munch, 1894)

$<$ artobserved.com> 
War (Krieg)

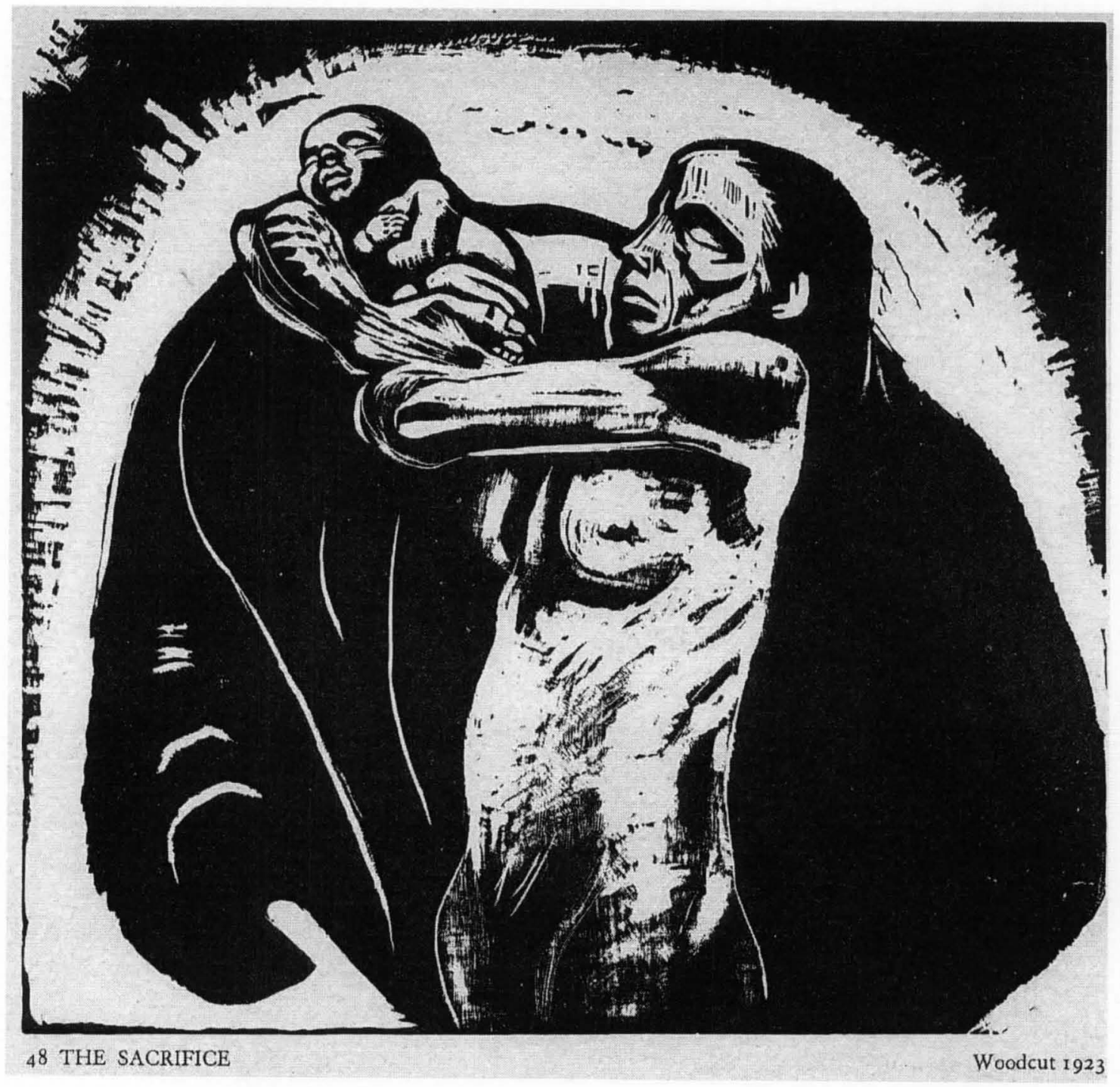

Figure 5: The Sacrifice (Das Opfer) (Kollwitz, 1922 - 1923)

<wikipaintings.org> 
War (Krieg)

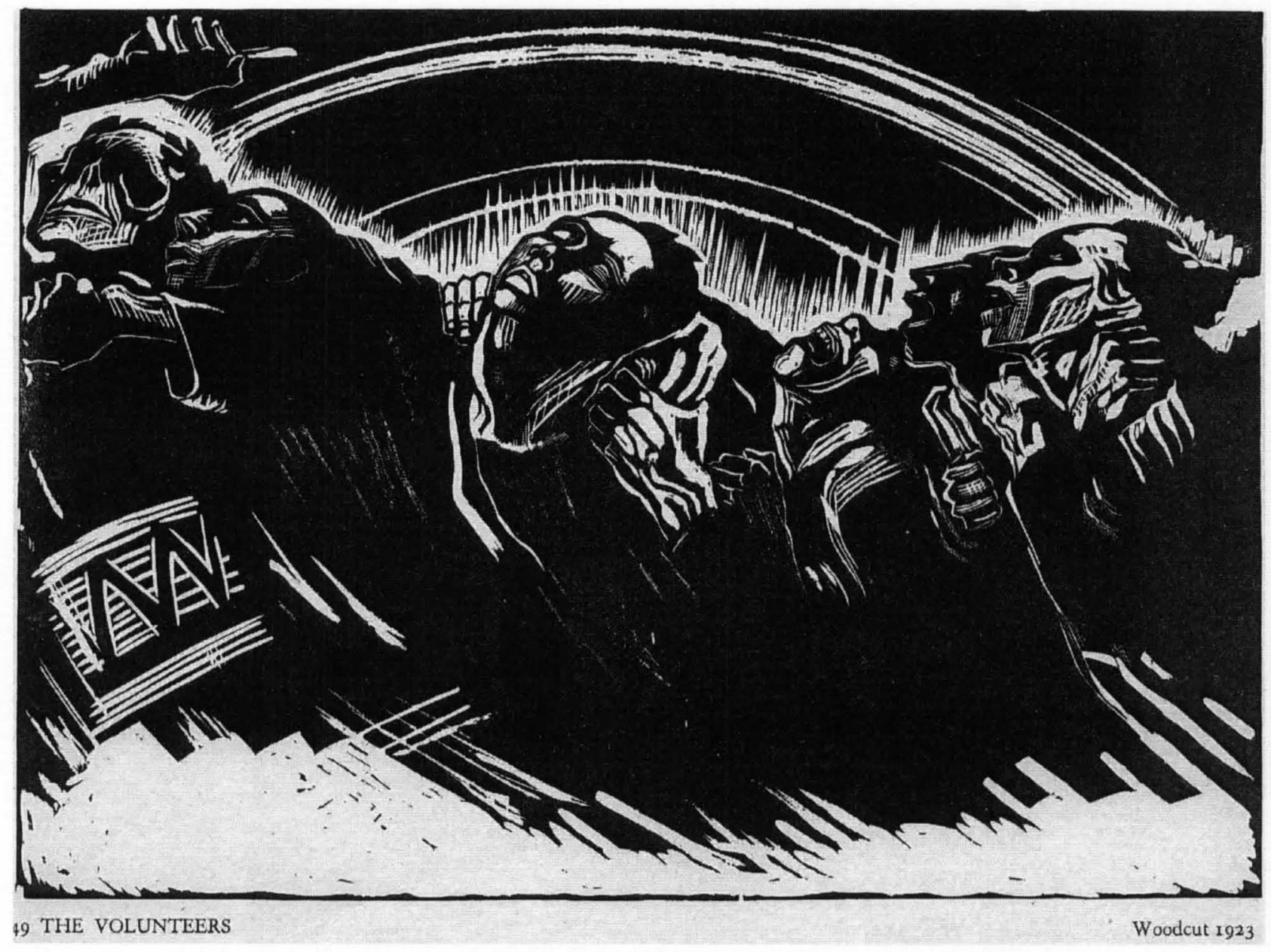

Figure 6: The Volunteers (Die Freiwilligen) (Kollwitz, 1922 - 1923)

$<$ wikipaintings.org $>$ 
War (Krieg)

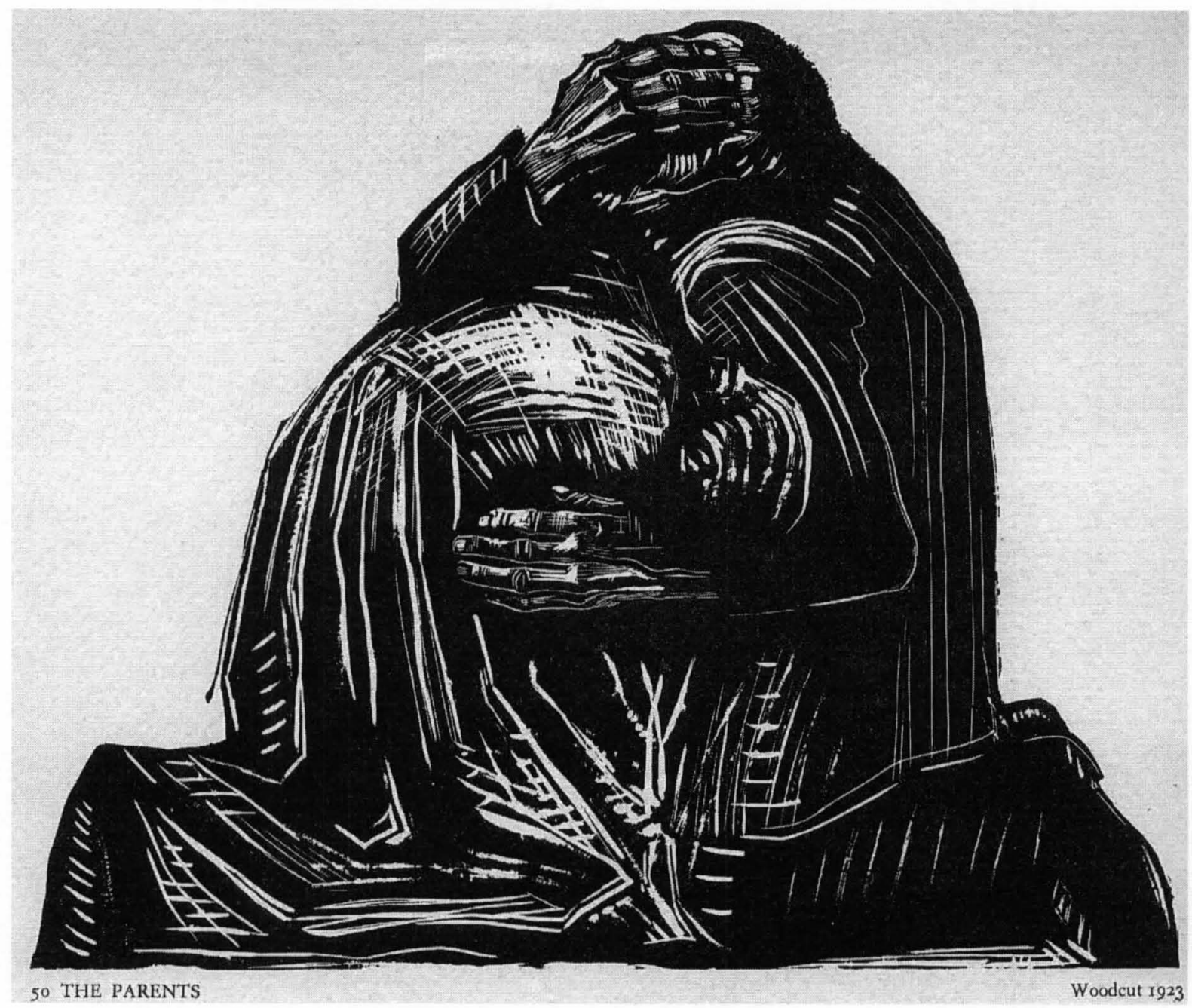

Figure 7: The Parents (Die Eltern) (Kollwitz, 1922 - 1923)

$<$ wikipaintings.org $>$ 
War (Krieg)

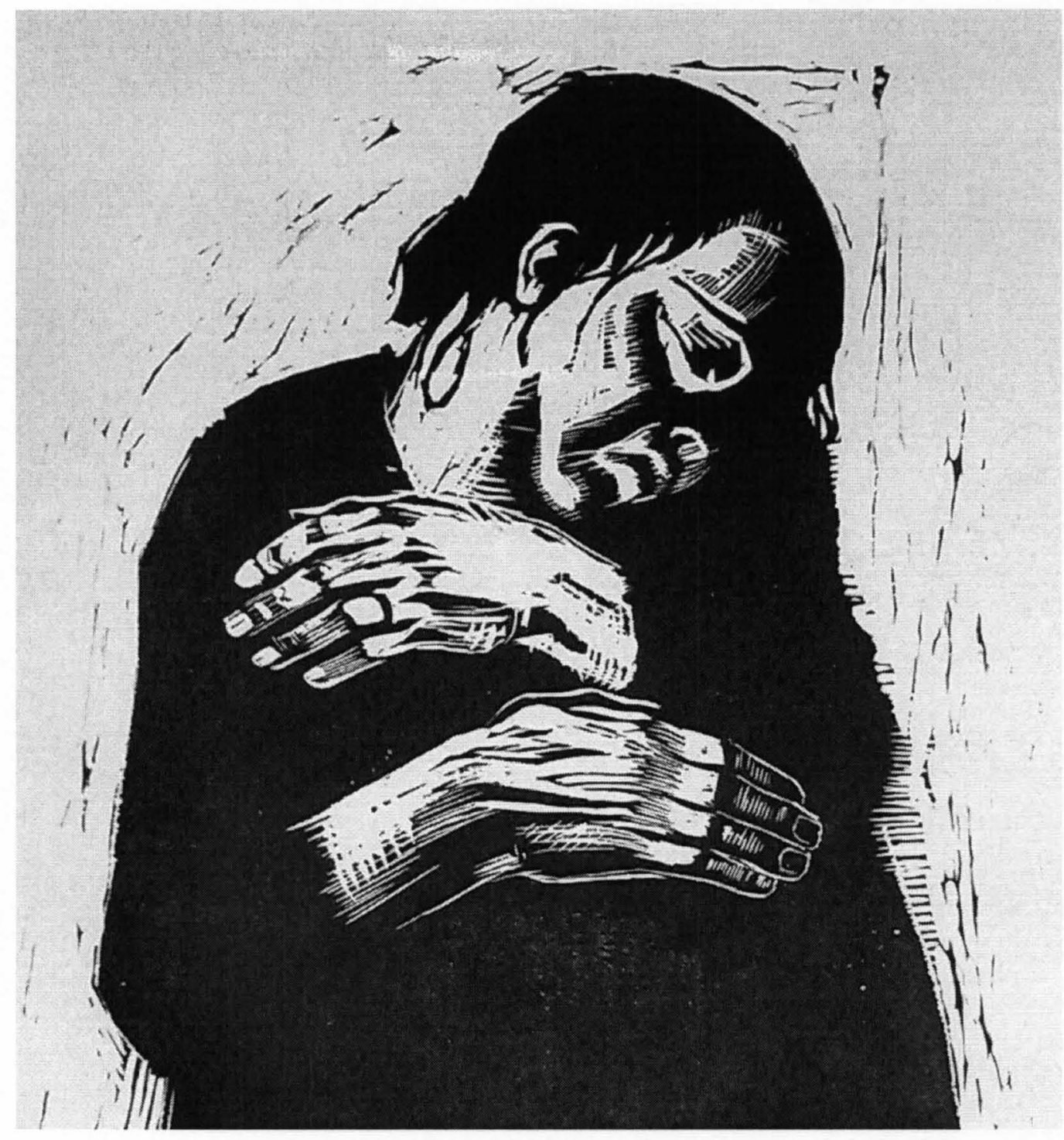

Figure 8: The Widow, I (Die Witwe, I) (Kollwitz, 1922 - 1923)

<webs.wichita.edu> 
War (Krieg)

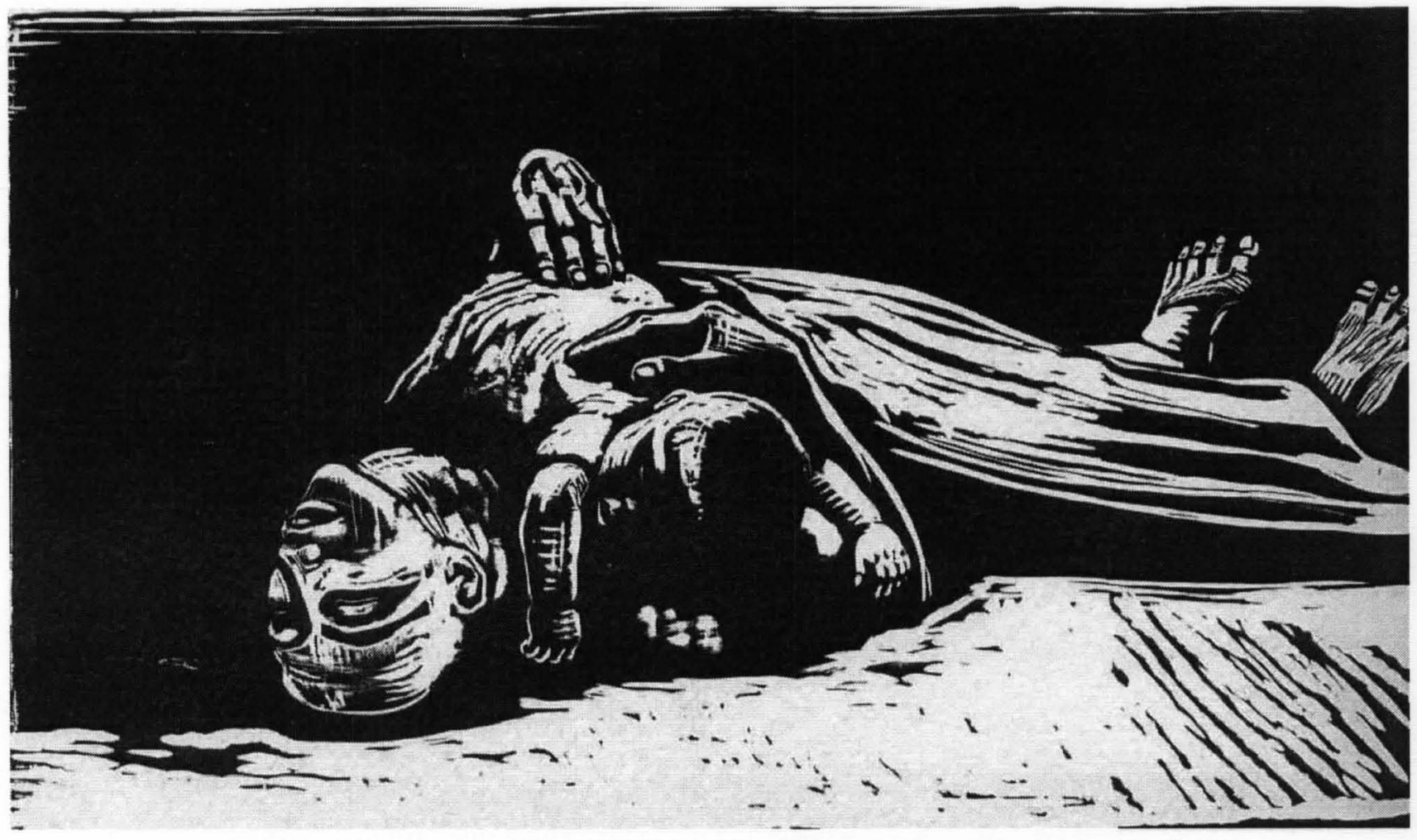

Figure 9: The Widow, II (Die Witwe, II) (Kollwitz, 1922 - 1923)

$<$ sorornex.tumblr.com $>$ 
War (Krieg)

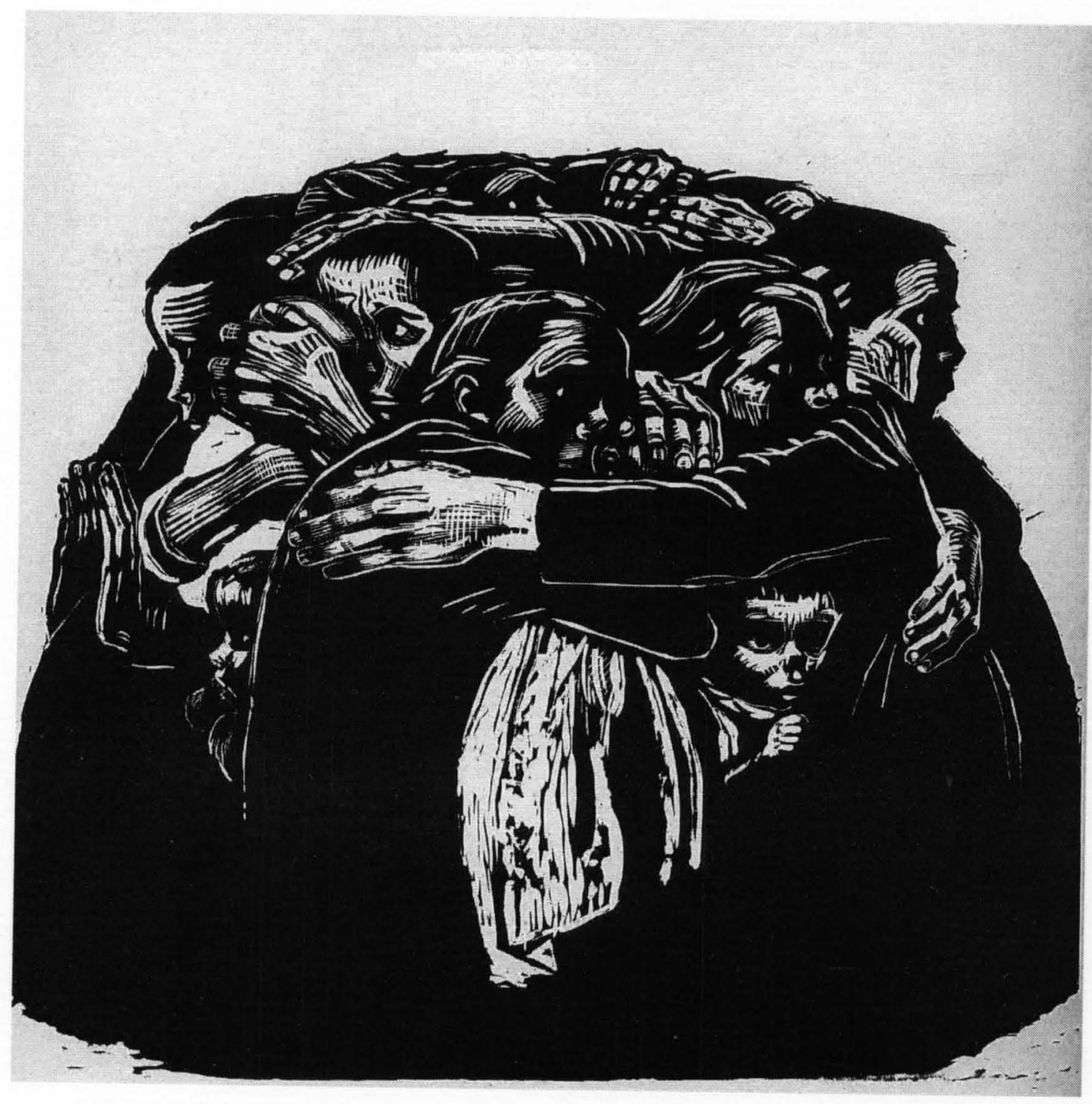

Figure 10: The Mothers (Die Mütter) (Kollwitz, 1922 - 1923)

<wikipaintings.com> 
War (Krieg)

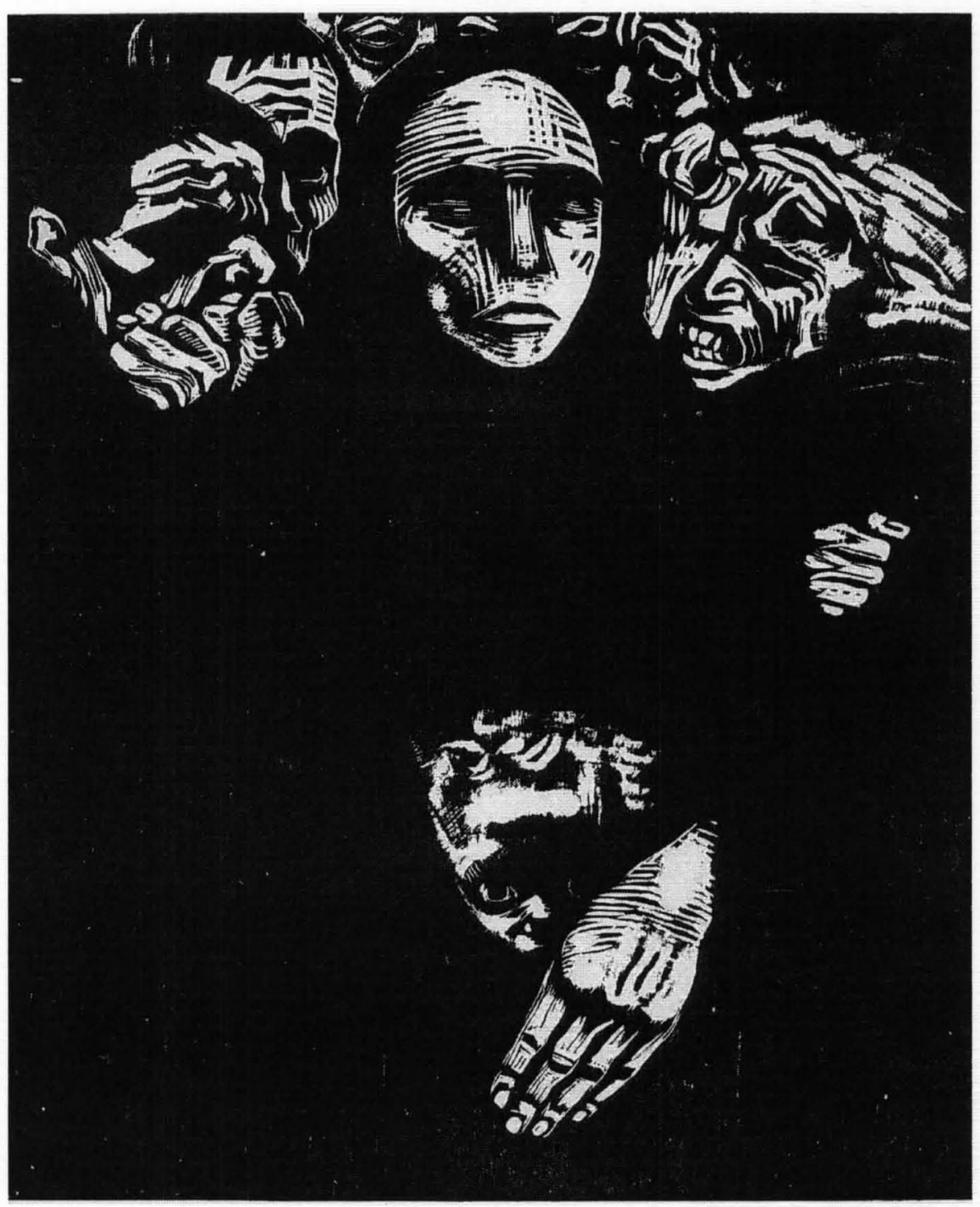

Figure 11: The People (Das Volk) (Kollwitz, 1922 - 1923)

$<$ wikipaintings.org $>$ 


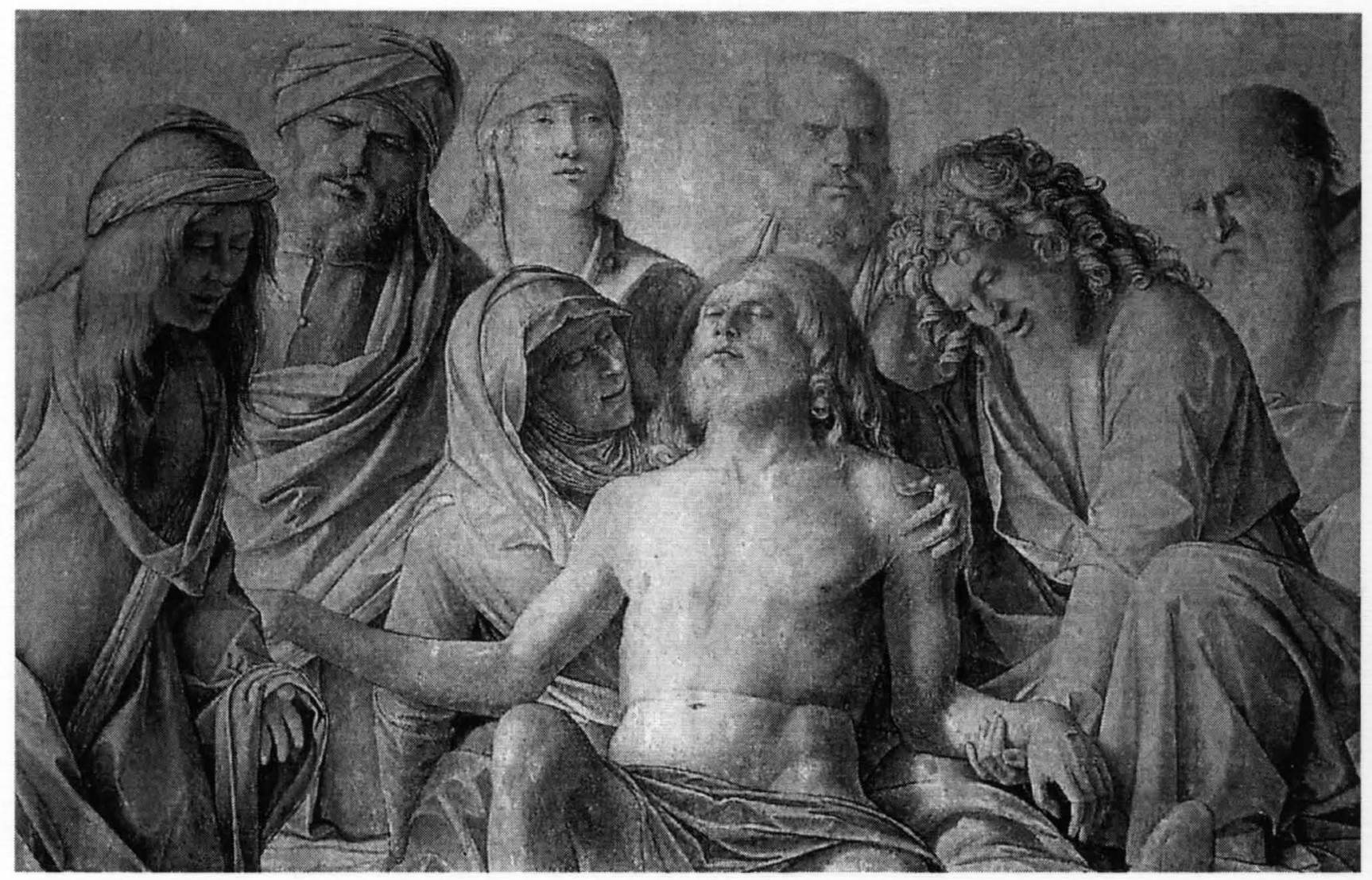

Figure 12: Lamentation Over the Body of Christ (Bellini, ca. 1500 )

$<$ wikipaintings.org $>$ 

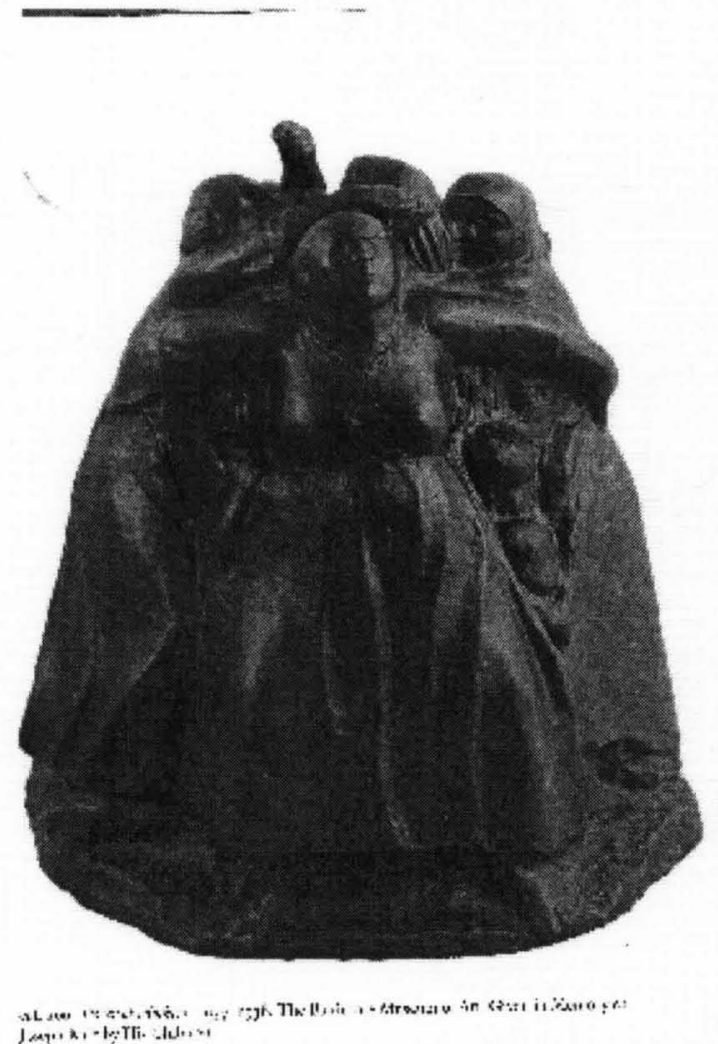

Figure 13: Tower of Mothers (Kollwitz, 1937)

(Prelinger 64) 


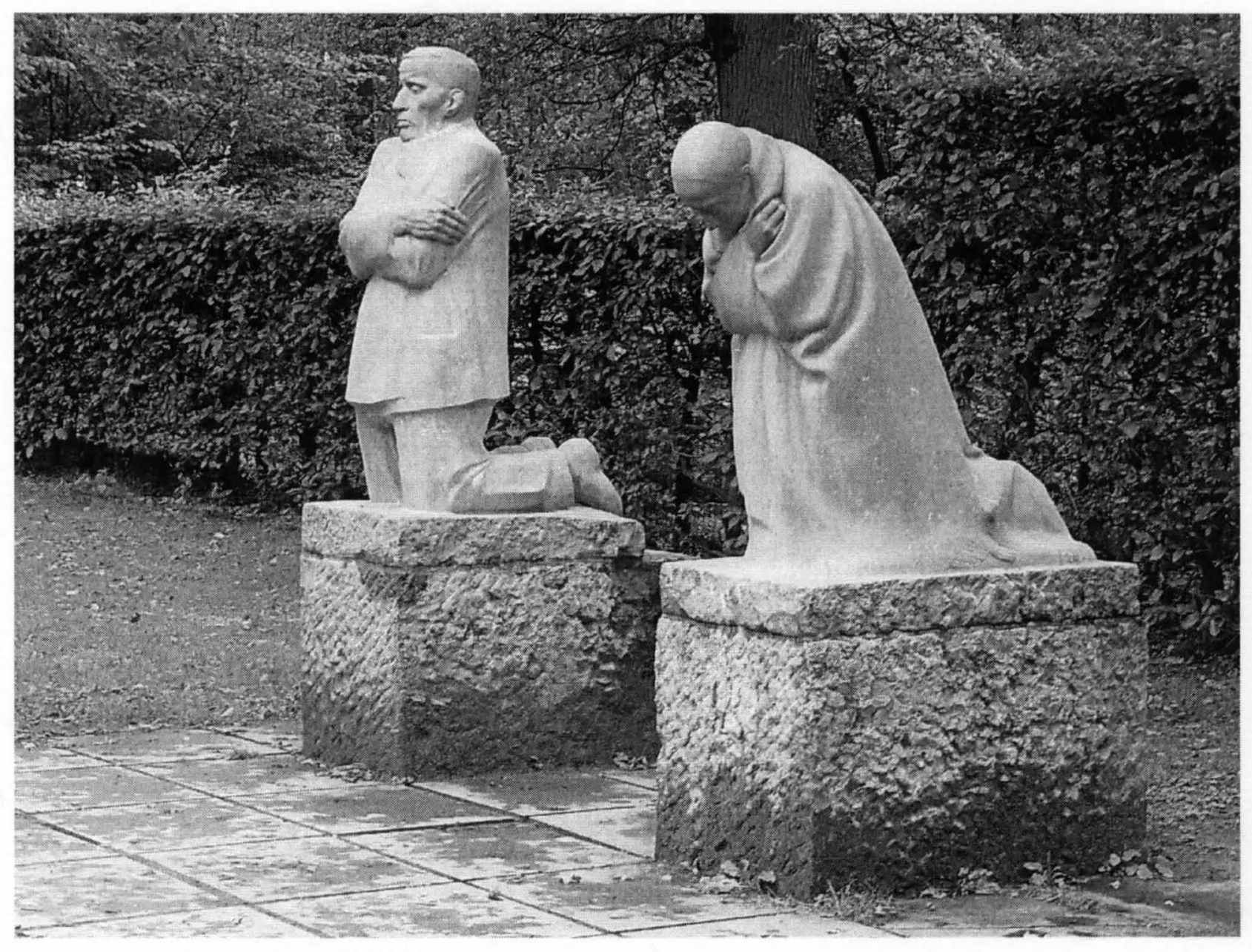

Figure 14: The Mourning Parents (Trauernden Eltern) (Kollwitz, 1914 - 1932)

<plough.com> 


\section{CURRICULUM VITAE}

NAME: Jennifer Brooke Goldberg

ADDRESS: 9107 Lexington Lane

Louisville, KY 40241

DOB: $\quad$ Knoxville, Tennessee - September 14, 1973

EDUCATION

\& TRAINING: $\quad$ B.A., Summa Cum Laude

The University of Tennessee-Knoxville

1991-94

M.A. English Literature

The University of Illinois at Urbana-Champaign

1995-97

Teacher Certification

Bradley University

1998-99

Ph.D., Humanities

University of Louisville

2006-12

AWARDS: Ph.D. Comprehensive Examinations Pass with Distinction (2010)

Graduate Travel Grant, University of Louisville (2008)

Graduate Travel Grant, University of Louisville (2007)

SES Undergraduate Development Grant, University of Louisville (Fall 2007)

SES Undergraduate Development Grant, University of Louisville (Fall 2005)

Honors Grant for Studying Drama in Stratford and London, University of Tennessee (1994)

Top Graduate, University of Tennessee, Knoxville (1994)

Ann Hight Gore for best performance in English Honors Program (1994)

Hodges Better English Scholarship (1993-94)

Roddy Upperclass Scholarship, University of Tennessee (1993-94)

Phi Kappa Phi Scholarship: Most Outstanding Junior (1993) 
PUBLICATIONS: "A Mixture of the Madonna and a Woman of the World": Virginia Woolf's Assessment of the Mother. Journal of the Association of Research on Mothering: Mothers and Daughters, 10.2 (October 2008)

NATIONAL MEETING PRESENTATIONS:

"Revisioning, Taking Liberties" (Lifting Belly High: A Conference on Women's Poetry Since 1900, Duquesne University, September 2008)

"Reclaiming the Maternal Body: Mitigating Loss in Elizabeth Clinton's The Countess of Lincoln's Nursery" (Association of the Research on Mothering Maternal Health and Well-being Conference, York University, Toronto, October 2007)

Section Chair: "The Practices of Everyday Life: Phones and Food" (Twentieth-Century Literature and Culture Conference, University of Louisville, February 2006)

Section Chair: "Religious Themes and Social Conscience in American and Canadian Literature" (Twentieth-Century Literature and Culture Conference, University of Louisville, February 2005) 